\title{
Taxonomia e variação geográfica das espécies do gênero Alouatta Lacépède (Primates, Atelidae) no Brasil
}

\author{
Renato Gregorin \\ Setor de Zoologia, Departamento de Biologia, Universidade Federal de Lavras. Caixa Postal 37, 37200-000 Lavras, Minas \\ Gerais, Brasil.
}

\begin{abstract}
Taxonomy and geographic variation of species of the genus Alouatta Lacépède (Primates, Atelidae) in Brazil. In this monograph, was studied non-geographic and geographic variation of taxa of Howling Monkeys, genus Alouatta Lacépède, 1799, occuring in Brazil, in order to solve the taxonomy of the group. For the morphological analysis, were examined a total of 1,286 specimens kept in five Brazilian and two North-American museums. The material consisted mostly of skin, skull and hyoid bone; skeleton or fluid-preserved specimens were scarse. The study was based on qualitative analysis of the morphological complexes in addition 18 morphometric characters of the skull and hyoid bone. Prior to making taxonomic decisions, was conducted a study of geographic, sexual, ontogenetic, and individual variation. Were recognized ten species of Alouatta occuring in Brazil and most of them were defined by discrete, but diagnostic characters. The species are: Alouatta caraya (Humboldt, 1812), A. fusca (Geoffroy Saint-Hilaire, 1812), A. clamitans Cabrera, 1940, A. belzebul (Linnaeus, 1766), A. discolor (Spix, 1823), A. ululata Elliot, 1912; A. juara (Linnaeus, 1766), A. macconnelli (Humboldt, 1812), A. puruensis Lönnberg, 1941, and A. nigerrima Lönnberg, 1941. Alouatta macconnelli and $A$. clamitans showed noticeable geographic variation on pelage coloration and some morphometric characters (polymorphism) difficulting their definition and geographic limits. Alouatta belzebul presented an accentuated geographic mosaic variation on coat coloration. Alouatta ululata and A. puruensis were defined in presenting sexual dicromism on pelage, but this character can be an artefate due the small sample and both taxa need further studies to confirm their validity. Alouatta belzebul mexianae Hagmann, 1908 was sinonimized with $A$. discolor; and the validity of Alouatta seniculus amazonica Lönnberg 1941 was not considered.

KEY WORDS. Brazilian species; howling monkeys; morphology; taxonomic revision; variation.
\end{abstract}

RESUMO. Neste estudo analisou-se a variação geográfica e não-geográfica de táxons de bugios, gênero Alouatta Lacépède, 1799, que ocorrem no Brasil, com o objetivo de esclarecer a taxonomia do grupo. Para a análise morfológica, examinou-se um total de 1.286 espécimes mantidos em cinco museus brasileiros e dois norte-americanos. $\mathrm{O}$ material consistiu basicamente de peles, crânios e ossos hióides; esqueletos e espécimes preservados em via úmida foram escassos. O estudo se baseou na análise qualitativa dos complexos morfológicos em adição a 18 morfométicos do crânio e osso hióide. Antes das decisões taxonômicas, elaborou-se um estudo de variação geográfica, sexual, ontogenética e individual. Reconheceu-se 10 espécies de Alouatta ocorrendo no Brasil, sendo a maioria definida por caracteres discretos, porém diagnósticos. São elas: Alouatta caraya (Humboldt, 1812), A. fusca (Geoffroy Saint-Hilaire, 1812), A. clamitans Cabrera, 1940, A. belzebul (Linnaeus, 1766), A. discolor (Spix, 1823), A. ululata Elliot, 1912; A. juara (Linnaeus, 1766), A. macconnelli (Humboldt, 1812), A. puruensis Lönnberg, 1941 e A. nigerrima Lönnberg, 1941. Alouatta macconnelli e $A$. clamitans mostraram notável variação geográfica na coloração da pelagem e algumas variáveis morfométricas (polimorfismo) o que dificultou as definições e limites dos táxons. Alouatta belzebul apresentou variação em mosaico na coloração da pelagem. Alouatta ululata e A. puruensis foram definidas pela presença de dicromatismo sexual na pelagem, mas este caráter pode ser um artefato e necessita estudos adicionais para corroborar sua validade. Sinonimizou-se Alouatta belzebul mexianae Hagmann, 1908 com A. discolor; e a validade de Alouatta seniculus amazonica Lönnberg 1941, não foi considerada.

PALAVRAS CHAVE. Bugio; espécies brasileiras; morfologia; revisão taxonômica; variação.

O gênero Alouatta Lacépède, 1799 é considerado monofilético por muitos autores, tais como Ford (1986) e MACPHEE et al. (1995), que propuseram uma diagnose baseada em caracteres exclusivamente derivados (apomórficos). Alouatta apresenta ampla distribuição geográfica na região Neotropical, ocorrendo desde o Estado de Vera Cruz, no México, até o Estado do Rio Grande do Sul, no Brasil e Corrientes, na Argentina. Com exceção do Equador e o oeste da Colômbia, não há registro de qual- 
quer população de Alouatta para a região transandina do Peru e Bolívia, tampouco para o Chile. Esta ampla distribuição geográfica engloba um número variado de formações vegetais e diversos biomas da América do Sul e da América Central.

As primeiras espécies de Alouatta foram descritas por LinNAEus (1766) e incluídas no gênero Simia Linnaeus, 1758: Simia belzebul Linnaeus, 1766 (= Alouatta belzebul) e S. seniculus Linnaeus, 1766 (= A. seniculus). O gênero Simia foi suprimido pelo Código Internacional de Nomenclatura Zoológica. Posteriormente, LACÉPÈDE (1799) criou o nome Alouatta incluindo somente a espécie lineana $S$. belzebul, logo esta é a espécie-tipo por monotipia. Autores subseqüentemente descreveram muitos táxons utilizando-se de nomes variados para se referir aos macacos bugios, tais como Mycetes Illiger, 1811 e Stentor Geoffroy SaintHilaire, 1812. Considerando a posterior suspensão do nome Simia Linnaeus, 1758 pelo Código Internacional de Nomenclatura Zoológica (ICZN 1922, Melville \& SMith 1987), o próximo nome disponível para os macacos bugios é Alouatta Lacépède, 1799. Posteriormente, Miranda-Ribeiro (1914) propôs o emprego de Cebus para os macacos bugios e criou Pseudocebus para incluir as espécies de macacos-prego. Entretanto, o trabalho de LACÉPÉDE (1766) tem prioridade sobre o de Miranda-Ribeiro (1914).

A partir do final do século XIX, o nome Alouatta foi aceito, estabilizando a nomenclatura para o gênero, enquanto o número de táxons do grupo da espécie elevou-se com a descrição ininterrupta de formas ao longo de toda sua história taxonômica, tais como: Alouatta palliata coibensis Thomas, 1902, Alouatta aequatorialis Festa, 1903, Alouatta seniculus rubiginosa Allen, 1904, A. s. caucensis Allen, 1904, A. s. rubicunda Allen, 1904, Alouatta belzebul mexianae Hagmann, 1908, Alouatta sara Elliot, 1910, A. ululata Elliot, 1912, Alouatta palliata inconsonans Goldman, 1913, Alouatta palliata quichua Thomas, 1913, Alouatta palliata trabeata Lawrence, 1933, A. palliata pigra Lawrence, 1933 e A. p. luctuosa Lawrence, 1933. ElLIot (1913) reconheceu 12 espécies para o gênero e somente três subespécies para compor Alouatta palliata, sendo esta a primeira revisão completa para Alouatta no século xx. O autor se baseou sua análise basicamente em caracteres da coloração da pelagem para a distinção dos táxons. De grande contribuição foi sua lista sinonímica, na qual invalida uma série de nomes descritos até aquela data e que de certa forma, mantinham o cenário nomenclatural e taxonômico do gênero confuso.

Em meados do século xx houve uma série de trabalhos importantes que discutiram a sistemática do gênero. Entre eles, destaca-se o trabalho de LöNNBERG (1941), importante devido à descrição minuciosa de muitas espécies que posteriormente foram sinonimizadas ou mesmo negligenciadas por um longo período tempo, mas que têm sido revalidadas recentemente, e.g. A. nigerrima (Groves 2001a). Embora LÖNnBERg (1941) tenha descrito os táxons e toda sua variação de forma convinvente e fornecido a história taxonômica detalhada, as questões referentes à nomenclatura deixam a desejar. Hershrovitz (1949) lidando com os primatas da Colômbia forneceu um estudo com- parativo baseado primariamente na morfologia do osso hióide e propôs um arranjo filogenético para o gênero, sugerindo a proximidade evolutiva entre $A$. nigerrima e $A$. seniculus. Contudo, o autor não expressou suas conclusões da filogenia na taxonomia, e manteve $A$. nigerrima como uma subespécie de $A$. belzebul em vez de considerá-la ao nível específico ou como subespécie de $A$. seniculus.

CABRERA (1958), em seu catálogo dos mamíferos sul-americanos, considerou 14 táxons para Alouatta, em cinco espécies (Tab. I). Apesar desta obra não ter sido uma revisão taxonômica propriamente dita, o autor efetuou uma série de mudanças nomenclaturais. O arranjo proposto por CABRERA (1958, Tab. I) para as espécies sulamericanas foi seguido em sua essência por cerca de 40 anos sem muitas alterações taxonômicas. Hill (1962) propôs um arranjo taxonômico para Alouatta com base nas obras de LAWRENCE (1933), para os táxons centro-americanos, e CABRERA (1958). Hill (1962) reconheceu seis espécies para o gênero: as mesmas cinco consideradas por CABRERA (1958), mais Alouatta villosa (Gray, 1845) da Guatemala e México. Para a América do Sul, Hill (1962) reconheceu 18 táxons, sendo para o Brasil quatro espécies e 12 subespécies (Tab. I), o maior número de táxons nominais reconhecidos na história taxonômica de Alouatta para o Brasil. Hill (1962) baseou-se na coloração da pelagem e secundariamente em outros aspectos da morfologia geral para a definião dos táxons. Embora de notória amplitude, o trabalho foi severamente criticado por HershKovitz (1964), principalmente pela ausência de análise de material para definir muitos táxons e pelo inacurado estudo morfológico comparativo.

Desde então Alouatta tem sofrido pequenas revisões na tentativa de esclarecer sua taxonomia e nomenclatura, com melhor tratamento dos dados biométricos mediante testes estatísticos, e com o emprego de caracteres moleculares e citogenéticos complementares aos morfológicos, para as proposições de relações de parentesco e a definição dos táxons (Lima \& Seuánez 1991, Consigliere et al. 1996, SAmpaio et al. 1996, Bonvicino et al. 1995, Oliveira et al. 2002, Cortés-Ortiz et al. 2003). Dentre os trabalhos, destaca-se o de Bonvicino et al. (1989) cujo estudo minucioso da variação da pelagem no complexo A. belzebul, com a conseqüente redefinição das subespécies $\mathrm{e}$ seus respectivos limites geográficos, é referência até o presente. Posteriomente, Groves (1993) forneceu uma lista atualizada das espécies de Alouatta, reconhecendo oito espécies: as cinco consideradas por CABrera (1958) mais A. coibensis, A. sara Elliot, 1910 e A. pigra Lawrence, 1933. Groves (1993) considerou muitos táxons subespecíficos como sinônimos, invalidando-os e reduzindo de forma notável a diversidade do gênero.

Bonvicino et al. (1995) elevaram ao nível específico $A$. straminea (Humboldt, 1812) e A. macconnelli, ambos ocorrendo no Escudo Guiano e considerados subespécies de $A$. seniculus, sendo o reconhecimento de duas espécies para a área uma questão em debate. Por fim, Groves (2001a) com base em dados da literatura mais recente, principalmente os citogenéticos, propôs um arranjo taxonômico mais atualizado para Alouatta (Tab. 
Tabela I. Principais arranjos taxonômicos para Alouatta desde meados do século XX. * Catálogo inclui apenas táxons sul-americanos; ${ }^{* *}$ grupos que ocorrem na América Central (excetuando A. p. aequatorialis).

\begin{tabular}{|c|c|c|c|c|}
\hline Cabrera $1958^{*}$ & HILL 1962 & RYLANDs et al. 1995 & Groves 2001a & Presente estudo \\
\hline A. caraya & A. caraya & A. caraya & A. caraya & A. caraya \\
\hline A. belzebul & A. belzebul & A. belzebul & A. belzebul & A. belzebul \\
\hline A. b. belzebul & A. b. belzebul & A. b. belzebul & A. nigerrima & A. discolor \\
\hline A. b. discolor & A. b. discolor & A. b. discolor & & A. ululata \\
\hline A. b. mexianae & A. b. mexianae & A. b. nigerrima & & \\
\hline A. b. nigerrima & A. b. nigerrima & A. b. ululata & & \\
\hline A. b. ululata & A. b. ululata & & & \\
\hline A. guariba & A. guariba & A. fusca & A. guariba & A. fusca \\
\hline A. g. beniensis & A. g. beniensis & A. f. clamitans & A. g. clamitans & A. clamitans \\
\hline A. g. clamitans & A. g. clamitans & A. f. fusca & A. g. guariba & \\
\hline A. g. guariba & A. g. guariba & & & \\
\hline A. palliata & A. palliata ** & A. palliata ${ }^{* *}$ & A. palliata ${ }^{\star *}$ & \\
\hline \multirow[t]{10}{*}{ A. palliata aequatorialis } & A. p. aequatorialis & A. p. aequatorialis & A. coibensis ** & Grupo não analisado \\
\hline & & A. p. palliata & A. pigra ** & \\
\hline & A. p. coibensis & A. p. mexicana & & \\
\hline & A. p. luctuosa & A. coibensis ** & & \\
\hline & A. p. mexicana & A. c. coibensis & & \\
\hline & A. p. pigra & A. c. trabeata & & \\
\hline & A. p. palliata & A. pigra ** & & \\
\hline & A. p. trabeata & & & \\
\hline & & A. seniculus & A. seniculus & \\
\hline & A. seniculus & A. s. amazonica & A. s. arctoidea & \\
\hline A. seniculus & A. s. amazonica & A. s. insulanus & A. s. juara & Grupo parcialmente analisado \\
\hline A. s. arctoidea & A. s. arctoidea & A. s. juara & A. s. seniculus & A. juara \\
\hline A. s. sara & A. s. insulanus & A. s. macconnelli & A. macconnelli & A. macconnelli \\
\hline A. s. seniculus & A. s. juara & A. s. puruensis & A. sara & A. nigerrima \\
\hline \multirow[t]{5}{*}{ A. s. straminea } & A. s. macconnelli & A. s. seniculus & & A. puruensis \\
\hline & A. s. puruensis & A. s. straminea & & \\
\hline & A. s. sara & A. seniculus ssp. & & \\
\hline & A. s. seniculus & A. arctoidea & & \\
\hline & A. s. straminea & A. sara & & \\
\hline
\end{tabular}

I). No plano taxonônomico, é digna de nota a contribuição de RYLANDS \& BRANDON-JONES (1998) que elucidaram as questões a respeito de diversos holótipos e de nomes corretos, principalmente para o grupo A. seniculus.

Apesar da contribuição notável de trabalhos usando a morfologia para a definição dos táxons de Alouatta, estes focaram basicamente a pelagem como principal fonte de informações, excetuando poucos estudos que foram importantes na descrição do crânio e do osso hióide como bons complexos anatômicos para empregar na sistemática (IHERING 1914, LÖNNBERG 1941, HershKovitz 1949, Hill 1962). É importante ressaltar que nas úl- timas duas décadas o número crescente de estudos citogenéticos forneceu uma gama substancial de dados evidenciando que as questões sobre a variação, definição dos táxons e os aspectos de cunho filogenético, que sempre permearam a história taxonômica de Alouatta, ainda se mantém. Certamente, uma maior integração dos dados morfológicos e citogenéticos disponíveis, e seu direcionamento para se entender a variação e a definição dos táxons de forma mais objetiva, é desejável neste momento. De fato, nota-se que muitos dos táxons de Alouatta que ocorrem no Brasil receberam relativamente pouca atenção por parte dos sistematas e conseqüentemente, seu quadro taxonômico prati- 
camente se manteve inalterado ao longo das últimas décadas, diferentemente dos táxons que ocorrem no restante da América do Sul e daqueles da América Central. Em adição, muitas das modificações efetuadas, ou sugestões de alterações taxonômicas, foram propostas sem um estudo profundo sobre a variação e tampouco sob o prisma de uma análise taxonômica metodologicamente explícita e consistente. Com o avanço no conhecimento deste diversificado grupo de primatas nas diversas áreas e com o aumento das coleções zoológicas, surgiram questões em vários níveis que até hoje geram considerável confusão, tais como, o emprego de nomes corretos, o reconhecimento dos táxons válidos, $\mathrm{e}$ se na categoria específica ou subespecífica. As delimitações da distribuição geográfica dos táxons muitas vezes são pouco informativas quando se desconsideram as subespécies (HIRsch et al. 1991, Groves 1993), resultando na obscuridade dos padrões zoogeográficos e da diversidade. Com base nestas prerrogativas, evidenciam-se questões, tais como: 1) Quantas entidades coesas de Alouatta podem ser consideradas para o Brasil após um estudo de variação? 2) Elas podem ser consideradas espécies válidas? 3 ) As espécies tidas como politípicas seriam monofiléticas?

\section{MATERIAL E MÉTODOS}

\section{Coleções}

Foi analisado um total de 1.131 espécimens coletados no Brasil e 155 provenientes de outras regiões da América do Sul permitindo tomar melhores decisões taxonômicas. O material estudado está representado por peles abertas ou cheias, geralmente em bom estado de conservação (denotadas pela letra $\mathrm{p}$ no material examinado), crânios (letra c) e ossos hióides (letra h). O material utilizado está depositado em cinco museus brasileiros e dois norte-americanos: (AMNH) American Museum of Natural History, Nova Iorque; (FMNH) Field Museum (Natural History), Chicago; (MHNCI) Museu de História Natural "Capão da Imbuia", Curitiba; (MNRJ) Museu Nacional, Universidade Federal do Rio de Janeiro, Rio de Janeiro; (MPEG) Museu Paraense Emílio Goeldi, Belém; (MZUSP) Museu de Zoologia da Universidade de São Paulo, São Paulo; e (UFPB) Coleção da Universidade Federal da Paraíba, João Pessoa.

\section{Procedimentos para a análise morfológica}

Inicialmente os exemplares foram separados em cinco classes de idade com base em caracteres cranianos: infante, espécime que apresenta dentição decídua ou quando permanente, com vários dentes ainda inclusos; jovem, espécime que apresenta apenas os terceiros molares ainda inclusos; subadulto, espécime com dentição completa, mas a sutura entre os ossos cranianos basiesfenóide e basioccipital ainda visível; adulto, espécime com os ossos basiesfenóide e basioccipital completamente fundidos e com as suturas faciais parcial ou totalmente visíveis; e velho, cujo crânio não tem as suturas faciais visíveis.

\section{Caracteres quantitativos}

Obteve-se as 18 medidas cranianas e do osso hióide a partir de indivíduos adultos. Os caracteres particulares à dentição foram medidos a partir da base do dente, na região de inserção na mandíbula, visando obter a informações, mesmo com ausência do dente. A delimitação das medidas (Fig. 1) e suas abreviaturas são: comprimento craniano (CCR), comprimento côndilobasal (CCB), largura zigomática (LZI), largura inter-orbital (LIO), comprimento palatal (CPA), altura craniana (ACR), largura craniana (LCR), largura palatal (LPA), largura da constrição pósorbital (LPO), largura mastóidea (LMT), altura do processo articular da mandíbula (APA), comprimento mandibular (CMA), largura condilar (LCO), comprimento da fileira superior de dentes (CDS), largura entre molares superiores (LMO), comprimento hióideo (CHI), largura hióidea (LHI) e largura do tentório (LTE).

\section{Caracteres qualitativos}

O estudo da pelagem se deu em dois níveis distintos: um referindo-se especificamente ao pêlo, com observações do seu tipo (cobertura, guarda, vibrissas entre outros), padrão de bandas, e o comprimento e a distribuição destes em áreas específicas do corpo. Em outro nível, a pelagem propriamente dita foi estudada incluindo a delimitação de campos cromatogenéticos (Hershrovitz 1968), e conseqüentemente o estudo do padrão de coloração do animal.

O osso hióide é singular em Alouatta, visto seu desenvolvimento e diferenciação em relação aos outros primatas Platyrrhini, mesmo Callicebus Thomas, 1903. Seguiu-se HershKovitz (1949) para a nomenclatura referente ao complexo hióideo.

\section{Análise estatística}

Alouatta apresenta um dimorfismo sexual acentuado (Schultz 1926, 1960, Ravosa \& Ross 1994) e, portanto, as amostras foram tratadas separadamente quanto aos sexos. Em adição, as diversas espécies foram divididas em várias amostras escolhidas ao longo de traçados elaborados previamente dentro da área de distribuição do táxon, geralmente nos seus maiores eixos. Devido a estes dois procedimentos que reduzem consideravelmente as amostras, uniu-se, na maioria das vezes, duas ou mais localidades próximas entre si para possibilitar o emprego dos testes de variância. Esta união foi elaborada mediante uma análise preliminar para certificar se as localidades apresentavam características da vegetação e relevo semelhantes e também a confirmação da ausência de barreiras geográficas efetivas previamente conhecidas.

Para testar a normalidade das amostras aplicou-se o teste Kolgomorov-Smirnoff. Subseqüentemente, aplicou-se o teste paramétrico $t$ de Student para o dimorfismo sexual e analisouse a variação intra-específica, comparando as amostras ao longo do eixo da distribuição de cada táxon. Para isto, empregouse novamente o teste $t$ de Student para as análises que envolveram apenas duas amostras com homogeneidade nas variâncias. Para as análises que envolveram mais de duas amostras, empregou-se o teste de variância de comparação múltipla. Para os casos de variâncias homogêneas utilizou-se o teste ANOVA, seguido daquele de Tukey e para as amostras que não mostraram homogeneidade em suas variâncias, empregou-se o teste Mann- 

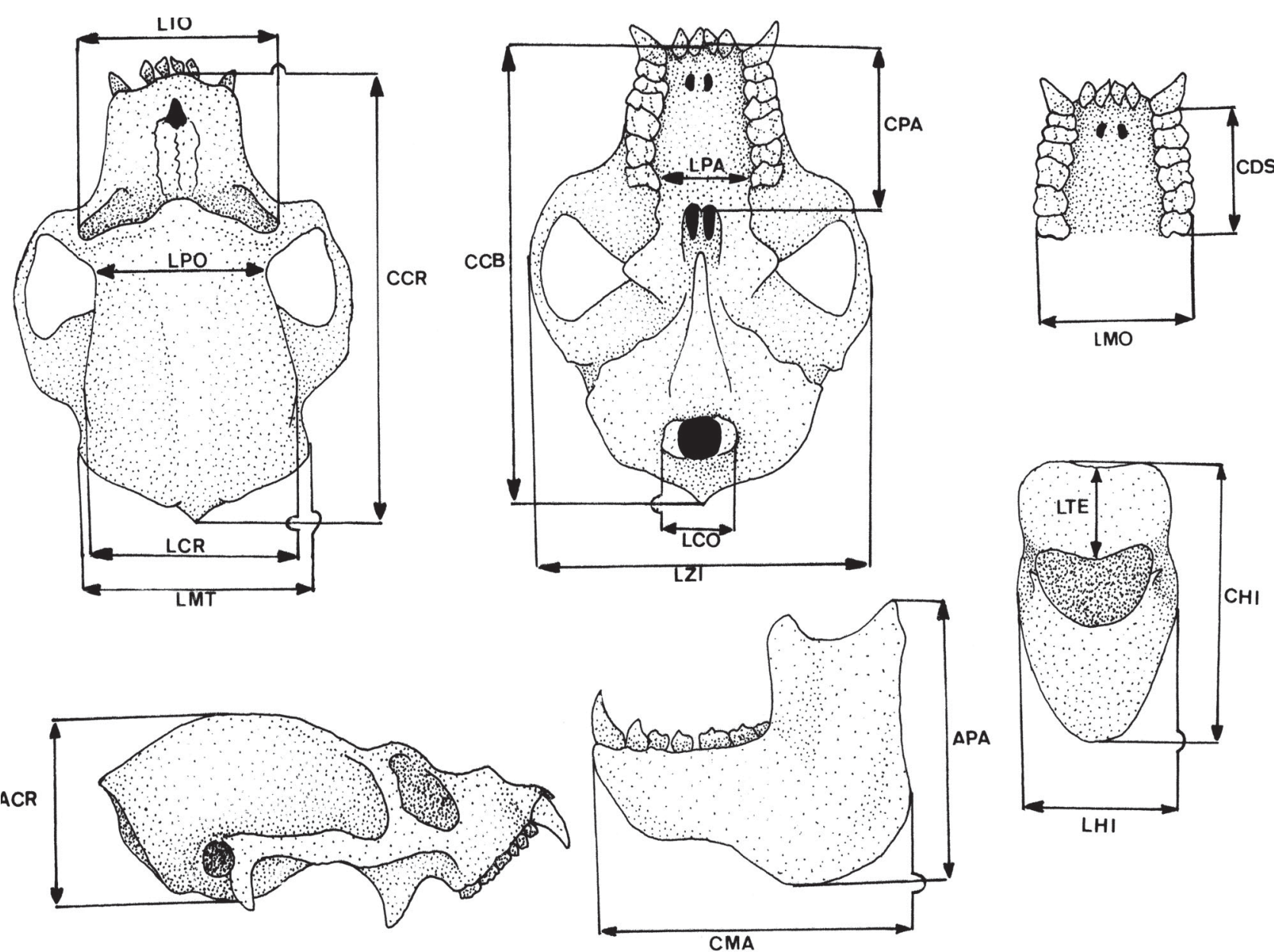

CMA

Figura 1. Esquema idealizado mostrando a delimitação das 18 medidas cranianas e do osso hióide empregadas na análise morfométrica.

Whitney, comparando uma a uma. Os testes foram significativos quando estes apresentaram probabilidade menor ou igual a $5 \%$ (p $\leq$ 0.05). Empregou-se também o teste multivariado de Análise de Componentes Principais (ACP) para cada grupo de espécie (ZAR 1999).

\section{Organização do trabalho}

Definição dos táxons. Definiu-se os táxons mediante estudo prévio da variação individual, sexual, populacional e geográfica, utilizando os caracteres morfométricos e qualitativos anteriormente padronizados. Uma considerável parcela das questões taxonômicas em Alouatta refere-se ao conceito empregado para reconhecer os táxons. Mesmo mais recentemente, onde há uma evidente necessidade e busca na explicitação da metodologia empregada, nota-se que nenhuma informação a este respeito é fornecida em muitos trabalhos taxonômicos sobre primatas. Assim, considera-se aqui as populações diagnosticáveis que compartilham características em comum (coesão), incluindo a variação, e que se diferenciam das demais nos atri- butos biológicos e geográficos como entidades independentes e de linhagem filogenética exclusiva, e portanto, reconhecidas como espécies. Este conceito é mais próximo ao filogenético de espécies proposto por CRACRAFT $(1983,1989)$. Não foram reconhecidas subespécies devido à ausência de vários aspectos para seu emprego, entre eles, os pontos de hibridação entre populações inferindo fluxo gênico, e espécies politípicas monofiléticas. O que se nota, são alguns táxons com variação notável e que se caracterizam por polimorfismo e não politipismo.

As espécies reconhecidas foram agrupadas em três áreas geográficas, a saber: I) Leste e Brasil central; II) Amazônia oriental e Nordeste; e III) Amazônia ocidental e central (ao norte do Rio Amazonas). Estes grupos não indicam coesão histórica em comum entre seus componentes (monofiletismo), mas sim uma separação prática. Por outro lado, para o processo de definição e diagnose das espécies baseou-se primariamente na comparação de táxons filogeneticamente mais próximos e em espécies politípicas historicamente reconhecidas (Tab. I). Neste 
último caso, as comparações têm o propósito de testar o monofiletismo das espécies politípicas e conseqüentemente, a validade das subespécies. Assim, considerou-se três agrupamentos taxonômicos (excetuando A. caraya) para a América do Sul e nas quais denominam-se aqui de "complexos de espécies" (Tab. I). São eles: 1) complexo "A. seniculus" que envolve os táxons historicamente considerados como subespécies ou aqueles cuja categoria taxonômica tem sido recentemente modificada (A. sara e A. macconnelli); 2) complexo "A. belzebul" composto pelas quatro ou cinco subespécies reconhecidas (Tab. I); e complexo " $A$. fusca" com as três subespécies reconhecidas.

Elaborou-se a sinonímia considerando somente os binômios a partir de LinNaeus (1758), embora na história nomenclatural e eventualmente no catálogo sinonímico aborda-se os nomes populares e/ou simples para o melhor entendimento de questões relevantes. A sinonímia inclui desde nomes inválidos até grafias incorretas e erros tipográficos. Trabalhos relacionados diretamente à taxonomia, os resultantes de inventários faunísticos e aqueles envolvendo outras áreas do conhecimento do grupo, mas direcionados a esclarecer a distribuição geográfica e a sistemática, tais como os citogenéticos e moleculares, também foram incluídos. Indubitavelmente que a grande soma de trabalhos elaborados abordando Alouatta em todas as áreas dificulta a elaboração de uma sinonímia completa. Registrouse a área de ocorrência de cada táxon reconhecido plotando em mapas os pontos que representam as localidades de coleta do material examinado, os relatos de campo fornecidos diretamente por pesquisadores e as localidades retiradas da literatura, principalmente as que descreveram inequivocamente o táxon. O trabalho enfoca estritamente os táxons de ocorrência no Brasil e, portanto não se inclui em mapas localidades de outros países discutidas no texto, embora elas delineam de maneira generalizada, a distribuição geográfica de cada táxon no continente sul-americano.

\section{RESULTADOS E DISCUSSÃO}

\section{Alouatta Lacépède, 1799}

Simia Linnaeus, 1766: 34; incluindo entre as 21 espécies: $S$. belzebul Linnaeus e $S$. seniculus Linnaeus. Espécie-Tipo: Simia sylvanus Linnaeus, 1758, por tautonomia (designada por THомаs 1911).

Cebus Erxleben, 1777: 44; espécies incluídas: C. belzebul Linnaeus, C. seniculus Linnaeus, C. capucinus Linnaeus, C. apella Linnaeus, C. trepidus Kerr, C. fatuellus Linnaeus, C. sciureus Linnaeus, C. lugubris. Espécie-tipo: Simia capucina, designada subseqüentemente por ELLIoT (1913).

Alouatta Lacépède, 1799: 570. Espécie-tipo: Simia beelzebut [sic] Linnaeus, por monotipia.

Mycetes Illiger, 1811: 70; espécies incluídas: M. belzebul Linnaeus e M. seniculus Linnaeus.

Aluata [sic]; Illiger, 1811: 70; como sinônimo de Alouatta Lacépède, 1799.

Stentor Geoffroy Saint-Hilaire, 1812: 107; espécies incluídas: $S$. seniculus Linnaeus, S. ursinus Humboldt, S. stramineus Humboldt, S. fuscus Humboldt, S. flavicaudatus Humboldt, S. niger Humboldt. Aluatta [sic]; Fischer, 1813:549.

Mycetus [sic]; Ihering, 1892: 122.

Alouata [sic]; Trouessart, 1897: 82.

Alonata [sic]; Neiva \& Penna, 1916: 106.

Eimia [sic]; Ruschi, 1964: 15.

Aloutta [sic]; Ximenez, 1973: 258.

Aluoatta [sic]; Rylands \& Brandon-Jones, 1998: 883.

\section{Descrição geral}

Dentre os caracteres diagnósticos, Alouatta apresenta osso hióide desenvolvido com o corpo central, o basehial, oco formando uma câmara de ressonância do som. Desenvolvimento acentuado da mandíbula no seu ramo vertical para o alojamento do hióide. Côndilos occipitais e forame magno em uma posição mais posterior que ventral no crânio, formando um ângulo interno obtuso com a coluna vertebral superior a $100^{\circ}$. Dimorfismo sexual acentuado no crânio e no osso hióide (Tab. II).

Na descrição geral aborda-se apenas a morfologia do osso hióide visto que este trabalho não visa a descrição do gênero. A morfologia craniana, a dentária e da pelagem já foram abordadas em outros trabalhos, tais como IHERING (1914), LÖNNBERG (1941), Hershrovitz (1949) e Hill (1962). Também, parte das observações sobre a anatomia do osso hióide no presente estudo foi devidamente relatada nas obras supracitadas e de MirandaRibeiro (1914).

A estrutura hióidea é desenvolvida e modificada em um aparato de ressonância em todas as espécies de Alouatta. Outros gêneros de primatas que apresentam o hióide modificado para emissão de som, mas e grau menos acentuado, é o sulamericano Callicebus e o africano Gorilla I. Geoffroy Saint-Hilaire 1852 (obs. pes.). Em Alouatta seu comprimento total varia de 20,4 a 43,7 mm nas fêmeas, e 32,6 a 79,1 mm nos machos e o dimorfismo sexual na estrutura é notório (Tab. II). Uma análise de séries ontogenéticas em Alouatta macconnelli e A. caraya mostra que o processo de hipermorfose ocorre nos machos. Indivíduos jovens de ambos os sexos apresentam os ossos hióides semelhantes em tamanho e forma. Quando adultos, as fêmeas retém a forma juvenil do osso, exceto o aumento proporcional das partes, enquanto nos machos adultos, há modificações na presença e no desenvolvimento de muitas das estruturas. O mesmo padrão de hipermorfose nos machos foi registrado por Ravosa \& Ross (1994) para o crânio de Alouatta. Comparando os hióides de Alouatta com os dos outros gêneros de primatas atelíneos, o complexo hióideo de Lagothrix Geoffroy Saint-Hilarie, 1812 e Ateles Geoffroy Saint-Hilaire, 1806, é composto por um corpo central, o basehial, e dois elementos adjacentes, o ceratohial e o epihial. Em Alouatta estes ossos estão fundidos formando uma estrutura única, composta por uma câmara principal oca e de paredes finas, a bula hióidea. Esta região origina-se a partir da inflação do basehial. A bula hióidea nos machos adultos de Alouatta é bem desenvolvida e de forma 


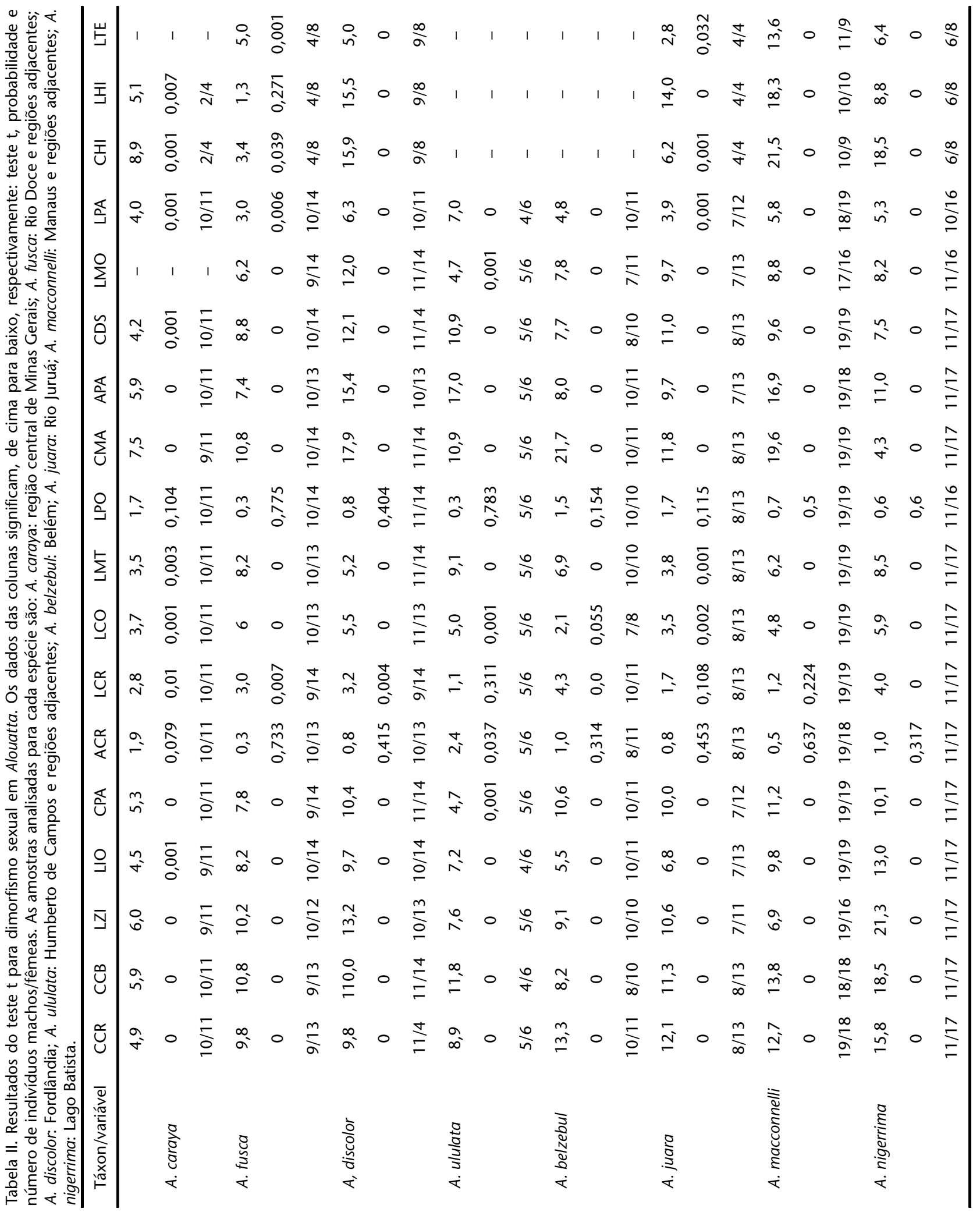

Revista Brasileira de Zoologia 23 (1): 64-144, março 2006 
globular, enquanto que nas fêmeas ela é menor, menos inflada e achatada dorso-ventralmente. Nos indivíduos machos, que apresentam a bula hióidea em grau máximo do desenvolvimento (os táxons amazônicos), há um sistema de trabéculas internas que fornece maior resistência à estrutura.

As regiões anterior e posterior do osso em Alouatta são notoriamente distintas. Enquanto a primeira é caracterizada por ser afilada e inserir-se entre os ramos mandibulares, ficando assim presa a uma musculatura potente e dificultando a sua mobilidade, a região posterior é expandida e ligada dorsalmente à cartilagem tireóide pelos ossos delgados e ligamentos tireohióideos. Este arranjo permite que esta região tenha uma maior mobilidade (LÖNNBERG 1941). A abertura hióidea está na porção póstero-ventral do osso e varia na forma e no tamanho. Em Alouatta caraya e no táxon centro-americano A. palliata, a abertura hióidea apresenta-se de forma quadrangular e ampla, sendo mais longa que larga. Em A. fusca, A. clamitans, A. belzebul, $A$. discolor e $A$. ululata a abertura é tão larga quanto longa, resultando em uma forma quadrada ou levemente ovalada. Nos demais táxons a abertura hióidea é reduzida e de forma semicircular, sendo mais larga que longa. A forma da abertura hióidea está diretamente relacionada à presença e ao desenvolvimento do tentório, que tem sua origem no dobramento da lâmina ventral na extremidade posterior do osso. O tentório apresenta formas variadas e resulta na formação de uma segunda câmara distinta, mais evidente e desenvolvida nos machos adultos que nas fêmeas. A origem do tentório a partir da parede ventral foi sugerida por IHERING (1914) e corroborado aqui mediante uma comparação entre exemplares machos de A. macconnelli em vários estágios ontogenéticos. Sua presença e suas características únicas entre as espécies faz com que o tentório tenha grande validade taxonômica e filogenética.

Látero-ventralmente à abertura hióidea há duas diminutas estruturas de aspecto lanceolado denominadas cornículos e que são homólogas aos cornos menores encontrados nos hióides de outros primatas. Nas espécies amazônicas Alouatta seniculus, A. macconnelli, A. puruensis e A. nigerrima ocorre uma expansão considerável na região imediatamente anterior aos cornículos resultando em uma inflação látero-ventral da bula hióidea. O outro par de prolongamentos látero-ventral, denominado de corno, são estruturas homólogas aos cornos maiores encontrados nos outros primatas. Os cornos são vestigiais em todas as espécies de Alouatta, exceto em A. palliata. Os cornos são relacionados à cartilagem tireóide mediante os ligamentos tireohióideos (Hershrovitz 1949).

\section{História taxonômica}

A maioria das espécies de primatas descritas por LinNaEus (1766), e pertencentes atualmente às infra-ordens Platyrrhini e Catarrhini, foi por ele incluída no gênero Simia. Posteriormente, Simia foi suprimido pela Comissão Internacional de Nomenclatura Zoológica (ICZn 1922: opinião 114). Segundo Melville \& Sмiтн (1987) "o nome Simia foi suprimido sob pleno poder para o propósito do princípio de prioridade, mas não para aqueles da homonímia" (Diretiva 24). Dentre as várias espécies descritas por Linnaeus (1766) no gênero Simia, estavam S. seniculus e S. belzebul. Sendo Simia um nome suprimido pela Comissão Internacional de Nomenclatura Zoológica (IczN 1922), as espécies $S$. seniculus e $S$. belzebul passaram a pertencer necessariamente a outro gênero.

Erxleben (1777) criou o gênero Cebus e este, assim como Simia, incluía uma série de espécies muito diferentes e que atualmente pertencem a gêneros distintos. Foram elas (em ordem de citação pelo autor): Cebus belzebul (= Alouatta belzebul), C. seniculus (= Alouatta seniculus), C. capucinus (Linnaeus, 1758), C. apella (Linnaeus, 1758), C. trepidus (Linnaeus, 1766) (sinônimo de $C$. apella), C. fatuellus (Linnaeus, 1766) e C. sciureus (Linnaeus, 1758) (= Saimiri sciureus). A diagnose do gênero fornecida por ErXLEBEN (1777) não é suficientemente clara e sua amplitude permite incluir todas as espécies acima mencionadas. Em adição, ErXLEBEN (1777) não designou espécie-tipo para Cebus, o que foi feito subseqüentemente por ELLIOT (1913) na qual indicou Cebus capucina como tal. Os conceitos dos gêneros Cebus, Alouatta e Saimiri, como reconhecidos no presente, mas incluídos em Cebus por ERXleben (1777), foi paulatinamente desenvolvido.

A descrição do gênero Alouatta por LACÉPÈDE (1799: 570) foi sucinta, entretanto inequívoca, como transcrito: "Alouatte, Alouatta: Quatre dents incisives à chaque mâchoire, tête pyramidale; point d'abajoues; queue prenante; fesses velues. Alouatte hurleur. Alouatta Beelzebut [sic]".

LACÉPÈDE (1799) incluiu em sua descrição apenas Simia belzebul sendo esta a espécie-tipo para Alouatta, por monotipia. Mesmo com a descrição inequívoca e pertinente de Alouatta por LACÉPÈDE (1799), vários autores criaram outros nomes para os macacos bugios. O gênero Mycetes, por exemplo, foi descrito por Illiger (1811) e incluiu as mesmas espécies lineanas: $M$. seniculus e M. belzebul. Apesar de IlLiger (1811) ter conhecimento do Alouatta Lacépède, publicado 12 anos antes (ILliger o citou em sua sinonímia), nenhuma argumentação foi fornecida para a mudança do nome. Neste sentido, sendo o nome Alouatta Lacépède mais antigo, este tem prioridade sobre Mycetes. Mesma atitude teve Geoffroy SAINT-Hilaire (1812), quando criou o gênero Stentor, incluindo as espécies $S$. seniculus Linnaeus, $S$. ursinus Humboldt, S. stramineus Humboldt, S. fuscus Humboldt e $S$. niger descrita por ele. Posteriormente, Stentor Geoffroy SaintHilaire também foi suprimido por pleno poder para os propósitos do princípio de prioridade e de homonímia, na Opinião 418 (Melville \& Smith 1987). Atualmente, Stentor Oken, 1815 é utilizado para designar um gênero de protozoários ciliados.

A partir de meados do século xx até o presente o nome Alouatta vem sendo utilizado pelos autores à exceção de poucos, em particular, MiRANDA-Ribeiro (1914), o qual levantou algumas questões sobre o nome correto para indicar os macacos bugios. Miranda-Ribeiro (1914) argumentou que o nome Cebus deveria ser o correto para os macacos bugios, pois ERXLEben (1777) ao descrevê-lo, colocou primeiramente em sua lista de espécies, Cebus belzebul e C. seniculus. O argumento apresenta-

Revista Brasileira de Zoologia 23 (1): 64-144, março 2006 
do por Miranda-Ribeiro (1914) não tem fundamento, pois se baseia na relação entre a espécie-tipo e a sua posição na lista fornecida pelo autor, e não em sua designação propriamente dita. Considerando a indicação de Simia belzebul como sua espécie-tipo (por monotipia) e a caracterização inequívoca feita por LACÉPÈDE (1799), Alouatta deve ser o nome mantido para os macacos bugios.

\section{TAXONOMIA DAS ESPÉCIES DO BRASIL}

\section{Leste e Brasil Central}

\section{Alouatta caraya (Humboldt, 1812)}

Caraya Azara, 1801: 208. Descrição não binomial.

Simia straminea Humboldt, 1812: 355, parágrafo 4 (espécie 10). Localidade-tipo: Originalmente designada como florestas do Grão-Pará e erroneamente restrita por CABRERA (1958) para o Rio Pará, Venezuela. Subseqüentemente, foi restrita novamente de forma equivocada para o Rio Jamundá (= Nhamundá), Faro, Estado do Pará, por Carvalho (1965). Descrição baseada no trabalho posterior de Geoffroy Saint-Hilaire (1812), que descreveu Stentor stramineus com base no espécime (Lectótipo) no 420 (368, 1822-362), fêmea, depositado no Muséum National d'Histoire Naturelle, Paris (Rode 1938, Rylands \& BRANDON-Jones 1998).

Simia caraya Humboldt, 1812: 355, parágrafo 5 (espécie 11); localidade-tipo: Paraguai. Baseado no trabalho posterior de Geoffroy SaInT-Hilaire (1812), que descreveu Stentor niger com base no espécime (Lectótipo) no 362 , macho, depositado no Muséum National d'Histoire Naturelle, Paris (Rode 1938).

Stentor stramineus; Geoffroy Saint-Hilaire, 1812: 108, parágrafo 2 (espécie 2); 1829: 21. Descrição baseada no espécime (Lectótipo) no 420 (368, 1822-362), fêmea, depositado no Muséum National d'Histoire Naturelle, Paris (Rode 1938, Rylands \& BRANdon-Jones 1998).

Stentor niger Geoffroy Saint-Hilaire, 1812: 108, parágrafo 3 (espécie 6). Localidade-tipo: Paraguai. Descrição baseada no espécime (Lectótipo) n 362, macho, depositado no Muséum National d'Histoire Naturelle, Paris, (Rode 1938). -Geoffroy Saint-Hilaire, 1829: 22. -Carneiro, 1908: 13.

Mycetes coraya [sic]; Illiger, 1815: 73.

Mycetes faunus Illiger, 1815: 107. Localidade-tipo: Paraguai. Descrição baseada no "caraya" de AzARA (1801).

M[ycetes] Belzebul [sic]; Olfers, 1818: 195, partim.

Mycetes niger; Kuhl, 1820: 31. Wied, 1826: 66. -Geoffroy SaintHilaire, 1851: 53. -Castelnau, 1855: 4. -Schlegel, 1876: 149. -Pelzeln, 1883: 5. -Jentink, 1887: 32. -Meerwarth, 1903: 125.

Mycetes barbatus Spix, 1823: 46, pls 32 e 33. Localidade-tipo: interior da Bahia, na Caatinga. Descrição baseada na ilustração de uma fêmea no Museum de Berlim. -Gray, 1845: 220; 1870: 41.

M[ycetes] niger; Wied, 1826: 66. -Geoffroy Saint-Hilaire, 1851: 53. Mycetes caraya; Lesson, 1827: 51. -Lesson, 840: 122, partim. Gray, 1845: 220. -Gray, 1870: 4. -Goeldi, 1893: 37.

Mycetes ater Desmarest, 1827: 285; como sinônimo de Stentor niger Geoffroy Saint-Hilaire (1812).

Cebus caraya; Fischer, 1829: 44. -Miranda-Ribeiro, 1914: 5.

M[ycetes] chrysurus; Geoffroy Saint-Hilaire, 1851: 52, partim.

Aluatta [sic] nigra; Slack, 1862: 518.

Alouatta beelzebul [sic]; Slack, 1862: 510; partim.

Mycetes belzebul; Cope, 1889: 148.

Alouatta nigra; Forbes, 1896: 195.

Alouata [sic] nigra; Trouessart, 1897: 33. -Allen, 1900: 227. Bertoni, 1939: 13.

Stentor ursinus; Carneiro, 1908.

Alouatta caraya; Cabrera, 1912: 24. -Ihering, 1914: 238. -Allen, 1916a: 586. -Miller, 1930: 16. -Cabrera, 1939: 15. -Cabrera \& Yepes, 1940:108. -Lönnberg, 1941: 35. -Vieira, 1944: 9. Vieira: 1951: 108. -Serra, 1952: 229. -Vieira, 1955: 381. Vieira, 1957: 153. -Cabrera, 1958: 153. -Carvalho, 1960: 125. -Hill, 1962: 139. -Ávila-Pires, 1966: 337. -Voss, 1973: 11. -Napier, 1976: 79. -Carvalho, 1980: 58. -Azevedo et al., 1982: 96. -Wolfheim, 1983: 211. -Thorington \& Anderson, 1984. -Stallings, 1989: 137. -Lorini \& Persson, 1990; 124. Hirsch et al., 1991: 239. -Anderson et al., 1993: 31. -Groves, 1993: 254. -Auricchio, 1995: 133. -Villalba et al., 1995: 173; -Brooks, 1996:16. -Anderson, 1997: 304. -Chame \& Olmos, 1997: 75. -Flesher, 2001: 19.

Alouatta straminea; Elliot, 1913: 265, como sinônimo de $A$. caraya.

Alouata [sic] caraya; Rode, 1938: 225.

Alouatta caraja [sic]; Chiarelli, 1972: 168.

Alouatta caraya caraya; McLaren et al., 1984: 466.

\section{Material examinado (total 136)}

Brasil: Bahia: Malhada: MNRJ: 21070-77 (p, c, h); Carinhanha: MNRJ: 21080-81 (p, c, h), 21082 (p, c); Cotegipe: MNRJ: 21078-79 (p, c, h); Santa Rita de Cassia: MZUSP: 857779 (p, c). Goiás: Aragarças: MPEG: 1522 (p, c); Bela Vista: MZUSP: 11110 (p); Goiânia: MZUSP: 1907 (p); Rio Palma: MNRJ: 2426 (p, c, h), 2427 (p), 2428-29 (p, c, h), 2754-55 (p), 2764 (p, c, h); São José do Tocantins: MZUSP: 6492 (c, h); Rio São Miguel: MNRJ: 2933 (p, c, h), 2935 (p, c, h). Maranhão: Gurupira, alto do Rio Paraíba: MPEG: 23046 (p, c, h). Mato Grosso: Cáceres: MNRJ: 2738 (p), 5831 (p, c), 5832 (p), 31305-06 (c), 31310 (c), 31322 (c); Jacaré, alto do Rio Xingu: MNRJ: 11704 (p, c, h); Maracaju: MNRJ: 4794 (p, c); Paratuval: MNRJ: 2736 (p); Porto Esperidião: MNRJ: 21069 (p, c), 2509-10 (p, c, h), 25012 (p, c, h); São Domingos, Rio das Mortes: MZUSP: $6958-59$ (p, c, h); Ilha Taimã: MZUSP: 1906 (p, c). Mato Grosso do Sul: Aquidauana: MZUSP: 7787 (p, c, h); Campo Grande: MNRJ: 4813 (p, c); Corumbá: MZUSP: 3364-65 (c, h); Miranda: MZUSP: 3769 (p, c, h); Porto XV: MZUSP: 19033-34 (p); Salobra: MZUSP: 589192 (p, c). Minas Gerais: Araguari: MNRJ: 4819 (p, c); Curvelo: MNRJ: 21083-84 (p, c, h), 31233 (c, h), 31241-42 (c, h), 31249 (c, h); Pirapora: MZUSP: 3052 (p, c), 3053 (c), 3054 (p, c, h), 3055 e 3056 (p, c), 3057 (c), 3058-61 (p, c), 3108-10 (p, c), 3288 (c); Presidente Olegário: MNRJ: 23115-20 (p, c), 23121 (c), 23122 (p, c). Paraná: Foz do Iguaçu: MHNCI: 219 (p, c), 222 
(p, c), 224 (p, c), 247 (p), 295 (p, c), 296 (p); Guaíra: MHNCI: 2550 (p, c); Rio Pacaraí: MZUSP: 7707 (p, c, h), 7708 (c, h), 7709 (p, c, h): Querência do Norte: MZUSP: 11153 (p), 11155 (p, c), 11156 (c), 11158-59 (p, c), 19176 (p), 19178 (p), 19182 (c); Sertão do Rio Paraná: MHNCI: 31-32 (p, c, h), 39 (p, c). Rio Grande do Sul: São Francisco de Assis: MPEG: 22181 (p, c); São Luiz Gonzaga: MNRJ: 21085-86 (p, c, h), 31259 (c, h), 31263 (c, h), 31267 (c, h), 31269 (c, h), 31277-79 (c, h), 31282-84 (c, h). São Paulo: Itapura: MZUSP: 1929 (p, c, h), 1930 (p, c, h), 1931 (c), 1942 (c, h); Rio Grande: MZUSP: 1401 (p, c, h), 1402-04 (c, h), 1405 (p), 1406 (c, h), 1407 (p, c, h), 1408-09 (c), 1411 (c), 1414 (c), 1416 (c). Tocantins: Barra do Rio São Domingos: MZUSP: 4240 (c); Conceição do Araguaia: MPEG: 1155 (c).

\section{Localidade-tipo}

Paraguai. Uma das primeiras citações de um primata identificável como A. caraya foi de AzARA (1801) em seu trabalho sobre os quadrúpedes do Paraguai, e na subseqüente descrição original do táxon por HumboldT (1812), não há indícios do coletor tampouco da localidade mais precisa da proveniência do material. O espécime na qual Simia straminea Humboldt, 1812 foi descrita é o mesmo de Stentor stramineus Geoffroy Saint-Hilaire, 1812, cujo material foi apropriado do Real Museu de Lisboa pela França no ano de 1808, durante a invasão francesa naquele país. Parte do material descrito por Geoffroy SaINT-Hilaire foi coletado pelo brasileiro Alexandre R. Ferreira, então diretor assistente do Real Museu de Lisboa (CARvalho 1965). Na descrição original, Humboldt (1812) menciona "Florestas do Grão Pará" que poderia ser a região do Rio Pará, na Venezuela, ou a Capitania do Grão Pará, Brasil. Entretanto, A. R. Ferreira coletou também nas Capitanias do Rio Negro, Mato Grosso e Cuiabá (RyLands \& BrANDON-Jones 1998). Assim, com a incerteza da proveniência mais restrita do material coletado por A. R. Ferreira, a localidade-tipo desta espécie ainda necessita de mais investigação (RYLAnDs \& BRANDON-Jones 1998). Como o espécime no qual Simia stramineus foi descrita se trata de $A$. caraya, conhecido há muito por não ocorrer na região da Floresta Amazônica, certamente que a localidade-tipo restrita para o Rio Pará (Venezuela) ou para qualquer área florestada do Estado do Pará, Brasil, é errônea.

\section{Distribuição geográfica}

A figura 2 mostra a distribuição geográfica de $A$. caraya no Brasil. Na Argentina, a espécie ocorre apenas nas regiões nordeste e norte (CRESPO 1952). No Paraguai A. caraya ocorre nas regiões norte, sul e leste do Chaco (Stallings 1989, Brooks 1996), e na Bolívia, nas porções leste e norte (LÖNNBERG 1941, ANDERson 1997). Há indícios, sem registro direto, da ocorrência no norte do Uruguai (Villalba et al. 1995).

No Brasil, $A$. caraya ocorre por toda a região central nos Estados do Mato Grosso, Mato Grosso do Sul, Goiás, Tocantins, Bahia, Minas Gerais e sul do Pará, Maranhão e Piauí (diagonal seca da América do Sul). Nos Estados da região Sul, a espécie ocorre em uma faixa na margem esquerda do Rio Paraná, possivelmente em simpatria com $A$. clamitans, como atestam os

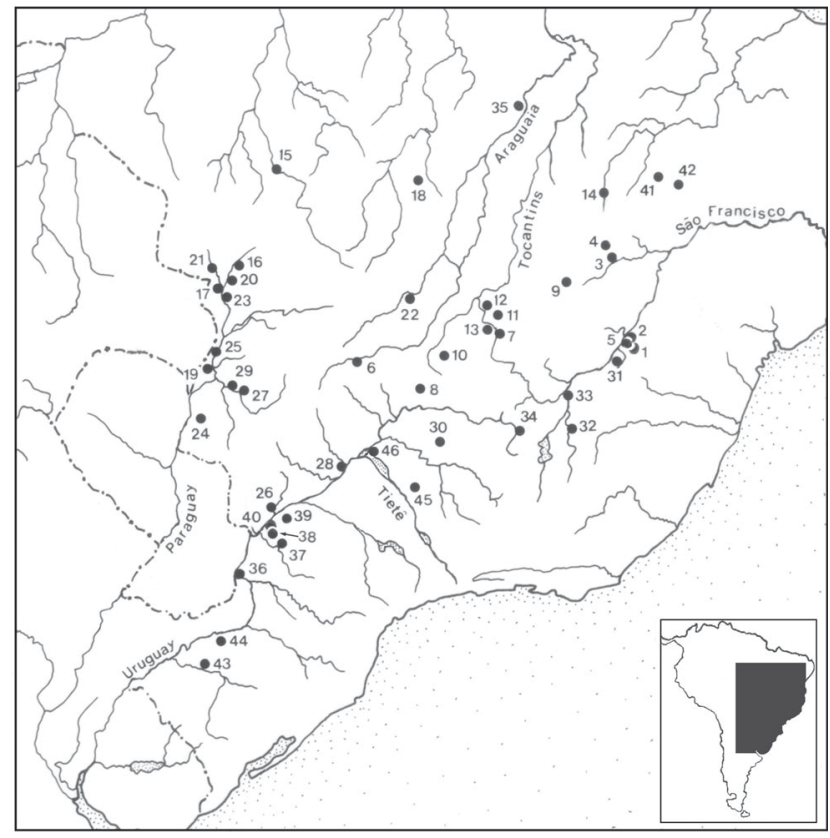

Figura 2. Mapa indicando a distribuição geográfica de $A$. caraya no Brasil. Este padrão de distribuição é basicamente concordante com o bioma Cerrado. Os dados sobre as coordenadas estão no Anexo I.

exemplares provenientes dos municípios de São Francisco de Assis e São Luiz Gonzaga, ambos no Estado do Rio Grande do Sul, e Querência do Norte e Rio Pacaraí, no Paraná (ver Material Examinado). No Estado de São Paulo, A. caraya ocorre nas regiões norte e noroeste. O ponto mais ao norte da distribuição da espécie é a região limítrofe entre o Cerrado e a hiléia, como atestam os exemplares do Rio Arrais, Mato Grosso, e alto Rio Parnaíba, Maranhão, e entre o Cerrado e a Caatinga, no Estado do Piauí (Chame et al. 1995, Chame \& Olmos 1997, Flesher 2001). Ao leste de sua distribuição, $A$. caraya ocorre ao longo de toda vertente oeste do complexo da cordilheira Atlântica, mas se ausentando na Floresta Pluvial Atlântica (stricto sensu).

Alouatta caraya apresenta a maior área de distribuição geográfica dentre as espécies do gênero que ocorrem no Brasil. Apesar de a espécie ser conhecida por estar associada diretamente às formações predominantemente abertas, como o Cerrado e o Pantanal, $A$. caraya é encontrado nas matas ripárias e capões de mata do Brasil central, assim como nas matas semi-decíduas do Paraguai e dos Estados de São Paulo e Minas Gerais.

\section{Caracteres Diagnósticos}

Dicromatismo sexual acentuado: coloração da pelagem no macho toda negra (Fig. 3) e na fêmea castanho-amarelado claro com uma faixa sagital dorsal larga, desde a cabeça até a base da cauda, de coloração castanho escuro a acinzentada (Fig. 4); pilosidade facial acentuada. Osso hióide no macho com 


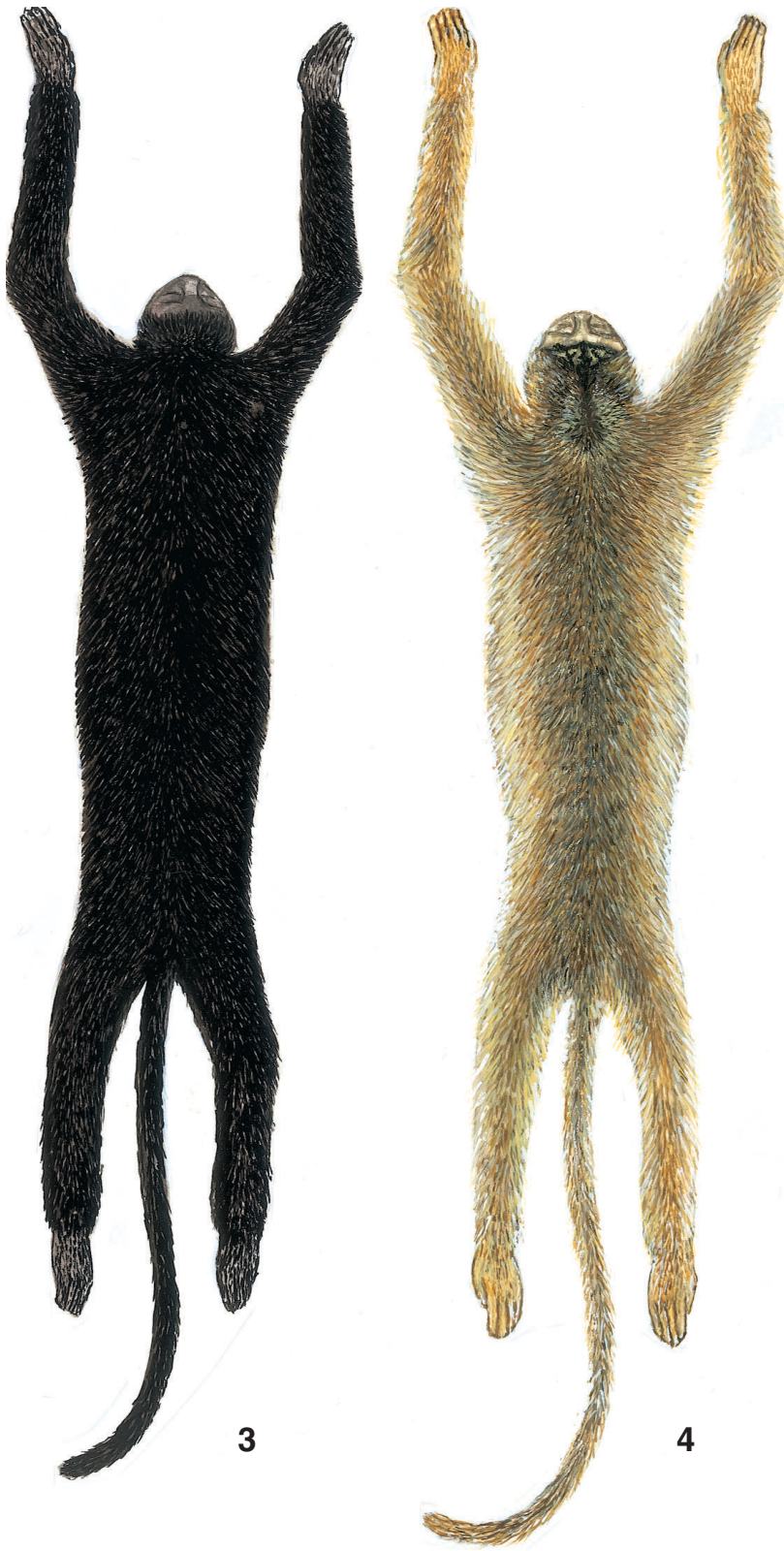

Figuras 3-4. Ilustração, em vista dorsal, definindo os padrões mais freqüentes de coloração da pelagem em A. caraya: (3) macho (MZUSP 3934); (4) fêmea (MZUSP 11155).

tentório ausente ou rudimentar, conferindo-lhe uma bula de forma retangular (Figs 5-8).

\section{Descrição geral}

As medidas cranianas e do osso hióide estão nas tabelas III e IV. Macho adulto com barba rala e negra, tornando-se castanho no pescoço. Coloração da pelagem do animal toda negra (Fig. 3), opaca e macia. Pêlos em todas as regiões do corpo de base castanho escuro com o terço apical negro. Face com pilosidade acentuada e de coloração castanho claro. Pêlos da região lateral muito longos. Fêmea adulta (Fig. 4) com barba rala cuja coloração varia desde amarela clara a castanho escuro, escurecendo no mento; pêlos nas regiões posteriores à orelha e pescoço mais claros e brilhantes. Cabeça com pelagem curta, variando desde amarela clara a castanho, com pêlos negros dispostos de maneira enfileirada, formando uma malha, quando observada dorsalmente. Região látero-dorsal com pêlos de base castanho escuro e ponta castanho claro. Região médio-dorsal com pelagem mais escura, formando uma faixa larga distinta, desde a cabeça até a base da cauda, de cor castanho escuro; pêlos nesta região com base castanho escuro e terço apical amarelado. Membros anteriores e posteriores com coloração castanho claro a amarela pálida, escurecendo na região mais externa do antebraço e coxa; pêlos nestas regiões uniformemente coloridos, sem bandeamento. Mãos e pés amarelos a dourados brilhantes, às vezes, de uma tonalidade acinzentada. Base da cauda com pêlos castanhos escuros clareando em direção à sua extremidade apical, na qual apresenta coloração castanho claro a amarela. Jovens de ambos os sexos apresentam uma coloração amarelada a castanho claro. A barba é menos desenvolvida que dos adultos e de cor castanho-avermelhado. Pêlos da cabeça de coloração amarela clara com pequenas fileiras de pêlos negros, como na fêmea adulta. Pêlos das regiões dorsal e lateral com a base castanho escuro e ápice castanho claro. Região lombar geralmente de coloração avermelhada e mais escura que o restante do dorso. Membros anteriores e posteriores castanhos de várias tonalidades; mãos e pés com pelagem mais brilhante e de coloração amarela a dourada. Cauda de cor castanho-avermelhado ou castanho-claro.

Comprimento total do hióide no macho adulto de 49,2 a 58,3 mm ( $\mathrm{N}=10)$. Tentório ausente; cornículos lanceolados e reduzidos. Bula hióidea de forma mais quadrilátera (Figs 5 e 7) que globular, afilando na extremidade anterior; abertura hióidea retangular e muito desenvolvida em relação ao osso todo. Comprimento total do osso hióide na fêmea adulta de 30,3 a 38,5 $\mathrm{mm}(\mathrm{N}=8)$. Tentório ausente; cornículos desenvolvidos (Figs 6 e 8) e de forma lanceolada. A forma da bula hióidea é semelhante àquela do macho. Os ossos nasais são curvos em vista lateral em ambos os sexos.

Cariótipo. números diplóide (2n) e fundamental (NF) iguais a 52 e 70, respectivamente (Mudry-de-PARgament et al. 1984, Oliveira 1996, Oliveira et al. 2002). Não há translocações Y-autossomo e o número diplóide é conservado em todos os indivíduos provenientes de regiões distintas.

\section{Variação}

Os dados ontogenéticos mostram que todos os indivíduos, de ambos os sexos, quando jovens apresentam a pelagem castanho-amarelada com dorso mais escuro. Durante o desenvolvimento ontogenético, a fêmea retém as características juvenis de pelagem castanho-amarelado claro enquanto os machos sofrem alterações no seu padrão de coloração. Indivíduos machos jovens (por exemplo, MZUSP 1408, 3109 e 8579; MNRJ

Revista Brasileira de Zoologia 23 (1): 64-144, março 2006 

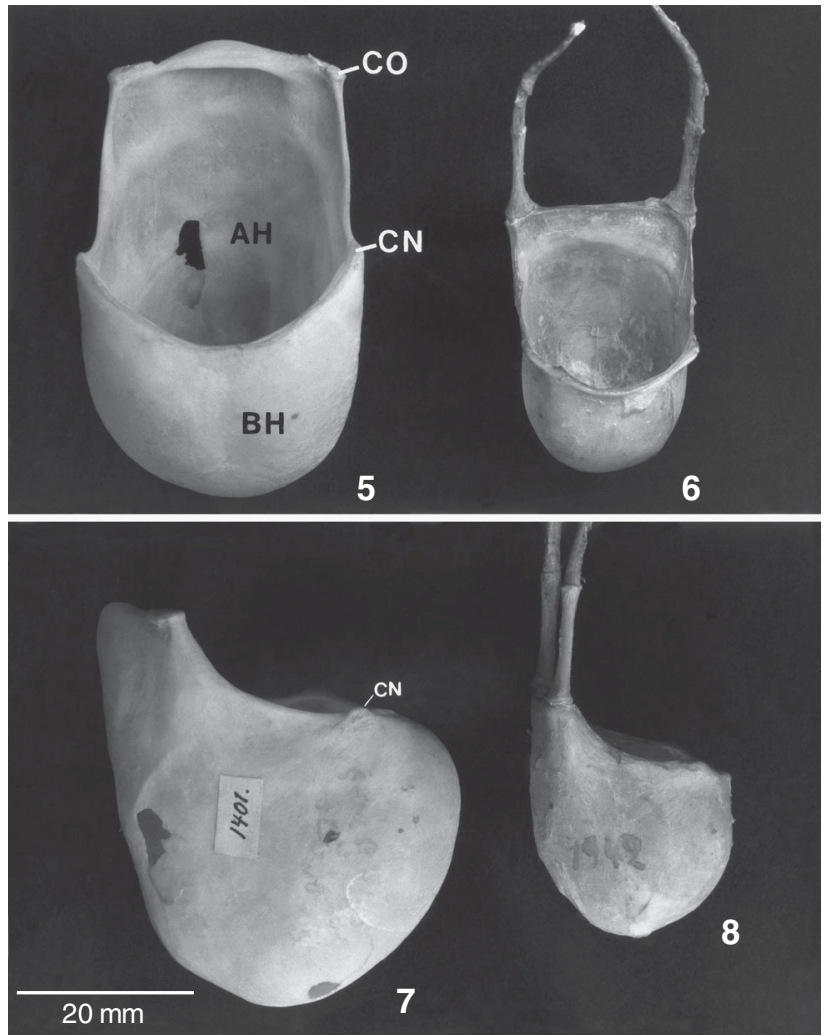

Figuras 5-8. Osso hióide de A. caraya: (5 e 7) indivíduo macho (MZUSP 1401) em vista ventral e lateral, respectivamente; (6 e 8) indivíduo fêmea (MZUSP 1942) em vista ventral e lateral respectivamente. Note a ausência (ou redução extrema) do tentório, a bula hióidea relativamente rasa e a abertura hióidea quadrangular. (AH) Abertura hióidea, $(\mathrm{BH})$ bula hióidea, $(\mathrm{CN})$ cornículo, $(\mathrm{CO})$ corno.

$4819,21082,21084$ e 5831) apresentam coloração castanhoamarelada com dorso castanho escuro. Na fase subadulta, os machos se tornam mais escuros e avermelhados (MZUSP 6958, 19034, 3108; MNRJ 21075, 23119) somado ao crescimento acentuado da barba. A pelagem dorsal escurece de castanho claro para castanho-avermelhado ou negra. Quando na fase adulta, os machos tornam-se totalmente negros e as fêmeas permanecem com o mesmo padrão de coloração castanho claro.

As variações individuais encontradas em relação ao padrão típico de coloração anteriormente descrito para as fêmeas adultas são: animais com pelagem amarela pálida muito brilhante, quase branca, por todo o corpo (MNRJ 2738 de Cáceres, MNRJ 2743 do Rio Arinos e MNRJ 11704 de Jacaré, todos do estado do Mato Grosso); pelagem apresentando a tonalidade acinzentada em animais de Malhada, Bahia (MNRJ 21073, 21074); os indivíduos provenientes de localidades próximas ao Rio Paraná, tais como Ilha Presidente Tibiriçá e Querência do Norte (MZUSP 7709, 11153, 11155, 28548), mostraram a região lombar e barba mais avermelhadas.
A variação individual na coloração da pelagem nos machos adultos é de menor intensidade e freqüência de campos cromatogênicos diferentes do habitual. Basicamente os animais têm coloração da pelagem completamente negra e apresentam uma variação quanto à presença de pêlos castanho-avermelhados em regiões específicas do corpo, dando uma aparência brilhante ao animal, principalmente na barba, dorso e cauda (MNRJ 2764 do Rio Palma, Goiás e MNRJ 25012 de Porto Espiridião, Mato Grosso). Outro padrão variante relatado refere-se à retenção de pêlos juvenis de cor amarela ou dourada, mesmo que de forma esparsa, nas regiões dorsal, membros e cauda. Este padrão foi encontrado nos indivíduos MZUSP 3056 e 3058 de Pirapora, Minas Gerais, MZUSP 6958 de São Domingos, Mato Grosso, e MZUSP 5892 de Salobra e MZUSP 19033-34 de Porto XV, ambos do Mato Grosso do Sul. Quatro indivíduos da região próxima ao Rio Paraná (MZUSP 6958 e 6959 do Mato Grosso, MZUSP 3769 do Mato Grosso do Sul e MZUSP 7707 do Paraná) apresentaram uma dobra incipiente, sugerindo a presença do tentório. De qualquer forma, esta condição é muito diferente daquelas encontradas nos demais táxons de Alouatta.

Para a análise estatística compararam-se cinco amostras definidas pela inclusão das seguintes localidades: 1) São Domingos das Mortes, Ilha Taimã, Salobra e Cáceres (Mato Grosso), e Corumbá e Miranda (Mato Grosso do Sul); 2) Pirapora e Curvelo (Minas Gerais); 3) Rio Grande e Itapura (São Paulo); 4) Rio Pacarai e Querência do Norte (Paraná); e 5) São Luiz Gonzaga (Rio Grande do Sul). As tabelas III e IV apresentam os dados da estatística descritiva das cinco. O resultado da análise de comparação múltipla das variâncias (ANOVA) para ambos os sexos evidenciou que as populações se mostraram significativamente semelhantes em todas as medidas. A ausência de tentório em quase todas as amostras analisadas não permitiu o estudo de variância para esta estrutura, mas uma comparação direta dos dados plotados na tabela III pode ser feita.

Alouatta caraya se diferencia notadamente dos táxons limítrofes por não apresentar o tentório. Para uma comparação direta, vide a descrição da estrutura hióidea na seção referente ao gênero e as figuras 5 e 7. A espécie também difere dos outros táxons de Alouatta por caracteres relacionados à coloração da pelagem, embora ela lembre superficialmente A. ululata. Assim, $A$. caraya se distingue da espécie limítrofe a leste, $A$. clamitans, por apresentar fêmeas de coloração amarelada em vez de castanho escuro a enegrecida, e machos totalmente negros em contraste com os ruivos a avelã de $A$. clamitans. $\mathrm{Na}$ área setentrional de sua distribuição, A. caraya limita-se com várias espécies do gênero, mas seu dicromatismo sexual a separa facilmente de A. belzebul, na qual também apresenta alguns indivíduos machos completamente negros, porém as fêmeas nunca são claras; $A$. caraya difere de $A$. juara e $A$. puruensis, táxons amazônicos, por estes terem a coloração da pelagem ruiva a dourada; $A$. caraya difere de $A$. ululata, táxon que ocorre no norte dos Estados do Maranhão, Piauí e Ceará, por este último apresentar os indivíduos machos com as extremidades do membro, da cauda e partes dorsais ruivas.

Revista Brasileira de Zoologia 23 (1): 64-144, março 2006 
Tabela III. Dados morfométricos ( $\mathrm{mm}$ ) de cinco amostras de A. caraya no Brasil (somente machos). Linha superior: média, desvio padrão e número de indivíduos analisados (em parênteses), respectivamente; linha inferior: mínimo e máximo.

\begin{tabular}{|c|c|c|c|c|c|}
\hline Variável & 1 - MT e MS & $2-M G$ & $3-S P$ & $4-P R$ & $5-R S$ \\
\hline \multirow[t]{2}{*}{$\mathrm{CCR}$} & $126,2 \pm 2,8(8)$ & $120,5 \pm 2,4(2)$ & $124,3 \pm 6,3(5)$ & $125,0 \pm 4,2(2)$ & $122,2 \pm 0,8$ \\
\hline & $123,3-130,6$ & $118,8-122,3$ & $118,8-132,5$ & $122,0-128,0$ & $121,5-123,2$ \\
\hline \multirow[t]{2}{*}{$\mathrm{CCB}$} & $114,9 \pm 3,4(8)$ & $111,1 \pm 4,8(2)$ & $110,4 \pm 4,3(5)$ & $114,4 \pm 6,4(2)$ & $113 \pm 1,6(3)$ \\
\hline & $111,8-121,3$ & $107,7-114,6$ & $104,8-116,8$ & $109,9-119,0$ & $111,2-114,4$ \\
\hline \multirow[t]{2}{*}{ LZI } & $83,7 \pm 3,3(6)$ & $84,1 \pm 6,1(2)$ & $82,8 \pm 3,2(5)$ & $85 \pm 1,4(2)$ & $83,8 \pm 1,5(3)$ \\
\hline & $81,5-90,4$ & $79,8-88,5$ & $78,8-86,2$ & $84,0-86,0$ & $82,4-85,4$ \\
\hline \multirow[t]{2}{*}{ LIO } & $62,1 \pm 2,2(8)$ & $63,9 \pm 4,3(2)$ & $62,5 \pm 3,7(5)$ & $61,1 \pm 1,8(2)$ & $62 \pm 2,8$ \\
\hline & $59,7-66,6$ & $60,8-67,0$ & $57,1-66,1$ & $59,8-62,4$ & $60,2-65,3$ \\
\hline \multirow[t]{2}{*}{ CPA } & $44,7 \pm 2,3(8)$ & $44,1 \pm 2,9(2)$ & $44,4 \pm 2,8(5)$ & $46,9 \pm 0,3(2)$ & $46,3 \pm 0,8$ \\
\hline & $41,6-48,8$ & $42-46,2$ & $41,7-48,5$ & $46,7-47,2$ & $45,4-47,0$ \\
\hline \multirow[t]{2}{*}{$A C R$} & $42,6 \pm 5,2(8)$ & $41,5 \pm 0,1(2)$ & $41,1 \pm 0,7(5)$ & $38,8 \pm 1,2(2)$ & $40,9 \pm 3,1(3)$ \\
\hline & $39,3-55,2$ & $41,4-41,6$ & $40,2-42,2$ & $38-39,7$ & $37,6-43,9$ \\
\hline \multirow[t]{2}{*}{ LCR } & $52,4 \pm 2,2(8)$ & $54,7 \pm 1,7(2)$ & $51,3 \pm 1,4(5)$ & $52,7 \pm 0,2(2)$ & $51,3 \pm 2,0$ (3) \\
\hline & $48,1-55,2$ & $53,5-56,0$ & $48,9-52,4$ & $52,5-52,9$ & $49,7-53,7$ \\
\hline \multirow[t]{2}{*}{ LCO } & $24,0 \pm 0,9(8)$ & $23,6 \pm 0,0(2)$ & $24,1 \pm 1,9(5)$ & $24,1 \pm 1,4(2)$ & $23 \pm 0,3(3)$ \\
\hline & $22,4-25,5$ & $23,6-23,7$ & $22,7-27,5$ & $23,1-25,2$ & $22,8-23,4$ \\
\hline \multirow[t]{2}{*}{ LMT } & $55,4 \pm 1,9(8)$ & $55,7 \pm 0,4(2)$ & $55,6 \pm 2,1(5)$ & $56,4 \pm 0,4(2)$ & $56,7 \pm 0,4(3)$ \\
\hline & $52,5-59,0$ & $55,4-56,1$ & $53,3-58,3$ & $56,1-56,8$ & $56,3-57,1$ \\
\hline \multirow[t]{2}{*}{ LPO } & $40,5 \pm 2(8)$ & $43,3 \pm 2,6(2)$ & $40,6 \pm 2,4(5)$ & $40,2 \pm 0,9(2)$ & $40,1 \pm 1,2(3)$ \\
\hline & $38,4-43,6$ & $41,5-45,2$ & $37,2-43,5$ & $39,6-40,9$ & $38,9-41,3$ \\
\hline \multirow[t]{2}{*}{ CMA } & $97,3 \pm 3,3(8)$ & $98 \pm 8,2(2)$ & $99,8 \pm 5,9(5)$ & $98,2 \pm 1,4(2)$ & $97 \pm 1,6(3)$ \\
\hline & $94,5-103,4$ & $92,2-103,8$ & $94,5-109,7$ & $97,2-99,2$ & $95,2-98,1$ \\
\hline \multirow[t]{2}{*}{ APA } & $76,5 \pm 5,1(8)$ & $76,7 \pm 8,6$ & $76,4 \pm 2,3(5)$ & $77,3 \pm 0,9(2)$ & $79 \pm 0,6(3)$ \\
\hline & $71,9-88,2$ & $70,6-82,9(2)$ & $74,1-79,0$ & $76,7-78,0$ & $78,4-79,6$ \\
\hline \multirow[t]{2}{*}{ CDS } & $42,5 \pm 1(8)$ & $42,3 \pm 2,0(2)$ & $42,3 \pm 1,5(5)$ & $42,2 \pm 0,21(2)$ & $41,7 \pm 0,6(3)$ \\
\hline & $40,7-44,1$ & $40,9-43,8$ & $40,6-44,6$ & $42-42,4$ & $41,1-42,4$ \\
\hline \multirow[t]{2}{*}{ LML } & $41,9 \pm 1,8(8)$ & $43,6 \pm 3,1(2)$ & $41,6 \pm 0,9(5)$ & $43,3 \pm 2,3(2)$ & $41,8 \pm 0,2(2)$ \\
\hline & $38,6-45,0$ & $41,4-45,9$ & $40,3-42,7$ & $41,7-45,0$ & $41,7-42,0$ \\
\hline \multirow[t]{2}{*}{ LPA } & $26,8 \pm 1,4(8)$ & $27,1 \pm 2,6(2)$ & $25,7 \pm 1,9(5)$ & $27,5 \pm 2,8(2)$ & $26,5 \pm 1,0(3)$ \\
\hline & $25,3-29,9$ & $25,3-29,0$ & $24,2-29,1$ & $25,5-29,6$ & $25,5-27,5$ \\
\hline \multirow[t]{2}{*}{$\mathrm{CHI}$} & $52,4 \pm 3,7(5)$ & - & $52,8 \pm 4,2(4)$ & $55,5(1)$ & $47,5 \pm 1,6(3)$ \\
\hline & $49,2-58,3$ & & $48,8-57,8$ & & $46,0-49,3$ \\
\hline \multirow[t]{2}{*}{ LHI } & $32,0 \pm 3,4(5)$ & - & $31,5 \pm 1,7(5)$ & $32,0(1)$ & $29,6 \pm 2,7$ (3) \\
\hline & $29,2-37,0$ & & $29,6-34,0$ & & $26,6-32,0$ \\
\hline \multirow[t]{2}{*}{ LTE } & $3,2 \pm 4,4(5)$ & - & 0,0 & $5,0(1)$ & $0,0(3)$ \\
\hline & $0,0-8,3$ & & & & \\
\hline
\end{tabular}

\section{História taxonômica}

A primeira obra que menciona a espécie Alouatta caraya de forma objetiva, porém não binomial, foi a de AzARA (1801) quando descreveu os quadrúpedes do Paraguai. O autor discorreu sobre a origem do nome "caraya" como sendo decorrente do termo indígena guarani Caayá (ou Karayá, segundo CABRERA 1939) que significa bugio-preto naquela língua. AzARA (1801) descreveu de forma relativamente minuciosa a pelagem de um macho escuro e uma fêmea mais clara, ambos adultos. A primeira descrição binomial da espécie foi de Humboldt (1812: 255, parágrafo 4) quando descreveu sua décima espécie do gênero Simia: "10. Simia straminea, stentorosa, pilis basin subfuscis, ápice straminei coloris". 
Tabela IV. Dados morfométricos ( $\mathrm{mm}$ ) de cinco amostras de $A$. caraya no Brasil (somente fêmeas). Linha superior: média, desvio padrão e número de indivíduos analisados (em parênteses), respectivamente; linha inferior: mínimo e máximo.

\begin{tabular}{|c|c|c|c|c|c|}
\hline Variável & 1 - MT e MS & $2-\mathrm{MG}$ & $3-S P$ & $4-P R$ & $5-R S$ \\
\hline \multirow[t]{2}{*}{ CCR } & $101,4 \pm 0,6(3)$ & $104,7 \pm 3,9(11)$ & $103,0 \pm 3,5(4)$ & $103,9 \pm 1,4(3)$ & $102,7 \pm 2,5(7)$ \\
\hline & $100,9-102,2$ & $95,2-109,0$ & $98-106,1$ & $102,3-105$ & $97,9-105,5$ \\
\hline \multirow[t]{2}{*}{$\mathrm{CCB}$} & $89,8 \pm 0,2(3)$ & $91,4 \pm 3,2(11)$ & $89,8 \pm 3,4(4)$ & $91,9 \pm 1,4(3)$ & $90,8 \pm 3,1(7)$ \\
\hline & $89,6-90,1$ & $85,6-97,0$ & $84,6-91,7$ & $90,2-93$ & $85,2-93,8$ \\
\hline \multirow[t]{2}{*}{ LZI } & $67,8 \pm 2,0(3)$ & $69,3 \pm 2,4(10)$ & $67,7 \pm 2,1$ & $68,3 \pm 0,8(3)$ & $67,5 \pm 1,1(6)$ \\
\hline & $66,3-70,2$ & $63,6-72,3$ & $65,7-70,0$ & $67,6-69,3$ & $65,6-68,6$ \\
\hline \multirow[t]{2}{*}{ LIO } & $53,2 \pm 0,5$ & $54,8 \pm 2,4(11)$ & $54,3 \pm 1,3(4)$ & $53,2 \pm 0,9(3)$ & $52,0 \pm 0,8(7)$ \\
\hline & $52,8-53,9$ & $48,8-57,7$ & $53,0-56,0$ & $52,4-54,2$ & $50,5-53,1$ \\
\hline \multirow[t]{2}{*}{ CPA } & $36,1 \pm 0,9(3)$ & $36,9 \pm 1,5(11)$ & $36,6 \pm 3,0(4)$ & $37,1 \pm 0,3(3)$ & $36,7 \pm 1,7(7)$ \\
\hline & $35,4-37,2$ & $34,7-39,5$ & $32,5-39,4$ & $36,8-37,5$ & $34,3-39,6$ \\
\hline \multirow[t]{2}{*}{ ACR } & $38,0 \pm 1,4(3)$ & $38,4 \pm 1,2(11)$ & $40 \pm 1,4(4)$ & $38,9 \pm 1,7(3)$ & $37,2 \pm 1,3(7)$ \\
\hline & $36,4-39,2$ & $36,0-40,0$ & $38,7-41,9$ & $37,3-40,8$ & $35,9-38,7$ \\
\hline \multirow[t]{2}{*}{ LCR } & $48,3 \pm 1,8(3)$ & $50,6 \pm 1,8(11)$ & $50,1 \pm 2,1(4)$ & $50,7 \pm 0,8(3)$ & $49,3 \pm 0,8(7)$ \\
\hline & $46,3-50$ & $45,9-52,3$ & $47,0-51,6$ & $49,9-51,6$ & $48,2-50,5$ \\
\hline \multirow[t]{2}{*}{ LCO } & $21,2 \pm 0,6(3)$ & $21,1 \pm 0,9(11)$ & $21,5 \pm 1,8(4)$ & $20,3 \pm 1,1(3)$ & $20,9 \pm 0,5(7)$ \\
\hline & $20,7-22,0$ & $19,1-22,5$ & $19,0-23,2$ & $19,3-21,5$ & $20,2-21,9$ \\
\hline \multirow[t]{2}{*}{ LMT } & $49,8 \pm 1,1$ & $50,1 \pm 1,7(11)$ & $50,7 \pm 0,9(4)$ & $51,1 \pm 0,5$ & $49,7 \pm 1,0(7)$ \\
\hline & $48,5-50,8$ & $47,2-52,5$ & $49,8-52,1$ & $50,8-51,7$ & $48,5-51,4$ \\
\hline \multirow[t]{2}{*}{ LPO } & $39,0 \pm 0,7(3)$ & $40,4 \pm 1,4(11)$ & $39,9 \pm 2,3(4)$ & $40,2 \pm, 02(3)$ & $39 \pm 0,6(7)$ \\
\hline & $38,2-39,6$ & $37,4-42,1$ & $36,5-41,9$ & $37,8-41,4$ & $37,8-40,1$ \\
\hline \multirow[t]{2}{*}{ CMA } & $77,4 \pm 1,4(3)$ & $79,4 \pm 2,6(11)$ & $77,1 \pm 3,6(4)$ & $80,6 \pm 0,9(3)$ & $77,7 \pm 2,2(7)$ \\
\hline & $75,9-78,8$ & $73,5-82,9$ & $72,0-80,5$ & $80,0-81,7$ & $74,0-80,6$ \\
\hline \multirow[t]{2}{*}{ APA } & $57 \pm 2,5$ & $57,2 \pm 4,0(11)$ & $54,9 \pm 3,3(4)$ & $62 \pm 1,6(3)$ & $58,3 \pm 1,0(7)$ \\
\hline & $55,3-60$ & $50,5-63,1$ & $50,8-59,0$ & $60,2-63,1$ & $56,8-59,8$ \\
\hline \multirow[t]{2}{*}{ CDS } & $35,5 \pm 1,2(3)$ & $36,1 \pm 1,1(11)$ & $35,2 \pm 2,4(4)$ & $36,3 \pm 0,2(2)$ & $35,9 \pm 0,6(7)$ \\
\hline & $34,4-36,9$ & $34,3-38,5$ & $31,6-37,0$ & $36,2-36,5$ & $34,9-36,7$ \\
\hline \multirow[t]{2}{*}{ LML } & $35,8 \pm 1,4(3)$ & $36,8 \pm 1,2(11)$ & $35,7 \pm 1,8(4)$ & $37,1 \pm 0,9(3)$ & $35,8 \pm 0,6(7)$ \\
\hline & $34,3-37,1$ & $35,3-39,7$ & $33,0-37,3$ & $36,1-38,0$ & $35,0-37,0$ \\
\hline \multirow[t]{2}{*}{ LPA } & $22,6 \pm 1,1$ & $23,4 \pm 1,2(11)$ & $23,1 \pm 0,8(4)$ & $24,3(3)$ & $23,1 \pm 0,9(7)$ \\
\hline & $21,3-23,5$ & $21,8-25,6$ & $22,5-24,4$ & $24,3-24,4$ & $21,8-24,3$ \\
\hline \multirow[t]{2}{*}{$\mathrm{CHI}$} & - & $35,1 \pm 2,5(11)$ & $33,4(1)$ & $35,6 \pm 0,9(2)$ & $33,3 \pm 2,5(7)$ \\
\hline & & $33,0-38,5$ & & $35,0-36,3$ & $30,0-37,9$ \\
\hline \multirow[t]{2}{*}{ LHI } & - & $21,1 \pm 1,9(11)$ & $20,6(1)$ & $20,4 \pm 0,2(2)$ & $19,9 \pm 1,8(7)$ \\
\hline & & $18,5-23,0$ & & $20,3-20,6$ & $17,4-23,2$ \\
\hline LTE & - & $0,0(11)$ & $0,0(1)$ & $0,0(2)$ & $0,0(7)$ \\
\hline
\end{tabular}

Como sinônimo Humboldt indicou Stentor stramineus Geoffroy Saint-Hilaire, 1812, trabalho que ainda não havia sido publicado na época. A proveniência do material foi "forêts du Grand-Parà". No parágrafo seguinte, Humboldt (1812: 355, parágrafo 5) descreveu Simia caraya como: "11. Simia caraya, stentorosa, capite et dorso pilis sterrimis vestitis. Caraya d'Azara".

Como referência (sinônimos) HumboldT indicou "Caraya d'Azara" e Stentor niger Geoffroy. Como na espécie anterior,
Humboldt (1812) baseou a descrição de Simia caraya no trabalho ainda não publicado de Geoffroy SaInt-Hilaire. De fato, comparando as descrições das espécies por Humboldt, publicadas em agosto de 1812, e aquelas de Geoffroy Saint-Hilaire, que escreveu seu primeiro manuscrito em 1803, mas só o publicou em outubro de 1812 (Thомаs 1913, rodapé), nota-se uma íntima relação entre os trabalhos. Mesmo com o acesso aos dados de GEOFFroY SAINT-Hilaire (1812), que analisou os espécimes pessoalmente, a 
prioridade dos nomes válidos se dá a Humboldt (1812). Assim, é provável que os táxons descritos por Humboldt e Geoffroy SAINTHilaire tenham sido baseados nos mesmos espécimes. Recentemente, Rylands \& Brandon-Jones (1998), na tentativa de esclarecer o nome correto para algumas espécies de Alouatta, em particular o do táxon que ocorre no Escudo Guiano, elucidaram de forma convincente e objetiva que o espécime o qual Simia straminea (e conseqüentemente Stentor stramineus) é de fato uma fêmea da espécie hoje designada como Alouatta caraya. A sinonimização de A. caraya e Stentor stramineus Geoffroy-SaintHilaire, 1812, mas não Simia straminea Humboldt, 1812, foi efetuada primeiramente por ElLIOT (1913). Estranhamente, ElLIOT (1913) considerou Stentor stramineus Geoffroy-Saint-Hilaire, 1812 como sinônimo de A. caraya e A. seniculus (Linnaeus, 1766). Partindo das informações que Humboldt (1812) descreveu no mesmo trabalho Simia straminea, baseado em uma fêmea, e Simia caraya, a partir de um macho (assim também o fez GEoffroy SAINTHilaire, 1812, descrevendo Stentor stramineus e S. niger, respectivamente), e sabendo-se que a espécie apresenta dicromatismo sexual (presumivelmente de desconhecimento dos autores à época), faz sentido a sinonimização de ambos os táxons descritos por Humboldt (1812). Assim, Rylands \& Brandon-Jones (1998: 896) consideram ambos os táxons como sinônimos, e Simia straminea como o sinônimo júnior, mantendo a prioridade para o nome Simia caraya.

Posteriormente aos trabalhos de Humboldt e Geoffroy SAINT-Hilaire, ambos datados de 1812, SPIX (1823: 23) descreveu Mycetes barbatus, caracterizada por apresentar machos de coloração negra, e fêmeas com pelagem castanho escuro no dorso e castanho mais claro no ventre: "Mycetes barbatus, Mas. corpus robustum, praegrande, supra dense pilosum... pili corporis conferti, nigerrimi... Foemina. Corpus minus robustum, supra cinerco vel nigricanti flavescens, subtus flavencens albicans".

Analisando a descrição do autor, fica evidente que a espécie em questão também se enquadra na definição de $A$. caraya. SPIX (1823) sinonimizou M. barbatus com Mycetes negro de Geoffroy Saint-Hilaire (1812) (= Stentor niger) e forneceu como hábitat da espécie o Estado da Bahia, na Caatinga. SPIX (1823) aparentemente desconhecia a descrição de Humboldt (1812), mas não a de Geoffroy Saint-Hilaire (1812). Mesmo assim, o autor não reconheceu nenhum dos dois nomes anteriormente criados, tampouco forneceu uma argumentação plausível para a mudança do nome do táxon em questão para M. barbatus. Assim, Mycetes barbatus é um sinônimo júnior de Simia caraya.

\section{Alouatta fusca (Geoffroy Saint-Hilaire, 1812)}

Simia guariba Humboldt, 1812: 355. Localidade-tipo: Brasil; restrita ao Rio Paraguassú, Estado da Bahia, Brasil por CABRERA (1958), sem qualquer argumentação. Homônimo júnior de [Simia] guariba Geoffroy Saint-Hilaire, 1806.

Simia ursina; Humboldt, 1812, pl. 30, nec texto.

Stentor fuscus Geoffroy Saint-Hilaire, 1812: 108. Localidade-tipo:

Brasil. Descrição baseada no espécime (Lectótipo) no 432
(456), macho, depositado no Muséum National d'Histoire Naturelle, Paris, (Rode 1938). -Geoffroy Saint-Hilaire, 1829: 21. -Carneiro, 1908.

Cebus fuscus; Desmarest, 1816: 340.

Cebus ursinus; Desmarest, 1816: 339.

Mycetes fuscus; Desmarest, 1820: 78. -Kuhl, 1820: 29, partim. Spix, 1823: 43, partim. -Lesson, 1827: 51, partim. Burmeister, 1854: 22. -Pelzeln, 1883: 8, partim.

Mycetes ursinus; Wied, 1823: 48; partim. -Wied, 1826: 48. Gray, 1845: 218, partim. -Geoffroy Saint-Hilaire, 1851: 52, partim. -Burmeister, 1854: 24. -Gray, 1870: 38, partim. Hensel, 1872: 12, partim. -Schlegel, 1876: 154. -Cabrera, 1900: 70. -Meewarth, 1903: 126.

M[ycetes] seniculus; Wagner, 1840: 180, partim.

Mycetes bicolor Gray, 1845: 219. Localidade-tipo: Brasil. Descrição baseada em um espécime macho depositado no Museu Britânico, ZD 1844.5.14.16, sendo este o Lectótipo da espécie.

M[ycetes] fuscus, Wagner, 1855: 67.

Mycetus [sic] ursinus; Ihering, 1892: 122; nec texto de Humboldt (1812).

Alouatta ursina; Forbes, 1896: 198, partim. -Elliot, 1913: 274; partim.

Alouata [sic] ursina; Trouessart, 1897: 34; partim, nec texto de Humboldt (1812).

Alouata [sic] fusca; Cabrera, 1912: 24.

Alouatta fusca fusca; Ihering, 1914: 248. -Vieira, 1955: 382. Napier, 1976: 80. -Kinzey, 1982: 458. -Santos et al., 1987: 126. -Mittermeier et al., 1984: 268. -Mittermeier et al., 1988: 59. -Rylands et al., 1988: 103. -Coimbra-Filho, 1990: 1076. -Rylands, 1994a: 161. -Rylands et al., 1995: 121. -Oliveira et al., 2002: 669.

Alouatta fusca; Chiarelli, 1972: 163, partim. -Mittermeier \& Coimbra-Filho, 1981: 85, partim. -Wolfheim, 1983: 214, partim. -Neville et al., 1988, partim. -Groves, 1993: 55, partim. -Oliveira, 1995: 181, partim.

Cebus fuscus; Miranda-Ribeiro, 1924: 211, partim.

Alouata [sic] ursina; Rode, 1938: 227; nec texto de Humboldt (1812).

Alouatta guariba; Cabrera \& Yepes, 1940: 109, partim. -Crespo, 1952: 117. -Hirsch et al., 1991: 239. -Rylands \& BrandonJones, 1998: 895, partim. -Groves, 2001: 184.

Alouatta guariba guariba; Cabrera, 1958: 155. -Hill, 1962: 129. -Ruschi, 1964: 15. -Ruschi, 1965: 14. -Groves, 2001a: 185. Alouatta fuscus; Nowak \& Paradiso, 1983: 398, partim.

\section{Material examinado (total 65)}

BRASIL, Espírito Santo: Conceição de Barra: MNRJ: 21134 (p, c); Pau Gigante: MZUSP: 2202 (p), 2205 (p, c, h), 2209 (c), 2210 (p, c), 2212 (p, c); Rio Doce: MNRJ: 21135-37 (p, c, h), 21138 (p); MZUSP: 2201 (p, c), 2203 (p, c), 2206 (p, c), 2207 (p, c, h), 2208 (p, c), 2211 (p, c), 2399 (c), 240-01 (p, c), 2402 e 2403 (c), 2404 (p, c), 2406-08 (p, c), 2414 (p, c, h), 19124 (c); Rio Mutum: MNRJ: 2395-96 (p), 2398 (p), 2760 (p, c, h); Santa Leopoldina: MZUSP: 6202 (p, c, h), 11183 (p, c), 19185 (p, c), 19186 (p, c), 19187 (c); 
Santa Teresa: MNRJ: 3902 (p, c, h), 3909 (p, c, h), 21138 (c, h); São Domingos: MNRJ: 21133 (p, c). Minas Gerais: Alegria Simonésia: MNRJ: 23173 (p, c); Floresta Central de Minas Gerais: MNRJ: 23163-64 (p, c); Machacalis: MZUSP: 7876-78 (p, c); Pocrane: MNRJ: 23172 (p, c), 23174-76 (p, c); Tarumirim: MNRJ: 23166 (p), 23169 (p, c); Teófilo Otoni: MNRJ: 21132 (p, c, h); MZUSP: 2734-35 (p, c, h), 2736 (p, c), 2737 (c), 2738 (p, c). RIO DE JANEIRO: Teresópolis: MNRJ: 1115-16 (p), 2394 (p), 2761 (p, c, h), 7257 (p, c, h), 7614 (p, c), 8552 (p), 30474 (p, c).

\section{Localidade-tipo}

Restrita por CABRERA (1958) para o Rio Paraguassú, Estado da Bahia, Brasil, sem qualquer argumentação, tampouco baseada em algum espécime referência (holótipo, lectótipo). Humboldt (1812), na descrição da espécie, mencionou "Habite le Brésil" e não havendo estudos posteriores esclarecendo sobre a proveniência mais restrita do espécime a qual o autor estava baseando a descrição, a localidade-tipo deve ser apenas Brasil como originalmente indicada.

\section{Distribuição geográfica}

Como pode ser observado no mapa da figura 9, A. fusca é restrita à parte central da costa leste brasileira, nos Estados da Bahia, Espírito Santo, Minas Gerais e Rio de Janeiro. Na Bahia, a espécie ocorre mais ao sul, nas localidades de Belmonte, Porto Seguro, Ilhéus, Una e Rio Mucuri (Wied 1826, CARneIro 1908, Coimbra-Filho 1990), e distribui-se por todo o Estado do Espírito Santo. Em Minas Gerais, $A$. fusca se distribui no noroeste do Estado, em localidades próximas ao Rio Jequitinhonha (RyLANDs et al. 1996) e no Rio de Janeiro, a única localidade registrada foi Teresópolis.

Alouatta fusca habita as regiões de floresta pluvial da costa Atlântica do leste do Brasil. A espécie corre sérios riscos de extinção decorrente de uma série de fatores, como a restrição de sua distribuição geográfica, caça predatória e o rápido avanço no processo de desmatamento local (Rylands et al. 1988, MACHADO et al. 1998). A situação se torna ainda mais drástica pela ausência de registros de populações em áreas legalmente protegidas.

\section{Caracteres diagnósticos}

Coloração da pelagem, em ambos os sexos, castanho escuro enegrecido com as pontas dos pêlos na região médio-dorsal amarelas, conferindo-lhe uma tonalidade levemente dourada; região lombar ruiva a alaranjada (Fig. 10); dicromatismo sexual ausente. Corpo hióideo quadrangular mais que ovalado, com tentório trapezoidal e medianamente desenvolvido (Fig. 16).

\section{Descrição geral}

As medidas cranianas e do osso hióide estão na tabela V. Nos adultos de ambos os sexos (Fig. 10), a barba é desenvolvida de coloração negra, tornando-se bruno-amarelada ou brunoavermelhada mais freqüentemente na região lateral do pescoço, posteriormente à orelha e na franja, conferindo-lhe um colorido brilhante; cabeça com pelagem curta e de coloração que

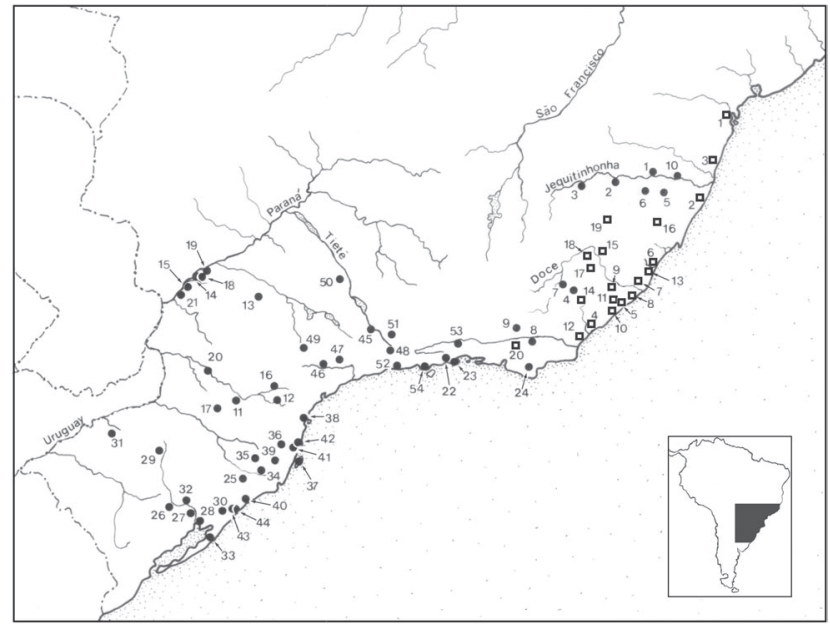

Figura 9. Mapa indicando a distribuição geográfica de $A$. clamitans (círculos) e $A$. fusca (quadrados) no Brasil. Este padrão de distribuição é basicamente concordante com o bioma Mata Atlântica (sensu lato) ao sul do rio São Francisco. Os dados sobre as coordenadas estão no Anexo I.

varia de bruna a castanho-avermelhado ou dourada. Coloração dorsal enegrecida com pelagem na região das espáduas e média dorsal amarela e flancos castanho-avermelhados escuros; pêlos na região média dorsal com bandas muito contrastantes entre o enegrecido e o dourado, sendo castanho escuro basalmente e clareando até a metade do pêlo e daí se torna enegrecido abruptamente; o quarto apical do pêlo é dourado ou dourado com uma pequena porção terminal enegrecida. Região lombar freqüentemnte alaranjada e raramente ruiva. Membros anteriores e posteriores castanho-enegrecidos por toda sua extensão com mãos e pés levemente dourados devido à presença de pêlos esparsos desta cor. Base da cauda de coloração ruiva dorsalmente e amarelada ventralmente, e daí clareando em direção apical, tornando-se castanho-amarelado ou castanho-avermelhado. A coloração da pelagem no jovem acompanha a do adulto, exceto pela dimuição dos pêlos dourados no dorso, barba e extemidades dos membros. Em adição, a coloração nos flancos é mais enegrecida nos jovens, tornando os indivíduos desta faixa etários mais escuros.

Osso hióide no macho adulto com comprimento total entre 49,0-60,1 mm ( $\mathrm{N}=8)$; tentório formado por uma lâmina lisa, (Figs 16 e 18) ou levemente côncava, e pouco desenvolvida (11,1-19,1 mm, N = 8); cornos e cornículos vestigiais; abertura hióidea desenvolvida, de forma quadrangular a levemente ovalada; ausência de trabéculas internas. Bula hióidea globular com a região anterior mais afilada. Os ossos nasais são curvos em vista lateral. Osso hióide na fêmea adulta de comprimento total entre $33,0-51,4 \mathrm{~mm}(\mathrm{~N}=5)$; tentório formado por uma placa estreita e lisa $(4,0-10,4 \mathrm{~mm}, \mathrm{~N}=5)$; cornículos lanceolados (Figs 17 e 19); abertura hióidea de forma quadrangular. 

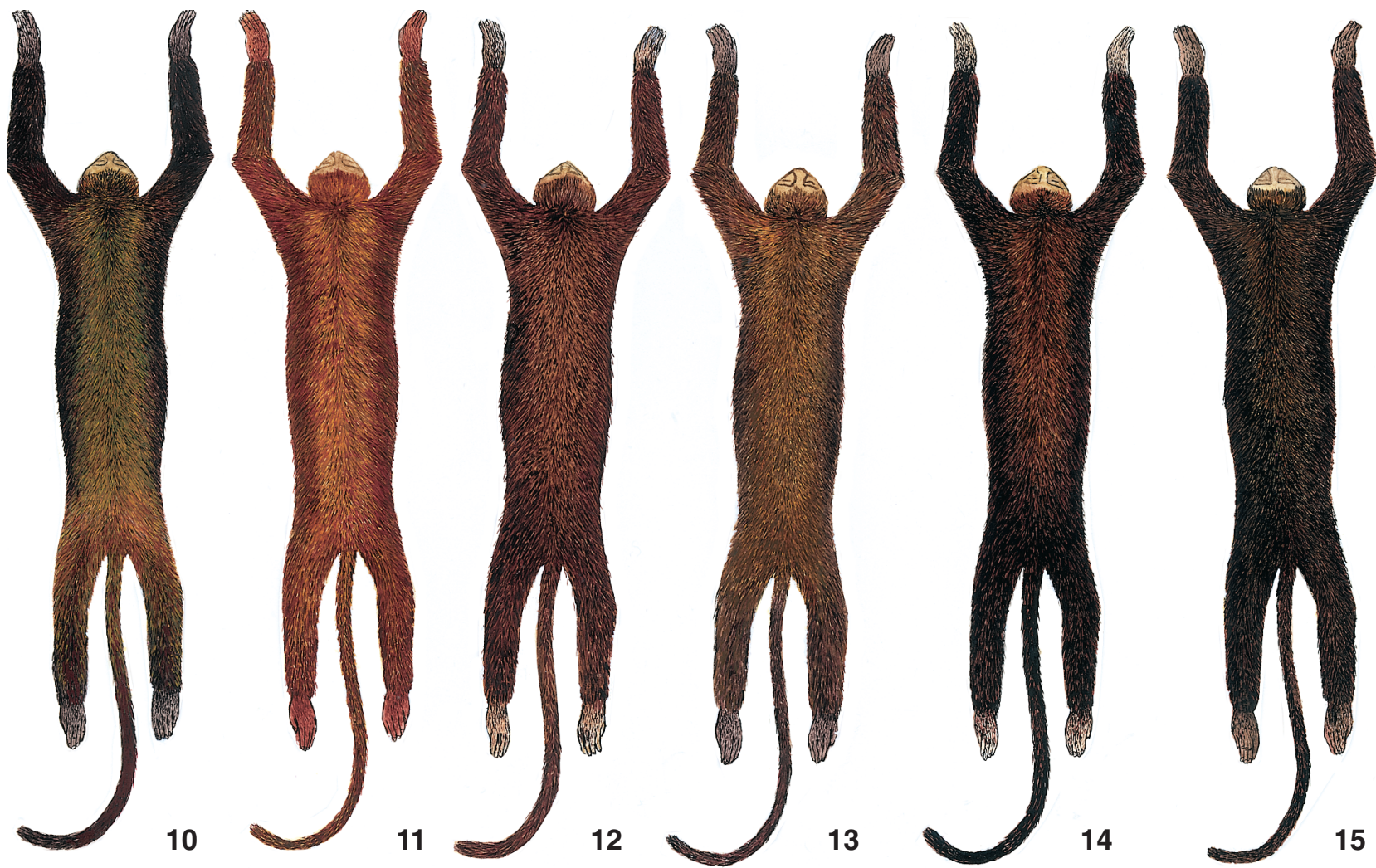

Figuras 10-15. llustração, em vista dorsal, mostrando os padrões mais freqüentes de coloração da pelagem em $A$. fusca (Fig. 10) e $A$. clamitans (Figs 11-15). (10) Ilustrado a partir do MZUSP 2208 (macho) e 2407 (fêmea), Rio Doce, ES (padrão também encontrado em parte de MG); (11) MZUSP 11118 (macho), Guaíba, RS (padrão também encontrado em parte de MG); (12) MZUSP 6487 (macho), Serra da Cantareira, SP; (13) MZUSP 5899, Lins, SP (padrão também encontrado em parte do RJ); (14) 8466, Anhembi, SP; (15) MZUSP 11122, Guaíba, RS. Note o dicromatismo sexual em A. clamitans, sendo acentuado nos espécimes do RS (Figs 11 e 15) e em menor grau nos indivíduos de SP (Figs 12-14).

Cariótipo. Número diplóide variando de 49 (macho) e 50 (fêmea) (RJ) a 52 (macho do ES); cromossomo sexual Y acrossômico e indivíduo macho do RJ com sistema sexual $\mathrm{X}_{1} \mathrm{X}_{2} \mathrm{X}_{3} \mathrm{Y}_{1} \mathrm{Y}_{2}$ (Oliveira 1995, Oliveira et al. 2002).

Variação

A análise do material mostrou que a variação na coloração da pelagem e morfologia hióide de $A$. fusca é reduzida. Embora táxon seja caracterizado por não apresentar dicromatismo sexual, algumas fêmeas adultas e os jovens mostram coloração geral da pelagem levemente mais escura que os machos adultos, mas nada comparado ao dicromatismo acentuado registrado para A. clamitans como será visto adiante. De fato, esta diferença está restrita à distribuição diferencial dos pêlos com a banda subterminal amarela entre os sexos e não pela presença de um pigmento diferente como ocorre em $A$. clamitans. Assim, a variação no padrão de coloração descrito acima para a pelagem em ambos os sexos está restrita a tonalidades mais escuras e opacas em alguns indivíduos (MZUSP
11183, Espírito Santo). Como exceção, um espécime macho adulto de Santa Leopoldina (MZUSP 19186) e um de Teresópolis (MNRJ 1116) apresentaram coloração da pelagem ruiva na barba e cabeça, e castanho-amarelada por todo o dorso, muito distinto dos demais indivíduos analisados de A. fusca; os membros são ruivos profundos e não bruno-avermelhados. Com base no espécime do Espírito Santo e outros de localidades próximas, KinZey (1982) sugeriu a possível hibridação entre as subespécies reconhecidas à época: $A$. f. fusca e $A$. f. clamitans. Mediante a variação nas tonalidades de ruiva e castanho na pelagem do segundo táxon, esta hibridação sugerida por KinzeY (1982) é impossibilitada de averiguação. Um espécime proveniente de Castro (Paraná) (MZUSP 2464) apresentou um padrão de coloração semelhante aos do Espírito Santo. A análise dos pêlos na região das espáduas mostrou que há uma variação no padrão de bandeamento restrito à porção apical da estrutura, cujo 1/4 apical pode ser completamente dourado ou apresentar sua extremidade enegrecida. Todos os espécimes anali-

Revista Brasileira de Zoologia 23 (1): 64-144, março 2006 
Tabela V. Dados morfométricos ( $\mathrm{mm}$ ) das amostras de A. fusca no Brasil. Linha superior: média, desvio padrão e número amostral (em parênteses), respectivamente. Linha inferior: mínima e máxima.

\begin{tabular}{|c|c|c|}
\hline Variável & Machos & Fêmeas \\
\hline & $115,5 \pm 4,6(12)$ & $99,7 \pm 3,2(20)$ \\
\hline \multirow[t]{2}{*}{$\mathrm{CCR}$} & $110, .0-122,1$ & $94,0-107,2$ \\
\hline & $107,0 \pm 4,1(12)$ & $88,6 \pm 3,3(20)$ \\
\hline \multirow[t]{2}{*}{$\mathrm{CCB}$} & $99,0-112,3$ & $81,6-96,0$ \\
\hline & $76,6 \pm 3,3(13)$ & $64,5 \pm 2,2(19)$ \\
\hline \multirow[t]{2}{*}{ LZI } & $68,7-81,1$ & $60,7-70,2$ \\
\hline & $59,2 \pm 2,4(13)$ & $52,41 \pm 1,6(21)$ \\
\hline \multirow[t]{2}{*}{ LIO } & $55,5-64,6$ & $49,0-54,6$ \\
\hline & $42,3 \pm 2,4(12)$ & $35,9 \pm 1,6(21)$ \\
\hline \multirow[t]{2}{*}{ CPA } & $38,2-46,6$ & $33,3-39,0$ \\
\hline & $38,3 \pm 2,1(13)$ & $37,3 \pm 1,9(20)$ \\
\hline \multirow[t]{2}{*}{ ACR } & $35,6-42,3$ & $32,8-40,3$ \\
\hline & $51,3 \pm 3,8(12)$ & $48,0 \pm 2,5(21)$ \\
\hline \multirow[t]{2}{*}{ LCR } & $47,2-62,0$ & $41,6-51,7$ \\
\hline & $24,5 \pm 4,3(13)$ & $21,0 \pm 0,9(18)$ \\
\hline \multirow[t]{2}{*}{ LCO } & $21,3-38,6$ & $18,7-22,9$ \\
\hline & $56,6 \pm 2,2(12)$ & $49,6 \pm 1,8(20)$ \\
\hline \multirow[t]{2}{*}{ LMT } & $52,5-59,3$ & $47,1-52,9$ \\
\hline & $40,5 \pm 1,4(12)$ & $39,7 \pm 1,2(21)$ \\
\hline \multirow[t]{2}{*}{ LPO } & $38,8-43,4$ & $37,5-42,0$ \\
\hline & $91,8 \pm 5,0(13)$ & $75,1 \pm 3,13(21)$ \\
\hline \multirow[t]{2}{*}{ CMA } & $82,2-101,0$ & $70,8-85,4$ \\
\hline & $73,1 \pm 6,9(13)$ & $58,1 \pm 4,2(20)$ \\
\hline \multirow[t]{2}{*}{ APA } & $62,2-81,2$ & $50,5-68,7$ \\
\hline & $40,5 \pm 1,3(13)$ & $35,6 \pm 1,1(20)$ \\
\hline \multirow[t]{2}{*}{ CDS } & $36,5-42,1$ & $34,0-38,0$ \\
\hline & $38,8 \pm 1,4(12)$ & $34,4 \pm 1,4(19)$ \\
\hline \multirow[t]{2}{*}{ LML } & $36,2-41,4$ & $31,0-36,8$ \\
\hline & $23,7 \pm 1,5(13)$ & $21,8 \pm 1,1(21)$ \\
\hline \multirow[t]{2}{*}{ LPA } & $20,9-26,3$ & $19,2-24,1$ \\
\hline & $57,2 \pm 4,2(9)$ & $39,1 \pm 6,8(6)$ \\
\hline \multirow[t]{2}{*}{$\mathrm{CHI}$} & $49,0-6,3$ & $33,0-51,4$ \\
\hline & $35,3 \pm 1,5(9)$ & $24,2 \pm 7,1(6)$ \\
\hline \multirow[t]{2}{*}{ LHI } & $32,4-37,7$ & $18,7-38,3$ \\
\hline & $13,9 \pm 2,7(9)$ & $6,3 \pm 2,2(6)$ \\
\hline LTE & $11,1-19,1$ & $4,0-10,4$ \\
\hline
\end{tabular}

sados na área de distribuição de $A$. fusca se mostraram semelhantes, não havendo variação geográfica na coloração da pelagem ou morfologia hióidea.

Para a melhor compreensão taxonômica, faz-se necessária um estudo de variação mais amplo, incluindo todos os padrões
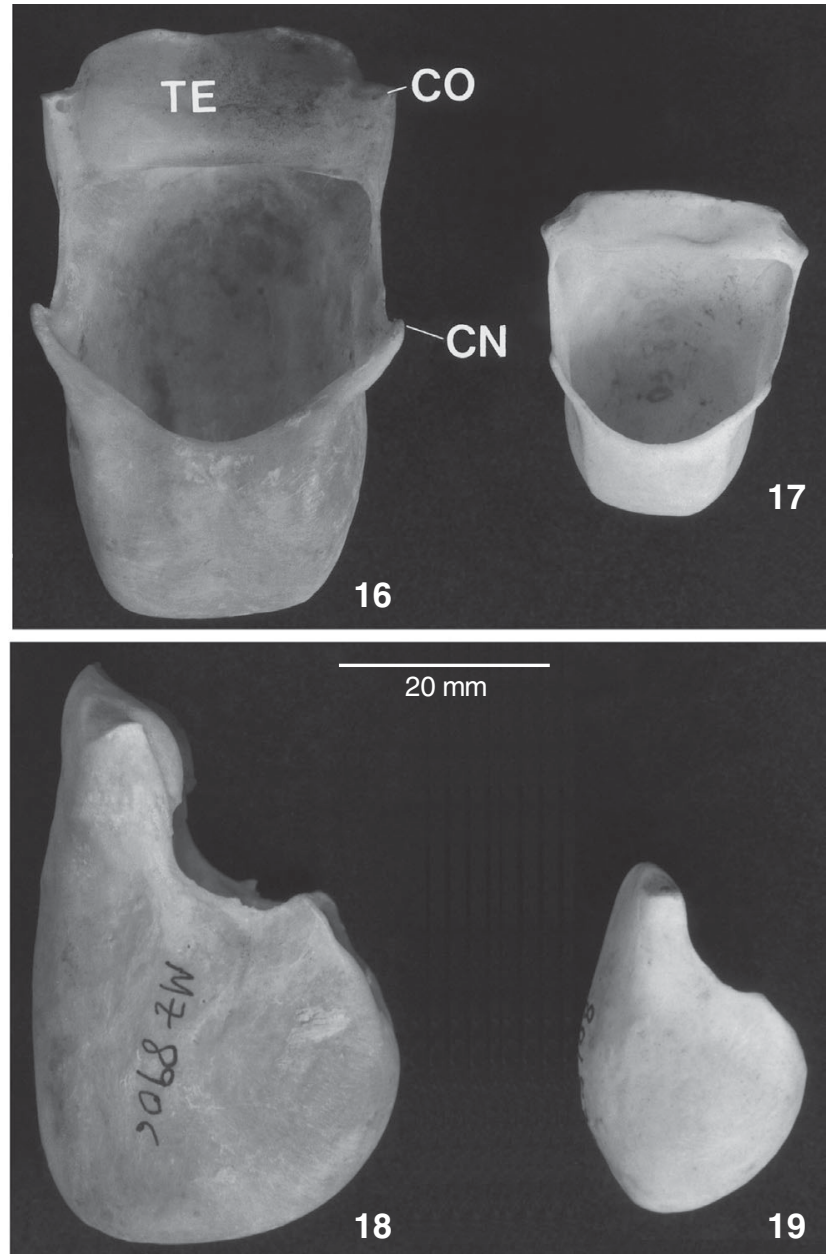

Figuras 16-19. Osso hióide encontrado em A. fusca e A. clamitans: (16 e 18) indivíduo macho (MZUSP 8906) em vista ventral e lateral, respectivamente; (17 e 19) indivíduo fêmea (MZUSP 8908) em vista ventral e lateral respectivamente. Note o tentório retangular e levemente côncavo, e o cornículo desenvolvido. Note também a abertura quadrangular e desenvolvida. (CN) Cornículo, (CO) corno, (TE) tentório.

de coloração registrados aqui para as populações ao longo da costa leste brasileira, desde o Rio Grande do Sul até o Espírito Santo (Figs 10-15). Embora a variação na coloração da pelagem seja elevada e de certa forma, regional, há apenas dois táxons, se se basearmos na presença do dicromatismo sexual, como sugerido por Rylands et al. (1988). Por outro lado, a variação observada sugere de maneira geral, que há três morfos distintos com base na coloração da pelagem ao longo deste transecto sul-norte (Rio Grande do Sul-Espírito Santo), embora existam variações intrapopulacionais, além das sexuais e ontogenéticas. Os morfos são: 1) os machos das populações meridionais (Rio Grande do Sul e Santa Catarina, e alguns espécimes do centro de Minas Gerais) 
tendem a ter pelagem castanho-avermelhado (cor de cobre) a avelã, enquanto que as fêmeas são muito escuras e o dicromatismo é acentuado; 2) nas populações centrais (São Paulo, Rio de Janeiro e Minas Gerais), os machos freqüentemente apresentam a pelagem ruiva (embora haja espécimes com coloração avelã como no Rio Grande do Sul), e as fêmeas são brunas, com o ápice dos pêlos dorsais ruivo-queimado; o dicromatismo é menos acentuado que no morfo 1 ; 3 ) nas populações do extremo norte da distribuição (Espírito Santo, noroeste do Rio de Janeiro e norte de Minas Gerais) não há dicromatismo e o padrão de coloração enegrecida com dorso dourado é bem distinto (embora haja um espécime do Paraná com este mesmo padrão).

Estudos recentes sobre as glândulas epidérmicas produtoras de pigmento (Hirano et al. 2003, Hirano com. pes.) em espécimes provenientes dos Estados de São Paulo e Santa Catarina (= A. clamitans) fornecem alguns dados importantes para compreensão do dicromatismo sexual e variação na coloração da pelagem naquele táxon. Contrário ao que se supõe, a coloração avermelhada da pelagem de $A$. clamitans não é proveniente de feomelanina presente no interior dos pêlos (Hershrovitz 1968), mas sim de pigmentação externa liberada por glândulas epidérmicas. Também, a variação de coloração desde o castanho-avermelhado, passando para a ruiva e atingindo a castanho-amarelado (avelã) está relacionada, nos machos, à idade e posição hierárquica nos bandos e não à geogra- fia. Este pigmento, segundo HiRANo (com. pes.) serve à função de marcação odorífera e visual e na manutenção da hierarquia. Assim, indivíduos machos alfa tendem a ter a coloração avelã, enquanto que os subadultos ou os muito velhos as têm ruiva ou castanho-avermelhada. Hirano (com. pes) ainda sugeriu que este importante sinalizador sexual visual, ausente nos espécimes de $A$. fusca, seria um mecanismo de isolamento pré-zigótico entre ambos os táxons. Ou seja, as fêmeas de A. clamitans não seriam atraídas visualmente pelos machos escuros de $A$. fusa.

A variação na coloração ao longo da costa Atlântica foi coincidente com variabilidade genética registrada por OLIVEIRA $(1995,1996)$ e Oliveira et al. (2002). Nestes estudos, as diferenças nos números diplóides e a diferença de duas translocações robertsonianas entre as populações centrais e meridionais (reconhecidas como A. f. clamitans) e as setentrionais (típicos $A . f$. fusca) levaram Oliveira et al. (2002) a sugerir um nível específico para ambos os táxons. Oliveira (1995) também registrou o cariótipo para um espécime do Rio de Janeiro semelhante ao do Espírito Santo (A. f. fusca), o que poderia corroborar os dados da coloração da pelagem. Infelizmente, o autor não forneceu uma localidade mais precisa para os espécimes analisados cariotipicamente, se a cidade ou o Estado do Rio de Janeiro.

Embora em uma projeção clinal, os dados morfométricos também corroboram, em termos gerais, os da coloração da pelagem em ambas as análises, de variância (Tab. VI) e na Análi-

Tabela VI. Teste Mann-Whitney comparando fêmeas de A. fusca (amostras 1-3) e A. clamitans (amostras 4-8). Fornecidas apenas as medidas que se mostraram significativamente diferentes (em parênteses a probabilidade, p). (1) norte de Minas Gerais; (2) Rio Doce e leste de Minas Gerais; (3) sul do Espírito Santo; (4) sudeste de Minas Gerais; (5) sul de Minas Gerais e Rio de Janeiro; (6) São Paulo; (7) Santa Catarina; (8) Rio Grande do Sul.

\begin{tabular}{|c|c|c|c|c|c|c|c|}
\hline Amostras & 2 & 3 & 4 & 5 & 6 & 7 & 8 \\
\hline \multirow[t]{2}{*}{1} & $p>0,05$ & $p>0,05$ & $p>0,05$ & $p>0,05$ & $p>0,005$ & $\operatorname{CMA}(0,025)$ & $p>0,005$ \\
\hline & & & & & & $\operatorname{APA}(0,035)$ & \\
\hline \multirow[t]{5}{*}{2} & - & $p>0,05$ & $\operatorname{LCO}(0,045)$ & $p>0,05$ & $\operatorname{LCR}(0,026)$ & $\mathrm{CPA}(0,012)$ & $\operatorname{CMA}(0,010)$ \\
\hline & & & & & $\operatorname{CMA}(0,038)$ & $\operatorname{ACR}(0,018)$ & \\
\hline & & & & & $\operatorname{LMO}(0,028)$ & $\operatorname{LCR}(0,018)$ & \\
\hline & & & & & & $\operatorname{CMA}(0,001)$ & \\
\hline & & & & & & $\operatorname{LMO}(0,004)$ & \\
\hline \multirow[t]{7}{*}{3} & - & - & $\operatorname{LCO}(0,040)$ & $p>0,05$ & $\operatorname{LCO}(0,045)$ & $\operatorname{CCR}(0,008)$ & $\operatorname{LMA}(0,020)$ \\
\hline & & & & & $\operatorname{LMA}(0,006)$ & CCB $(0,020)$ & \\
\hline & & & & & $\operatorname{CMA}(0,063)$ & $\mathrm{CPA}(0,012)$ & $\mathrm{CMA}(0,015)$ \\
\hline & & & & & $\operatorname{LMO}(0,012)$ & $\operatorname{LMA}(0,014)$ & \\
\hline & & & & & & $\operatorname{CMA}(0,001)$ & \\
\hline & & & & & & APA $(0,003)$ & \\
\hline & & & & & & $\operatorname{LMO}(0,005)$ & \\
\hline 4 & - & - & - & $p>0,05$ & $\operatorname{LCO}(0,045)$ & $\operatorname{LCO}(0,029)$ & $\operatorname{LCO}(0,036)$ \\
\hline 5 & - & - & - & - & $p>0,05$ & $\operatorname{LTE}(0,033)$ & $p>0,05$ \\
\hline \multirow[t]{2}{*}{6} & - & - & - & - & - & $\operatorname{CCR}(0,030)$ & $p>0,05$ \\
\hline & & & & & & $\operatorname{CMA}(0,030)$ & \\
\hline 7 & - & - & - & - & - & - & LZI $(0,001)$ \\
\hline
\end{tabular}

Revista Brasileira de Zoologia 23 (1): 64-144, março 2006 
se de Componentes Principais (ACP). Os testes estatísticos revelam uma tendência clinal, onde os espécimes do extremo norte da distribuição são menores que aqueles meridionais (São Paulo e Santa Catarina), com populações do Rio de Janeiro e Minas Gerais refletindo dimensões intermediárias. Assim, os resultados da análise de variância para as fêmeas plotados na tabela $\mathrm{V}$ mostram que as populações de $A$. fusca, principalmente do Espírito Santo (populações 2 e 3 - áreas nucleares do táxon) diferiram em algumas variáveis daquelas de São Paulo (3 a 5 variáveis) e Santa Catarina (5 a 7 variáveis), as áreas nucleares de $A$. clamitans. Por outro lado, se comparadas a $A$. fusca, elas apresentam diferenças em menor grau entre si ou mesmo inexistem (Tab. VI), indicando que não há variação geográfica convincente nos dados morfométricos para as amostras meridionais.

Na ACP para os machos, os dois primeiros componentes (CPs) foram responsávies por 83\% da variação, com o PC1 abrangendo 75\% e cujas principais variáveis responsáveis são relacionadas ao comprimento (eixo longitudinal) craniano (Tab. VII). O CP2 foi responsável apenas por 8,0 \% da variação e as principais variáveis foram relacionadas à largura das estruturas cranianas. Analisando a figura 20, nota-se que no eixo do primeiro (e mais importante) componente, os espécimes de Minas Gerais (parte) e ES referidos aqui como $A$. fusca estão dipostos em um extremo da distribuição, e na zona de contato com $A$. clamitans, estão os espécimes de SP e alguns de Minas Gerais. Os espécimes de Santa Catarina e Rio Grande do Sul estão posicionados no outro extremo da distribuição, evidenciando a variação contínua no tamanho e forma craniana. Observa-se também que os espécimes de Rio Novo e Caratinga, ambos de Minas Gerais e de coloração da pelagem característica de $A$. clamitans (MENDEs 1989), estão agrupados com aqueles do extremo norte da distribuição, sugerindo mais uma coesão geográfica (latitudinal) que taxonômica das variáveis morfométricas.

A tabela VII mostra o resultado da ACP para as fêmeas de $A$. fusca e A. clamitans, cujos três primeiros PCs foram responsáveis por $80,8 \%$ da variação, com as respectivas contribuições: $57,8 \%, 15,2 \%$ e $7,7 \%$. Como nos machos, as variáveis relacionadas ao comprimento foram as que mais contribuíram para o CP1 e a largura craniana (LCR) que mais contribui para o CP2. A figura 21 mostra a distribuição dos valores para as fêmeas, e de mesma forma que nos machos, há uma separação extrema entre os espécimes do Espírito Santo e Minas Gerais, assinalados como A. fusca, e aqueles de Santa Catarina e Rio Grande do Sul, designados por A. clamitans. Entretanto, há uma considerável zona de sobreposição impossibilitando uma separação nítida entre os dois táxons com base na análise multivariada. Exceção a um espécime proveniente de Pocrane, Minas Gerais, cuja pelagem é característica de $A$. fusca, mas as dimensões maiores são coincidentes com as fêmeas de Santa Catarina.

Após esta análise populacional comparativa, conclui-se que 1) a pelagem engrecida com a região médio-dorsal amarela-dourada e a lombar alaranjada, 2) a ausência de dicromatismo sexual devido à ausência de glândulas de pigmento, 3) o cariótipo
Tabela VII. Resultados da PCA nos machos e fêmeas, incluindo espécimes de $A$. fusca e $A$. clamitans. Os "eigenvalue" dos PCs foram 100,82 e 11,45, para machos e 34,23; 9,01 e 4,58, para fêmeas. Em negrito, as variáveis que mais contribuíram para os Componentes Principais

\begin{tabular}{ccccccc}
\hline & \multicolumn{2}{c}{ Machos } & & \multicolumn{3}{c}{ Fêmeas } \\
\cline { 1 - 3 } Variáveis & PC1 & PC2 & & PC1 & PC2 & PC3 \\
\hline CCR & $\mathbf{0 , 5 8 4}$ & 0,112 & & $-\mathbf{0 , 5 8 1}$ & 0,297 & $-0,203$ \\
CCB & $\mathbf{0 , 4 4 0}$ & $-0,059$ & & $-\mathbf{0 , 4 9 7}$ & 0,160 & $-0,083$ \\
LIO & 0,272 & $\mathbf{0 , 5 2 0}$ & & $-0,170$ & 0,082 & $-\mathbf{0 , 3 3 3}$ \\
CPA & 0,237 & $-0,205$ & & $-0,252$ & $-0,039$ & $-0,085$ \\
LCR & 0,057 & 0,296 & & $-0,175$ & $-\mathbf{0 , 8 9 6}$ & $-0,251$ \\
LCO & 0,051 & 0,064 & & $-0,033$ & 0,041 & 0,014 \\
LMT & 0,098 & 0,043 & & $-0,263$ & 0,063 & $-0,125$ \\
LPO & 0,070 & $\mathbf{0 , 7 3 7}$ & & $-0,100$ & $-0,135$ & $-0,403$ \\
CMA & $\mathbf{0 , 5 6 1}$ & $-0,187$ & & $-\mathbf{0 , 4 6 0}$ & $-0,226$ & $\mathbf{0 , 7 6 9}$ \\
\hline
\end{tabular}

distinto no número diplóide e nos rearranjos robertsonianos, e 4) uma tendência na diminuição das dimensões cranianas, demonstram que há dois táxons na costa leste brasileira ao sul do Rio São Francisco, e que o táxon mais setentrional deve ser designado por $A$. fusca. O reconhecimento destes dois táxons, desde IHERING (1914) até recentemente, sempre foi acatado majoritariamente pelos autores, mas em nível subespecífico. Com base nos estudos morfológicos qualitativos e quantitativos, acrescido aos citogenéticos, a posição pioneira de considerar os táxons ao nível específico, como efetuada aqui, é embasada pela presença de autapomorfias na coloração da pelagem e cariótipo, pelas inferências dos dados no isolamento reprodutivo (devido à ausência de pigmentos sinalizadores nos machos em um dos táxons) e pela potencial inviabilidade dos híbridos devidos às diferenças citogenéticas (Oliveira et al. 2002). O desafio maior agora é definir, de forma precisa, toda a variação existente em $A$. fusca e a sua distribuição geográfica precisa, uma vez que as amostras ainda são relativamente pouco numerosas para este nível de estudo. Neste aspecto, foca-se a atenção para os espécimes da região serrana no interior do Estado do Rio de Janeiro, considerados, de forma geral, como A. clamitans, mas que apresentam a coloração de pelagem semelhante àqueles que definem $A$. fusca. VIEIRA (1955: 382) reconheceu as duas subespécies ocorrendo no Estado do Rio de Janeiro: $A$. f. fusca para Rio de Janeiro (mas sem especificação se a cidade ou o Estado) e A. f. clamitans para o litoral do Estado. VIEIRA (1955) analisou espécimes do MZUSP e MNRJ para a elaboração de seu catálogo e provavelmente os espécimes do Rio de Janeiro citados por ele devem ser provenientes de Teresópolis, os mesmo analisados no presente trabalho.

\section{História taxonômica}

A história taxonômica de $A$. fusca é demasiadamente complexa devido ao conceito da espécie e qual nome empregar a ela. Assim, para o devido esclarecimento sobre a história taxonômica e nomenclatural do táxon, necessita-se da recapitulação de tra- 

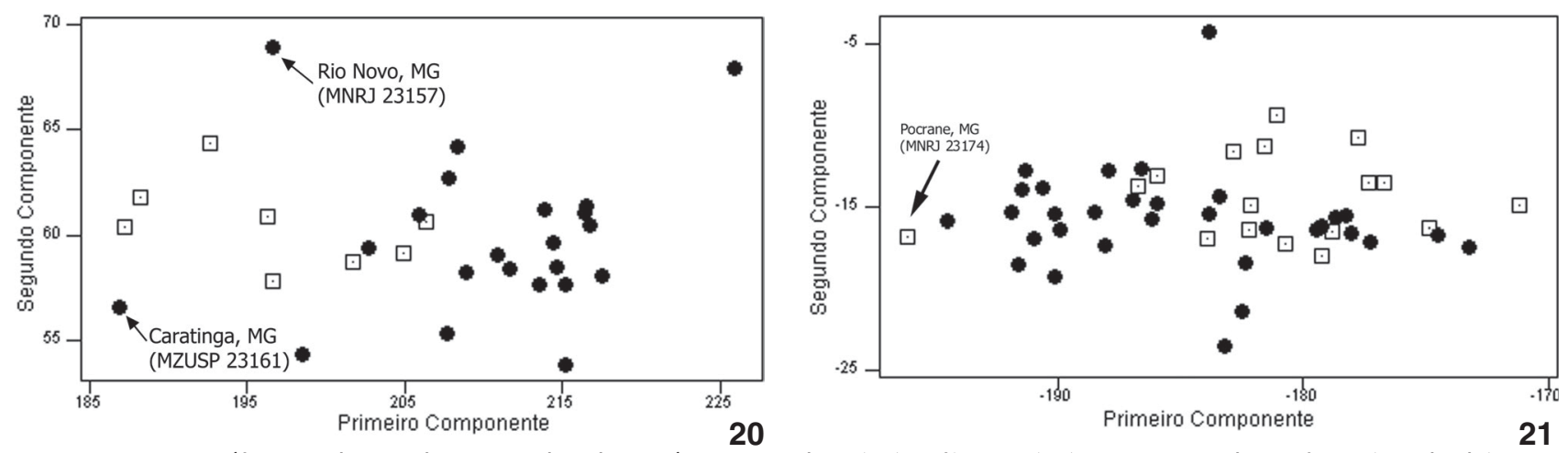

Figuras 20-21. Gráfico resultante da ACP incluindo espécimes machos (20) e fêmeas (21) representando $A$. fusca (quadrado) e $A$. clamitans (círculo). Note que o CP1 discrimina os espécimes no gradiente latitudinal, exceto um de Pocrane, MG, que apresentou proporções cranianas acentuadas para a média dos espécimes da área.

balhos que datam do século xviII, muito antes de $A$. fusca ter sido formalmente descrita. A história taxonômica de $A$. fusca é relacionada com a de $A$. belzebul e remonta de 1648, quando Jorge MARCGRAVE descreveu informalmente algumas espécies de mamíferos coletados na costa nordestina, mais especificamente nos arredores de Recife, no Estado do Pernambuco, entre os anos de 1640 e 1644 (Thomas 1911). Entre as formas descritas por MarCgRAVE (1648), estava uma espécie de bugio que o autor descreveu informalmente como: "Guariba,... Os cabelos de todo o corpo são pretos, longos e lustrosos... Debaixo do queixo e garganta, os cabelos são mais longos e terminam numa barba redonda, semelhante ao cabrito... Encontram-se estes animais, em grande quantidade, nos bosques, onde emitem um grande grito, que pode ser ouvido de longe". (MARCGRAVE, 1648: 226; tradução por Mons. J. P. MagalhãEs, 1942).

Analisando a transcrição acima e considerando a designação de "guariba", nome vernacular muito utilizado para se referir aos primatas do gênero Alouatta (Murphey 1976, CoImbraFilHo et al. 1995), conclui-se que a espécie em questão realmente pertencia ao gênero. De acordo com a descrição de MARCGRAVE (1648), a espécie habitava as florestas (bosques) da costa Atlântica do Estado do Pernambuco. Sabe-se hoje que a única espécie de Alouatta que habita a costa leste brasileira, ao norte do Rio São Francisco, é A. belzebul, descrita formalmente por LinNAeus em 1766 como Simia belzebul, com base na descrição de Marcgrave, sendo um sinônimo desta, "guariba".

Posteriormente, Geoffroy SAINT-Hilaire (1806) ao descrever Ateles belzebuth designou o nome guariba em substituição ao Simia belzebuth [sic] Linnaeus (= Alouatta belzebul). A designação do nome guariba por Geoffroy SaInt-Hilaire (1806: 272; rodapé) foi feita, segundo o próprio autor, com a finalidade clara (e proposital) de substituir $S$. belzebuth [sic] Linnaeus, evitando confusão com a espécie que ele estava descrevendo no mesmo artigo, Ateles belzebuth, como atesta a transcrição: "Il ne faudra pas confondre avec notre belzebuth le Simia belzebuth de Linnée quì est le même que l'ouarine de Buffon. Je propose de donner à cette espèce le nom de guariba qu'elle porte au Brésil, ou du moins dans l'ouvrage de Marcgrave, le seul auteur qui en ait parlé de visu. Le caraya de M. d'Azzara m'en paroit différent aussí bien que de l'alouatte (Simia seniculus). Ces trois espèces constitueront le genre des hurleurs".

A transcrição acima deixa claro o propósito de Geoffroy SAINT-Hilaire (1806) em distinguir ambas as espécies mediante a substituição do nome belzebuth [sic] Linnaeus por guariba, e neste caso, embora não escrita explicitamente de forma binomial, entende-se que guariba foi incluído no gênero Simia.

Recentemente, Rylands \& BRANDON-Jones (1998: 895) negaram tal propósito entendendo que a criação do nome guariba tinha um caráter informal (vernacular), como transcrito: “...the guariba is not mentioned binominally in the footnote on page 272 of the binominal text, and SAINT-Hilaire (1806) was apparently proposing it only as a vernacular name...".

Como exposto acima, a intenção de substituição dos nomes por Geoffroy Saint-Hilaire (1806) é clara pela sua própria colocação, e contra a idéia do nome ser apenas vernacular, como assumido por Rylands \& BRANDON-Jones (1998). A posição defendida aqui é reforçada pelo fato de que o nome guariba já existia vernacularmente (LinNAEus 1766 o considerou assim seguindo Marcgrave) e não faz sentido Geoffroy Saint-Hilaire (1806) focar e recriar o nome apenas de forma popular se ele já existia neste contexto. É importante ressaltar que alguns autores nos séculos XVIII e XIx (inclusive LINNAEus) escreviam os nomes científicos de forma simples (não binomial), mas que indicavam uma relação de inclusão em algum gênero, sendo tais nomes válidos. Neste sentido, considera-se o [Simia] guariba Geoffroy Saint-Hilaire, 1806 como implicitamente binomial e portanto, ele caracteriza um sinônimo júnior de Simia belzebul Linnaeus, 1766.

Geoffroy SaInT-Hilaire (1806) teria evitado a confusão se seguisse a grafia correta dada por LinNaEus (1766), Simia belzebul, palavra distinta de belzebuth descrito para Ateles, mas também empregado pelo autor para o bugio da Amazônia. Isto certamente dispensaria a substituição por guariba e evitaria toda esta confusão. Ademais, não havia necessidade de substituição de 
nomes, pois o nome belzebul (ou belzebuth) estava designando espécies distintas em gêneros diferentes, Simia e Ateles.

A. relação entre $A$. belzebul e $A$. fusca se inicia quando Humboldt (1812: 355) descreveu Alouatta guariba como segue: "Simia guariba, stentorosa, pilis casteneo-fuscis, apice fere aurei coloris".

Pela descrição acima, nota-se que se trata de um táxon cuja pelagem apresenta a coloração castanho escuro com as pontas dos pêlos douradas. Apesar de concisa, a descrição caracteriza as populações de Alouatta que habitam o leste do Brasil, particularmente para a região do Espírito Santo. Entretanto, considerando o exposto anteriormente (em concordância com HeRshKoviTz 1963, e contrário a Rylands \& BRANDON-Jones 1998), Simia guariba Humboldt, 1812, é um homônimo júnior de [Simia] guariba Geoffroy Saint-Hilaire, 1806 (= S. belzebul Linnaeus). Subseqüentemente, Geoffroy SaINT-Hilaire (1812) descreveu Stentor fuscus com as mesmas características de Simia guariba Humboldt, 1812, e este deve ser o nome considerado para a espécie em questão.

Contudo, em ambos os casos, há discrepâncias entre o conceito do táxon (descrição) e o nome empregado. Por exemplo, Humboldt (1812) descreveu um animal de pelagem dorsal castanho com ápices dos pêlos dourados, coloração ausente nos Alouatta do Nordeste e do Pará, embora na sinonímia de Simia guariba o autor tenha incluído o Simia belzebul de GMELIN (1788), o mesmo táxon de LinNaEus (1766). Situação semelhante foi notada em Geoffroy Saint-Hilaire (1812) quando descreveu Stentor fuscus como um animal de pelagem castanho escuro com as extremidades dos pêlos douradas, mas incluiu "guariba" Marcgrave e o Simia belzebul Linnaeus na sinonímia, ambos reconhecidos hoje como Alouatta belzebul e cuja coloração negra é distinta daquela descrita pelo autor para Stentor fuscus.

Humboldt (1812) gerou mais confusão quando descreveu Simia ursina para a Venezuela ("Habite la province de Venezuela, celles de la Nouvelle-Andalousie et de la Nouvelle-Barcelone, et lês bords du bas-Orénoque"), mas indicou uma prancha que caracterizava claramente o táxon da costa leste do Brasil, A. fusca (IHERING 1914, CABRERA 1940). Infelizmente não houve indicação do espécime na qual Simia ursina foi descrita e ela foi sinonimizada com Simia guariba e Stentor fuscus, prevalecendo em geral, o primeiro como sinônimo sênior (GrAY 1845, I. Geoffroy Saint-Hilaire 1851, Slack 1862, Hensel 1872, Forbes 1896, Trouessart 1897, Cabrera 1900, Meerwarth 1903, Elliot 1913, Rode 1938). Por outro lado, Allen (1916b), Tate (1939) e Cabrera (1940, 1958) reconheceram nos animais do norte da Venezuela a espécie de Humboldt ( $=$ A . seniculus arctoidea - Rylands \& BRANDONJONEs 1998). Simia ursina Humboldt, 1805, por ser um homônimo de Simia hamadryas ursinus Kerr, 1792, foi substituído por Alouatta seniculus arctoidea Cabrera, 1940.

Gray (1845) descreveu Mycetes bicolor como um animal de coloração negra e a pelagem nas laterais e região lombar amarelada devido a um bandeamento sub-central amarelo queimado dos pêlos. Ele forneceu como hábitat da espécie "Brazils". ElLIoT (1913), seguido por CABRERA (1958) e Groves (2001a), sinonimizou
Mycetes bicolor Gray com Alouatta fusca (de fato, ElLIoT alocou ambos os táxons como sinônimos de Alouatta ursina). Pela descrição de Gray $(1845,1870)$ e seus comentários sobre um macho adulto de $M$. bicolor que se assemelhava a $A$. caraya, devido à sua coloração praticamente toda negra, e analisando a variação de coloração existente em $A$. fusca, conclui-se que o espécime que GRAY (1845) descreveu como Mycetes bicolor pode ser uma forma enegrecida de A. fusca. Entretanto, NAPIER (1976) analisou o espécime depositado [Lectótipo] no Museu Britânico e na qual Mycetes bicolor foi descrito, e não conseguiu concluir a que táxon de Alouatta o padrão de coloração de M.bicolor se assemelhava. NAPIER (1976) comentou que M. bicolor de Gray poderia estar mais relacionada a $A$. belzebul que a $A$. fusca, mas preferiu catalogar como Alouatta sp. Pela descrição orginal "Black, hair rather rigid, uniform black, sides of the loins varied with yellow; hair of this part black, with a broad subcentral reddish-yellow band", mantém-se a posição em considerar Mycetes bicolor Gray, 1845, sinônimo júnior de Stentor fuscus Geoffroy Saint-Hilaire, 1812.

Após o trabalho de Geoffroy Saint-Hilaire (1812) descrevendo Stentor fuscus, a maioria dos autores utilizou-se deste nome entendendo que [Simia] guariba deveria se sinônimo júnior de A. belzebul (Desmarest 1820, Kuhl 1820, Spix 1823, Schlegel 1876, Pelzeln 1883, Ihering 1894, Hershrovitz 1963, Mittermeier \& Coimbra-Filho 1981, Wolfheim 1983, LangGuth et al. 1987, Rylands et al. 1988, Groves 1993). IHERING (1914) pioneiramente reconheceu em $A$. fusca duas subespécies: $A$. $f$. fusca para se referir às populações setentrionais que ocorrem nos Estados de Minas Gerais, Bahia e Espírito Santo, e A.f.guariba, para as populações de distribuição mais meridional, desde o Estado do Rio de Janeiro até o Rio Grande do Sul. As diferenças na coloração da pelagem foram corroboradas no presente estudo após um estudo mais amplo de variação, mas as diferentes formas do osso hióide entre os táxons setentrional e meridional como proposto por IHERING (1914: 248) não procedem.

A partir da idéia de que guariba, e não fusca, poderia ser empregado como o real nome para o táxon do leste e sudeste do Brasil, CABRERA (1940) em seu trabalho sobre a nomenclatura de macacos sul-americanos, modificou o nome da subespécie que ocorre mais ao norte para $A$. g. guariba e criou o nome $A$. $g$. clamitans para o táxon meridional. Um ano depois, LÖNNBERG (1941) criou o nome A. fusca iheringii para substituir A.f. guariba designado por IHERING (1914) pelo fato de $A . f$. guariba ser homônimo e pré-ocupado por guariba Geoffroy Saint-Hilaire (1806) (entendendo que este era sinônimo de $A$. belzebul Linnaeus). Entretanto, o autor aparentemente não teve acesso ao trabalho de CABRERA (1940), o qual criara, um ano antes, o nome clamitans para a mesma finalidade. Conseqüentemente, A. guariba iheringi é um sinônimo júnior de $A$. clamitans.

A complicada questão nomenclatural de $A$. fusca, devido ao número excessivo de nomes e combinações, foi retomada por HershKovitz (1949) quem concluiu que o nome correto para a espécie de Alouatta do leste do Brasil era A. fusca por, novamente considerar guariba criado por Geoffroy SAINT-HiLAIRE (1806) 
como válido e, portanto, sinônimo de A. belzebul. Embora Alouatta guariba Humboldt venha sendo empregado com freqüência em trabalhos mais recentes para designar o táxon da Mata Atlântica do sul do Rio São Francisco (Muller et al. 2000, RYLANDS et al. 2000, Groves 2001a), este nome é homônimo júnior de [Simia] guariba Geoffroy Saint-Hilaire, 1806 e proibitivo para designar os bugios do leste do Brasil.

Até IHerING (1914), o táxon que habita a costa leste do Brasil, ao sul do Rio São Francisco, sempre foi considerado monotípico, e mesmo após o reconhecimento de duas subespécies pelo autor, e um aumento considerável das coleções e dos relatos de campo, as definições de ambos os táxons e principalmente, seus limites geográficos são imprecisos. Em particular, os trabalhos de destaque que se direcionaram a esclarecer estas questões foram os de Kinzey (1982) e Rylands et al. (1988). Kinzey (1982) detalhou a variação de $A$. fusca baseado na análise dos exemplares depositados no MZUSP reconhecendo duas subespécies, mas com algumas modificações em relação aos trabalhos de IHERING (1914), tais como: 1) o registro de ocorrência de A. f. clamitans até a margem sul do Rio Doce e não apenas até o Estado do Rio de Janeiro; 2) a ocorrência de possíveis híbridos entre as duas subespécies em alguns pontos na margem sul do Rio Doce (nunca comprovados); 3) uma possível variação clinal em A. f. clamitans, cujos machos das populações mais ao sul apresentam uma coloração castanho-avermelhado adquirindo uma rufosidade maior em direção ao norte, contra o padrão distribuído homogeneamente como aceito tradicionalmente (observação corroborada aqui); 4) as subespécies são parapátricas e não alopátricas (observação corroborada aqui); e 5) o autor critica a supervalorização do dicromatismo sexual em $A$. $f$. clamitans, uma vez que ele é incipiente em muitas populações (discordante com os dados do presente estudo).

Posteriormente, RYLANDS et al. (1988) reviram as definições das subespécies e os respectivos limites geográficos propostos por IHERING (1914) e KINZEY (1982), e concluíram que a coloração per se não é um bom caráter para defini-las, mas somente a presença do dicromatismo sexual. Os autores também atualizaram a distribuição geográfica proposta por KINZEY (1982), ampliando a área de ocorrência de $A$. f. clamitans com registros mais ao norte, na margem direita do Rio Jequitinhonha, no Estado de Minas Gerais, e conseqüentemente, restringindo a área de ocorrência de $A$. f. guariba. Esta restrição na distribuição de $A$. $f$. guariba foi seguida por MACHADO et al. (1998).

Após o exposto acima, considera-se $A$. fusca como uma espécie válida e distinta de seu táxon filogenéticamente mais próximo, A. clamitans, pelos vários caracteres de pelagem, cariológicos e tamanho.

\section{Alouatta clamitans Cabrera, 1940 comb. nov.}

Mycetes fuscus; Kuhl, 1820: 29, partim. -Spix, 1823: 43, partim. -Lesson, 1827: 51, partim. -Schlegel, 1876: 155. -Pelzeln, 1883: 8, partim. -Ihering, 1894: 29. -Meerwarth, 1903: 126. M[ycetes] ursinus; Wied, 1826: 48, partim. -Gray, 1845: 218, partim.
-I. Geoffroy Saint-Hilaire, 1851: 52, partim. -Burmeister, 1854:

24. -Gray, 1870: 38. -Hensel, 1872: 12, partim.

M[ycetes] seniculus; Wagner, 1840: 180, partim.

Aluatta [sic] ursina; Slack, 1862: 517; partim.

Mycetes seniculus; Hensel, 1867: 363; partim.

Mycetus [sic] ursinus; Ihering, 1892: 122.

Alouata [sic] fusca; Cabrera, 1912: 24.

Alouatta ursina; Elliot, 1913: 274; partim.

Alouatta fusca guariba; Ihering, 1914: 248.

Alouatta fusca; Chiarelli, 1972: 163, partim. -Mittermeier \& Coimbra-Filho, 1981: 85, partim. -Wolfheim, 1983: 214, partim. -Langguth et al., 1987: 37, figura 1. -Lorini \& Persson, 1990: 124. -Persson \& Lorini, 1990: 88. -Rylands et al., 1988. -Groves, 1993: 55, partim. -Pereira et al., 1995: 171. -Oliveira, 1995: 181. -Rylands et al., 1995: 121. -Rylands et al., 1996: 31, partim.

Cebus fuscus; Miranda-Ribeiro, 1924: 211, partim.

Alouatta guariba; Cabrera e Yepes, 1940: 109, partim. -Hirsch et al., 1991: 239, partim. -Rylands \& Brandon-Jones, 1998: 895, partim. -Groves, 2001a: 184.

Alouatta guariba clamitans Cabrera, 1940: 404. Localidade-tipo restrita aqui para São Sebastião, Estado de São Paulo, Brasil. Lectótipo MZUSP 97, fêmea adulta. -Crespo, 1952: 117. Cabrera, 1958: 54. -Hill, 1962: 129. -Voss, 1973: 11.-Crespo, 1974: 9. -Ávila-Pires \& Golvêa, 1977:15. -Groves, 2001a: 185. -Muller et al., 2000: 107.

Alouatta fusca iheringii Lönnberg, 1941: 23; em substituição ao Alouatta fusca guariba. Vieira, 1944: 11. Anthony et al., 1949: 132.

Alouatta fusca clamitans; Hershkovitz, 1949: 395, figura 56. Vieira, 1955: 382. -Napier, 1976: 80. -Carvalho, 1980: 58. Silva, 1981. -Kinzey, 1982: 458. -Vaz, 1983: 34. -Mittermeier et al., 1984: 268. -Mittermeier et al., 1988: 59. -Rylands et al., 1988: 103. Coimbra-Filho, 1990: 1076. -Hirsch et al., 1994: 5. -Rylands, 1994a: 161. -Oliveira et al., 2002: 669. Alouatta fusca calamitans [sic]: Ruschi, 1964: 15.

Alouata [sic] fusca clamitans: Vaz, 1981: 105.

Alouatta fuscus: Nowak e Paradiso, 1983: 398, partim.

\section{Material examinado (total: 159)}

BRASIL, Minas Gerais: Caratinga: MNRJ: 23161 (p, c), 23165 (c), 23168 (p, c); Porto Novo: MNRJ: 3907 (p); Rio Matipó: MZUSP: 3530 (c, h), 3531 (p, c, h); Rio Novo: MNRJ: 23157 (p, c, h); PARANÁ: Bituruna: MHNCI: 37 (p, c); Campo do Tenente: MHNCI: 1851 (p, c, h); Castro: MHNCI: 292 (p), 293 (p), 2504 (p, c); MZUSP: 2464 (p, c, h); Icaraima: MNRJ: 23177 a 23179 (p), 23180 (p, c); Porto Camargo: MZUSP: 7711 (p, c), 7712 (animal inteiro, via úmida); Palmas: MHNCI: 33 (p, c, h); Palmeira: MHNCI: 36 (p, c); Querência do Norte: MZUSP: 11154 (p, c), 11157 (p, c); Sertão do Rio Paraná: MHNCI: 31-32 (p, c, h), 39 (p e c), 41 (p, c); Rio de Janeiro: Angra dos Reis: MNRJ: 24101 (c); Parati: MNRJ: 8452 (c); Três Rios: MNRJ: 31359 (c); Rio Grande do Sul: Bom Jesus: MZUSP: 11117 (p), 11125 (p), 19167-69 (c), 11170 (p, c), 19171 (c), 11172-75 (p, c), 11191 (p); Cachoeira do Sul: 
MPEG: 22182 (c, h); 22213 (c, h); Guaíba: MZUSP: 11111-19 (p, c), 11120 (p), 11121-23 (p, c), 11139 (p); Panambi: MZUSP: 3189 (c); São Francisco de Paula: MZUSP: 19167 a 19169 (p); São Leopoldo: MPEG: 22212 (c, h); São Luiz Gonzaga: MNRJ: 31281 (c, h); Viamão: MZUSP: 11124 (p, c), 11125-26 (c), 11128 (c), 11130 a 11132 (c), 11135 (c), 11136 (p, c), 19183 (p, c), 19184 (c); Santa Catarina: Bom Retiro: MNRJ: 23177 (c); Corupá: MZUSP: 426 (p, c), 429 e 430 (c), 579 (p, c), 204 (p); Florianópolis: MHNCI: 291 (p, c); Garuva: MZUSP: 7128 (c), 7129 (c), 7131-32 (c); Ibirama: MNRJ: 21163 (p, c, h), 21164 (p, c), 21165 (p, c, h), 21166 (p, c), 31237-38 (c, h), 31240 (c, h), 31244-46 (c, h), 3125254 (c, h), 31256-58 (c, h); Jacinto Machado: MZUSP: 11186 (p), 11190 (c); Jaraguá do Sul: MZUSP: 10410 a 10414 (c); Joinville: MZUSP: 1669 a 1671 (c, h), 1672 (p, c, h), 1687 (c, h); São Joaquim: MZUSP: 19065 (c), 19067 (p, c), 19068 (c), 19070 (c), 19073 (p, c), 19074 (c); Xapecó: MNRJ: 21159-60 (p, c, h), 21161 (p), 21162 (p, c, h); São Paulo: Anhembi: MZUSP: 8464 (p, c, h), 846566 (p, c), 8467 (c), 8906 (p, c, h), 8907 (p, c), 8908 (p, c, h); Apiaí: MZUSP: 2442 (c); Serra da Cantareira, São Paulo: MZUSP: 5864 (p, c, h), 5865 (p), 5866 (p, c, h), 5867 (p, c), 5868 (p, c, h), 5869 (p), 6487 (p, c); Lins: MZUSP: 5899 (p, c, h), 590 (p, c); Paranapiacaba: MZUSP: 407 (p, c, h), 408 (c), 409 (c, h), 412 (c, h); Presidente Tibiriçá, Ilha: MZUSP: 25849 (animal inteiro, via úmida); São Paulo: MZUSP: 314 (c, h), 317 (p, c), 2344-46 (c), 3287 (p), 5898 (p, c), 6737 (p, c, h), 10365 (p, c, h), 19125 (p, c), 19532 (c, h); São Sebastião: MZUSP: 97 (p, c).

\section{Lectótipo e Localidade-tipo}

Restrita aqui, com base em lectótipo, para São Sebastião, Estado de São Paulo, Brasil. A designação prévia da localidadetipo por CABRERA (1940) é demasiadamente confusa e desconsiderada aqui, pois o autor ao descrever $A$. guariba clamitans, indicou como tipo qualquer espécime da série que IHERING (1914) analisou para a descrição da subespécie meridional $A$. fusca guariba (= A. f. clamitans), portanto estes são os sintipos. Por sua vez, IHERING (1914) mencionou apenas quatro exemplares de A. g. clamitans, todos depositados no MZUSP, embora o autor tivesse um número maior de exemplares disponíveis para estudo: considerou-se potencial material analisado por IHERING todo espécime depositado no MZUSP coletado até 1914, totalizando 22 exemplares. Os quatro espécimes de $A$. clamitans mencionados por IHERING (1914) foram: MZUSP 409, macho jovem de Paranapiacaba; MZUSP 1671, macho de Joinville; e MZUSP 413 e 315, ambos fêmeas. Destes, apenas os dois primeiros puderam ser analisados no presente estudo pois se encontram no MZUSP. Os demais não estão mais no acervo MZUSP e IHERING não forneceu a proveniência do material. Posteriormente, CABrera (1958) restringiu a localidade-tipo para a Serra da Cantareira, Estado de São Paulo, com base na afirmação de VieIRA (1944) sobre a abundância da espécie lá. Como a localidade-tipo restrita por CABRERA não foi baseada em um espécime (tipo) e que nenhum dos potenciais espécimes analisados por IHERING (1914) é proveniente da Serra da Catareira, esta restrição é invalidada aqui. Com base nos sintipos indicados por
CABrera (1940), ou seja, todo material disponível à época para IHERING (1914) analisar, designa-se aqui o lectótipo e paralectótipos de Alouatta clamitans. Esta designação visa formalizar os espécimes-referência que contém as características que definem Alouatta clamitans e no qual o nome se apóia. O lectótipo e paralectótipo foram escolhidos considerando as seguintes condições: que fossem sintipos, que o estado do material fosse bom, que os espécimes apresentassem, quando possível, mais de uma peça (ao menos crânio e pele), que retratesse a espécie, e que os espécimes fossem adultos.

Lectótipo: MZUSP 97, fêmea adulta, coletada em setembro de 1896 por B. Bicego. Material em boas condições, composto por crânio e pele aberta. Localidade-tipo: São Sebastião, Estado de São Paulo, Brasil (2350'S, $\left.42^{\circ} 20^{\prime} \mathrm{W}\right)$. Dimensões cranianas (em milímetros): comprimento total do crânio: 97,0; comprimento côndilo-basal: 86,6; largura zigomática: 64,3; largura inter-orbital: 53,7; comprimento palatal: 36,3; largura craniana: 48,7; largura condilar: 21,3; largura mastóidea: 52,0; largura da constrição pós-orbital: 39,5; comprimento mandibular: 75,9; altura do processo articular da mandíbula: 55,3; comprimento da fileira superior de dentes (excluindo os caninos): 34,6; largura entre molares: 33,8.

Paralectótipos: MZUSP 407, macho adulto, coletado em 1900. Material composto por crânio em bom estado, mas faltando os incisivos superiores e dois incisivos inferiores soltos, pele aberta, mas fragmentada em três partes, e osso hióide em boas condições. Material proveniente de Alto da Serra (atual Paranapiacaba), Estado de São Paulo, Brasil (234ㄴ ${ }^{\prime}$, $\left.46^{\circ} 17^{\prime} \mathrm{W}\right)$. MZUSP 409, macho adulto, coletado em 24 de agosto de 1900. Não há coletor. Material composto apenas por pele aberta em bos estado de preservação. Material coletado em Alto da Serra (atual Paranapiacaba). Este espécime foi citado por IHERING (1914). MZUSP 1671, macho adulto, coletado por Grossmann. Não há data de coleta. Material composto por crânio em boas condições. Apesar de, na etiqueta constar pele, esta não foi encontrada durante a revisão. Material proveniente de Joinville, Santa Catarina, Brasil $\left(26^{\circ} 18^{\prime} \mathrm{S}, 48^{\circ} 50^{\prime} \mathrm{W}\right)$. Este espécime foi citado por IHERING (1914).

\section{Distribuição geográfica}

Alouatta clamitans ocorre na região de Misiones, nordeste da Argentina (Crespo 1952, Di BitetTr et al. 1994) e Brasil. A figura 9 mostra a distribuição da espécie no Brasil, onde $A$. clamitans ocorre por toda a vertente Atlântica desde o extremo sul até os Estados do Rio de Janeiro e Minas Gerais. Mais detalhadamente, $A$. clamitans ocorre desde a região serrana central do Estado do Rio Grande do Sul até São Paulo, exceto nas regiões norte e noroeste do último, áreas de ocorrência de $A$. caraya. No Rio de Janeiro, A. clamitans ocorre no litoral e porção norte do Rio de Janeiro. Em Minas Gerais, a espécie ocorre na região do Rio Jequitinhonha (RyLANDs et al. 1988, Rylands et al. 1996) e seu limite ocidental é a Serra do Espinhaço. Os registros mais sul da espécie foram fornecidos por Printes et al. (2001).

Revista Brasileira de Zoologia 23 (1): 64-144, março 2006 
Alouatta clamitans ocorre em simpatria com A. caraya em alguns pontos de sua distribuição, principalmente no nordeste da Argentina e nas regiões adjacentes à margem leste do Rio Paraná, como atestam os exemplares de São Luiz Gonzaga e Guaíra no Rio Grande do Sul, e Sertão do Rio Paraná e Querência, ambas no norte do Paraná (ver Material Examinado). Alouatta clamitans habita as regiões de floresta pluvial sempre verde da costa Atlântica do leste do Brasil, florestas semidecíduas do interior do Estado de São Paulo e as matas de Araucaria das regiões montanas dos Estados da região sul do Brasil.

\section{Diagnose}

Dicromatismo sexual: machos adultos apresentam pelagem dorsal com várias tonalidades de pigmentos vermelhos, desde o ruivo profundo ao ruivo-amarelado (avelã), e membros e cauda invariavelmente mais escuros que o dorso (Figs 11-13). Fêmeas escuras, com coloração da pelagem dorsal e membros castanho-enegrecidos a castanho-avermelhados (Figs 14 e 15). Corpo hióideo quadrangular mais que ovalado e com tentório trapezóide, medianamente desenvolvido (Figs 16-19).

\section{Descrição geral}

As medidas cranianas e do osso hióide estão na tabela VIII. Machos adultos com barba desenvolvida cuja coloração varia desde castanho-avermelhado a ruiva (Figs 11-13), tornando-se sempre mais avermelhada na região lateral do pescoço e posteriormente à orelha; cabeça com pelagem curta e de coloração castanho-avermelhado; coloração dorsal variando desde castanhoavermelhado a castanho-amarelado (avelã); pêlos na região médio-dorsal e entre as espáduas, com a metade basal castanhoavermelhado escuro, faixa subapical castanho-avermelhado mais claro a ruiva, e extremo apical, quando diferenciado, mais escuro que a banda subapical. Flancos de coloração variando desde castanho-avermelhado a avelã, invariavelmente mais escuros que a porção dorsal. Membros anteriores variando desde castanhoavermelhados escuros a ruivos, apresentando campos cromatogenéticos vermelhos nas regiões laterais externas dos braços e nas mãos; membros posteriores de coloração castanho escuro a ruiva, apresentando campos cromatogenéticos vermelhos nos pés; cauda com coloração variando desde castanho-avermelhado escuro a ruiva e neste último caso, clareando na região apical tornando-se avelã. Para uma descrição mais precisa localmente vide abaixo na descrição da Variação.

Na fêmea adulta, barba relativamente rala, se comparada aos machos, e bruna, tornando-se ruiva na região do pescoço e ao redor da orelha (Figs 14-15); pelagem da cabeça curta e de coloração castanho escuro a vermelha. Coloração dorsal variando desde enegrecida a castanho-avermelhado escuro, muitas vezes, com campos castanho-amarelados ou acinzentados dispersos irregularmente pelo dorso. Lateral com pêlos mais longos que o dorso e de coloração castanho-avermelhado. Membros anteriores com pelagem castanho escuro ou ruiva, clareando na região das mãos; membros posteriores de coloração castanho escuro com manchas ruivas ou amarelas distribuídas aleatoriamente ao longo de toda a perna, e clareando na região dos pés; cauda castanho escuro ou ruiva tornando-se castanhoamarelado na região apical.

Ossos hióide no macho adulto com comprimento total de 53,5 a 70,8 mm $(\mathrm{N}=9)$; tentório formado por uma lâmina lisa, ou levemente côncava (Figs 16 e 18), e pouco desenvolvida $(11,0-21,0 \mathrm{~mm}, \mathrm{~N}=9)$; cornos e cornículos vestigiais; abertura hióidea desenvolvida, de forma quadrangular a levemente ovalada; ausência de trabéculas internas. Bula hióidea globular com a região anterior mais afilada. Osso hióide na fêmea adulta com comprimento total de 35,5 a 63,6 mm ( $\mathrm{N}=13)$; tentório formado por uma placa estreita e lisa (3,0-11,7 mm, $\mathrm{N}=12)$; cornículos lanceolados; abertura hióidea de forma quadrangular (Figs 17 e 19). Ossos nasais em ambos os sexos curvos em vista lateral.

O número diplóide apresenta considerável variação: 45 e 46 nas populações de Santa Catarina e Paraná; 48 a 50 nas populações de São Paulo. Há translocações y-autossomo (Oliveira 1995, 1996, Oliveria et al. 2002).

\section{Variação}

A análise do material mostrou uma ampla variação no padrão de coloração e no grau de dicromatismo sexual. Para os espécimes machos, registrou-se um total de três morfos referentes à coloração da pelagem, definindo de maneira geral, três áreas de ocorrência. Este número é maior que os dois morfos (ou três seguindo Kinzey 1982) que se conheciam e que definiam as subespécies $A$. f. clamitans e $A$. f. fusca. Com o intuito de descrever mais detalhadametne a variação da coloração da pelagem deste grupo, tratou-se separadamente os indivíduos machos e fêmeas adultos, assim como as regiões ao longo de sua área de distribuição, principalmente no eixo sul-norte (Rio Grande do Sul-Minas Gerais).

Variação na coloração da pelagem dos machos adultos os indivíduos provenientes dos Estados do Rio Grande do Sul e Santa Catarina apresentam coloração castanho-avermelhado a ruiva-dourada muito brilhante na região dorsal e o restante do corpo, incluindo os flancos, membros e cauda, ruiva escura (Fig. 11). Este padrão ocorre na totalidade dos espécimes do Rio Grande do Sul e em parte daqueles de Santa Catarina. Os pêlos na porção médio-dorsal apresentam base castanho escuro clareando gradativamente até o ápice castanho-avermelhado. Os pêlos no restante das regiões apresentam coloração castanho escuro. Alguns poucos indivíduos apresentam um padrão de coloração geral mais escuro com o corpo homogeneamente castanho escuro e apenas as regiões da nuca e espáduas com pêlos de pontas douradas. Todos os indivíduos analisados apresentaram a pelagem muito lanosa.

No Paraná, o único exemplar macho (MZUSP 2464) analisado proveniente de Castro, região oeste do Estado, apresentou coloração geral castanho escuro por todo o corpo com as regiões da cabeça e do dorso amareladas; os pêlos nestas regiões apresentam três bandas: a basal é equivalente a $2 / 3$ do comprimento total do pêlo e de coloração castanho escuro, uma faixa estreita subapical enegrecida e a apical amarela-avermelhada. A região

Revista Brasileira de Zoologia 23 (1): 64-144, março 2006 
lombar apresenta tonalidade alaranjada; os pêlos são escuros na base, clareando gradativamente até se tornarem ruivoavermelhados mais claros nas pontas. Os membros anteriores e posteriores, e a cauda, são castanho-avermelhados escuros; base dos pêlos castanhos escuros e ápice ruivo. Este indivíduo se assemelha ao padrão geral de coloração da pelagem registrada para os espécimes do Espírito Santo.

No Estado de São Paulo predominam os animais de coloração tipicamente ruiva profunda, tanto nas amostras da Serra do Mar quanto do Planalto. Os animais apresentam o dorso castanho-avermelhado brilhante e os membros, cauda, flancos e barba castanho escuro (Fig. 12). Os pêlos dorsais, da cabeça, braços e coxas são castanhos escuros na base e ligeiramente dourados nas pontas; no restante das regiões do corpo, os pêlos são castanhos escuros ao longo de toda a estrutura. Poucos espécimes mostraram coloração semelhante àquele do Rio Grande do Sul.

Os animais do Estado do Rio de Janeiro, excetuando os de Teresópolis, apresentaram a coloração predominantemente castanho escuro, com uma pelagem bruna distribuída por quase todo o corpo e dourado na região dorsal. As populações das regiões central e meridional de Minas Gerais, como atestam os indivíduos de Caratinga (MNRJ 23161), Rio Matipó (MZUSP 3531), Porto Novo (MNRJ 3907) e Rio Novo (MNRJ 23157), têm a coloração da pelagem castanho-avermelhado com o dorso amarelado (avelã) (Fig. 13). Os dois últimos espécimes foram considerados como possíveis híbridos por Kinzey (1982).

Variação de coloração da pelagem nas fêmeas adultas. A variação nas fêmeas é de menor intensidade e, portanto, menos discrepante que nos machos. As populações analisadas desde o Rio Grande do Sul até São Paulo apresentam coloração castanho escuro por todo o corpo, com as regiões da nuca e das espáduas, assim como uma extensa faixa médio-dorsal, de cor avermelhada ou levemente dourada, resultando em uma tonalidade mais clara e brilhante ao animal (Fig. 14). Os demais espécimes são homogeneamente mais escuros, de um castanho-avermelhado enegrecido (Fig. 15).

Dicromatismo sexual. Analisando o exposto acima, observa-se que a coloração nos machos tende a escurecer gradativamente no sentido sul-norte enquanto que o processo inverso ocorre nas fêmeas. Sendo assim, nas áreas mais ao sul da distribuição da espécie (por exemplo, os Estados do Rio Grande do Sul e Santa Catarina) o dicromatismo é expresso de forma mais acentuada, uma vez que o contraste na coloração, entre machos e fêmeas, foi o máximo registrado para A. clamitans. Em São Paulo e Minas Gerais o dicromatismo está presente de forma mais suave ou ocorre de forma incipiente. Contudo, a questão levantada por RyLANDs et al. (1988) quanto à falta de maior definição e nível de dicromatismo sexual em algumas regiões, principalmente naquela limítrofe das duas espécies, $A$. fusca e A. clamitans, ainda permanece devido ao baixo número amostral para Minas Gerais, área de peripatraia entre os dois táxons.

A tabela VIII apresenta os dados da estatística descritiva para os indivíduos machos e fêmeas de, no máximo, quatro amostras disponíveis e cuja separação foi por Estado. Embora política, esta separação faz sentido, pois reflete a variação latitudinal da coloração da pelagem ao longo da Mata Atlântica. As amostras são: 1) Rio Novo, Caratinga e Porto Novo, Minas Gerais; 2) São Paulo, Anhembi, Serra da Cantareira e Paranapiacaba, São Paulo; 3) Joinville, Jaraguá do Sul, Guaruva, Ibirama e Bom Retiro, Santa Catarina; e 4) São Joaquim, Jacinto Machado, Guaíba, Viamão e Bom Jesus, Rio Grande do Sul. Como apreciado na tabela VIII, as variáveis cranianas nos machos decrescem de Minas Gerais para Santa Catarina, mas espécimes do Rio Grande do Sul se tornam novamente menores em relação aos provenientes de Santa Catarina. O mesmo padrão acontece com as fêmeas (Tab. VIII).

\section{História taxonômica}

A história taxonômica de $A$. clamitans já foi discutida anteriormente na descrição de $A$. fusca. Com o reconhecimento de duas subespécies para os bugios da costa leste brasileira por IHERING (1914), as populações meridionais foram denominadas de A. fusca guariba pelo autor. Assumindo guariba como prioritário para a subespécie setentrional, CABRERA (1940: 404) se sentiu compelido a criar um novo nome para o táxon meridional criando A. guariba clamitans como transcrito: “...dijo Ihering: a la forma meridional le damos la denominación de Alouatta fusca guariba subsp. n.; pero aquel distinguido naturalista ignoraba que este nombre había sido ya empleado justamente para la outra subespécie, que es la representada em la mencionada lámina de Humboldt, de modo que em realidad la forma del Sur no tiene todavia nombre, por lo que propongo denominar-la Alouatta guariba clamitans".

No ano seguinte, as mesmas argumentações foram apresentadas por LÖNNBERG (1941: 23), que propôs a mudança do nome Alouatta fusca guariba para Alouatta fusca iheringi como segue: “ Unfortunately the name guariba is preocupied... In such a case the specific or subspecific name guariba cannot be used again without bringing confusion. To avoid this I take the liberty of proposing the name Alouatta fusca iheringi n. n. for the subspecies in question instead $A$. fusca guariba".

LÖNNBERG (1941), provavelmente desconhecia o trabalho de Cabrera (1940) que fora publicado meses antes e, portanto, esta mudança nomenclatural não procede.

\section{Possível hibridação entre $A$. caraya e $A$. clamitans}

O fenômeno de hibridação entre $A$. caraya e A. clamitans foi reportado anteriormente POR LORINI \& PERSSON (1990) e o padrão coloração da pelagem reportada pelas autoras foi confirmada no presente estudo mediante a análise dos mesmos espécimes estudados. Os três possíveis híbridos analisados são fêmeas e provenientes da região de Sertão do Rio Paraná, extremo noroeste do Estado do Paraná. Embora esta área se estenda por uma faixa de cerca de $30 \mathrm{Km}$ e sem registro de sintopia entre os dois táxons (F. PAssos, com. pes.), os indícios para a suposta hibridação são: 2) os três indivíduos do Sertão do Rio Parará compartilham claramente padrões de coloração da 
Tabela VIII. Dados morfométricos ( $\mathrm{mm}$ ) de sete amostras de A. clamitans no Brasil. Linha superior: média, desvio padrão e número amostral (em parênteses), respectivamente. Linha inferior: mínima e máxima.

\begin{tabular}{|c|c|c|c|c|c|c|c|}
\hline \multirow{2}{*}{ Variável } & \multicolumn{4}{|c|}{ Machos } & \multicolumn{3}{|c|}{ Fêmeas } \\
\hline & Minas Gerais & São Paulo & Santa Catarina & Rio Grande do Sul & Minas Gerais & São Paulo & Santa Catarina \\
\hline \multirow[t]{2}{*}{$\mathrm{CCR}$} & $110,3 \pm 9,5(2)$ & $120,1 \pm 3,8(6)$ & $124,2 \pm 3,3(11)$ & $122,8 \pm 3,8(7)$ & $101,28 \pm 3,5(9)$ & $104,1 \pm 2,9(13)$ & $103,2 \pm 3,7(9)$ \\
\hline & $103,5-117,0$ & $115,0-125,5$ & $117,0-127,3$ & $119,0-130,2$ & $97,0-106,9$ & $96,6-106,8$ & $96,5-93,3$ \\
\hline \multirow[t]{2}{*}{$\mathrm{CCB}$} & $106,1 \pm 07(2)$ & $110,7 \pm 2,2(5)$ & $114,1 \pm 2,6(9)$ & $112,9 \pm 3,9(7)$ & $90,2 \pm 3,3(9)$ & $90,66 \pm 2,7(13)$ & $88,97 \pm 3,6(8)$ \\
\hline & $105,6-106,7$ & $107,7-112,7$ & $108,9-118,4$ & $110,0-121,3$ & $86,6-97,0$ & $85,2-94,3$ & $82,6-93,3$ \\
\hline \multirow[t]{2}{*}{ LZI } & $78,7(1)$ & $78,8 \pm 2,9(6)$ & $79,9 \pm 2,1(11)$ & $78,7 \pm 3,9(7)$ & $66,9 \pm 3,8(9)$ & $56,4 \pm 1,7(13)$ & $62,9 \pm 2,5(9)$ \\
\hline & & $74,0-82,4$ & $74,3-81,5$ & $75,5-87,4$ & $61,1-73,3$ & $61,8-68,0$ & $58,5-67,0$ \\
\hline \multirow[t]{2}{*}{ LIO } & $55,7 \pm 3,8(2)$ & $60,6 \pm 3,9(6)$ & $62,4 \pm 1,7(11)$ & $63,5 \pm 3,6(7)$ & $53,9 \pm 2,0(9)$ & $53,5 \pm 1,5(13)$ & $54,0 \pm 1,7(9)$ \\
\hline & $53,0-58,4$ & $54,4-66,5$ & $59,0-65,2$ & $59,6-71,2$ & $51,2-57,3$ & $49,6-55,8$ & $51,0-57,5$ \\
\hline \multirow[t]{2}{*}{ CPA } & $39,4 \pm 0,6(2)$ & $45,2 \pm 2,5(6)$ & $45,0 \pm 2,3(11)$ & $45,8 \pm 2,5(7)$ & $36,2 \pm 0,7(8)$ & $37,7 \pm 1,9(13)$ & $35,8 \pm 2,0(9)$ \\
\hline & $38,9-39,8$ & $41,8-48,0$ & $40,5-48,0$ & $43,3-50,9$ & $35,3-37,0$ & $33,4-41,0$ & $32,6-38,0$ \\
\hline \multirow[t]{2}{*}{$A C R$} & $36,9 \pm 1,4(2)$ & $37,7 \pm 2,0(5)$ & $39,9 \pm 1,6(11)$ & $38,9 \pm 0,3(7)$ & $38,6 \pm 2,4(9)$ & $37,0 \pm 1,1$ & $37,4 \pm 1,1(9)$ \\
\hline & $35,8-37,9$ & $35,7-40,8$ & $36,8-41,8$ & $38,5-39,5$ & $35,3-42,4$ & $35,3-39,5$ & $36,0-39,6$ \\
\hline \multirow[t]{2}{*}{ LCR } & $51,5 \pm 0,6(2)$ & $50,5 \pm 1,3(6)$ & $52,2 \pm 1,6(11)$ & $51,4 \pm 1,8(7)$ & $51,4 \pm 2,8(9)$ & $49,6 \pm 1,8(13)$ & $48,3 \pm 3,9(9)$ \\
\hline & $50,8-51,7$ & $48,1-51,8$ & $49,0-54,3$ & $49,9-55,2$ & $48,3-56,9$ & $46,0-52,7$ & $38,7-52,1$ \\
\hline \multirow[t]{2}{*}{ LCO } & $22,3 \pm 0,7(2)$ & $23,2 \pm 1,1(5)$ & $23,0 \pm 1,0$ & $23,4 \pm 1,2(7)$ & $21,3 \pm 0,8(9)$ & $20,6 \pm 0,6(13)$ & $20,4 \pm 0,8(8)$ \\
\hline & $21,8-22,8$ & $21,3-24,4$ & $21,2-24,6$ & $22,0-25,3$ & $19,4-22,1$ & $19,6-21,8$ & $19,4-22,0$ \\
\hline \multirow[t]{2}{*}{ LMT } & $57,5 \pm 2,1(2)$ & $57,5 \pm 2,4(5)$ & $58,4 \pm 1,8(11)$ & $57,6 \pm 1,6(7)$ & $52,2 \pm 1,0(9)$ & $51,4 \pm 2,3(13)$ & $51,5 \pm 1,7(8)$ \\
\hline & $56,0-59,0$ & $55,0-61,5$ & $55,2-61,0$ & $55,5-60,0$ & $51,0-53,6$ & $47,1-54,9$ & $49,9-53,8$ \\
\hline \multirow[t]{2}{*}{ LPO } & $45,2 \pm 7,9(2)$ & $38,6 \pm 1,9(6)$ & $39,0 \pm 1,8(11)$ & $39,7 \pm 2,3(7)$ & $40,5 \pm 2,2(9)$ & $40,7 \pm 2,6(13)$ & $39,2 \pm 1,5(8)$ \\
\hline & $39,6-50,8$ & $36,0-41,0$ & $35,0-41,4$ & $37,7-44,7$ & $37,6-44,2$ & $38,2-48,8$ & $37,5-41,6$ \\
\hline \multirow[t]{2}{*}{ CMA } & $88,5 \pm 0,7(2)$ & $95,9 \pm 3,2(6)$ & $101,1 \pm 1,9(8)$ & $100,4 \pm 4,1(7)$ & $77,9 \pm 3,3(9)$ & $79,4 \pm 2,1(13)$ & $39,2 \pm 2,2(8)$ \\
\hline & $87,9-89,0$ & $91,5-101,0$ & $98,3-103,8$ & $93,5-105,8$ & $71,1-82,0$ & $75,2-82,2$ & $74,8-80,0$ \\
\hline \multirow[t]{2}{*}{ APA } & $73,3 \pm 7,0(2)$ & $78,8 \pm 4,8(6)$ & $80,7 \pm 4,3(11)$ & $80,0 \pm 4,3(7)$ & $62,2 \pm 5,6(9)$ & $61,4 \pm 2,5(13)$ & $58,0 \pm 4,7(8)$ \\
\hline & $68,3-78,3$ & $72,3-85,0$ & $73,0-87,3$ & $75,6-88,7$ & $55,3-71,4$ & $56,3-65,0$ & $50,5-63,0$ \\
\hline \multirow[t]{2}{*}{ CDS } & $37,6 \pm 0,8(2)$ & $41,1 \pm 0,7(4)$ & $41,8 \pm 1,7(10)$ & $41,2 \pm 0,3(2)$ & $36,2 \pm 1,1(7)$ & $35,5 \pm 1,9(12)$ & $36,7 \pm 0,6(3)$ \\
\hline & $37,0-38,2$ & $40,2-41,9$ & $39,4-45,0$ & $40,9-41,4$ & $34,6-38,2$ & $33,0-38,9$ & $36,0-37,2$ \\
\hline \multirow[t]{2}{*}{ LML } & $36,7(1)$ & $39,3 \pm 1,8(5)$ & $41,8 \pm 1,2(8)$ & $41,2 \pm 1,7(2)$ & $36,3 \pm 1,5(7)$ & $35,8 \pm 1,1(11)$ & $36,8(1)$ \\
\hline & & $36,4-41,0$ & $39,8-44,0$ & $39,9-42,4$ & $33,8-38,6$ & $34,0-37,7$ & \\
\hline \multirow[t]{2}{*}{ LPA } & $21,7 \pm 0,9(2)$ & $23,3 \pm 2,0(6)$ & $25,1 \pm 1,8(11)$ & $25,4 \pm 2,7$ (5) & $22,2 \pm 0,8(9)$ & $21,93 \pm 1,3(13)$ & $22,5 \pm 2,6(5)$ \\
\hline & $21,0-22,3$ & $20,5-25,8$ & $22,0-28,0$ & $23,0-29,3$ & $21,0-24,1$ & $19,2-24,6$ & $18,2-25,5$ \\
\hline \multirow[t]{2}{*}{$\mathrm{CHI}$} & $53,5(1)$ & $64,9 \pm 5,4(3)$ & $63,7 \pm 3,0(4)$ & $60,8(1)$ & $38,3 \pm 3,4$ (3) & $38,6 \pm 2,5(9)$ & - \\
\hline & & $60,9-70,8$ & $60,7-66,3$ & & $36,0-42,2$ & $34,5-41,6$ & \\
\hline \multirow[t]{2}{*}{ LHI } & $36,8(1)$ & $36,9 \pm 5,3(3)$ & $44,5 \pm 4,4(4)$ & $38,3(1)$ & $20,3(1)$ & $23,6 \pm 3,3(10)$ & - \\
\hline & & $30,8-41,0$ & $40,2-50,6$ & & & $19,7-32,0$ & \\
\hline \multirow[t]{2}{*}{ LTE } & $11,0(1)$ & $11,5 \pm 4,77(3)$ & $14,7 \pm 3,1$ & $12,6(1)$ & $5,7 \pm 1,9(2)$ & $5,1 \pm 2,5(10)$ & - \\
\hline & & $11,5-21,0$ & $11,1-18,2$ & & $4,4-7,0$ & $3,0-11,0$ & \\
\hline
\end{tabular}

pelagem típicos de $A$. clamitans e $A$. caraya, ou seja, a coloração castanho-avermelhada dos machos adultos da primeira e o castanho claro amarelado das fêmeas adultas da segunda; 3) observando as figuras 22-24, nota-se que os padrões de coloração são diferentes entre os indivíduos o que indica que não há a fixação de campos cromatogenéticos nos indivíduos desta população, e portanto, não podem ser considerados como um caráter distinto das duas espécies em questão. Os padrões de coloração da pelagem dos três indivíduos serão descritos abaixo e estão ilustrados nas figuras 22-24. 

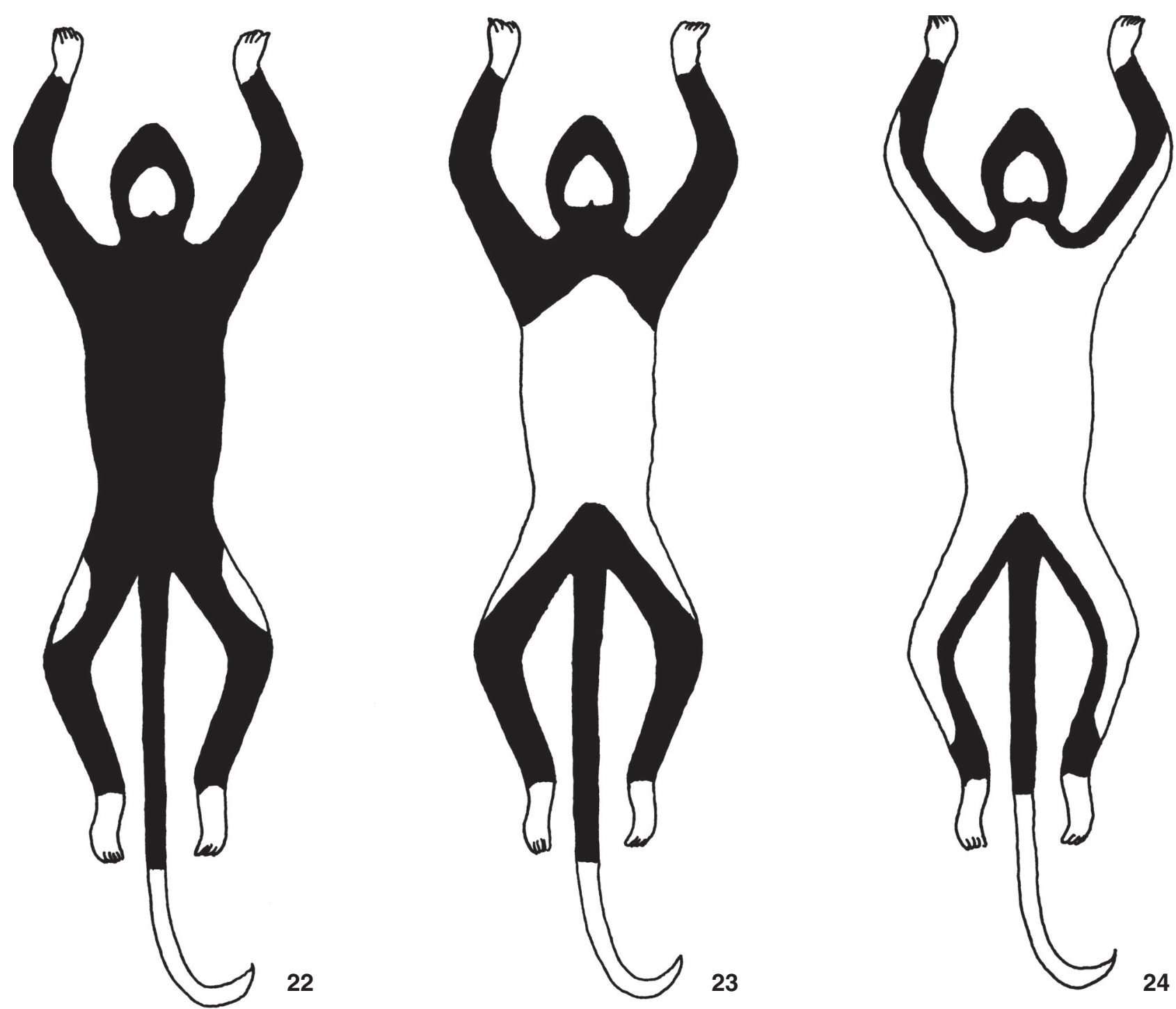

Figuras 22-24. Ilustração, em vista dorsal, mostrando os padrões de coloração da pelagem nos possíveis híbridos entre $A$. caraya e $A$. clamitans no noroeste do Estado do Paraná: (22) MHNCl 031; (23) MNHCl 032; (24) MHNCl 033. As áreas negras indicam coloração ruiva e as brancas, castanho-clara. Modificado de LoRINI \& PERSSON (1990).

O indivíduo MHNCI 031 (Fig. 22) apresenta a pelagem castanho-avermelhado exceto as regiões das mãos, pés, lado externo das coxas e metade terminal da cauda de cor castanhoamarelado mais claro. O indivíduo MHNCI 032 (Fig. 23) apresenta as mãos, pés, metade terminal da cauda e região dorsal desde as espáduas até a base da cauda e porção externa das coxas, de cor castanho claro amarelada; restante do corpo castanho-avermelhado. O exemplar MHNCI 039 (Fig. 24) tem a pelagem quase que castanho-amarelado claro, exceto a barba, cabeça, regiões internas dos braços e pernas e metade basal da cauda de cor castanho-avermelhado.

\section{Amazônia Oriental e Nordeste}

\section{Alouatta discolor (Spix, 1823) sp. rev.}

Mycetes discolor Spix, 1823: 48, pl. 34. Localidade-tipo: Forte Curupá (= Gurupá), Pará, Brasil. Descrição baseada em um espécime macho montado no Museu de Munique. -Minding, 1829: 51. Mycetes [sic] beelzebul; Gray, 1845: 220, 1870: 41; partim. Aluatta beelzebul [sic]; Slack, 1862: 518; partim.

Mycetes belzebul; Schlegel, 1876: 151. -Meerwarth, 1903: 126; partim.

Alouatta beelzebul [sic]; Forbes, 1896: 197; partim, nec Linnaeus 
(1766). -Elliot, 1913: 270; partim.

Alouata belzebul; Goeldi \& Hagmann, 1904: 41, partim.

Mycetes (Alouata) [sic] belzebul var. mexianae Hagmann, 1908:

6. Localidade-tipo: ilha de Mexiana, Pará, Brasil. Descrição

baseada em sete crânios no Museu de Zoologia de Strasburgo.

Alouatta discolor; Ihering, 1914: 231.

Alouatta belzebul; Chiarelli, 1972: 167. -Napier, 1976: 77. -Silva, 1981. -Wolfheim, 1983: 209. -Langguth et al., 1987. George et al., 1988. -Bonvicino et al., 1989. -Hirsch et al., 1991. -Groves, 1993: 254. -Groves, 2001a: 183. Partim.

Alouatta belzebul tapajozensis Lönnberg, 1941: 27. Localidadetipo: margem direita do Rio Tapajós, Pará. Restrito para Aveiros, Pará, Brasil por Bonvicino et al., (1989), uma das localidades na qual o material analisado por LÖNNBERG (1941) foi coletado.

Alouatta belzebul discolor; Cruz Lima, 1945: 73. -Vieira, 1955: 382. -Cabrera, 1958: 152. -Hill, 1962: 137. -Coimbra-Filho, 1990: 1076. -Auricchio, 1995: 132.

Alouatta belzebul tapojozensis [sic]; Groves, 1993: 254.

\section{Material examinado (total 208)}

BRASIL: Pará: Rio Bacajá: MZUSP: 25450 (c, h); Barreira: MZUSP: 18972 (p, c); Boiuçú: MZUSP: 5472 (p); Bom Jardim: MZUSP: $5409-10$ (p, c), 5411 (c), 5568 (p, c), 5572 (p), 5573-74 (p, c), 5748 (p), 7110 (c), 18996 (c), 24833 (p, c); Serra do Cachimbo: MPEG: 1726 (p); MZUSP: 8063 (p), 8066 (p, c, h), 8067 (c), 8068 (p), 8071 (p, c); Caxiricatuba: AMNH 94958, 94960-61 (p, c); MZUSP: 5328 (p, c), 5565 (p, c), 5566 (p, c, h), 5567 (p, c), 5570 (p, c), 6022 (c), 10563 (c), 10565 (c), 18997 (p), 19032 (p), 19118 (c); Rio Cururú: MPEG: 532 (p, c), 533 (p); Fordlândia: AMNH 133532-33 (p, c, h), 13536-537 (p, c, h), 133879-881 (c, h); FMNH 92087-090 (p, c, h), 92091-092 (p, c), 92093-95 (p, c, h), 92098-099 (p, c, h); MNRJ: 3908 (p), 4723 (c), 4729 (c, h), 4808-09 (p, c, h), 4839 (p, c, h), 21093 (p, c); MZUSP: 18892 (p), 1890 (p), 18966 (p, c), 18967 (p, c, h), 18968-70 (p, c), 18971 (p, c, h), 18973 (p, c, h), 18974-975 (p, c), 18976-977 (p, c, h), 18978 (p, c), 18979-81 (p, c, h), 18982 (c), 18983-87 (p, c, h), 18988 (p, c), 18989 (p, c, h), 18991-95 (p, c, h), 18998-0 (p), 6022 (p); Itaituba: MPEG: 8127 (p); Ilha Mexiana: MPEG: 17 (número de campo) (p, c, h); Monte Cristo: MZUSP: 3645 (p); Piquiatuba: MZUSP: $5329-30$ (p, c), 5333 (p, c), 5574 (p, c), 10495 (c, h); Porto Moz: MNRJ: 24110 (c), 31346 (c); Prainha: MNRJ: 11603 (p, c, h); Santarém: MNRJ: 11598 (p), 23138 (p); MPEG: 01 (c), 8125 (p, c), 8126 (c), 8492 (c, h), 13251 (c); MZUSP: 3644 (p), 24256 (c, h); Taperinha: MPEG: 4771 (c), 5016 (c), 5087-88 (c, h), 5089-90 (c), 5091-92 (c, h), 5093 (c), 5095-96 (c), 5104 (c), 5124 (c, h), 5125-27 (c), 5128 (c, h), 5129 (c), 5130-31 (c, h), 5132-34 (c), 5135 (c, h), 5136-38 (c), 5151-57 (c), 5158 (c, h), 5159-72 (c), 5173 (c, h), 5174-76 (c), 5177 (c, h), 5178 (c), 5179 (c, h), 5180-81 (c), 5183 (c), 5182 (c, h), 5184-85 (c), 5186 (c, h), 5187-88 (c), 5189 (c, h), 5190-91 (c), 5193-96 (c), 5197-98 (c, h), 5199-0 (c), 5202-03 (c), 5205-09 (c), 5671-75 (c), 5676-77 (c, h), 5678 (c), 5679-81 (c, h), 5682 (c), 5696 (c); MZUSP: 18935 (p, c, h), 18972 (p). Tauary AMNH 94951-957 (p, c).

\section{Revista Brasileira de Zoologia 23 (1): 64-144, março 2006}

\section{Localidade-tipo}

Forte Curupá (= Gurupá), margem sul do Rio Amazonas, entre os Rios Tapajós e Xingu, Estado do Pará, Brasil (SPIX 1823). Não há uma localidade mais precisa que Ilha Mexiana para $A$. b. mexiana Hagmann, 1908. Bonvicino et al (1989) restringiram a localidade-tipo de Alouatta belzebul tapajozensis Lönnberg, 1941 para Aveiros, margem direita do Rio Tapajós, uma das localidades na qual o material analisado por LÖNNBERG (1941) foi coletado. Desta localidade, LöNNBERG (1941) analisou três machos e cinco fêmeas, todos adultos.

\section{Distribuição geográfica}

A figura 25 mostra que $A$. discolor é endêmica ao Brasil distribuindo-se ao sul do Rio Amazonas, desde a margem direita do Rio Tapajós até o baixo Rio Tocantins e presumivelmente, na Ilha Mexiana. Este padrão é concordante com outras espécies de mamíferos, como Mico argentatus (Linnaeus, 1771) (VIvo 1991) e Dasyprocta punctata Gray, 1842 (IACK-XIMENES, com. pes.). Os pontos registrados mais ao sul da distribuição para a espécie são Fordlândia e Serra dos Carajás, ambos no Estado do Pará, e Rio Santa Helena (Mato Grosso), um tributário do Rio Teles Pires (Pinto \& Setz 2000), onde A. discolor ocorre em simpatria com $A$. puruensis. Contudo, na área compreendida entre o leste dos Rios Tapajós-Teles Pires e os Rios Iriri-Xingu não há amostras em coleções nem dados de campo suficientes para postular uma distribuição geográfica com maior precisão. A presença de A. discolor na margem oeste do Rio Tapajós, como atestam os

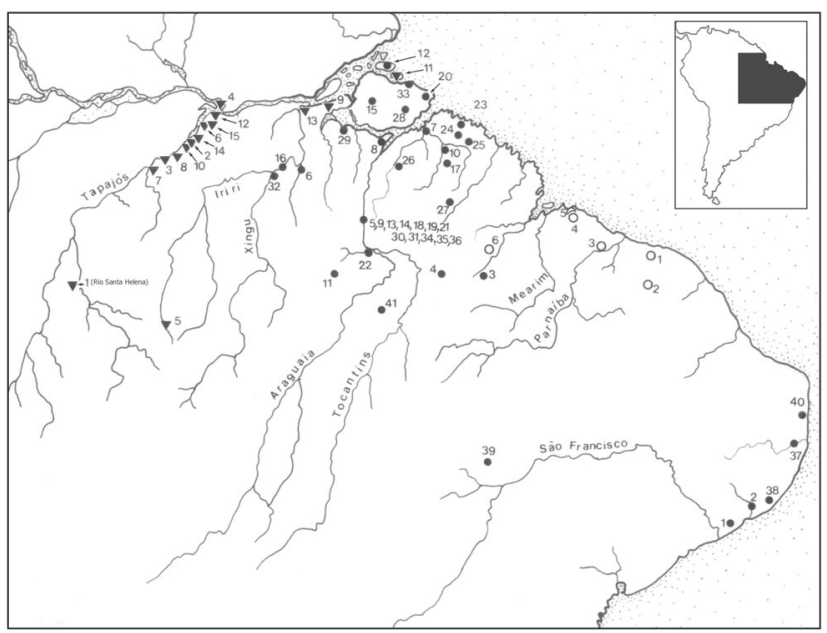

Figura 25. Mapa indicando a distribuição geográfica de três espécies do complexo "A. belzebul": círculos fechados: $A$. belzebul; círculos abertos: $A$. ululata; triângulos: $A$. discolor. Note a distribuição parapátrica entre os três táxons e a distribuição presentemente disjunta de $A$. belzebul. As localidades do médio Tocantins estão detalhadas no mapa da figura 38. Note também que a distribuição de $A$. belzebul e $A$. discolor é concordante com biomas florestais e $A$. ululata coincidente com a vegetação xerófila da costa norte do Nordeste. 
exemplares provenientes de Itaituba (MPEG 8127) e de Fordlândia (AMNH 133589), ainda necessita de dados adicionais para sua comprovação. Estes espécimes podem ter sido coletados na margem oposta, ou ter ocorrido erro no processo de registro do material. Alouatta discolor habita a Floresta Pluvial Equatorial Amazônica e parece estar mais restrita às regiões de inundação que às matas de terra firme.

\section{Caracteres diagnósticos}

Pelagem negra com mãos, pés, ápice da cauda e faixa dorsal ampla, desde a cabeça até a região lombar, de coloração ruiva a castanho-avermelhado (Fig. 26). Pêlos laterais distintamente longos. Osso hióide no macho ovalado com tentório reduzido formando uma placa estreita e completamente lisa (Figs 30 e 32). Abertura hióidea tão larga quanto longa, e ovalada.

\section{Descrição geral}

As medidas cranianas e do osso hióide estão na tabela IX. Pelagem nos adultos de ambos os sexos (Fig. 26) semelhante, com barba desenvolvida e ruiva na região mentoniana, e escurecendo lateralmente. Pêlos da cabeça curtos, em direções variadas; pelagem da cabeça negra ou ruiva. Pelagem por todo o corpo de coloração negra, exceto as mãos, pés, terço apical da cauda e dorso, desde a região da cabeça até a região lombar, de coloração ruiva a castanho-amarelado. Pêlos médio-dorsais com três faixas: base ruiva, região mediana negra e ápice ruivo, ou duas, e neste caso, com a base castanho escuro e o ápice ruivo; pêlos da região lombar sem bandas distintas, com matizes desde a base de cor castanho escuro até tornar-se ruiva no ápice. Pelagem lateral distintamente mais longa que a dorsal e de cor negra. Pelagem brilhante e macia. Pelagem no jovem negra opaca com a região lombar castanho-amarelado. Mãos e pés ruivos. Cauda negra com a metade apical ruiva escura, embora de forma não muito nítida.

Osso hióide no macho adulto com comprimento total de 55,4 a 69,1 mm ( $\mathrm{N}=27$ ); A forma geral é ovalada (Figs 30 e 32), sem saliências externas e sem uma tendência de alargamento lateral em direção à região posterior. Tentório, no geral, pouco desenvolvido: 3,2 a $19,6 \mathrm{~mm}(\mathrm{~N}=27)$, formando uma placa lisa e estreita, nunca côncava ou inflada (convexa). Cornos e cornículos vestigiais. Bula hióidea desenvolvida com paredes lisas, exceto na região ventral, onde apresenta uma constrição na região mais anterior; trabéculas internas, às vezes, presentes. Abertura da bula desenvolvida e ovalada. Osso hióide na fêmea adulta (Figs 31 e 33) com comprimento total de 37,0 a 43,1 mm $(\mathrm{N}=9)$. Tentório reduzido ou ausente: atinge até $6,3 \mathrm{~mm}(\mathrm{~N}=8)$. Cornículos lanceolados. Bula hióidea não inflada e de paredes lisas. Abertura desenvolvida. Os ossos nasais nos machos adultos são retos em vista lateral.

\section{Variação}

A variação reduzida na coloração da pelagem de A. discolor mostrou ser individual e/ou ontogenética, independente da localidade ou sexo. O padrão mais freqüente de coloração da pelagem é aquele descrito acima: negra com as extremidades dos membros, cauda e uma faixa dorsal ruivas. Em dois indivíduos provenientes de Caxiricatuba (MZUSP 5566) e Fordlândia (MZUSP 18979), a faixa dorsal estende-se desde a cabeça até as laterais da cauda. Todos os espécimes mais enegrecidos são jovens ou subadultos e este padrão mais escuro é resultante da ausência de alguns campos cromatogenéticos ruivos nas mãos e pés, ou principalmente, pela faixa ruiva dorsal mais fraca. Em todos os espécimes adultos os campos cromatogenéticos ruivos estão presentes de forma acentuada. Esta variação levou Bonvicino et al. (1989) a considerar o táxon como polimórfico para o caráter coloração da pelagem.

As extremidades distais dos membros e cauda geralmente são ruivas, mas podem apresentar-se castanho-amarelados. Além da variação na coloração das extremidades dos membros, A. discolor apresenta uma variação no ápice da cauda. No geral, os indivíduos apresentam apenas uma diminuta porção distal da cauda de coloração avermelhada. Em um indivíduo de Fordlândia (MZUSP 18971) e outro de Caxiricatuba (MZUSP 5565), este campo cromatogênico estende-se por uma faixa estreita dorsal até o terço apical. Esta variação na extensão da faixa ruiva da cauda pode estar relacionada à idade, uma vez que os indivíduos que apresentaram este padrão eram todos velhos. A variação mais notável na coloração da pelagem é ontogenética, cujos indivíduos jovens são mais escuros devido à ausência da extensa faixa dorsal ruiva ou castanhoavermelhado, ou esta quando presente, é de forma restrita à região lombar e fraca. Em todos os indivíduos adultos esta faixa ocupa toda a área dorsal dos indivíduos desde a nuca até a base da cauda. Raramente se encontram machos com a faixa restrita apenas à região lombar ou ao centro do corpo como ilustrado por Bonvicino et al. (1989).

Para a análise estatística nos machos, foram escolhidas quatro amostras, sendo que apenas duas possibilitaram a análise de variância. As amostras foram provenientes de: 1) Caxiricatuba e Taperinha, 2) Prainha, 3) Fordlândia e 4) Porto de Moz, todas no Estado do Pará. Não houve amostras de indivíduos fêmeas para a última localidade. A estatística descritiva para ambos os sexos estão na tabela IX. Uma comparação entre as amostras de indivíduos machos de Taperinha (amostra 1) e Fordlândia (amostra 3) mostrou que o comprimento côndilo-basal (CCB) e a largura interorbital (LIO) foram significativamente maiores nos indivíduos da primeira localidade. O mesmo pode ser dito para a largura interorbital (LIO) nas fêmeas. Contudo, estas diferenças podem ser caracterizadas como de caráter geográfico, não sendo substanciais para a separação das populações em níveis taxonômicos diferenciados para expressar tais divergências.

Testes univariados ( $t$-Student) foram aplicados para comparar diretamente $A$. discolor com $A$. belzebul e A. ululata (independente da categoria taxonômica, se espécie ou subespécie) e A. nigerrima, uma espécie peripátrica (ocorre na margem oposta do Rio Tapajós) e que tem sido considerada filogeneticamente próxima a $A$. discolor (HershKovitz 1949, Bonvicino et al. 1989, Coimbra-Filho 1990). A amostra de $A$. belzebul inclui a maioria 

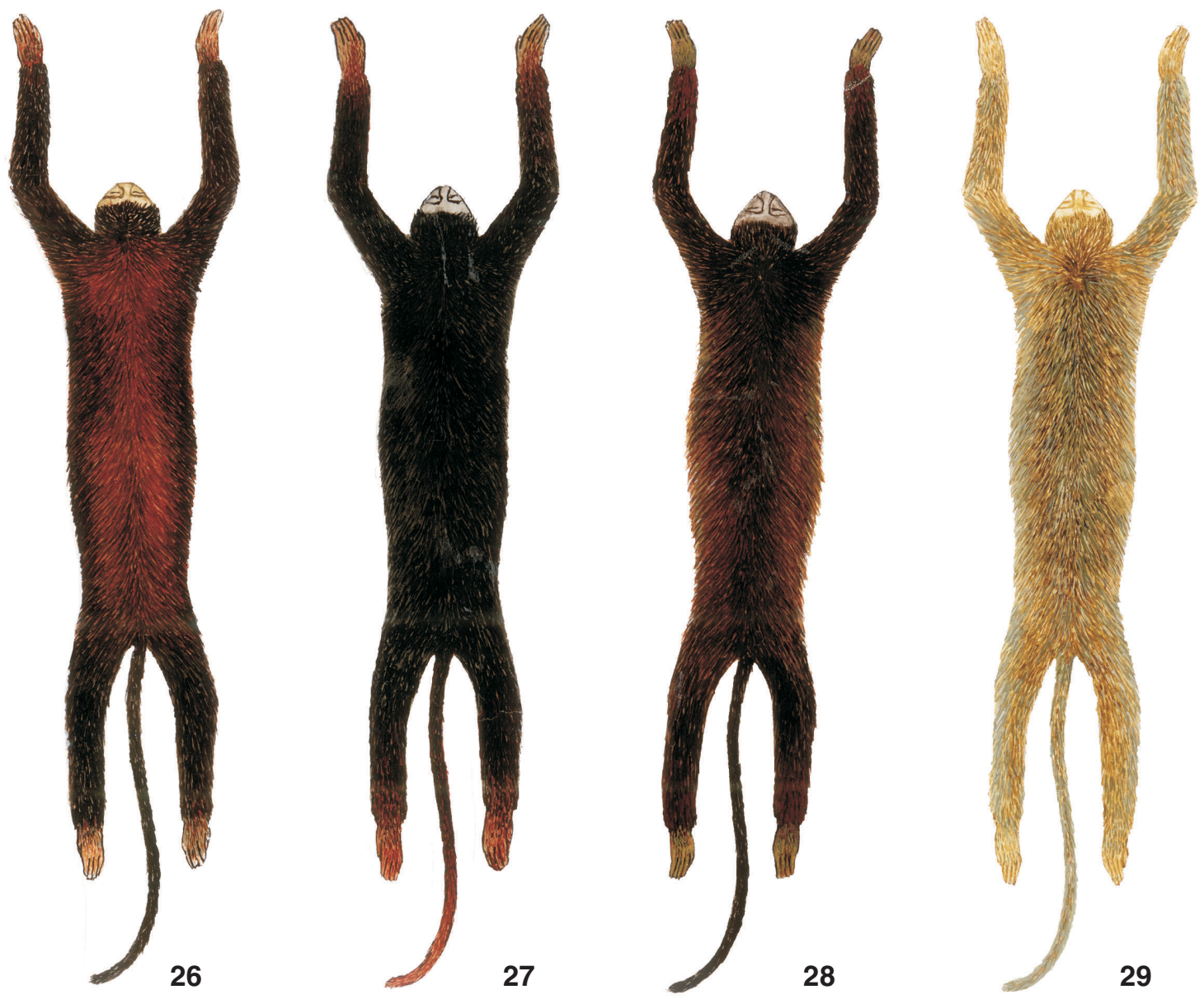

Figuras 26-29. llustração, em vista dorsal, mostrando os padrões de coloração da pelagem no complexo "A. belzebul": (26) A. discolor (MZUSP 5565); (27) A. belzebul (MZUSP 8911); (28) A. ululata, macho (MZUSP 2879); (29) A. ululata, fêmea (MZUSP 2486). Note o dicromatismo sexual diagnóstico de $A$. ululata. $O$ padrão de coloração ilustrado para $A$. belzebul é o registrado com maior freqüência.

dos espécimes analisados, excetuando as populações do Nordeste e da Ilha Tocantins, cujos indivíduos são bem menores e se destoam da média para a espécie (ver argumentação em $A$. belzebul a seguir). Alouatta discolor se diferenciou estatisticamente de $A$. belzebul em nove das 18 variáveis analisadas nos machos e apenas duas nas fêmeas (Tab. X). Isto indica alguma distinção que, se somado aos dados qualitativos, tais como forma do tentório e da bula hióide, e a coloração da pelagem, assegura o reconhecimento e validade de ambos os táxons. Todas as variáveis que distinguiu estatisticamente $A$. discolor de A. ululata são relacionadas às medidas de largura craniana, sugerindo que os crânios são mais largos na primeira. Em comparação a $A$. nigerrima, $A$. discolor se diferenciou em oito variáveis nos machos e sete nas fêmeas, majoritariamente com probabilidades muito baixas, consolidando as diferenças marcantes apresentadas também pelos caracteres cranianos, do osso hióide e da pelagem.
Os resultados da Análise de Componentes Principais (ACP) incluindo as variáveis cranianas dos quatro táxons compondo tradicionalmente o complexo A. belzebul (A. belzebul, $A$. discolor, A. ululata e $A$. nigerrima) estão resumidos abaixo (Tabs XI e XII). O gráfico ilustrado na figura 34 contém os resultados da ACP em machos, cujos três primeiros Componentes Principais (CPs) foram responsáveis $80,8 \%$ da variação (Tab. XI), sendo que as variáveis que mais contribuíram para as PCs estão relacionadas ao comprimento craniano. Diferentemente da análise univariada, observa-se na figura 34 que não é possível distinguir as populações representando os quatro táxons, embora A. nigerrima tenha boa parte das variáveis cranianas distintamente maiores e ela pode ser diferenciada dos outros três táxons examinados por caracteres qualitativos (hióide e nasais).

O gráfico na figura 35 mostra os resultados da ACP em fêmeas e a tabela XII indica as variáveis que mais contribuíram para os Componentes Principais. É importante notar que nesta 
Tabela IX. Dados morfométricos (mm) de quatro amostras de A. discolor do Pará, Brasil: (1) Caxiricatuba e Taperinha; (2) Prainha; (3) Fordlândia; (4) Porto de Moz. As medidas estão definidas na figura 1. Linha superior: média, desvio padrão e número de indivíduos analisados (em parênteses), respectivamente; linha inferior: mínimo e máximo.

\begin{tabular}{|c|c|c|c|c|c|c|c|}
\hline \multirow{2}{*}{ Variável } & \multicolumn{4}{|c|}{ Machos } & \multicolumn{3}{|c|}{ Fêmeas } \\
\hline & 1 & 2 & 3 & 4 & 1 & 2 & 3 \\
\hline \multirow[t]{2}{*}{ CCR } & $124,3 \pm 3,4(34)$ & $117,2(1)$ & $122,0 \pm 5,1(11)$ & $119,1(1)$ & $104,9 \pm 3,4(13)$ & $99,4(1)$ & $104,3 \pm 2,3(12)$ \\
\hline & $117,0-131,4$ & & $112,1-129,7$ & & $99,6-110,4$ & & $99,7-108,0$ \\
\hline \multirow[t]{2}{*}{$\mathrm{CCB}$} & $112,5 \pm 4,8(34)$ & $107,1(1)$ & $111,3 \pm 5,7(10)$ & $105,0(1)$ & $92,5 \pm 3,0(13)$ & $88,0(1)$ & $91,9 \pm 2,1(12)$ \\
\hline & $103,0-120,7$ & & $103,7-122,6$ & & $88,3-96,7$ & & $88,2-95,2$ \\
\hline \multirow[t]{2}{*}{ LZL } & $83,2 \pm 2,8(34)$ & $79,9(1)$ & $82,0 \pm 6,6(10)$ & $79,9(1)$ & $69,4 \pm 2,1(13)$ & $63,8(1)$ & $68,6 \pm 1,9(11)$ \\
\hline & $78,4-90,0$ & & $64,3-88,1$ & & $64,4-71,5$ & & $63,8-70,6$ \\
\hline \multirow[t]{2}{*}{ LIO } & $64,6 \pm 2,4(35)$ & $58,7(1)$ & $62,5 \pm 3,7(10)$ & $64,1(1)$ & $57,3 \pm 3,7(13)$ & $56,1(1)$ & $55,7 \pm 2,1(12)$ \\
\hline & $61,7-73,3$ & & $52,3-65,1$ & & $52,7-68,8$ & & $51,0-58,4$ \\
\hline \multirow[t]{2}{*}{ CPA } & $47,0 \pm 2,8(34)$ & $43,5(1)$ & $47,3 \pm 3,8(11)$ & $43,8(1)$ & $37,5 \pm 1,8(13)$ & $35,5(1)$ & $37,1 \pm 1,3(12)$ \\
\hline & $41,4-54,6$ & & $40,2-54,8$ & & $34,6-41,0$ & & $34,5-39,8$ \\
\hline \multirow[t]{2}{*}{$A C R$} & $39,2 \pm 2,1(34)$ & $37,3(1)$ & $40,2 \pm 2,9(9)$ & $37,0(1)$ & $39,2 \pm 3,2(13)$ & $36,5(1)$ & $39,2 \pm 1,7(12)$ \\
\hline & $36,7-49,1$ & & $37,3-46,8$ & & $36,1-49,0$ & & $36,8-43,4$ \\
\hline \multirow[t]{2}{*}{ LCR } & $53,7 \pm 2,0(35)$ & $51,5(1)$ & $53,1 \pm 3,5(9)$ & $50,5(1)$ & $51,4 \pm 1,7(13)$ & $48,6(1)$ & $51,3 \pm 1,7(12)$ \\
\hline & $50,0-58,0$ & & $46,4-58,1$ & & $48,0-54,5$ & & $48,7-55,1$ \\
\hline \multirow[t]{2}{*}{$\mathrm{LCO}$} & $23,9 \pm 1,2(35)$ & $21,3(1)$ & $23,4 \pm 0,9(10)$ & $22,0(1)$ & $22,0 \pm 0,8(11)$ & $20,9(1)$ & $21,7 \pm 0,6(12)$ \\
\hline & $21,7-26,7$ & & $21,8-25,1$ & & $20,9-23,6$ & & $20,1-22,1$ \\
\hline \multirow[t]{2}{*}{ LMT } & $57,2 \pm 2,4(35)$ & $54,3(1)$ & $57,0 \pm 3,4(11)$ & $53,1(1)$ & $52,8 \pm 1,2(13)$ & $37,9(1)$ & $51,4 \pm 1,3(12)$ \\
\hline & $51,6-61,7$ & & $49,4-61,8$ & & $50,6-54,3$ & & $49,4-53,6$ \\
\hline \multirow[t]{2}{*}{ LPO } & $42,5 \pm 2,9(35)$ & $39,8(1)$ & $42,3 \pm 2,1(11)$ & $44,0(1)$ & $42,6 \pm 2,2(13)$ & $42,7(1)$ & $42,3 \pm 1,2(12)$ \\
\hline & $37,1-55,2$ & & $39,1-45,3$ & & $39,4-45,7$ & & $40,8-45,5$ \\
\hline \multirow[t]{2}{*}{ CMA } & $99,0 \pm 2,8(34)$ & $94,5(1)$ & $97,0 \pm 70,0(11)$ & $95,2(1)$ & $79,3 \pm 2,6(13)$ & $71,7(1)$ & $78,6 \pm 2,0(12)$ \\
\hline & $94,2-106,6$ & & $78,0-102,8$ & & $76,1-83,2$ & & $75,4-81,5$ \\
\hline \multirow[t]{2}{*}{ APA } & $76,8 \pm 4,2(35)$ & $72,2(1)$ & $76,1 \pm 7,5(10)$ & $72,5(1)$ & $58,0 \pm 2,9(13)$ & $55,5(1)$ & $57,9 \pm 1,9(12)$ \\
\hline & $71,0-85,3$ & & $56,5-81,6$ & & $52,4-63,8$ & & $54,3-60,8$ \\
\hline \multirow[t]{2}{*}{ CDS } & $41,9 \pm 1,5(35)$ & $40,4(1)$ & $42,1 \pm 2,2(11)$ & $39,1(1)$ & $35,8 \pm 1,2(13)$ & $34,1(1)$ & $36,0 \pm 1,0(12)$ \\
\hline & $39,3-47,6$ & & $36,9-45,0$ & & $33,3-37,5$ & & $34-37,7$ \\
\hline \multirow[t]{2}{*}{ LMO } & $43,1 \pm 1,9(33)$ & $42,4(1)$ & $43,4 \pm 3,0(11)$ & $41,8(1)$ & $37,5 \pm 1,3(11)$ & $35,5(1)$ & $37,0 \pm 1,2(12)$ \\
\hline & $38,9-47,6$ & & $35,6-47,1$ & & $34,6-39,5$ & & $34,5-39,3$ \\
\hline \multirow[t]{2}{*}{ LPA } & $27,3 \pm 2,0(33)$ & $27,5(1)$ & $28,3 \pm 3,0(11)$ & $28,5(1)$ & $23,9 \pm 1,3(13)$ & $22,4(1)$ & - \\
\hline & $23,0-31,2$ & & $20,6-31,6$ & & $21,8-26,9$ & & \\
\hline \multirow[t]{2}{*}{$\mathrm{CHI}$} & $63,6 \pm 3,1(19)$ & $68,3(1)$ & $61,8 \pm 8,3(9)$ & - & $43,1(1)$ & - & $39,6 \pm 1,5(7)$ \\
\hline & $59,0-69,6$ & & $42,3-68,1$ & & & & $37,0-42$ \\
\hline \multirow[t]{2}{*}{ LHI } & $41,7 \pm 4,1(19)$ & $39,0(1)$ & $38,9 \pm 5,8(9)$ & - & $29,3(1)$ & - & $25,3 \pm 1,8(7)$ \\
\hline & $35,4-52,1$ & & $23,9-43,2$ & & & & $22,8-27,8$ \\
\hline \multirow[t]{2}{*}{ LTE } & $12,8 \pm 4,8(19)$ & - & $11,0 \pm 3,9(9)$ & - & $3,7(1)$ & - & $2,2 \pm 6,7(7)$ \\
\hline & $3,2-24,7$ & & $4,3-16,2$ & & & & $0,0-6,3$ \\
\hline
\end{tabular}

análise, os CPs são menos informativos individualmente que em machos, sendo os quatro primeiros responsáveis por apenas $69,4 \%$ da variação total. Contudo, diferentemente dos machos, quando contrastando os dois primeiros e mais importantes PCs, nota-se uma leve distinção entre $A$. nigerrima e os demais táxons.
Alouatta discolor é válida por apresentar uma série de autapomorfias, duas das quais merecem atenção, tanto pela sua definição inequívoca como pela sua distribuição homogênea entre os indivíduos: 1) a forma geral ovalada do osso hióide e 2) a lâmina do tentório estreita, curva e lisa (Figs 30 e 32). Contu- 

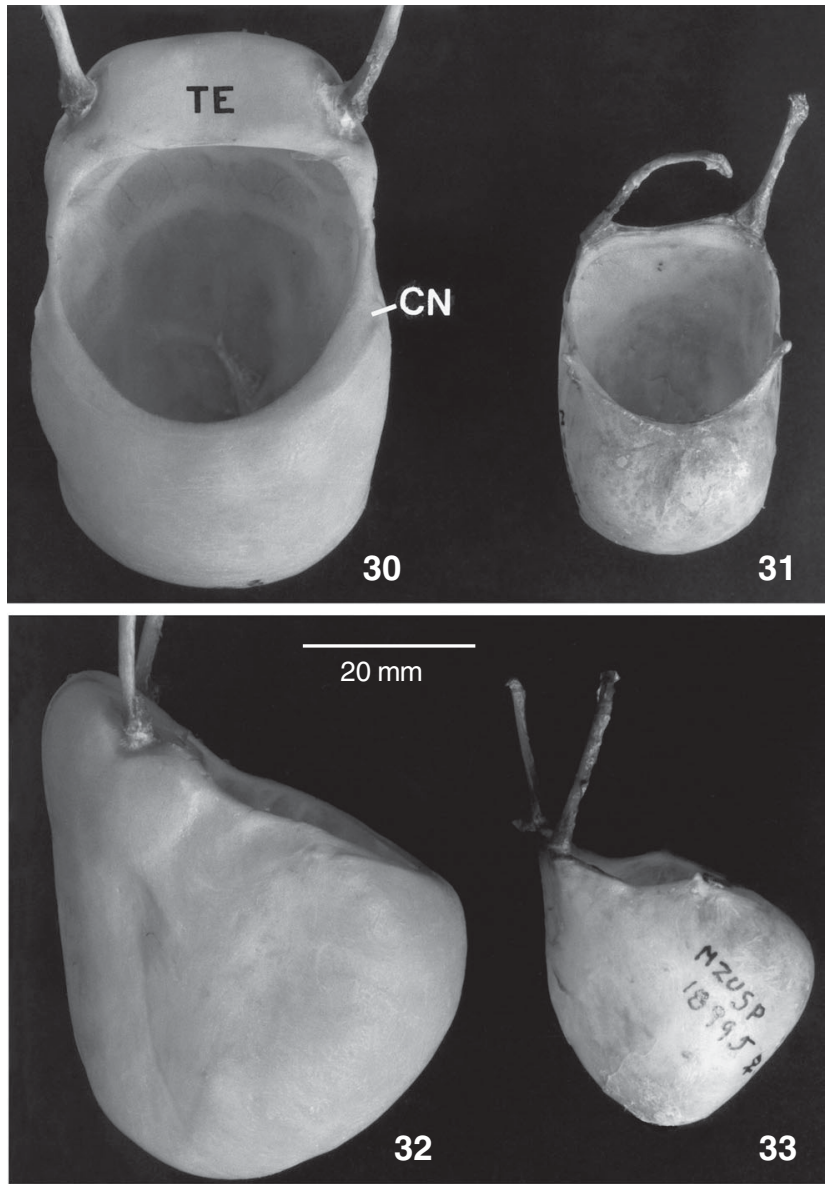

Figuras 30-33. Osso hióide de $A$. discolor: (30 e 32) indivíduo macho (MZUSP 18976) em vista ventral e lateral, respectivamente; (31 e 33) indivíduo fêmea (MZUSP 18995) em vista ventral e lateral, respectivamente. Note a abertura hióidea ovalada e a região superior curva em A. Note também o tentório estreito e liso. (CN) Cornículo, (TE) tentório.

do, o estreitamenteo do tentório em $A$. discolor é visualizado pela sua relação com o comprimento total do osso hióideo, mais que pela sua dimensão absoluta como fornecida nas tabelas XI e XII. As médias desta relação (LTE/CHI) acompanhadas pelos extremos (mínima-máxima) e pelo desvião padrão (SD), nos machos e nas fêmeas de $A$. discolor são, respectivamente: 0,183 (0,0-,293; $\mathrm{SD}=0,063 ; \mathrm{n}=29)$ e $0,06(0,0-0,15 ; \mathrm{SD}=0,055 ; \mathrm{n}=8)$. Em $A$. belzebul, as médias em machos e em fêmeas, são superiores, indicando tentórios proporcionalmente mais largos: 0,268 $(0,165-$ $0,362 ; \mathrm{SD}=0,05 ; \mathrm{n}=19)$ e $0,129(0,057-0,21 ; \mathrm{SD}=0,05 ; \mathrm{n}=8)$. O único macho de $A$. ululata analisado mostrou a relação 0,33 . As proporções em $A$. nigerrima foram as maiores dos quatro táxons, com machos e fêmeas apresentando, respectivamente, $0,356(0,271-0,412 ; \mathrm{SD}=0,05 ; \mathrm{n}=6)$ e $0,298(0,188-0,53 ; \mathrm{SD}=$ $0,129 ; \mathrm{n}=8)$. Este estreitamento do tentório em $A$. discolor con-
Tabela X. Resultado do test t-Student comparando os quatro táxons tradicionalmente reconhecidos como subespécies de $A$. belzebul. Plotadas apenas as variáveis estatisticamente significantes e suas respectivas probabilidades ( $p)$.

\begin{tabular}{|c|c|c|}
\hline \multirow{2}{*}{ Táxons } & Macho & Fêmea \\
\hline & A. discolor & A. discolor \\
\hline \multirow[t]{7}{*}{ A. belzebul } & $\operatorname{CCR}(p=0,039)$ & $C C B(p=0,018)$ \\
\hline & $C C B(p=0,044)$ & $\operatorname{LTE}(p=0,28)$ \\
\hline & $\mathrm{LIO}(p=0,000)$ & \\
\hline & $\operatorname{LCR}(p=0,012)$ & \\
\hline & $\mathrm{LPO}(\mathrm{p}=0,036)$ & \\
\hline & CMA $(p=0,040)$ & \\
\hline & $\operatorname{LTE}(p=0,000)$ & \\
\hline \multirow[t]{6}{*}{ A. ululata } & LZI $(p=0,003)$ & LZI $(p=0,000)$ \\
\hline & LIO $(p=0,002)$ & $\operatorname{LCO}(p=0,021)$ \\
\hline & $\operatorname{LCR}(p=0,020)$ & APA $(p=0,001)$ \\
\hline & $\mathrm{LPO}(\mathrm{p}=0,033)$ & LMO $(p=0,002)$ \\
\hline & $\mathrm{LMO}(\mathrm{p}=0,000)$ & \\
\hline & LPA $(p=0,005)$ & \\
\hline \multirow[t]{8}{*}{ A. nigerrima } & $\operatorname{CCR}(p=0,000)$ & $C C B(p=0,000)$ \\
\hline & $C C B(p=0,000)$ & LZI $(p=0,000)$ \\
\hline & LZI $(p=0,000)$ & CPA $(p=0,028)$ \\
\hline & LIO $(p=0,000)$ & $\operatorname{LMT}(p=0,000)$ \\
\hline & LMT $(p=0,005)$ & CMA $(p=0,044)$ \\
\hline & CMA $(p=0,023)$ & $\operatorname{CDS}(p=0,000)$ \\
\hline & LHI $(p=0,000)$ & $\operatorname{LTE}(p=0,000)$ \\
\hline & $\operatorname{LTE}(p=0,000)$ & \\
\hline
\end{tabular}

fere uma forma mais ovalada que semicircular a abertura hióidea.

Em adição, o comprimento acentuado dos pêlos laterais e a faixa dorsal ruiva muito ampla que se estende por todo o dorso do animal, na vasta maioria dos espécimes de Alouatta discolor, a difere da espécie parapátrica A. belzebul (Figs 26 e 27). Alouatta discolor distingue-se de $A$. nigerrima, táxon que ocorre na margem oposta do Rio Tapajós, por este ser totalmente negro, e apresentar a estrutura hióide mais robusta com tentório trapezoidal e largo. Alouatta discolor se diferencia de A. macconnelli, cuja ocorrência é a margem superior do Rio Amazonas, por esta ter a pelagem dorsal dourada com cauda e membros ruivos, apresentar as dimensões cranianas e hióideas maiores e ter tentório trapezoidal, mais largo e inflado lateralmente. A comparação entre $A$. discolor e $A$. ululata será vista adiante na descrição do segundo táxon.

\section{História taxonômica}

A história taxonômica de $A$. discolor é permeada por uma série de equívocos em seu conceito e está estreitamente relacionada à de $A$. ululata, táxon que será descrito adiante e que ocorre no norte dos Estados do Maranhão, Piauí e Ceará. Aqui serão explorados apenas alguns pontos de interesse, pois a história

Revista Brasileira de Zoologia 23 (1): 64-144, março 2006 
Tabela XI. Resultados da PCA, nos machos do tradicional complexo A. belzebul. O primeiro Componente (PC1) responde por 55,8 \%, e o PC2 e PC3 por $15,5 \%$ and $9,4 \%$ da variação, respectivamente. Em negrito, as variáveis que mais contribuíram para os Componentes Principais.

\begin{tabular}{cccc}
\hline Variáveis & PC1 & PC2 & \multicolumn{1}{c}{ PC3 } \\
\hline CCR & $-\mathbf{0 , 4 5 7}$ & $-0,273$ & $-0,103$ \\
CCB & $-\mathbf{0 , 5 2 7}$ & $-\mathbf{0 , 5 6 0}$ & 0,273 \\
LZI & $-0,238$ & 0,152 & $-\mathbf{0 , 5 0 8}$ \\
LIO & $-0,162$ & 0,031 & $-0,205$ \\
CPA & $-0,244$ & $-0,046$ & $-0,114$ \\
LCR & $-0,098$ & 0,028 & $-0,246$ \\
LCO & $-0,054$ & $-0,025$ & $-0,029$ \\
LMT & $-0,155$ & 0,159 & $-0,282$ \\
LPO & $-0,035$ & 0,161 & $-\mathbf{0 , 3 2 6}$ \\
CMA & $-\mathbf{0 , 3 9 3}$ & 0,236 & 0,107 \\
APA & $-\mathbf{0 , 3 7 4}$ & $\mathbf{0 , 6 7 6}$ & $\mathbf{0 , 4 7 7}$ \\
CDS & $-0,115$ & $-0,027$ & $-0,097$ \\
LMO & $-0,116$ & 0,096 & $-0,259$ \\
LPA & $-0,078$ & 0,099 & $-0,198$ \\
\hline
\end{tabular}

Tabela XII. Resultados da PCA, nas fêmeas, do tradicional complexo A. belzebul. O primeiro Componente (PC1) responde por apenas $29,9 \%$ e o PC2, PC3 e PC4 por $22,6 \%, 9,4 \%$ e $7,5 \%$ da variação, respectivamente. Em negrito, as variáveis que mais contribuíram para os Componentes Principais.

\begin{tabular}{crrrr}
\hline Variáveis & PC1 & \multicolumn{1}{c}{ PC2 } & \multicolumn{1}{c}{ PC3 } & \multicolumn{1}{c}{ PC4 } \\
\hline CCB & $-0,264$ & 0,168 & $\mathbf{0 , 4 5 9}$ & 0,200 \\
LZI & $-0,281$ & $-\mathbf{0 , 3 6 4}$ & 0,175 & 0,142 \\
LIO & $-\mathbf{0 , 3 6 1}$ & 0,206 & $-0,047$ & $-0,164$ \\
CPA & $-0,293$ & 0,142 & $-0,108$ & $-0,235$ \\
LCR & $-0,184$ & $-\mathbf{0 , 4 0 2}$ & 0,100 & $-0,094$ \\
LCO & $-0,207$ & 0,338 & 0,261 & $-0,204$ \\
LMT & $-0,177$ & 0,017 & 0,162 & $\mathbf{0 , 6 3 8}$ \\
LPO & $-0,246$ & 0,265 & $\mathbf{0 , 4 0 5}$ & 0,010 \\
CMA & $-0,233$ & 0,373 & 0,036 & 0,038 \\
APA & $-\mathbf{0 , 3 4 7}$ & 0,333 & $-0,027$ & $-0,069$ \\
CCB & $-0,295$ & 0,094 & $-0,043$ & $-\mathbf{0 , 5 0 2}$ \\
CCB & $-0,104$ & $-\mathbf{0 , 3 8 3}$ & $-0,202$ & $-0,092$ \\
LZI & $-\mathbf{0 , 3 2 8}$ & 0,099 & $-\mathbf{0 , 4 5 8}$ & 0,196 \\
LIO & 0,292 & 0,106 & $-0,471$ & 0,309 \\
\hline
\end{tabular}

taxonônomica de $A$. discolor foi detalhada em LöNnBERG (1941). SPIX (1823) descreveu Mycetes discolor como um animal de extremidades dos membros e dorso ruivos, fornecendo como hábitat, as margens do Rio Amazonas. A descrição de M. discolor por SPIX (1823: 28-29) segue: "Mycetes discolor, facie bubalina, manibus,
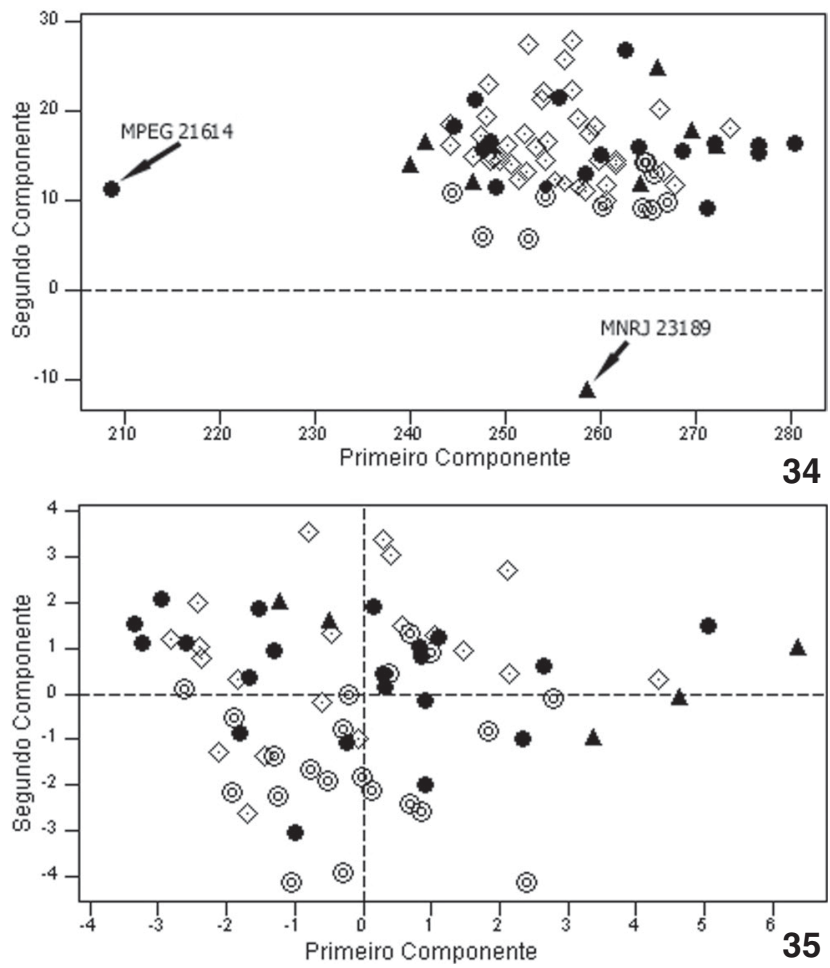

Figuras 34-35. Gráficos resultantes da ACP incluindo espécimes machos (34) e fêmeas (35) representando $A$. discolor (losango), A. belzebul (círculos preenchidos), A. ululata (triângulos) e A. nigerrima (círculos abertos). O exemplar do MPEG em destaque apresentou um comprimento craniano pequeno para a média enquanto o inverso ocorreu para o espécime do MNRJ.

pedibus caudaeque apice ferrugineis; dorso castaneo nigroque variegato; barba, lumbis, reliqua cauda et quatuor pedibus nigerrimis; pilis mollioribus, subrelucentibus. Habitat in sylvis riparris fluminis Amazonae nec non Tocantins prope urbem Para".

Considerando a descrição acima e a proveniência do material como a floresta Amazônica, mas não na região do Rio Tocantins nem a cidade do Pará (= Belém, local de ocorrência de $A$. belzebul), o táxon a qual Spix se refere pode ocorrer na margem direita do Rio Tapajós. Isto contraria a opinião de ElLIOT (1912) que considerou a descrição e a figura de SPIX (1823) não diagnósticas para qualquer espécie de Alouatta conhecida até aquela data. Digna de nota é a discrepância entre a descrição textual e a figura indicada por SPIX (1823), cujo espécime ilustrado era um jovem (LöNNBERG 1941), daí a coloração geral da pelagem mais enegrecida, o que dificultou o reconhecimento da espécie mediante comparação com espécimes adultos. Assim, após SpIX (1823), Mycetes discolor foi sinonimizada, compondo o gradiente de variação de $A$. belzebul (Linnaeus), e tornando-se obscura por praticamente um século.

Revista Brasileira de Zoologia 23 (1): 64-144, março 2006 
A história taxonômica da espécie se tornou ainda mais confusa quando Dollman (1910) nomeou os espécimes de Miritiba, Estado do Maranhão por Mycetes discolor Spix (1823). Dollman (1910) se baseou na análise de machos adultos os quais lembram A. discolor no padrão geral de coloração. Subseqüentemente, ELLIOT (1912) revisou a mesma série de espécimens de Dollman (1910) proveniente do Maranhão e concluiu, baseado na descrição e figura original de SPIX (1823), que o táxon descrito por aquele autor não existia, porque o espécimem na qual $A$. discolor foi descrita e depositado no Museu de Berlim era um típico A. belzebul, considerando-o um sinônimo júnior desta. Neste sentido, o espécime do Maranhão representava para ElLIot (1912) um novo táxon e que levou o autor a descrever Alouatta ululata.

O nome discolor foi reempregado, primeiramente para designar uma espécie válida por IHERING (1914), após comparação dos espécimes provenientes do Rio Tapajós e de Miritiba, e como uma subespécie de Alouatta belzebul por autores subseqüentes (Cruz Lima 1945, Vieira 1955, Cabrera 1958, Hill 1962, Cormbra-Filho 1990); esta última condição perdurou até o táxon ser novamente sinonimizado com A. belzebul por Groves (1993, 2001a). Ambos os caracteres diagnósticos do osso hióide, mais a coloração da pelagem, diferenciando $A$. discolor de táxons filogenéticamente próximos, $A$. ululata e $A$. belzebul, são suficientemente confiáveis para validar o táxon e em nível específico. Em concordância com estes dados, os exemplares provenientes de localidades imediatamente a leste da ocorrência de $A$. discolor (primariamente referidos como A. belzebul) são completamente negros (espécimes coletados de Cachoeira do Espelho e Largo do Souza, ambas no Rio Xingu, e Rio Bacajá), e nenhuma zona de intergradação foi definitivamente comprovada, confirmando a fragilidade em considerá-la em nível subespecífico.

LÖNNBERG (1941) analisou 18 espécimes provenientes de Aveiros, Prainha, Marai, and Itapoama, todos da margem direita do Rio Tapajós, considerando-os como representando uma raça da típica $A$. belzebul. LÖNNBERG (1941) manteve a confusão nomenclatural ao identificar os espécimes de Miritiba (Maranhão) como A. discolor em concordância com Dollman (1910), e contrastando com a opinião de ELLIot (1912) e IHERING (1914). Adicionalmente, LÖNNBERG (1941) considerou as populações do Rio Tapajós como uma entidade distinta, mas relacionada a A. belzebul. Ao reconhecer o nome discolor para o táxon de Miritiba, Maranhão, o autor sentiu-se compelido a criar um novo nome para o táxon do Rio Tapajós: Alouatta belzebul tapajozensis. O que chama a atenção é a posição convicta de LÖNNBERG (1941) sobre a distinção do táxon do Rio Tapajós quando ele escreve: "It appears thus evident that in this region (em referência à margem leste do Tapajós) a distinct geographical race or subspecies has been developed (referindo-se a $A$. discolor)". Posteriormente, na página 33, Lönnberg afirma: "this appears to strengthen the opinion expressed above that they are distinct from the typical Alouatta belzebul living further east. It is thus a matter of taste, if they (referindo-se aos espécimes do Tapajós) might be regarded as a quite independent species or as race of belzebul". Embora LÖNNBERG (1941) fosse um excelente taxonomista com descrições eloqüentes dos espécimes que analisou, suas opiniões nomenclaturais foram equivocadas na criação do nome $A$. belzebul tapajozensis.

Em adição aos caracteres autapomórficos que definem $A$. discolor per se, são dignos de análise as questões que relacionam a validade e a categoria taxonômica deste táxon com a definição de A. belzebul (Linnaeus). O trabalho que descreveu mais detalhadamente os padrões de variação da coloração da pelagem na espécie politípica $A$. belzebul foi elaborado por Bonvicino et al. (1989). Neste estudo, os autores reconheceram quatro subespécies, $A$. $b$. belzebul, $A$. $b$. nigerrima, $A$. $b$. discolor e $A$. $b$. ululata, com base na coloração da pelagem e propuseram um processo de filtro do fluxo gênico pelo Rio Tocantins no sentido oesteleste da distribuição, resultando em uma maior parcela de animais de pelagem negra na margem direita deste Rio. Este trabalho tem sido uma das bases para a diagnose e a manutenção das quatro subespécies de $A$. belzebul. Contudo, os dados mais recentes fornecem algumas modificações a respeito do monofiletismo do complexo A. belzebul somado a alguns pequenos equívocos notados durante a análise do mesmo material estudado pelos autores.

Primeiramente, Bonvicino et al. (1989) analisaram a espécie politípica $A$. belzebul considerando-a aprioristicamente como um grupo monofilético, mas dados citogenéticos (Lima \& SEUÁNEZ 1989) e moleculares posteriores (FIGUEIREDo et al. 1998), somado àqueles da morfologia do osso hióide e nasais, indicam que A. nigerrima está mais relacionada filogeneticamente às espécies A. macconnelli e A. juara (como será visto adiante). Partindo do princípio que os autores consideraram A. nigerrima como participando da mesma história evolutiva que $A$. belzebul e táxons filogeneticamente mais próximos, os resultados sobre a variação ou interpretações sobre o polimorfismo na coloração da pelagem no complexo A. belzebul torna-se falseável mediante as premissas errôneas de monofiletismo do grupo. Em adição, a ilustração mostra que os padrões de coloração ruiva dorsal no tipo D (A. discolor) de Bonvicino et al. (1989) estão mal delimitados, pois na grande maioria dos espécimes, a faixa ruiva se estende por todo o dorso do animal, desde a nuca até a região lombar e não fica restrita a região médio-posterior das costas como ilustrada pelos autores.

A análise da freqüência dos padrões de coloração da pelagem mostra resultados discrepantes daqueles apresentados pelos autores, uma vez que a maioria dos indivíduos analisados e restritos à margem direita do Rio Tapajós apresentou dorso ruivo (exceto alguns poucos juvenis que mostram a pelagem mais enegrecida), contrariando as proporções (e portanto o elevado nível de polimorfismo) fornecidas por Bonvicino et al. (1989) para a referida área. Por fim, dois exemplares (MNRJ 5927 e 5984) de Lago do Batista, indicados pelos autores como apresentando campos cromatogenéticos vermelhos de fato são completamente negros, confirmando-os como sendo A. nigerrima. De mesma forma, a ocorrência de um espécime com padrão de coloração 
descrito para $A$. discolor em Itaituba e outro de Fordlândia necessita de averiguações. Assim, não se pode considerar A. nigerrima como representando uma população melânica do complexo $A$. belzebul, como sugerido por Bonvicino et al. (1989), e tampouco afirmar que $A$. discolor é variável na coloração ruiva dorsal se se levar em conta apenas os adultos. Conseqüentemnte, os dados indicam que o polimorfismo acentuado quanto aos campos cromatogéticos avermelhados está restrito à subespécie $A . b$. belzebul, a qual tem espécimes variando do completamente vermelho ao negro, com muitas formas intermediárias, e ele não pode ser aplicado a nenhum outro táxon, particularmente a $A$. discolor e A. ululata. Sendo assim, os conceitos das subespécies assumidos pelos autores para, ao menos parte do complexo $A$. belzebul, são frágeis ou mesmo equivocados.

Hagmann (1908) descreveu uma nova subespécie para Alouatta belzebul nomeada como $A$. $b$. mexianae em referência à proveniência do material, a Ilha de Mexiana. A descrição do autor é restrita ao crânio, superficial e não comparativa em termos dos caracteres qualitativos. O autor somente forneceu algumas medidas de crânios e as comparou com algumas de A. belzebul típico. As medidas fornecidas por HaGmann (1908) se mostraram semelhantes em ambos os táxons e nenhum outro caráter craniano ou argumentação foi apresentada pelo autor para a criação deste novo táxon para a ilha Mexiana. A análise de um exemplar proveniente da Ilha Mexiana (MPEG 17, número de campo; animal coletado em dezembro de 1994) mostra um padrão de coloração da pelagem coincidente com aquele encontrado no típico $A$. discolor do Rio Tapajós. Como A. b. mexianae e $A$. discolor apresentam distribuição praticamente contínua tanto nos caracteres como na área de ocorrência (as principais ilhas do complexo Marajó são habitadas por vários táxons de Alouatta o que não caracteriza uma barreira efetiva para os macacos bugios), eles são considerados como sinônimos, prevalecendo o nome discolor pelo princípio da prioridade.

\section{Alouatta ululata Elliot, 1912 sp. rev.}

Alouatta discolor; Dollman, 1910: 422, nec Spix (1823). -Ihering, 1914: 233, nec Spix (1823).

Alouatta ululata Elliot, 1912: 32. Localidade-tipo: Miritiba (atual Humberto de Campos), Estado do Maranhão, Brasil; 1913: 267. [Holó]tipo: British Museum, ZD 1911.10.16.10, macho adulto (pele e crânio). [Pará]tipo: ZD 1911.10.16.12, fêmea adulta (pele e crâno) (NAPIER 1976).

Alouatta belzebul; Ihering, 1914: 233; partim. -Lönnberg, 1941; partim. -Napier, 1976: 77; partim. -Wolfheim, 1983: 209; partim. -Ávila-Pires, 1989: 429. -Hirsch et al., 1991; partim. -Groves, 1993: 254; partim. -Fernandes, 1995. -Groves, 2001a: 183; partim.

Alouatta belzebul ululata; Cruz Lima, 1945: 71; lâmina 2, fig. 1. -Vieira, 1955: 383; 1957: 126. -Cabrera, 1958: 153. -Hill, 1962: 136. -Mittermeier \& Coimbra-Filho, 1981: 85. Langguth et al., 1987: 37; fig. 1. -Bonvicino et al., 1989: 139. -Coimbra-Filho, 1990: 1076. -Auricchio, 1995: 132.

\section{Material examinado (total I34)}

BRASIL: Ceará: Bom Jardim e Cinta Sulidon, São Benedito: MNRJ: 21096 (p), 23141-42 (p, c); Goiabeira, Granjá: MNRJ: 23140 (p, c, h); Maranhão: Boa Vista: MZUSP: 2484-85 (p, c), 2486 (p, c, h); Miritiba (atual Humberto de Campos): MNRJ: 2752 (p); MPEG: 07-08 (c); MZUSP: 2747 (c), 2748-50 (p, c), 2751 (c), 2753 (p, c), 2754 (c), 2879 (p, c), 2880-81 (p, c), 290 (p, c), 2942-44 (hióide); Igarapé das Palmeiras, Primeira Cruz: MPEG: 21974 (p, c, h); Santa Luzia: MNRJ: 21088 (p, c), 23136 $(\mathrm{p}, \mathrm{c}), 23137$ (p, c), 23188-89 (p, c), 23198 (p, c), 2320 (p, c), 23210 (p, c), 23213 (p, c).

\section{Localidade-tipo}

Miritiba, atual Humberto de Campos, norte do Estado do Maranhão.

\section{Distribuição geográfica}

A figura 25 indica que $A$. ululata apresenta distribuição restrita ao norte dos Estados do Maranhão, Piauí e Ceará. Este táxon ocorre desde Humberto de Campos (= Miritiba), no Maranhão, até São Benedito, no Ceará. Guedes et al. (2000) registraram duas localidades adicionais para o Ceará (Ladeira do Mucambo e Cinta da Boa Vista). A distribuição mais ao sul e oeste da espécie é a região limítrofe entre a vegetação de transição tipicamente aberta e a floresta pluvial amazônica. O limite de distribuição à leste coincide com o término da vegetação de transição e o início da Caatinga.

A distribuição de Alouatta ululata é praticamente coincidente com a vegetação de transição com elevada freqüência de babaçu (Attalea speciosa Mart. Ex. Spreng.). Contudo, a espécie pode ser encontrada em ambientes mais mésicos com formações tipicamente florestais, mesmo que de forma periférica, como atestam os exemplares de São Benedito (brejo de Ipiapaba, divisa CE/PI) e Santa Luzia e os relatos de VieIra $(1944,1955)$, para o alto do Rio Mearim, ambos situados a sudoeste do Maranhão.

\section{Características diagnósticas}

Dicromatismo sexual presente: coloração da pelagem no macho negra brilhante com mãos, pés, extremidade da cauda e flancos ruivos a castanho-avermelhados (Fig. 28); fêmea com coloração parda-amarelada e pêlos acinzentados esparsos, resultando em uma tonalidade olivácea (Fig. 29).

\section{Descrição geral}

As medidas cranianas e do osso hióide estão na tabela XIII. O macho adulto apresenta barba densa com coloração negra na região do mento, tornando-se ruiva no pescoço e posteriormente à orelha. Pêlos da cabeça curtos e negros dispostos em várias direções. Dorso castanho-avermelhado com estreita faixa sagital negra, ou todo negro com poucas manchas ruivas distribuídas de forma irregular, dando uma aparência geral avermelhada e brilhante ao animal (Fig. 28); região lombar com pêlos longos e negros. Região lateral com pelagem castanhoavermelhado misturando-se a pêlos dourados esparsos; pêlos laterais distintamente mais longos que os dorsais. Membros 
Tabela XIII. Dados morfométricos ( $\mathrm{mm}$ ) das amostras (ambos os sexos) de A. ululata no Maranhão. Linha superior: média, desvio padrão e número de indivíduos analisados (em parênteses), respectivamente; linha inferior: mínimo e máximo.

\begin{tabular}{ccc}
\hline Variável & Macho & Fêmea \\
\hline CCR & $124,7 \pm 5,3(7)$ & $103,7 \pm 3,8(8)$ \\
& $118,4-134,6$ & $96,0-107,3$ \\
CCB & $114,8 \pm 6,5(10)$ & $89,9 \pm 4,8(8)$ \\
& $106,8-129,2$ & $81,3-96,0$ \\
LZI & $80,6 \pm 5,0(9)$ & $64,8 \pm 2,8(8)$ \\
& $71,6-86,0$ & $61,2-69,4$ \\
LIO & $62,3 \pm 3,3(11)$ & $53,8 \pm 2,3(8)$ \\
& $57,6-67,2$ & $51,4-57,3$ \\
CPA & $46,0 \pm 3,7(11)$ & $36,0 \pm 1,8(8)$ \\
& $41,8-53,4$ & $33,0-38,5$ \\
ACR & $39,1 \pm 2,9(11)$ & $40,7 \pm 1,8(8)$ \\
& $36,5-43,0$ & $38,0-44,0$ \\
LCR & $52,3 \pm 2,3(11)$ & $52,4 \pm 1,8(8)$ \\
& $49,5-57,0$ & $50,0-55,0$ \\
LCO & $23,7 \pm 0,9(11)$ & $21,0 \pm 0,8(8)$ \\
& $22,1-25,1$ & $19,8-22,2$ \\
LMT & $55,9 \pm 2,7(11)$ & $50,2 \pm 1,4(8)$ \\
LHI & $50,8-60,8$ & $48,5-52,8$ \\
LTE & $41,0 \pm 1,2(11)$ & $41,4 \pm 2,2(8)$ \\
LPO & $38,8-43,0$ & $38,7-45,9$ \\
& $100,0 \pm 5,2(10)$ & $76,0 \pm 3,1(8)$ \\
CMA & $93,4-109,2$ & $71,8-80,1$ \\
& $80,6 \pm 5,9(11)$ & $53,2 \pm 2,7(8)$ \\
& $71,8-91,1$ & $50,0-58,9$ \\
& $41,8 \pm 2,5(11)$ & $35,0 \pm 0,5(8)$ \\
& $37,4-46,4$ & $34,2-35,8$ \\
& $40,7 \pm 2,2(10)$ & $35,3 \pm 1,0(1)$ \\
& $38,0-44,2$ & $32,6-37,1$ \\
& &
\end{tabular}

anteriores e posteriores com coloração variando desde castanho-avermelhado a negra, com pêlos esparsos dourados. Mãos e pés castanhos-avermelhados a ruivos. Cauda negra com o terço apical ruivo, ou totalmente ruiva; pêlos dourados distribuídos esparsadamente por toda a cauda. Pelagem brilhante, macia e longa. As fêmeas adultas têm a barba rala, ruiva no queixo, tornando-se castanho na região do pescoço. Cabeça com pêlos castanho-avermelhados dispostos em direções variadas. Regiões dorsal, lombar e lateral com pelagem castanho claro a acinzentada, resultando em uma tonalidade olivácea muito brilhante (Fig. 29); região médio-dorsal, às vezes, com uma faixa sagital distinta de coloração bruna, desde a cabeça até a base da cauda. Pêlos dorsais monocromáticos, sem faixas distintas. Membros anteriores e posteriores de mesma coloração que a região médio-dorsal, ou ligeiramente escurecidos, clareando nas mãos e nos pés. Cauda de coloração castanhoavermelhado clareando na extremidade apical para uma tonalidade amarelada.

O macho jovem tem a pelagem toda negra, excetuando as extremidades das mãos, pés e cauda, cuja coloração é ruiva escura. Pêlos ruivos esparsos pelas regiões lombar, das espáduas e da nuca. A fêmea jovem tem a barba e cabeça com pelagem bruna a castanho-avermelhado claro. Dorso e lateral de coloração castanho claro brilhante, exceto na região lombar, onde se torna mais escura. Membros anteriores, posteriores e cauda com coloração marrom chocolate.

Osso hióide no macho adulto com comprimento total $63,7 \mathrm{~mm}(\mathrm{~N}=1)$. Tentório desenvolvido e liso: $21,1 \mathrm{~mm}(\mathrm{~N}=$ 1) (Figs 36 e 37). Cornos e cornículos reduzidos ou vestigiais. Região ventral da bula hióidea lisa. Abertura hióidea tão larga quanto longa, de forma quadrada. Sulco contornando lateralmente à abertura hióidea. Não há osso hióide de fêmea disponível nas coleções estudadas. Ossos nasais nos machos adultos são curvos em vista lateral.

Cariótipo. Não há registro de cariótipo na literatura.

\section{Variação}

A variação na coloração de A. ululata é individual, embora a análise seja influenciada pela baixa amostragem e pelo reduzido número de localidades. O padrão de coloração da pelagem mais freqüente nos machos é aquele descrito acima. A variação registrada refere-se basicamente ao número e intensidade das manchas ruivas que ocorrem no dorso e membros dos machos, onde se encontra desde indivíduos com poucos campos cromatogenéticos de coloração castanho escuro, resultando em uma aparência bruna do animal (MZUSP 2484 e 2879 de Miritiba, MA, e MNRJ 21096 e 23142 de São Benedito, CE), a animais com muitas manchas dorsais e laterais castanhoavermelhado a ruiva, dando uma aparência mais rufa e brilhante aos espécimes (MZUSP 2748 de Miritiba, MNRJ 23213 de Santa Luzia, MA, e MNRJ 23140 de Granjá, CE). A presença de pêlos dourados no corpo também variou, podendo ocorrer por toda a lateral do animal (MNRJ 23142 de São Benedito) ou por poucos pontos isolados e esparsos nos membros anteriores, cauda e dorso (MNRJ 2752 de Miritiba). O exemplar de Boa Vista, MZUSP 2484, apresentou uma faixa dourada e muito brilhante circundando toda a região posterior do pavilhão auditivo externo. A coloração na fêmea em geral é castanho claro acinzentada com uma tonalidade olivácea (Fig. 29), mas ocorrem variações bruscas desde indivíduos cuja pelagem é negra com poucos campos ruivos no dorso (MZUSP 2880, Miritiba) a indivíduos com pelagem castanho escuro com a presença de pêlos dourados espalhados pelo corpo, principalmente nos flancos, membros e cauda (MZUSP 2750 e 2752 de Miritiba). 


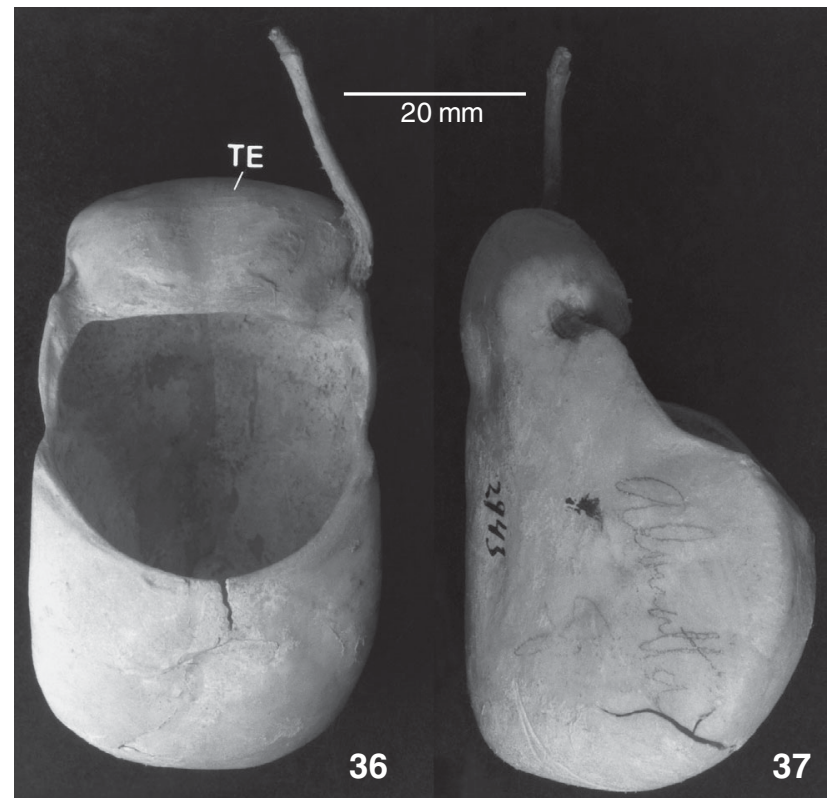

Figuras 36-37. Osso hióide de A. ululata, indivíduo macho (MZUSP 2943): (36) vista ventral; (37) vista lateral. Note o tentório largo, retangular e inflado latero-ventralmente. (TE) Tentório.

Após analisar os espécimes do norte do Maranhão e Ceará, e toda sua variação, certifica-se que os exemplares provenientes desta região pertencem a um táxon distinto de $A$. belzebul (Linnaeus) e de $A$. discolor (Spix, 1823), espécies filogeneticamente próximas. Alouatta ululata difere de suas espécies mais próximas por apresentar dicromatismo sexual e algumas regiões do crânio serem menores (Tab. XIII). Em adição, A. ululata habita um tipo de vegetação particular: enquanto que as espécies $A$. belzebul e A. discolor estão restritas à floresta pluvial equatorial amazônica, A. ululata habita uma vegetação xerófita com uma formação predominantemente aberta e com elevada freqüência de babaçu. Alouatta ululata se diferencia de $A$. caraya, a outra espécie que habita áreas de vegetação mais aberta e de distribuição parapátrica, por apresentar fêmeas com coloração da pelagem mais olivácea (contra o castanho claro amarelado de $A$. caraya) e os machos apresentrarem campos cromatogenéticos ruivos no dorso (contra o totalmente negro de $A$. caraya), e por ter a morfologia hióide diferenciada, principalmente pela presença de um tentório desenvolvido (estrutura ausente em A. caraya).

A revalidação formal do táxon, e ao nível específico, é considerada como uma hipótese a ser testada com dados adicionais, tais como os citogenéticos, estudos morfológicos complementares incluindo mais espécimes, e um incremento nos estudos da biologia destas populações. A única grande série deste táxon, excluindo a do MZUSP, está depositada no Museu Britânico a qual não foi analisada por mim. Segundo R. Thorington (com. pes.), lá encontram-se indivíduos machos claros e fêmeas escuras o que divergem parcialmente dos resultados alcançados no presente estudo, questionando assim a presença do dicromatismo sexual e conseqüentemente, a diagnose de $A$. ululata. Contudo, a descrição da coloração da pelagem por ElLIOT (1912) daquela série não deixa dúvidas quanto ao dicomatismo sexual do táxon, contrariando as informações do Dr. Thorington. De fato, a série de $A$. ululata do Museu Britânico foi obtida por Schwanda, o mesmo coletor do material depositado no MZUSP, a maior série desta espécie nos museus brasileiros, e é de se estranhar que ela seja muito diferente em ambos os museus. Assim, a convicção de que os espécimes do norte do Ceará, Maranhão e Piauí referem-se a um táxon distinto de $A$. belzebul é baseada em exemplares de museus brasileiros e eles caracterizam uma espécie dicromática. Somente após estudos mais aprofundados de variação morfológica e citogenética aliados aos dados ecológicos podem esclarecer se a espécie deve ser invalidada ou se o padrão de coloração peculiar encontrado nos indivíduos do Maranhão e Ceará é apenas uma variação de $A$. belzebul, talvez relacionada ao hábitat de vegetação mais aberta.

\section{História taxonômica}

Como já exposto e em LÖNNBERG (1941), a história taxonômica de $A$. ululata está diretamente relacionada àquela de $A$. discolor. Dollman (1910) foi o primeiro autor a descrever o padrão de coloração de $A$. ululata baseado em uma série enviada ao Museu Britânico e cuja proveniência era Miritiba, Estado do Maranhão $\mathrm{O}$ autor estava convicto que os exemplares que estava analisando pertenciam a $A$. discolor devido à coloração da pelagem negra e dorso castanho-avermelhado, padrão este superficialmente coincidente com aquele descrito, mas não figurado, por SPIX (1823).

Posteriormente, Elliot (1912) discerniu os animais de Miritiba descritos minuciosamente por Dollman (1910) daqueles do Rio Tapajós, descritos por SpIx (1823), ambos designados por discolor. ЕlLiot (1912) criou o nome A. ululata para indicar o táxon do Maranhão (= A. discolor Dollman, 1910), caracterizando-o por apresentar dicromatismo sexual e o colorido ruivo mais acentuado e brilhante se comparado à espécie do oeste do Pará, na qual o autor denominou de $A$. belzebul [assim como Dollman, ElLıot (1912) questionou a validade de $A$. discolor (Spix) considerando-a apenas como uma variação de $A$. belzebul (Linnaeus)]. Posteriormente, IHERING (1914) reavaliou a sistemática dos bugios e com base nos exemplares do Museu de Zoologia da USP, e considerou $A$. ululata apenas como uma variação de $A$. belzebul. Após o trabalho de IHERING (1914), os autores têm concordado com a categoria subespecífica de $A$. ululata (Cruz Lima 1945, VieirA 1955, 1957, Cabrera 1958, Hill 1962, Mittermeier \& Coimbra-FiLHo 1981, Langguth et al. 1987, Bonvicino et al. 1989, CoimbraFILHo 1990) ou mesmo negado a validade do táxon (LÖNNBERG 1941, Wolfheim 1983, Ávila-Pires 1989, Groves 1993, 2001a). A coloração da pelagem nos machos de $A$. ululata difere de $A$. discolor pela primeira mostrar os campos ruivos a castanhoavermelhados nos flancos, com uma faixa médio-dorsal negra, enquanto que $A$. discolor tem a região médio-dorsal ruiva e flancos enegrecidos. As fêmeas são marcadamente diferentes em ambos

Revista Brasileira de Zoologia 23 (1): 64-144, março 2006 
os táxons, pois em $A$. ululata elas são castanho claro levemente acinzentadas enquanto que em $A$. discolor elas apresentam o mesmo padrão que os machos.

A exposição acima mostra que o táxon habita uma formação vegetal diferenciada, apresenta características da pelagem conspícuas não registradas para qualquer espécime de $A$. belzebul ou A. discolor, e tampouco há registros confiáveis de hibridação entre os táxons. Assim, considera-se o táxon que ocorre no norte dos estados do Maranhão, Piauí e Ceará como uma espécie boa e designada pelo nome $A$. ululata.

\section{Alouatta belzebul (Linnaeus, 1766)}

Guariba Marcgrave, 1648: 226.

L'Ouarine Buffon, 1767: 5.

Simia belzebul Linnaeus, 1766: 37; localidade-tipo: Brasilia (= Brasil). Restrita por Thomas (1911) para o Estado do Pernambuco, Brasil, e posteriormente para o Rio Capim, Estado do Pará, Brasil, por Cabrera (1958). Descrição baseada primariamente na obra de Marcgrave (1648). Material tipo inexistente ou desconhecido.

[Cebus] belzebul; Erxleben, 1777: 44.

Simia Beezebul [sic]; Gmelin, 1788: 35. -Shaw, 1800: 70, partim. S[simia] (Sapajous) Beelzebub [sic]; Kerr, 1792: 75.

Alouatta beelzebut [sic]; Lacépède, 1799: 570.

Simia beelzebul [sic]; Cuvier, 1798: 10. -Thunberg, 1823a: 1.

Simia belzebub [sic]; Anderson, 1804: 471. -Bewich, 1824: 473;. Simia beelzebuth [sic]; Desmarest, 1804: 9.

[Simia] guariba; Geoffroy Saint-Hilaire, 1806: 272, rodapé. Nome criado para substituir Simia belzebul Linnaeus.

C[ercopithecus] Beezebul [sic]; Goldfus, 1809: 72.

Mycetes belzebul; Illiger, 1811: 70. Schlegel, 1876: 151. Pelzeln, 1883: 5.

Stentor guariba; Humboldt, 1812: 354; como sinônimo de Simia guariba Humboldt (1812).

[Aluatta] [sic] nigra Fischer, 1813: 550; Nome criado para substituir Simia belzebul Linnaeus.

Mycetes seniculus niger: Spix, 1814: 333; como sinônimo de Simia belzebul Linnaeus (1766).

Mycetes beelzebul [sic]; Illiger, 1815: 69. -Gray, 1845: 220; Wallace, 1854: 451; partim. -Forbes, 1896: 197; partim.

Mycetes rufimanus Kuhl, 1820: 21. Localidade-tipo desconhecida. Descrito a partir de um espécime depositado no Leiden Museum. -Desmarest, 1820: 79. -Lesson, 1827: 52. -Minding, 1829: 51. -Geoffroy Saint-Hilaire, 1851: 53.

C[ebus] Beelzebuth [sic]; Fischer, 1829: 43.

Simia belzebut [sic]; Richard, 1835: 140.

Mycetes belzebul; Gray, 1845: 220. -Schlegel, 1876: 150. -Jentink, 1887: 33.

Aluatta Beelzebul [sic]; Slack, 1862: 518; partim.

Mycetes flavimanus [sic]; Bates, 1864: 295.

Mycetes belzebuth [sic]; Bates, 1864: 176.

Alouata belzebul [sic]; Trouessart, 1897: 33; 1904: 21; partim. Goeldi \& Hagmann, 1904: 41.

Revista Brasileira de Zoologia 23 (1): 64-144, março 2006
Alouatta belzebul; Goeldi, 1902: 372. -Meerwarth, 1903: 126; partim. -Serra, 1952: 229; partim. -Carvalho, 1965: 10. Chiarelli, 1972: 167; partim. -Napier, 1976: 77; partim. Mittermeier \& Coimbra-Filho, 1981: 85; partim. -Wolfheim, 1983: 209; partim. -Armada et al., 1987. -Langguth et al., 1987. -Silva \& Neves, 1988: 520. -Lima \& Seuánez, 1989. Schneider et al., 1991. -Groves, 1993: 254; partim. Fernandes, 1995; partim. -Almeida et al., 1995: 174. Coimbra-Filho et al, 1995: 176. -Chame \& Olmos, 1997: 74. Alouatta beelzebul [sic]; Elliot, 1913: 270; partim. -Cabrera, 1940: 109; partim.

Alonata belzebeu [sic]; Neiva \& Penna, 1916: 106.

Alouatta belzebul belzebul; Cruz Lima, 1945: 69, pl. 1. -Cabrera, 1958: 151. -Vieira, 1955: 382. -Hill, 1962: 134. -Pine, 1973: 58. -Bonvicino et al., 1989: 139. -Coimbra-Filho, 1990: 1076. -Rylands, 1994b: 153. -Auricchio, 1995:132.

A[louatta] belzebul belzebul; Hershkovitz, 1949399.

Alouatta belzebub belzebub [sic]; Carvalho \& Toccheton, 1969: 219.

\section{Material examinado: total 191.}

BRAsIL, Alagoas: Serra Branca, Murici: MNRJ: 25671-672 (p, c), 25905 (p, c); Usina Sinimbú: MZUSP: 8298 (p, c); Maranhão: Aldeia São Pedro, Barra do Corda: MPEG: 23047-048 (p, c, h); MZUSP: 7978-79 (p); Imperatriz: MNRJ: $21089-090$ (p, c), 23134135 (p, c); Rio Maracaçumé: MPEG 1021 (c, h); PARÁ: Rio Amazonas: MZUSP: 19511 (animal inteiro, via úmida); Igarapé Arapari: MPEG: 12145 (p), 12157 (p), 12175 (c, h), 12421 (c); Ilha Bandeira: MPEG: 12344 (p, c), 12345-346 (p, c, h), 12347 (p, c); Belém: MPEG: 21595 (c); MZUSP: 1904 (p, c); BR 010 (Km 93): MZUSP: 8910 (p, c, h), 8611 (p, c), 8936 (p, c, h), 8937-38 (p, c), 8939 (c); Cametá: MZUSP: 5256 (p), 5405 (c), 5406 (p, c), 5407 (p, c, h), 5408 (p, c), 5505 (p); 10489 (c); Canoal: MPEG: 11845 (c, h), 11898 (c), 12375 (p, c, h), 12376 (p, c), 12377 (p), 12378-379 (p, c), 1240-402 (c); Vale do Caraípe: MPEG: 12380382 (p, c, h), 12383 (p, c), 12384 (p), 12385-387 (p, c, h), 12388 (p, c), 12389 (p), 12390-391 (p, c), 12392-393 (p, c, h), 12394396 (p, c); Serra dos Carajás: MPEG: 11294 (p, c), 11295 (p, c, h), 11829 (p), 11830-831 (p, c, h); Ilha Caviana: MPEG: 01 e 02 (número de campo) (p, c, h), 10 (número de campo) (p, c, h), 23049 (p, c); Chaves, Ilha de Marajó: MPEG: 1781-83 (p); Chiqueirinho: MPEG: 12134-137 (p, c, h), 12139 (p, c, h), 12141 (p), 12155 (p, c, h); Cachoeira do Espelho: MZUSP: 20927 (p, c), 20928 (p), 20929 (p, c); Itupiranga: MPEG: 21614 (c), 22164 (c, h); Jacundá: MPEG: 12142 (p, c), 12143 (p, c, h), 12144 (p), 12146147 (p, c), 12150 (p, c), 12158 (p, c); Igarapé Maguarí: MPEG: 12140-141 (p); Marabá: MNRJ: 2758 (p, c); MPEG: 14 (p); Maracanã: MNRJ: 21092 (p, c), 21094 (p); Murixaba: MPEG: 12312 (c, h), 12314-315 (c, h); Nova Timboteua: MNRJ: 21091 (p, c, h), 21095 (p, c, h); Ourém: MPEG: 8840 (p), 8842 (c), 8844 (c, h), 8849 (c, h); Paragominas: MNRJ: 23183 (p, c), 23184-187 (p, c), 23190 (p, c), 23191 (p, c), 23192-197 (p, c), 23199 (p, c), 23201-209 (p, c), 23211-212 (p, c), 24102 (c, h); Piratuba: MPEG: 601 (p); Ponta de Pedra, Rio Arari, Ilha de Marajó: MPEG: 8157 
(p, c, h), 8881 (p, c, h); Rio Pracupy, Portel: MPEG: 597 (p); Rampa: MPEG: 12342-343 (p, c); Santo Antônio: MZUSP: 13483 (p, c, h); Santarém: MPEG: 20182 (c); São Miguel: MPEG: 12138 (p, c); Saúde: MPEG: 12148 (p, c), 12149 (p, c, h), 12151-154 (p, c); Timbozal: MPEG: 11844 (c, h), 11847-848 (p), 12156 (p, c, h); Ilha Tocantins: MPEG: 12348 (p, c, h), 12349-354 (p, c), 12355 (p), 12356-358 (p, c, h), 12359 (p), 12360 (p, c), 12361-362 (p, c, h), 12363 (p, c), 12364 (p, c, h), 12365 (p, c), 12366 (p, c, h), 12367-371 (p, c), 12372 (p), 12373-374 (p, c); Usina Hidrelétrica de Tucuruí: MPEG: 12595 (p, c), 12596 (p), 12598 (c), 21968969 (c); Vila Brabo: MPEG: 11846 (p); Xambiobá, Araguaina: MPEG: 10934 (p). Paraíba: Fazenda Pacatuba, Sapé: UFPB: 41416 (p, c, h).

\section{Localidade-tipo}

Linnaeus (1766) apenas indicou "Habitat in Brasilia" a proveniência de Simia belzebul. THомаs (1911: 124) fixou a localidade-tipo para o Estado do Pernambuco, Brasil em referência ao material coletado por MarcGrave (1648) e na qual LinNAEus baseou a descrição da espécie (ver também CARvalHo 1965). Posteriormente, CABRERA (1958) restringiu a localidade-tipo para o Rio Capim, Estado do Pará, Brasil, onde, segundo o autor, espécimes do táxon são obtidos com freqüência. Esta restrição por CABrera (1958) demonstra vários equívocos e deve ser desconsiderada: 1) o autor desconhecia a obra de Thomas (1911), 2) a restrição de uma localidade para o Estado do Pará é muito distante daquela onde o material de MARCGRAVE poderia ter sido coletado e que foi referência para a descrição de $A$. belzebul, ou seja, na costa nordestina do Brasil, e 3) não há espécimes em coleções nacionais, e provavelmente nas estrangeiras, provenientes do Rio Capim como afirmado por CABRERA (1958).

\section{Distribuição geográfica}

As figuras 25 e 38 mostram que $A$. belzebul é endêmico ao Brasil e de distribuição disjunta, ocorrendo tanto na Floresta Amazônica, nos Estados do Amapá, Pará e Maranhão, como na Mata Atlântica nordestina, nos Estados do Piauí, Pernambuco, Paraíba, Alagoas e Rio Grande do Norte. Alouatta belzebul ocorre desde o complexo dos Rios Xingu-Iriri até o centro-norte do Maranhão, coincidindo com o término da Floresta Amazônica (esta distribuição inclui as Ilhas Marajó, Pará e Caviana). A ocorrência de $A$. belzebul em uma estreita faixa no Estado do Amapá, desde Mazagão até o Oiapoque foi registrada por FernANDes (1995). Na região Nordeste, A. belzebul ocorre na Floresta Atlântica desde a margem norte do Rio São Francisco, no estado de Alagoas, até Baia Formosa, no Rio Grande do Norte (Coimbra-Filho et al. 1995, CoImbra-Filho \& CÂmara 1996). Estes autores têm proposto que as localidades nordestinas de nome Guariba ou Guaribas devam ser pontos de ocorrência de espécies de Alouatta. Entretanto, na área proposta por CoIMBrAFILHO et al. (1995) putativamente podem ocorrer três táxons distintos (A. belzebul, A. ululata e $A$. caraya) e qualquer referência a uma destas espécies se torna arbitrária.

Na região mais ao norte, entre os Rios Xingu e Tocantins,

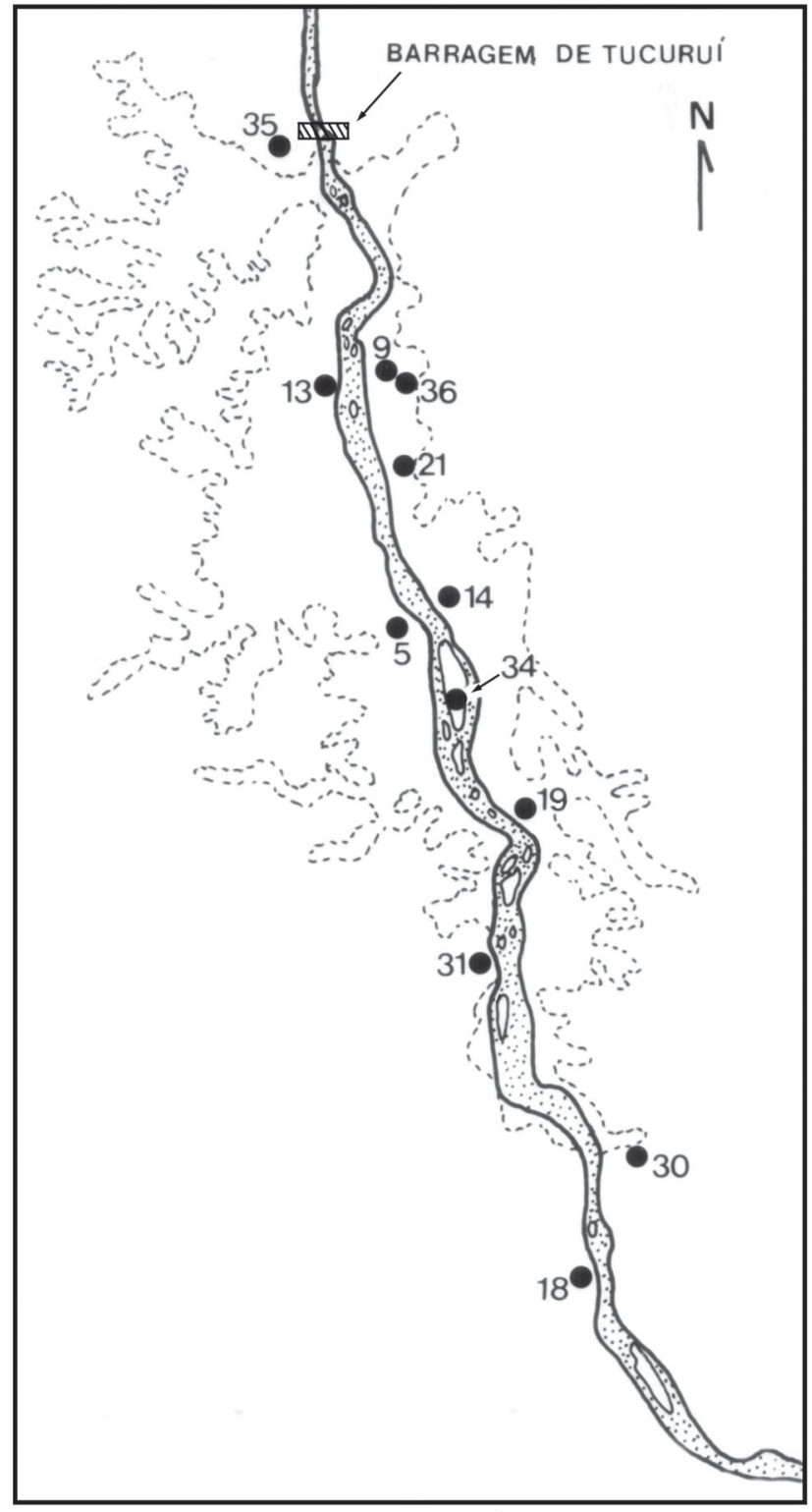

Figura 38. Mapa de distribuição geográfica de A. belzebul na região do médio e baixo rio Tocantins, PA, obtido mediante análise de espécimes e compilação de literatura. As coordenadas das localidades estão no Anexo I e foram extraídas, em sua maioria, de Mascarenhas \& Mello (1987).

A. belzebul é parapátrico com A. discolor e no sul do Estado do Amapá e na Ilha Pará (= Ilha Macapá), a espécie é simpátrica com A. macconnelli. Alouatta belzebul é restrita ao hábitat florestal e seu limite de distribuição provavelmente é a região limítrofe entre as florestas equatoriais brasileiras e as formações predominantemente abertas, como o Cerrado, as matas de babaçu e a Caatinga. 


\section{Caracteres diagnósticos}

Definido por uma combinação exclusiva de caracteres: coloração da pelagem, no geral, toda negra com as mãos, pés e terço apical da cauda de cor ruiva a castanho-avermelhado (Fig. 27). Osso hióide no macho com tentório retangular e desenvolvido, abertura hióidea ovalada e com sulco lateral presente; cornos inseridos posteriormente e cornículos desenvolvidos (Figs 39 e 41).

\section{Descrição geral}

As medidas cranianas e do osso hióide estão nas tabelas XIV e XV. A coloração da pelagem nos adultos de ambos os sexos, como descrita abaixo (Fig. 27), refere-se ao padrão mais freqüente registrado para a espécie. A grande variação de coloração registrada para $A$. belzebul será detalhada mais adiante. Barba densa e de coloração negra a ruiva. Pêlos da cabeça curtos e de coloração negra a castanho-avermelhado; pelagem dorsal macia, de pêlos curtos e coloração negra opaca. Flancos, membros anteriores e posteriores totalmente negros, excetuando as mãos e pés que são ruivos a castanho-avermelhados. Cauda desde a base até seu terço apical de coloração negra, e daí até a extremidade, ruiva a castanho-avermelhada. A pelagem no jovem é pouco densa, de coloração negra por todo o corpo, exceto nas extremidades das mãos, pés, cauda e manchas pequenas castanhoavermelhados espalhadas irregularmente pelo dorso.

Osso hióide macho adulto com omprimento total de 54,4 a 75,6 mm ( $\mathrm{N}=17)$. Tentório: 11,8 a $29,7 \mathrm{~mm}(\mathrm{~N}=17)$. Cornículos reduzidos ou vestigiais e de forma lanceolada (Figs 39 e 41). Bula hióidea larga e, no geral, com trabéculas internas. Abertura hióidea tão larga quanto longa, resultando em uma forma geralmente quadrada ou evenetualmente, ovalada. Sulco distinto contornando lateralmente a abertura hióidea presente (Figs 39 e 41). Os ossos nasais são curvos em vista lateral.

Osso hióide na fêmea adulta com comprimento total de $37,0$ a 48,3 mm ( $\mathrm{N}=9)$. Tentório desenvolvido e liso: 2,2 a 10,7 $\mathrm{mm}(\mathrm{N}=10)$. Cornículos lanceolados e reduzidos. Bula hióidea com abertura desenvolvida com paredes lisas e comprimida dorso-ventralmente (Figs 40 e 42).

Cariótipo. Número diplóide igual a 50 nas fêmeas e 49 nos machos. Translocação Y-autossomo presente (ARMADA et al. 1987, Lima \& SEUÁNEZ 1989).

\section{Variação}

A variação encontrada em $A$. belzebul, mesmo que restrita à coloração da pelagem, indubitavelmente é uma das mais acentuadas entre os táxons de Alouatta analisados (vide Bonvicino et al. 1989 para mais detalhes). O padrão de coloração mais freqüente encontrado em $A$. belzebul é aquele de pelagem toda negra com as regiões das mãos, pés e terço apical da cauda ruiva ou castanho-avermelhado (Fig. 27). Este padrão corresponde àquele originalmente descrito por LinnaEus (1766) e KuHL (1820). No entanto, variações deste padrão ocorrem desde indivíduos totalmente negros, como os provenientes de Jacundá (MPEG 12142, 12144), Igarapé Arapari (MPEG 12145),
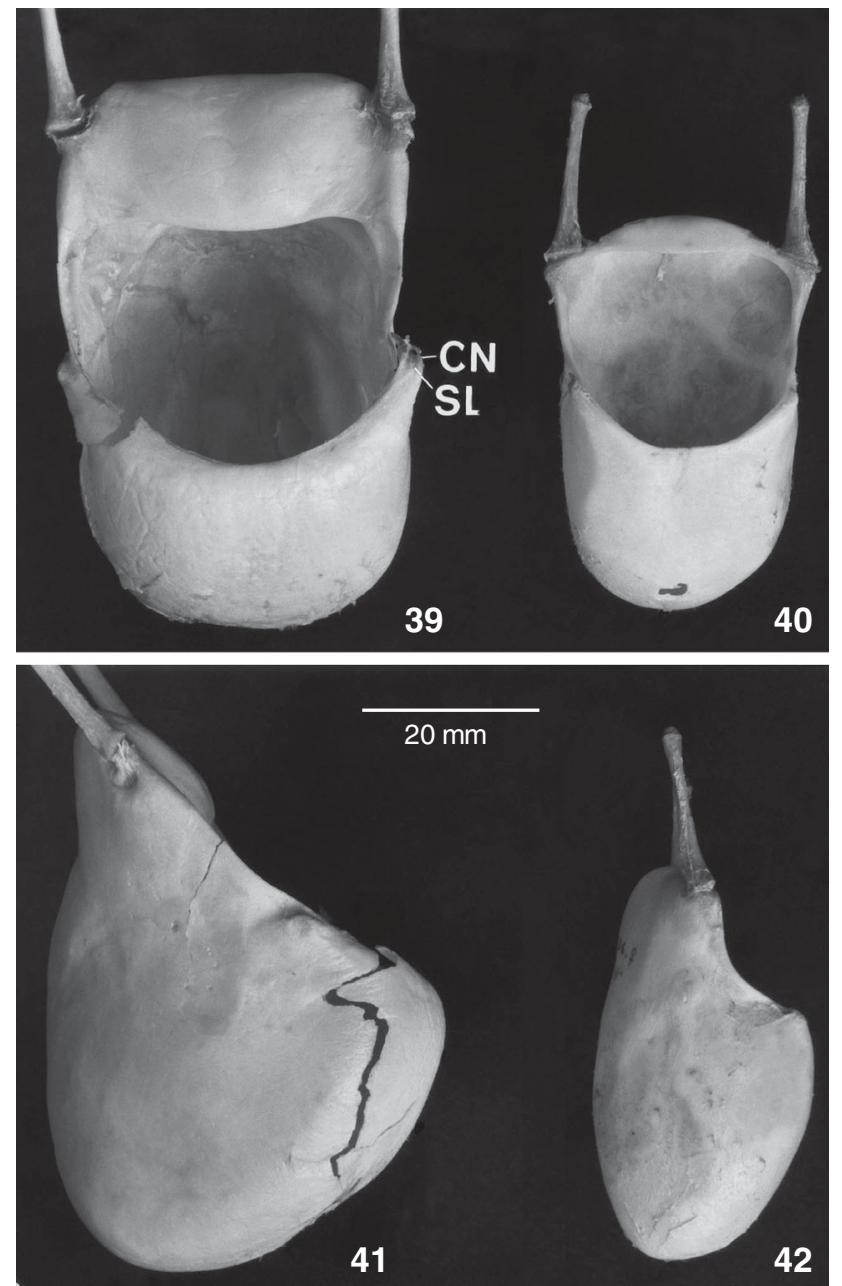

Figuras 39-42. Osso hióide de $A$. belzebul: (39 e 41) indivíduo macho (MZUSP 25448) em vista ventral e lateral, respectivamente; (40 e 42) indivíduo fêmea (MZUSP 8936) em vista ventral e lateral, respectivamente. Note o tentório largo, retangular e inflado lateroventralmente, em vez de estreito e liso como em A. discolor (Fig. 30). Note também a abertura hióidea semicircular, quase quadrangular, em vez de ovalada como registrada para $A$. discolor. (CN) Cornículo, (SL) sulco lateral.

Saúde (MPEG 12149, 12154), Vale do Caraípe (MPEG 12380, 12382 a 12385), Cachoeira do Espelho (MZUSP 20927 a 20929) a completamente ruivos como aqueles provenientes da Usina Hidrelétrica de Tucuruí (MPEG 12596) e Jacundá (MPEG 12150). Entre estes dois extremos do espectro, há outros padrões de coloração para a espécie, tais como: indivíduos completamente negros, excetuando o terço apical da cauda castanhoavermelhado a olivácea, todos provenientes do vale do Caraípe (MPEG 12388 a 12396); indivíduos negros com extremidades dos membros, cauda, cabeça e nuca de cor ruiva a castanho-

Revista Brasileira de Zoologia 23 (1): 64-144, março 2006 
Tabela XIV. Dados morfométricos (mm) de seis amostras de A. belzebul (somente machos): (1) Região Nordeste; (2) Maracanã, Nova Timboteua, Paragominas e estrada BR 010; (3) Margem direita do rio Tocantins; (4) Ilha Tocantins; (5) Cachoeira do Espelho, Largo do Souza e rio Bacajá; (6) Margem esquerda do rio Tocantins. As medidas estão definidas na figura 1. Linha superior: média, desvio padrão e número de indivíduos analisados (em parênteses), respectivamente; linha inferior: mínimo e máximo.

\begin{tabular}{|c|c|c|c|c|c|c|}
\hline Variável & 1 & 2 & 3 & 4 & 5 & 6 \\
\hline \multirow[t]{2}{*}{$\mathrm{CCR}$} & $110,1(1)$ & $126,0 \pm 4,3(9)$ & $129,1 \pm 7,9(5)$ & $117,9 \pm 6,2(8)$ & $124,0(1)$ & $122,9 \pm 7,8(10)$ \\
\hline & & $119,6-133,0$ & $120,2-137,2$ & $104,4-123,8$ & & $103,7-130,9$ \\
\hline \multirow[t]{2}{*}{$\mathrm{CCB}$} & $96,3(1)$ & $113,9 \pm 6,4(9)$ & $118,8 \pm 8,0(5)$ & $108,9 \pm 7,7(8)$ & $114,0(1)$ & $112,3 \pm 9(10)$ \\
\hline & & $105,4-126,2$ & $110,0-126,8$ & $91,9-118,4$ & & $91,5-124,6$ \\
\hline \multirow[t]{2}{*}{ LZI } & $74,3(1)$ & $81,1 \pm 4,0(11)$ & $84,4 \pm 5,0(5)$ & $79,7 \pm 5(7)$ & $80,0(1)$ & $80,8 \pm 5,3(10)$ \\
\hline & & $72,0-87,0$ & $79,0-90,2$ & $69,8-84,9$ & & $67,6-85,2$ \\
\hline \multirow{2}{*}{ LIO } & - & $62,4 \pm 2,9(11)$ & $62,2 \pm 3,1(5)$ & $60,2 \pm 3,1(8)$ & $59,5(1)$ & $61,3 \pm 3,5(11)$ \\
\hline & & $56,1-66,0$ & $58,6-66,5$ & $54,2-64,2$ & & $54,5-65,7$ \\
\hline \multirow[t]{2}{*}{ CPA } & $36,6(1)$ & $45,9 \pm 2,8(11)$ & $49,3 \pm 5,7(5)$ & $44,3 \pm 3,4(8)$ & $45,3(1)$ & $46,1 \pm 5,0(9)$ \\
\hline & & $41,3-51,4$ & $43,4-57,7$ & $36,3-47,6$ & & $37,2-51,7$ \\
\hline \multirow[t]{2}{*}{ ACR } & - & $39,6 \pm 1,1(9)$ & $39,6 \pm 1,9(5)$ & $37,1 \pm 3,0(8)$ & $39,6(1)$ & $37,1 \pm 2,5(11)$ \\
\hline & & $38,1-41,1$ & $37,8-42,6$ & $31,2-40,3$ & & $30,0-39,2$ \\
\hline \multirow[t]{2}{*}{ LCR } & $51,8(1)$ & $54,9 \pm 1(11)$ & $55,4 \pm 2,5(5)$ & $52,5 \pm 2,3(8)$ & $53,5(1)$ & $54,2 \pm 2,4(11)$ \\
\hline & & $53,5-57,4$ & $51,8-58,7$ & $50,2-57,8$ & & $49,6-57,7$ \\
\hline \multirow[t]{2}{*}{ LCO } & $21,0(1)$ & $23,6 \pm 1,6(8)$ & $23,9 \pm 0,9(5)$ & $23,1 \pm 0,8(8)$ & $23,2(1)$ & $23,4 \pm 1,2(11)$ \\
\hline & & $21,8-26,4$ & $22,9-25,0$ & $21,7-24,1$ & & $20,6-25,3$ \\
\hline \multirow[t]{2}{*}{ LMT } & $52,1(1)$ & $58,0 \pm 2,4(11)$ & $58,6 \pm 5,1(5)$ & $54,6 \pm 2,2(8)$ & $58,7(1)$ & $56,8 \pm 2,6(11)$ \\
\hline & & $54,0-61,2$ & $52,2-63,7$ & $51,4-58,9$ & & $50,4-60,5$ \\
\hline \multirow[t]{2}{*}{ LPO } & $39,5(1)$ & $40,8 \pm 1,4(11)$ & $43,3 \pm 2,4(5)$ & $41,8 \pm 3,8(8)$ & $40,5(1)$ & $40,5 \pm 1,9(11)$ \\
\hline & & $38,9-43,1$ & $40,1-46,6$ & $37,8-49,9$ & & $37,9-42,5$ \\
\hline \multirow[t]{2}{*}{ CMA } & $86,4(1)$ & $100,4 \pm 2,8(11)$ & $103,9 \pm 5(5)$ & $95,5 \pm 6,2(8)$ & $95,1(1)$ & $97,6 \pm 7,3(11)$ \\
\hline & & $95,4-105,0$ & $96,7-108,8$ & $80,6-100,3$ & & $79,0-105,4$ \\
\hline \multirow[t]{2}{*}{ APA } & - & $78,7 \pm 6(11)$ & $81,8 \pm 5,6(5)$ & $75,7 \pm 6,7(8)$ & $70,2(1)$ & $74,7 \pm 8,0(11)$ \\
\hline & & $66,5-88,3$ & $74,3-87,2$ & $61,2-84,0$ & & $58,5-87,5$ \\
\hline \multirow[t]{2}{*}{ CDS } & $36,1(1)$ & $41,5 \pm 1,7(10)$ & $43,1 \pm 2,0(5)$ & $41 \pm 1,7(6)$ & $40,9(1)$ & - \\
\hline & & $37,5-43,3$ & $40,5-45,3$ & $37,8-42,4$ & & \\
\hline \multirow[t]{2}{*}{ LMO } & $39,5(1)$ & $42,9 \pm 1,5(9)$ & $42,8 \pm 2,7(5)$ & $40,3 \pm 2,7(7)$ & $42,0(1)$ & $42,2 \pm 3,1(10)$ \\
\hline & & $41,0-45,8$ & $40,2-46,6$ & $35,0-43,2$ & & $34,3-45,7$ \\
\hline \multirow[t]{2}{*}{ LPA } & $22,1(1)$ & $27,3 \pm 2,1(11)$ & $26,4 \pm 1,6(5)$ & $25,9 \pm 2,9(7)$ & - & $26,4 \pm 2,9(10)$ \\
\hline & & $23,9-32,0$ & $24,6-29$ & $24,6-29,0$ & & $20,6-30,7$ \\
\hline \multirow[t]{2}{*}{$\mathrm{CHI}$} & $50,5(1)$ & $75,6(1)$ & $67,6 \pm 4,0(4)$ & $59,9 \pm 3,6(6)$ & - & $59,2 \pm 9,7(8)$ \\
\hline & & & $63,2-72,9$ & $56,8-66,7$ & & $42,4-73,8$ \\
\hline \multirow[t]{2}{*}{ LHI } & $33,5(1)$ & $44,3(1)$ & $46,9 \pm 5,8(4)$ & $39,6 \pm 0,8(6)$ & - & $37 \pm 5,7(7)$ \\
\hline & & & $41,4-53,8$ & $38,5-40,7$ & & $26,3-43,6$ \\
\hline \multirow[t]{2}{*}{ LTE } & $14,8(1)$ & $29,7(1)$ & $20,8 \pm 3,5(4)$ & $17,5 \pm 1,4(6)$ & - & $14,2 \pm 4,0(8)$ \\
\hline & & & $16,2-24,1$ & $15,7-19,3$ & & $7,0-21,4$ \\
\hline
\end{tabular}

avermelhado provenientes de Jacundá (MPEG 12350, 12358) e Ilha Tocantins (MPEG 12362 a 12365, 12373); indivíduos negros com as extremidades dos membros, cauda, cabeça, nuca, cotovelo, joelho, coxa e base da cauda de coloração avelã a ruiva, provenientes de Paragominas (MNRJ 23209), Ourém (MPEG 8849), Timbozal (MPEG 11848), Jacundá (MPEG 12142),
Saúde (MPEG 12351), Ilha Tocantins (MPEG 12361) e Usina de Tucuruí (MPEG 12595).

Analisando os vários padrões de coloração da pelagem com suas respectivas freqüências nas populações, e contrastando-os com suas áreas de ocorrência, é possível perceber que, além da acentuada variação individual existente, há uma tendência a 
Tabela XV. Dados morfométricos (mm) de seis amostras de A. belzebul (somente fêmeas): (1) Alagoas e Paraíba; (2) Maracanã, Nova Timboteua, Paragominas e estrada BR-010; (3) Margem direita do rio Tocantins; (4) Ilha de Marajó; (5) Ilha Tocantins; (6) Cachoeira do Espelho, Largo do Souza e rio Bacajá; (7) Margem esquerda do rio Tocantins. As medidas estão definidas na figura 1. Linha superior: média, desvio padrão e número de indivíduos analisados (em parênteses), respectivamente; linha inferior: mínimo e máximo.

\begin{tabular}{|c|c|c|c|c|c|c|c|}
\hline Variável & 1 & 2 & 3 & 4 & 5 & 6 & 7 \\
\hline \multirow[t]{2}{*}{$\mathrm{CCR}$} & $92,8 \pm 5,2(2)$ & $106,4 \pm 2,5(15)$ & $107,4 \pm 2,5(7)$ & $102,3(1)$ & $104,8 \pm 2,0(6)$ & $104,8(1)$ & $105,8 \pm 3,2(10)$ \\
\hline & $89,1-96,5$ & $99,1-109,4$ & $101,9-109,4$ & & $101,9-107,6$ & & $100,5-110,4$ \\
\hline \multirow[t]{2}{*}{$\mathrm{CCB}$} & $78,0 \pm 11,3(2)$ & $94,4 \pm 2,4(14)$ & $95,2 \pm 3(7)$ & $86,8(1)$ & $90,8 \pm 1,8(7)$ & $93,0(1)$ & $93,1 \pm 3,4(10)$ \\
\hline & $70,0-86,0$ & $90,3-97,4$ & $89,2-98,0$ & & $88,0-93,0$ & & $86,5-97,0$ \\
\hline \multirow[t]{2}{*}{ LZI } & $59,4 \pm 7,4(2)$ & $68,9 \pm 1,5(14)$ & $69,4 \pm 2,7(6)$ & - & $67,2 \pm 1,4(7)$ & $70,2(1)$ & $68,6 \pm 2,5(9)$ \\
\hline & $54,2-64,7$ & $66,5-72,2$ & $64,8-71,8$ & & $64,8-69,1$ & & $65,8-74,4$ \\
\hline \multirow[t]{2}{*}{ LIO } & $50,2 \pm 6,7(2)$ & $56,0 \pm 2,0(15)$ & $56,8 \pm 2,4(7)$ & $54,7(1)$ & $54,3 \pm 2,3(6)$ & $57,0(1)$ & $54,6 \pm 2,1(9)$ \\
\hline & $45,5-55,0$ & $52,2-58,4$ & $53,2-59,8$ & & $51,2-57,3$ & & $52,5-58,8$ \\
\hline \multirow[t]{2}{*}{ CPA } & $29,6 \pm 5,1(2)$ & $37,2 \pm 1,8(15)$ & $36,7 \pm 1,4(7)$ & $32,0(1)$ & $36,3 \pm 0,5(7)$ & $37,2(1)$ & $37,4 \pm 2,0(10)$ \\
\hline & $26,0-33,3$ & $34,7-420$ & $34,9-39,1$ & & $35,5-37,0$ & & $32,8-39,8$ \\
\hline \multirow[t]{2}{*}{$A C R$} & $38,0(1)$ & $38,8 \pm 1,4(15)$ & $38,5 \pm 1,7(7)$ & $41,0(1)$ & $38,3 \pm 1,5(6)$ & $40,4(1)$ & $38,3 \pm 1,2(9)$ \\
\hline & & $36,5-41,8$ & $35,9-41,4$ & & $36,4-40,2$ & & $36,3-39,7$ \\
\hline \multirow[t]{2}{*}{ LCR } & $49,6(2)$ & $51,7 \pm 2(15)$ & $52,8 \pm 1,5(7)$ & $52,7(1)$ & $51,6 \pm 1,7(7)$ & $49,3(1)$ & $53,0 \pm 2,2(10)$ \\
\hline & $49,6-49,6$ & $48,4-55,1$ & $50,4-55,0$ & & $49,7-54,8$ & & $50,2-57,8$ \\
\hline \multirow[t]{2}{*}{$\mathrm{LCO}$} & $20,7 \pm 0,4$ & $22,1 \pm 1(12)$ & $21,5 \pm 0,9(5)$ & $20,8(1)$ & $21,3 \pm 1,2(7)$ & $22,0(1)$ & $21,8 \pm 0,7(9)$ \\
\hline & $20,4-21,0$ & $20,7-24,6$ & $20,2-22,4$ & & $20,1-22,7$ & & $20,6-23$ \\
\hline \multirow[t]{2}{*}{ LMT } & $47,3 \pm 0,1(2)$ & $52 \pm 1,9(14)$ & $52,3 \pm 2,4(7)$ & - & $50,3 \pm 1,4(7)$ & $54,2(1)$ & $52,5 \pm 2,0(9)$ \\
\hline & $47,2-47,4$ & $49,4-55,0$ & $47,7-55,8$ & & $48,7-52,8$ & & $49,2-56,3$ \\
\hline \multirow[t]{2}{*}{ LPO } & $39,8 \pm 2,0(2)$ & $41,6 \pm 2,6(14)$ & $43,2 \pm 1,6(7)$ & $43,1(1)$ & $42,4 \pm 1,8(7)$ & $40,8(1)$ & $41,7 \pm 1,6(10)$ \\
\hline & $38,4-39,8$ & $36,6-45,2$ & $41,1-45,2$ & & $40,2-46,2$ & & $39,0-44,2$ \\
\hline \multirow[t]{2}{*}{ CMA } & $69,1 \pm 9,1(2)$ & $80,0 \pm 1,8(14)$ & $80,7 \pm 2,1(7)$ & - & $79,0 \pm 1,0(7)$ & $79,0(1)$ & $79,6 \pm 3(10)$ \\
\hline & $62,7-75,6$ & $77,0-82,4$ & $77,6-84,2$ & & $78,0-80,5$ & & $74,4-84,3$ \\
\hline \multirow[t]{2}{*}{ APA } & $55,6(1)$ & $59,7 \pm 4,2(14)$ & $60,6 \pm 3,8(7)$ & - & $57,6 \pm 2,5(6)$ & $60,7(1)$ & $58 \pm 2,9(10)$ \\
\hline & & $53,1-68,6$ & $55,1-64,3$ & & $53,7-61,7$ & & $53,2-62,7$ \\
\hline \multirow[t]{2}{*}{ CDS } & $31,0 \pm 8,5(2)$ & $36,0 \pm 0,9(14)$ & $36,6 \pm 0,7(7)$ & $34,9(1)$ & $35,3 \pm 0,6(7)$ & $35,2(1)$ & $35,9 \pm 1,5(10)$ \\
\hline & $25,0-37,0$ & $34,5-37,6$ & $35,8-38,0$ & & $34,4-36,3$ & & $33,6-37,5$ \\
\hline \multirow[t]{2}{*}{ LMO } & $34 \pm 1,4(2)$ & $36,9 \pm 1,4(13)$ & $36,6 \pm 1,2(7)$ & $36,1(1)$ & $36,4 \pm 1,1(6)$ & $37,0(1)$ & $37,1 \pm 0,7(9)$ \\
\hline & $33,0-35,0$ & $35,0-39,6$ & $34,6-38,3$ & & $34,9-37,6$ & & $35,8-38,3$ \\
\hline \multirow[t]{2}{*}{ LPA } & $21,5 \pm 1,0(2)$ & $23,5 \pm 1,1(15)$ & $23,4 \pm 1,1(6)$ & $24,1(1)$ & $23,0 \pm 1,7(6)$ & $25,0(1)$ & $23,7 \pm 0,7(10)$ \\
\hline & $20,5-22,0$ & $21,0-25,4$ & $21,7-24,6$ & & $20,5-24,9$ & & $22,4-24,6$ \\
\hline \multirow[t]{2}{*}{$\mathrm{CHI}$} & $29,0(1)$ & $44,0 \pm 3,0$ (4) & $44,0 \pm 3,0(4)$ & $37,5(1)$ & - & $44,6(1)$ & $37,7 \pm 1,0(2)$ \\
\hline & & $41,3-48,3$ & $41,3-48,3$ & & & & $37,0-38,5$ \\
\hline \multirow[t]{2}{*}{ LHI } & $19,2(1)$ & $27,8 \pm 0,1$ (3) & $27,8 \pm 0,1(3)$ & $25,0(1)$ & - & $25,8(1)$ & $23,3 \pm 1,8(2)$ \\
\hline & & $27,7-28,0$ & $27,7-28,0$ & & & & $22,0-24,6$ \\
\hline \multirow[t]{2}{*}{ LTE } & $6,1(1)$ & $5,7 \pm 2,2(3)$ & $5,7 \pm 2,2(3)$ & $3,0(1)$ & - & $7,0(1)$ & $4,5 \pm 3,3(2)$ \\
\hline & & $4,0-8,3$ & $4,0-8,3$ & & & & $2,2-6,9$ \\
\hline
\end{tabular}

ocorrer mudanças geográficas na coloração da pelagem ao longo do eixo leste-oeste da área de distribuição da espécie, corroborando parcialmente o proposto por Bonvicino et al. (1989). Mesmo considerando a gradação quanto à presença de campos que variam desde o totalmente negro a totalmente ruivo, discerne-se com certa facilidade aqueles animais escuros (negros ou com es- cassos campos cromatogenéticos castanhos) daqueles indivíduos mais avermelhados (com muitos campos cromatogenéticos de pigmentação vermelha, desde o padrão mais freqüente de coloração descrito anteriormente até o completamente ruivo, mas nunca como aquele registrado para A. discolor). Ao analisar a freqüência destes padrões, verifica-se que há uma tendência a ocor- 
rer animais com maior número de campos cromatogenéticos vermelhos na margem direita e uma freqüência maior de animais mais escuros na margem esquerda do Rio Tocantins. Na margem esquerda daquele rio, 22 (61,1\%), dos 36 indivíduos analisados apresentaram padrão de pelagem totalmente negra, quatro $(11,1 \%)$ são animais muito escuros, com escassos campos cromatogenéticos vermelhos e $10(27,8 \%)$ indivíduos com o padrão típico de $A$. belzebul, com campos cromatogenéticos vermelhos nas extremidades dos membros e cauda. Na margem leste do Rio Tocantins, dos 66 espécimes analisados, 57 (86,4\%) apresentaram padrão tipicamente de $A$. belzebul, quatro (6\%) animais totalmente ruivos e apenas cinco $(7,6 \%)$ indivíduos totalmente negros. Nas populações que habitam as ilhas fluviais Tocantins e Bandeira, dos 30 indivíduos analisados, 28 (93,3\%) apresentaram padrão tipicamente de $A$. belzebul e apenas $2(6,7 \%)$ apresentaram pelagem totalmente negra.

As tabelas XIV e XV mostram os dados biométricos para as amostras de machos e de fêmeas, respectivamente, em um transecto leste-oeste. As amostras são provenientes das seguintes localidades: 1) Estados de Alagoas e Paraíba, região Nordeste; 2) Estrada BR-010, Maracanã, Nova Timboteua, Ourém e Paragominas, Pará; 3) Canoal, Chiqueirinho, Vila Brabo, Jacundá, Santo Antônio e Murixiba, todos à margem direita do Rio Tocantins, Pará; 4) Igarapé Taperebá e Ponta de Pedras, Ilha de Marajó, Pará; 5) Ilha Tocantins, Rio Tocantins, Pará; 6) Cachoeira do Espelho, Largo do Souza e Rio Bacajá, Rio Xingu, Pará; 7) Vale do Caraípe, Igarapé Araripe, Itupiranga, Saúde, São Miguel, Rampa e Timbozal, todas à margem esquerda do Rio Tocantins, Pará. A análise de variância entre os indivíduos machos evidenciou que as amostras provenientes da margem direita do Rio Tocantins (3) são significativamente maiores que aquela da Ilha Tocantins (5). Neste caso, as medidas divergentes e suas respectivas probabilidades são: comprimento total do crânio (CCR) ( $\mathrm{p}=$ 0,03), comprimento côndilo-basal (CCB) ( $\mathrm{p}=0,049)$, largura craniana (LCR) $(p=0,015)$, largura mastóidea (LMA) $(p=0,016)$ e comprimento mandibular (CMA) $(p=0,07)$. As medidas do osso hióide que se mostraram significativamente diferentes foram: largura do osso (LHI) entre as amostras 3 e 5 ( $p=0,010)$, e a largura do tentório (LTE), entre as amostras 3 e $7(p=0,017)$ e 5 e $7(p=0,028)$. Esta tendência na diminuição das proporções em mamíferos de médio porte confinados a ilhas (como os espécimes da Ilha Tocantins) em relação aos táxons ou populações continentais foi revelada por ANDERson \& HANDLEy (2002). Os autores concluíram que esta dimunição está relacionada a fatores ambientais e pressões seletivas, tais como limitação de itens alimentares, embora não se tenha registro do grau de fluxo entre as populações da Ilha Tocantins e do continente. É importante ressaltar que o único indivíduo macho analisado para a região costeira do Nordeste mostrou-se muito menor que as médias das outras amostras (Tab. XIV).

O resultado da análise de variância para as amostras fêmeas está expresso na tabela XVI e mostra uma maior divergência entre as populações testadas. Os dados também mos- tram que há diferenças significativas para as fêmeas entre os indivíduos do Nordeste (1) e aquelas das demais amostras.

Tabela XVI. Análise de variância para as amostras de indivíduos fêmeas de $A$. belzebul. Fornecidas apenas as medidas que se mostram significativamente diferentes (em parênteses a probabilidade, p): 1) região Nordeste; 2) norte do Pará; 3) margem direita do rio Tocantins; 5) ilha Tocantins; 7) margem esquerda do rio Tocantins.

\begin{tabular}{|c|c|c|c|c|}
\hline Variável & 2 & 3 & 5 & 7 \\
\hline \multirow[t]{7}{*}{1} & $\operatorname{CCR}(0,002)$ & $\operatorname{CCR}(0,040)$ & $\operatorname{CCR}(0,045)$ & $\operatorname{CCR}(0,031)$ \\
\hline & CCB $(0,026)$ & CCB $(0,040)$ & CCB $(0,040)$ & CCB $(0,031)$ \\
\hline & LZI $(0,026)$ & LZI $(0,045)$ & LZI $(0,040)$ & LZI $(0,033)$ \\
\hline & $\operatorname{LMA}(0,026)$ & CPA $(0,040)$ & $\mathrm{CPA}(0,040)$ & $\operatorname{LCR}(0,031)$ \\
\hline & $\operatorname{CMA}(0,026)$ & $\operatorname{LMO}(0,045)$ & $\operatorname{LMA}(0,040)$ & $\operatorname{LMA}(0,033)$ \\
\hline & $\operatorname{LMO}(0,041)$ & & CMA $(0,040)$ & $\operatorname{LMO}(0,033)$ \\
\hline & $\operatorname{LTE}(0,045)$ & & & $\operatorname{LTE}(0,031)$ \\
\hline \multirow[t]{3}{*}{2} & - & $p>0,05$ & CCB $(0,006)$ & $p>0,05$ \\
\hline & & & LZI $(0,033)$ & \\
\hline & & & $\operatorname{LMA}(0,043)$ & \\
\hline \multirow[t]{3}{*}{3} & - & - & $\operatorname{CCR}(0,038)$ & LPO $(0,035)$ \\
\hline & & & CCB $(0,012)$ & \\
\hline & & & $\operatorname{SDS}(0,043)$ & \\
\hline 5 & - & - & - & $p>0,05$ \\
\hline
\end{tabular}

Os caracteres que diferenciam $A$. belzebul de A. discolor e A. ululata já foram comentados anteriormente nas descrições dos dois últimos táxons. Alouatta belzebul distingue-se de $A$. macconnelli, que ocorre ao norte do Rio Amazonas, por esta apresentar a coloração dorsal dourada com os membros ruivos-avermelhados e possuir um hióide completamente distinto: o tentório é trapezoidal e largo em A. macconnelli e retangular e mais estreito em $A$. belzebul, além das diferenças na posição dos cornos, cuja inserção é látero-ventral no primeiro táxon e posterior no segundo.

\section{História taxonômica}

A questão nomenclatural da espécie é simples exceto pela quantidade expressiva de grafias incorretas e erros tipográficos. O primeiro relato da espécie $A$. belzebul foi de Marcgrave (1648) que descreveu um animal proveniente da região costeira do Estado de Pernambuco e na qual o autor denominou-a vernacularmente de "Guariba". LinNaEus (1766) foi quem pioneiramente descreveu $A$. belzebul com base na descrição de Marcgrave, colocando em sua sinonímia "Guariba". Linnaeus (1766) forneceu "Brasilia" como proveniência da espécie. Os detalhes sobre o emprego do nome guariba já foi exposto na descrição de $A$. fusca.

Mycetes rufimanus foi descrito por KuHL (1820: 31) baseado em um espécime depositado no Leiden Museum e adquiri- 
do por Temminck do Bullock Museum (Londres). O táxon foi descrito como: "Mycetes rufimanus, Niger, manibus 4 caudaeque dimidia parte apicali rufis...".

A descrição acima, embora sucinta, indica um animal de pelagem negra com as extremidades avermelhadas coincidente com a coloração de A. belzebul. Posteriormente, a sinonimização segura de Mycetes rufimanus Kuhl com Mycetes belzebul (Linnaeus) foi proposta por Schlegel (1876).

\section{Amazônia Ocidental e Oriental (norte do Rio Amazonas) Alouatta nigerrima Lönnberg, 1941}

Mycetes caraya; Wallace, 1854: 451, nec Humboldt (1812).

Mycetes villosus; Pelzeln, 1883: 5, nec Gray (1845).

Alouatta beelzebul [sic]; Elliot, 1913: 27, partim.

Alouatta nigerrima Lönnberg, 1941: 33. Localidade-tipo: Patinga, Estado do Amazonas (restrita por CABRERA, 1958). Lectótipo: NRM A63 3316, macho adulto no Museu Sueco de História Natural, indiado por CABRERA (1958) e designado formalmente aqui. -Cruz Lima, 1945: 78. -Anthony et al., 1949: 132. Serra, 1952: 229; 1957: 45. -Groves, 2001a: 184.

Alouatta belzebul nigerrima; Hershkovitz, 1949: 398. -Cabrera, 1958: 152. -Hill, 1962: 138. -Ayres \& Milton, 1981: 5. Armada et al., 1987: 283. -Bonvicino et al., 1989: 139. Coimbra-Filho, 1990: 1076. -Fernandes, 1995: tabela 1. Auricchio, 1995: 132.

Alouatta belzebul: Chiarelli, 1972: 167, partim. -Napier, 1976: 77, partim. -Wolfheim, 1983: 209, partim. -George et al., 1988: 36, partim. -Hirsch et al., 1991: 239, partim. -Groves, 1993: 254, partim.

Alouatta belzebul nigerriman [sic]: Muniz \& Kingston, 1989: 271.

\section{Material examinado (total 98)}

BRASIL: Amazonas: Borba AMNH 92321 (p, c); Igarapé Aruá, Rio Madeira AMNH 91786-87 (p, c); Lago do Batista: FMNH 50884-85 (p, c); MNRJ: 5927 (p), 5984 (p, c, h), 6042 (c), 604345 (c, h), 6046 (c), 6047 (c, h), 6048 (c), 6049 (c, h), 6050-51 (c), 6052 (c, h); MZUSP: 4815 (p, c, h), 5289-90 (p, c, h), 5291 (p, c), 5292 (p), 5293-96 (p, c), 5297 (p, c, h), 5298 (p, c), 5396 (p, c), 5398 (p), 5399 (p, c, h), 540-02 (p, c), 5404 (p, c, h), 10490 (c), 10492-93 (c, h), 10494 (c), 10564 (c), 10566 (c, h), 10570 (c), 10574 (c, h), 54816 (p); Rosarinho, Rio Madeira: AMNH 9232230 (p, c); Villa Bella Imperatriz (= Parintins): AMNH 2331 (p, c), 93096-99 (p, c), 93677-83 (p, c). PARÁ: Aramanay AMNH 9502831 (p, c); Boiuçú: MZUSP: 522 (p); Itaituba: MPEG: 8126 (p), 8128-29 (p, c), 8478 (c), 8493 (c), 8495 (c); MZUSP: 3646 (p); Óbidos; MZUSP: 3643 (c); Oriximiná: MPEG: 02 (p), 501 (p, c, h), 502 (p), 515 (p, c, h), 692-93 (p, c, h), 695-96 (c, h), 697-98 (p, c, h), 699 (c), 701 (p); Parque Nacional do Tapajós: MZUSP: 19119 (hióide); Samaúma: MZUSP: 1903 (p); Urucurituba: FMNH 94934 (p, c, h), 94936 (p, c, h); MZUSP: 1901 (p), 1902 (p, c, h).

\section{Série-tipo e localidade-tipo}

Cabrera (1958) restringiu a localidade-tipo para Patinga, Estado do Pará, margem esquerda do Rio Tapajós. Segundo o autor, um dos machos analisados por LÖNNBERG (1941) para a descrição do táxon provém de Patinga, embora LöNnBERG (1941) em momento algum, no artigo, tenha indicado um espécime particular para a descrição da espécie.

Aqui, designa-se formalmente o lectótipo e os paralectótipos de A. nigerrima com base nos dados do material mencionados em LönNBERG (1941) e os complementares fornecidos pelo Museu Sueco de História Natural. A designação do lectótipo aqui visa formalizar o espécime-referência que contém as características que definem Alouatta nigerrima e no qual o nome se apóia. Considerando que não há problemas taxonômicos e primando pela estabilidade, mantém-se como lectótipo o espécime indicado inicialmente por CABRERA (1958).

Lectótipo: NRM A63 3316 (número original: 316), macho adulto, coletado em 3 de maio de 1934 por A. M Olalla. Material, em boas condições, composto por crânio, pele e esqueleto com os ossos das mãos e pés na pele. Localidade: Patinga (margem esquerda do Rio Tapajós), Estado do Pará, Brasil $\left(02^{\circ} 40^{\prime} \mathrm{S}\right.$, $\left.55^{\circ} 10^{\prime} \mathrm{W}\right)$ (Gyldenstolpe 1951, VAnzolini 1992). Dimensões externas e cranianas (transcritas de LÖNNBERG 1941): comprimento total do corpo (incluindo a cauda): $1320 \mathrm{~mm}$; comprimento total da cauda: $690 \mathrm{~mm}$; comprimento do pé: $150 \mathrm{~mm}$; comprimento total do crânio: $135 \mathrm{~mm}$; comprimento ocipto-nasal: 105,5 mm; comprimento côndilo-basal: $127,5 \mathrm{~mm}$; constrição interorbital: $20 \mathrm{~mm}$; largura da caixa craniana: $52 \mathrm{~mm}$; largura zigomática: $85,5 \mathrm{~mm}$; comprimento do palato: $50 \mathrm{~mm}$; comprimento da série de molares superiores: $36,5 \mathrm{~mm}$; comprimento da série de molares inferiores: $41 \mathrm{~mm}$; comprimento dos nasais: $25 \mathrm{~mm}$.

Paralectótipos: NRM A61 1467 (número original 1467), macho juvenil, coletado em 24 de janeiro (não consta o ano). Material: crânio, pele e esqueleto com os ossos das mãos e pés na pele. Localidade: Lago Batista (sul do Rio Amazonas) ( $02^{\circ} 18^{\prime} \mathrm{S}-$ $58^{\circ} 15^{\prime} \mathrm{W}$ ), Estado do Amazonas, Brasil. NRM A61 1530 (número original 1530), fêmea adulta, coletada em 22 de março de 1936 (data na descrição original: entre 19 e 26 de março). Material: crânio, pele e esqueleto com os ossos das mãos e pés na pele. Localidade: Lago Batista (sul do Rio Amazonas), Estado do Amazonas, Brasil. NRM A611629 (número original 1629), macho adulto, coletado em 8 de maio de 1936 (não consta o dia na descrição original). Material: crânio, pele e esqueleto com os ossos das mãos e pés na pele. Localidade: Lago Tapayuma (= Tapaiúna) (sul do Rio Amazonas) $\left(03^{\circ} 23^{\prime} \mathrm{S}-58^{\circ} 16^{\prime} \mathrm{W}\right)$, Estado do Amazonas, Brasil. NRM A62 0305 (número original 305), fêmea adulta, coletada em 27 de abril de 1934. Material: crânio, pele e esqueleto com os ossos das mãos e pés na pele. Localidade: Irocanga (ao

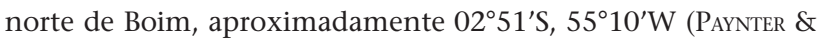
Traylor 1991, Vanzolini 1992), Estado do Pará, Brasil.

\section{Distribuição geográfica}

Como pode ser apreciado na figura 43, A. nigerrima é endêmico ao Brasil e apresenta sua distribuição geográfica basicamente ao sul do Rio Amazonas entre os Rios Tapajós e Madeira. Na margem norte do Rio Amazonas, a espécie ocorre na região de Oriximiná e Óbidos, ambas no Estado do Pará. A ocor- 


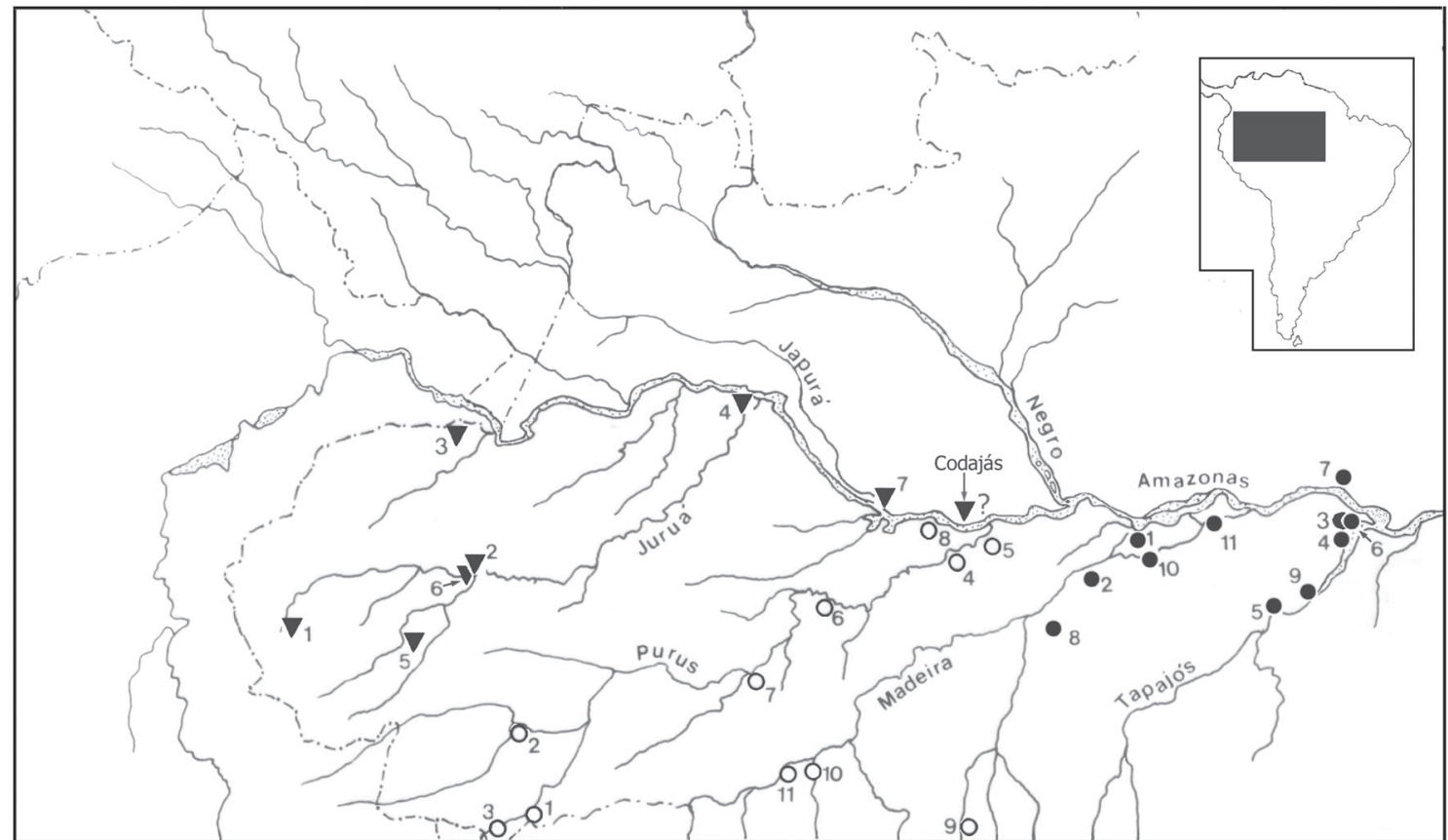

Figura 43. Mapa de distribuição geográfica de três espécies do complexo "A. seniculus" no Brasil: 1. Círculos fechados: $A$. nigerrima; círculos abertos: $A$. puruensis; triângulos: $A$. juara. Note que a identificação dos espécimes provenientes de Codajás, AM ainda necessita de confirmação posterior. Também registrei espécimes que podem ser identificados como A. juara para Oxapampa, Peru.

rência de $A$. nigerrima em Oriximiná foi questionada por BoNVICINo et al. (1989), sob a argumentação de que os espécimes depositados no Museu Goeldi (MPEG 02, 501, 502, 692-93, 69599 e 701) pertenciam ao zoológico e sem procedência confiável. No registro de campo do material consta que os exemplares foram coletados em uma ilha próxima a Oriximiná no ano de 1933 e a veracidade da procedência do material foi confirmada por Cruz Lima (1945).

\section{Caracteres diagnósticos}

Pelagem de coloração toda negra, longa e brilhante (Fig. 44). Osso hióide no macho com tentório desenvolvido e de forma trapezoidal; abertura hióidea semicircular; cornos no hióide dos machos posicionados ventralmente (Figs 51 e 53).

\section{Descrição geral}

As medidas cranianas e do osso hióide estão na tabela XVII. Pelagem nos adultos de ambos os sexos toda negra e brilhante (Fig. 44). Barba densa; franja formando um pequeno topete e voltada para trás. Pelagem longa e áspera, principalmente nos flancos. Pêlos da região médio-dorsal com duas faixas: metade basal castanho-avermelhado e a apical negra.

Osso hióides com comprimento total de 62,0 a $80,0 \mathrm{~mm}$ $(\mathrm{N}=9)$. Tentório desenvolvido: 8,7 a 31,8 mm $(\mathrm{N}=9)$, inflado e de forma trapezoidal; cornículos lanceolados e reduzidos; abertura hióidea semicircular (Figs 51 e 53); região ventral na base dos cornículos inflada; trabéculas internas, em geral, presentes.
Região na base dos cornos, inflada; inserção dos cornos lateroventralmente. Os ossos nasais são curvos em vista lateral. Osso hióide na fêmea adulta com comprimento total de 38,6 a 43,7 $\mathrm{mm}(\mathrm{N}=8)$. Tentório presente e desenvolvido: 8,0 a $19,4 \mathrm{~mm}(\mathrm{~N}$ = 8); cornículos lanceolados; abertura hióidea semicircular. Bula hióidea comprimida dorso-ventralmente (Figs 52 e 54).

Cariótipo. Número diplóide igual a 50 (ARMAda et al. 1987, Lima \& SEuÁNEZ 1989), mas com muitas diferenças qualitativas em relação à $A$. belzebul (Linnaeus). Os pares cromossômicos 8 , 12,13 e 14 presentes em $A$. nigerrima não têm suas contrapartes em $A$. belzebul e o inverso ocorre como os pares $4,6,10$ e 23 (ARMADA et al. 1987).

\section{Variação}

Este táxon mostrou-se muito homogêneo por toda a área amostrada, exceto pelos exemplares de Lago do Batista (MZUSP 5289 e 5294) que apresentaram poucos pêlos de cor olivácea esparsos na região lombar. Dois exemplares de Urucurituba (MZUSP 1901 e 1902) apresentaram alguns pêlos na região lateral do tronco de tonalidade avermelhada. Os exemplares MZUSP 1903 e 3646 provenientes de Sumaúma e Itaituba, respectivamente, apresentaram pelagem toda negra típica de $A$. nigerrima, mas o crânio e osso hióide como de $A$. discolor, táxon que ocorre na margem oposta do Rio Tapajós. Desconsiderouse o material ósseo uma vez que podem ter sido misturados.

A comparação direta entre as amostras do Lago do Batis- 


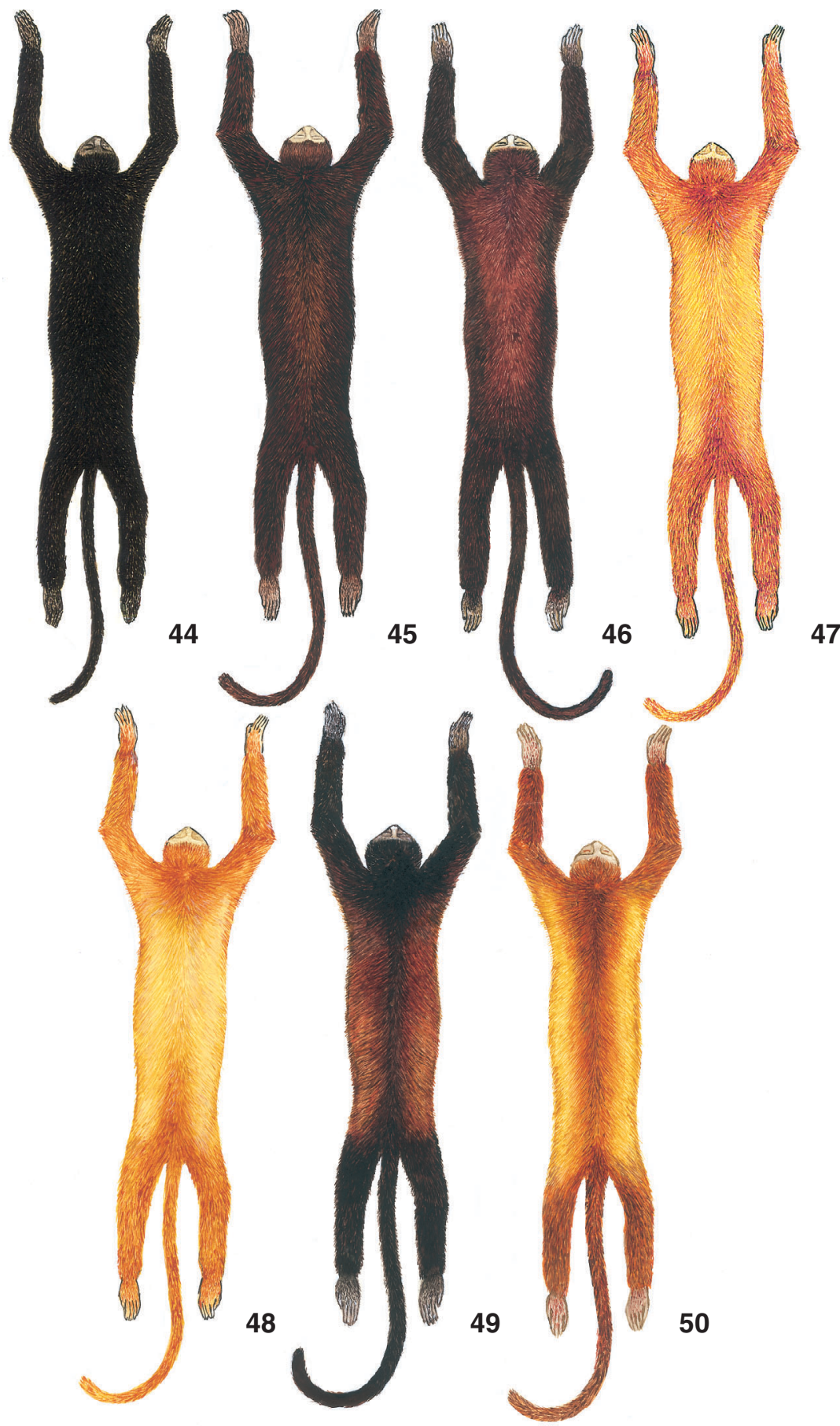

Figuras 44-50. Ilustração, em vista dorsal, mostrando os padrões de coloração da pelagem no complexo "A. seniculus": (44) A. nigerrima (MZUSP 5295); (45) A. juara, fêmea (MZUSP 7733, AM); (46) A. puruensis, macho (MNRJ 23147, AM); (47) A. puruensis, fêmea (MZUSP 7333, AC); (48) A. macconnelli, macho (MZUSP 19161, AP); (49) A. macconnelli, fêmea (MZSUP 19082, AM); (50) A. macconnelli, fêmea (MZUSP 5797, AM). Note a coloração marrom-avermelhada diagnóstica de $A$. juara (Fig. 45) e que facilmente a diferencia de $A$. macconnelli (Figs 48-50) e de $A$. seniculus típico (não representado na figura). Note também o dicromatismo sexual diagnóstico de $A$. puruensis (Figs 46-47), e a variação de coloração nos animais da margem norte do rio Amazonas (Figs 48-50). Neste caso, destaque para os espécimes de Itapiranga (AM), representados na figura 50 e cuja pelagem apresenta vários campos cromatogenéticos negros. 

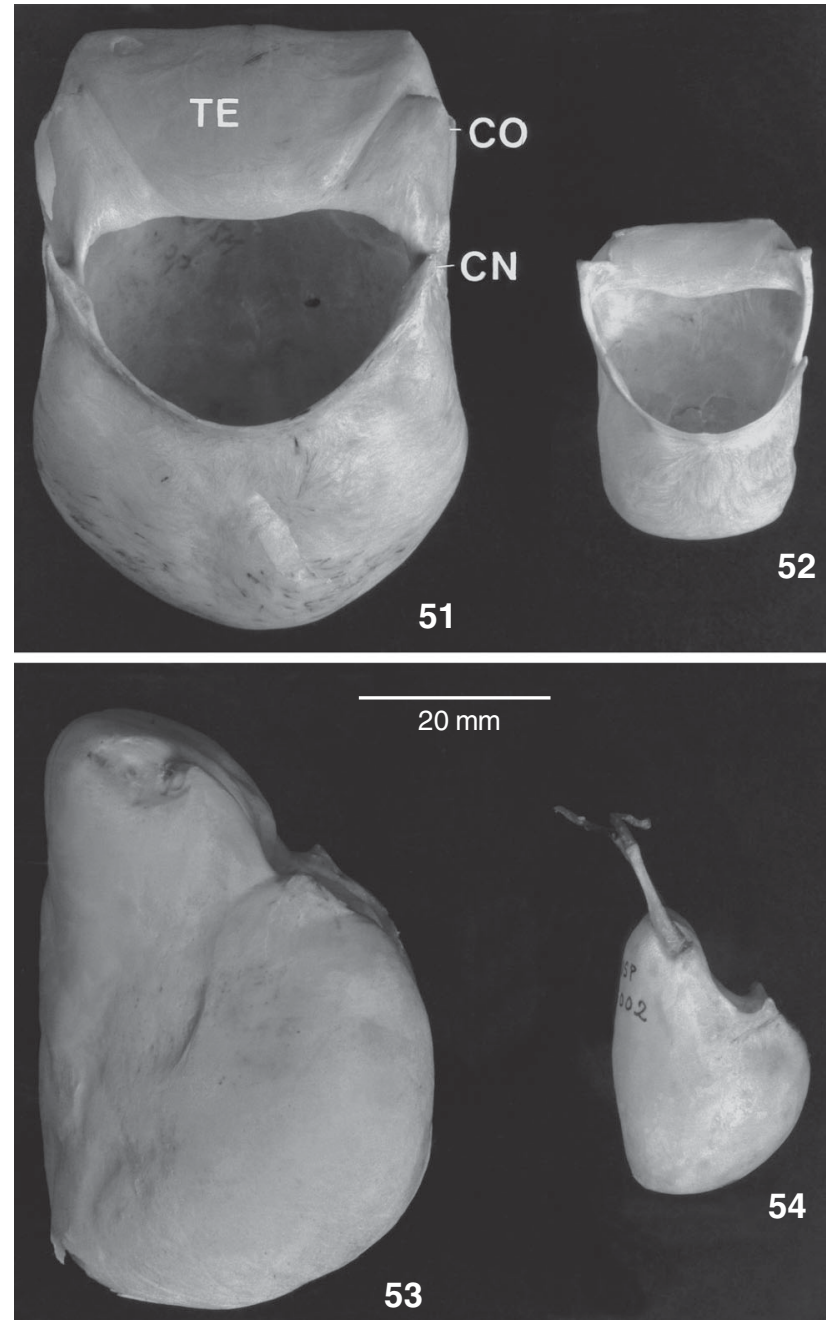

Figuras 51-54. Osso hióide de A. nigerrima: (51 e 53) indivíduo macho (MZUSP 19003) vista ventral e lateral, respectivamente; (52 e 54) indivíduo fêmea (MZUSP 19002) em vista ventral e lateral respectivamente. Note a posição ventral de inserção dos cornos nos machos, em vez de anterior como em $A$. belzebul e $A$. discolor. Note também o tentório amplo e retangular conferindoIhe uma abertura hióidea reduzida e semicircular, mais que quadrangular ou ovalada. CN: cornículo; CO: corno; TE: tentório.

ta, margem leste do Rio Madeira, Estado do Amazonas (amostra 1) e Aruam, margem oeste do Rio Tapajós (amostra 2), Estado do Pará, pode ser feita mediante os dados na tabela XVII. As amostras se mostraram muito homogêneas quanto aos dados biométricos.

Alouatta nigerrima difere acentuadamente do táxon que ocorre na margem oposta do Rio Tapajós, A. discolor, por apresentar a pelagem toda negra, em detrimento daquela com as extremidades dos membros e da cauda, e o dorso ruivos. Em
Tabela XVII. Dados morfométricos $(\mathrm{mm})$ de duas amostras (ambos os sexos) de $A$. nigerrima no Brasil. Linha superior: média, desvio padrão e número de indivíduos analisados (em parênteses), respectivamente; linha inferior: mínimo e máximo.

\begin{tabular}{|c|c|c|c|c|}
\hline \multirow{2}{*}{ Variável } & \multicolumn{2}{|l|}{ Macho } & \multicolumn{2}{|l|}{ Fêmea } \\
\hline & Lago Batista & Aruam & Lago Batista & Aruam \\
\hline \multirow[t]{2}{*}{ CCR } & $127,9 \pm 4,0(11)$ & $139,2(1)$ & $106,6 \pm 3,1(18)$ & $104,4(1)$ \\
\hline & $120,8-133,3$ & & $100,5-112,7$ & \\
\hline \multirow[t]{2}{*}{$\mathrm{CCB}$} & $118,8 \pm 3,7(11)$ & $126,2(1)$ & $96,7 \pm 1,8(18)$ & $92,4(1)$ \\
\hline & $110,2-123,7$ & & $93,4-100,0$ & \\
\hline \multirow[t]{2}{*}{ LZL } & $78,7 \pm 1,0(11)$ & - & $66,0 \pm 1,7(18)$ & $64,8(1)$ \\
\hline & $77,3-80,7$ & & $62,0-68,6$ & \\
\hline \multirow[t]{2}{*}{ LIO } & $66,1 \pm 2,2(11)$ & $65,7(1)$ & $55,8 \pm 1,8(18)$ & $55,3(1)$ \\
\hline & $62,4-70,0$ & & $51,7-59,0$ & \\
\hline \multirow[t]{2}{*}{ CPA } & $46,9 \pm 2,3(11)$ & $50,2(1)$ & $38,7 \pm 1,9(18)$ & $37,3(1)$ \\
\hline & $42,7-50,0$ & & $34,6-42,2$ & \\
\hline \multirow[t]{2}{*}{$\mathrm{ACR}$} & $39,1 \pm 1,6(11)$ & $38,5(1)$ & $38,6 \pm 1,1(18)$ & - \\
\hline & $36,8-42,3$ & & $37,1-40,7$ & \\
\hline \multirow[t]{2}{*}{ LCR } & $53,2 \pm 1,1(11)$ & $52,9(1)$ & $50,7 \pm 1,8(18)$ & $51,0(1)$ \\
\hline & $52,1-56,1$ & & $47,0-54,7$ & \\
\hline \multirow[t]{2}{*}{ LCO } & $24,5 \pm 1,3(11)$ & $25,2(1)$ & $22,1 \pm 1,1(18)$ & $20,8(1)$ \\
\hline & $22,4-26,2$ & & $19,9-24,3$ & \\
\hline \multirow[t]{2}{*}{ LMT } & $54,8 \pm 1,3(11)$ & $58,8(1)$ & $48,9 \pm 2,0(18)$ & $49,8(1)$ \\
\hline & $52,7-57,6$ & & $45,4-52,1$ & \\
\hline \multirow[t]{2}{*}{ LPO } & $41,7 \pm 1,9(11)$ & $39,0(1)$ & $41,2 \pm 1,9(18)$ & $41,2(1)$ \\
\hline & $39,6-46,7$ & & $38,8-45,3$ & \\
\hline \multirow[t]{2}{*}{ CMA } & $101,1 \pm 4,0(11)$ & $105,0(1)$ & $81,9 \pm 2,2(18)$ & $76,0(1)$ \\
\hline & $90,6-104,7$ & & $76,2-87,0$ & \\
\hline \multirow[t]{2}{*}{ APA } & $77,6 \pm 5,6(11)$ & - & $59,46 \pm 3,4(18)$ & $55,0(1)$ \\
\hline & $68,0-84,0$ & & $52,1-65,1$ & \\
\hline \multirow[t]{2}{*}{ CDS } & $42,0 \pm 1,1(11)$ & $44,2(1)$ & $37,9 \pm 1,5(18)$ & $37,2(1)$ \\
\hline & $40,5-43,8$ & & $35,4-40,8$ & \\
\hline \multirow[t]{2}{*}{ LMO } & $42,2 \pm 1,4(11)$ & $45,5(1)$ & $37,2 \pm 1,6(18)$ & $36,8(1)$ \\
\hline & $39,3-43,8$ & & $33,7-40,5$ & \\
\hline \multirow[t]{2}{*}{ LPA } & $27,0 \pm 1,9(10)$ & - & $23,5 \pm 1,0(15)$ & $23,5(1)$ \\
\hline & $23,6-30,5$ & & $21,6-25,0$ & \\
\hline \multirow[t]{2}{*}{$\mathrm{CHI}$} & $66,1 \pm 3,2(6)$ & - & $40,8 \pm 1,8(8)$ & - \\
\hline & $63,0-71,0$ & & $38,6-43,7$ & \\
\hline \multirow[t]{2}{*}{ LHI } & $49,1 \pm 6,5(5)$ & - & $25,9 \pm 1,6(8)$ & - \\
\hline & $42,8-58,4$ & & $23,5-28,8$ & \\
\hline \multirow[t]{2}{*}{ LTE } & $23,6 \pm 3,8(6)$ & - & $12,2 \pm 5,5(8)$ & - \\
\hline & $17,4-27,4$ & & $80,-22,4$ & \\
\hline
\end{tabular}

adição, A. nigerrima tem a forma geral do osso hióide quadrangular em vista ventral e de dimensões maiores, tentótio desenvolvido e de forma trapezoidal, conferindo-lhe uma abertura hióidea semicircular, em vez de hióide ovalado com tentório 
estreito e liso, resultando em uma abertura hióidea ampla. Os ossos nasais são curvos em perfil na primeira espécie enquanto são retos em $A$. discolor. Alouatta nigerrima difere de $A$. juara, $A$. puruensis e A. macconnelli por estes apresentarem a coloração da pelagem completamente ruiva e/ou dourada. O tentório retangular e inflado de $A$. nigerrima se contrapõe ao ovalado registrado para A. juara e o côncavo em A. puruensis. Alouatta nigerrima distingue-se de $A$. caraya por esta última apresentar fêmeas com pelagem castanho-amarelada clara em vez de negra. Adultos de $A$. caraya não apresentam tentório no hióide como em A. nigerrima.

\section{História taxonômica}

O primeiro registro de um primata que lembra A. nigerrima foi de WaLlace (1854) quando observou exemplares de guariba do alto Rio Amazonas, designando-os por Mycetes caraya. O nome dado por WALLACE (1854) provavelmente deve-se à coloração negra da pelagem do macho observado, a qual é semelhante à coloração do macho adulto de A. caraya. Entretanto, não há registros de uma espécie com dicromatismo sexual peculiar (como em A. caraya) para a região do Rio Amazonas.

Posteriormente, Pelzeln (1883) designou o nome Mycetes villosus para dois exemplares provenientes de Borba, Estado do Amazonas, com referência ao trabalho de Gray (1845). Este mesmo autor descreveu um táxon de nome M. villosus baseado em indivíduos de pelagem negra uniforme, brilhante e longa, e provenientes do Brasil. Sclater (1872) concluiu que o espécime a qual Gray (1845) baseou-se para a descrição de Mycetes villosus era proveniente da América Central e não do Brasil, sendo confirmada posteriormente por NAPIER (1976). A decisão de NAPIER (1976), por sua vez, foi baseada na análise dos manuscritos de Gray (1845) e na etiqueta do espécime na qual $A$. villosus foi descrita, que consta como procedência, México. Neste sentido, o nome villosus refere-se exclusivamente a um táxon que ocorre na América Central, atualmente sinônimo de $A$. pigra, e não na floresta Amazônica brasileira.

LÖNNBERG (1941) descreveu Alouatta nigerrima baseado no material coletado por A. M. Olalla, cuja proveniência era Icoranga, Patinga, Lago do Batista e Lago Tapaiúma, todos no Estado do Amazonas, região entre os Rios Madeira e Tapajós. O autor não especificou o holótipo (lectótipo designado aqui), mas forneceu uma diagnose precisa e comparações enriquecedoras com o táxon peripátrico $A$. discolor (o autor denominou este de $A$. belzebul tapajozensis). Esta comparação foi motivada pelo fato de LÖNNBERG (1941), assim como a maioria dos autores até recentemente, considerar ambos os táxons como filogeneticamente próximos e fazendo parte da politípica A. belzebul. Entre os caracteres diagnósticos de A. nigerrima fornecidos por LÖNNBERG (1941), e de acordo com o presente estudo, estão a coloração da pelagem completamente negra e ossos nasais curvos, em perfil. Por outro lado, discordo de LÖNNBERG (1941) quando conclui que a variação nas dimensões cranianas é inaplicável para distinguir os táxons, pois como demonstrado aqui, $A$. nigerrima mostra uma série considerável de variáveis estatisti- camente maiores que $A$. discolor (Tab. X). Em sentido oposto, LönNBERG (1941) forneceu uma série de caracteres cranianos diagnósticos para $A$. nigerrima que, após a análise de séries maiores, mostraram-se variáveis e não confiáveis para a definição dos táxons, como a forma do pterigóide e da fossa glenóide, espessura da crista supra-orbital e a curvatura do palato. E por fim, o autor deixou de discorrer sobre a morfologia hióidea, muito útil para distinguir A. nigerrima de A. discolor.

A peculiaridade de $A$. nigerrima foi notada por Cruz Lima (1945), embora o peso excessivo dado à coloração da pelagem como caráter de definição e parentesco dos táxons, impossibilitou o autor de relacionar esta espécie de coloração completamente negra com outras próximas geograficamente de pelagem ruiva ou dourada (A. macconnelli e A. juara). Assim, Cruz Lima (1945: 78) concluiu: "As nossas observações dos cranios e tambores hióideos confirmam a independencia desta forma (em referência a $A$. nigerrima) das demais especies brasileiras conhecidas, como indicavam os caracteristicos externos... Para a definitiva classificação desta forma seria necessaria uma comparação com as especies negras da America Central...".

HershKovitz (1949) considerou A. nigerrima subespécie de $A$. belzebul baseado na coloração da pelagem, mas decididamente esclareceu, com base na morfologia hióidea (em acordo com Cruz Lima 1945), que o primeiro táxon pudesse ser filogeneticamente mais próximo a A. seniculus que a A. belzebul. Entretanto, HershKOVITz (1949) também manteve uma posição conservadora e alocou o táxon como uma subespécie de A. belzebul. Após Hershrovitz (1949), o táxon foi tratado subespecificamente (CABrera 1958, Hill 1962, Armada et al. 1987, Bonvicino et al. 1989 , Coimbra-Filho 1990) ou mesmo tendo sua validade ignorada (NAPier 1976, Wolfheim 1983).

Recentemente, $A$. nigerrima foi reconhecida ao nível específico por Rylands et al. (2000) e Groves (2001a). Embora $A$. nigerrima tenha sido eventualmente tratado ao nível específico, este é o primeiro estudo a incluir, concomitantemente, uma série ampla de espécimes e localidades, empregando vários complexos anatômicos acompanhados de uma análise propondo uma hipótese de parentesco sob o prisma filogenético. Deste modo, os resultados da análise morfológica do osso hióide e do crânio aliados aos dados citogenéticos (ARMada et al. 1987, OLIVEIRA 1995) e moleculares (W. Figueiredo com. pes.) (Tab. XVIII), indicam que $A$. nigerrima está mais relacionado a $A$. macconnelli que a $A$. belzebul, evidenciando aqui o não monofiletismo de $A$. belzebul e a fragilidade no reconhecimento de suas subespécies. De fato, o parentesco entre A. nigerrima e A. belzebul como tradicionalmente aceito, baseou-se na semelhança geral da coloração negra compartilhada entre os dois táxons. É importante ressaltar que os caracteres de pelagem são muito empregados na sistemática de primatas e em muitos casos, embora eles sejam importantes para definir os táxons, não o são para propor relações de parentesco. Assim, conclui-se que a aproximação filogenética de $A$. nigerrima e $A$. macconnelli baseado em fontes distintas de caracteres e a singularidade da pelagem to-

Revista Brasileira de Zoologia 23 (1): 64-144, março 2006 
Tabela XVIII. Caracteres selecionados para a comparação entre três táxons amazônicos de Alouatta. Os dados do osso hióide referem-se somente aos machos. *padrão mais freqüente.

\begin{tabular}{|c|c|c|c|}
\hline Caráter/táxon & A. belzebul & A. nigerrima & A. macconnelli \\
\hline Desenvolvimento do hióide (mm) & $42,4-75,6$ & $63,0-71,0$ & $61,6-79,1$ \\
\hline Desenvolvimento do Tentório (mm) & $7,0-29,7$ & $17,4-27,4$ & $17,3-31,3$ \\
\hline Forma do Tentório & retangular & trapezoidal & trapezoidal \\
\hline Inserção dos cornos & posterior & ventral & ventral \\
\hline Cornículo & evidente & vestigial & vestigial \\
\hline Forma dos nasais em perfil & reto & curvo & curvo \\
\hline Coloração da pelagem & negra com as extremidades ruivas* & negra & dorso dourado com membros e cauda ruivos \\
\hline $2 \mathrm{~N}$ & 50 & 50 & $47-49$ \\
\hline Micro-cromossomos & ausente & ausente & presente \\
\hline
\end{tabular}

talmente negra diferenciando o primeiro táxon dos demais pertencentes ao complexo A. seniculus (Tab. I), cuja coloração é ruiva a alaranjada, não deixa dúvidas sobre seu reconhecimento como uma espécie válida.

\section{Alouatta macconnelli Elliot, 1910}

Simia seniculus; Audebert, 1797: 7; pl. 1; nec Linnaeus (1766). Thunberg, 1823b: 2, nec Linnaeus (1766). -Richard, 1835: 140; partim.

Stentor seniculus; Geoffroy Saint-Hilaire, 1812: 107, 1829: 21; partim.

Mycetes stramineus; Desmarest, 1820: 78; nec Humboldt. -Kuhl, 1820: 29; nec Humboldt. -Spix, 1823: 45; pl. 31; nec Humboldt. -Lesson, 1827: 51; nec Humboldt. -Minding, 1829: 5; nec Humboldt. -Bates, 1864: 175; nec Humboldt.

Mycetes seniculus: Lesson, 1827: 50; partim. -Schomburgk, 1848: 768; partim. -Geoffroy Saint-Hilaire, 1851: 52. -Gray, 1870: 39; partim. -Schlegel, 1876: 156; partim. -Cabrera, 1900: 69. -Meerwarth, 1903: 12; partim.

Mycetes auratus Gray, 1845: 220. Localidade-tipo: Orinoco, Brasil (Hill, 1962). Descrição baseada em um espécime provavelmente fêmea depositado no British Museum ZD 1844.5.14.15 (pele) e ZD 1845.6.17.3 (crânio) (NAPIER 1976). Aluatta [sic] senicula; Slack, 1862: 516; partim.

Alouatta senicula; Forbes, 1896: 192 partim.

Alouata [sic] seniculus; Trouessart, 1897: 32; 1904: 21. -Goeldi e Hagmann, 1904: 42.

Alouatta macconnelli Elliot, 1910: 80. Localidade-tipo: costa de Demerara, Guiana. [Holó]tipo: British Museum ZD 1908.3.7.3 (pele e crânio) (NAPIER, 1976). -Allen, 1911: 271. -Elliot, 1913: 281. -Sanderson, 1949: 765. -Bonvicino et al., 1995. -Groves, 2001a: 182.

Alouatta seniculus; Thomas, 1912: 84; partim. -Elliot, 1913: 277; partim. -Lönnberg, 1941: 12; partim. -Chiarelli, 1972: 166; partim. -Napier, 1976: 83; partim. -Mittermeier \& CoimbraFilho, 1981: 82; partim. -Wolfheim, 1983: 228; partim. -Nunes et al., 1988: 94; figura 8; partim. -Rylands \& Keuroghlian, 1989:
291; partim. -Hirsch et al., 1991; partim. -Lima et al.,1990; partim. -Groves, 1993: 255; partim. -Fernandes, 1995: 1; partim.

Alouatta straminea; Ihering, 1914: 250.

Alouatta seniculus macconnelli; Allen, 1916b: 233. -Hill, 1962: 122. Alouata [sic] seniculus Rode, 1938: 225; partim.

Alouatta senicula stramineus; Tate, 1939: 218; nec Humboldt. Alouatta senicula macconnelli; Tate, 1939: 218.

Alouatta seniculus straminea; Cruz Lima, 1945: 75, pl. 2; nec Humboldt. -Cabrera, 1958: 157; nec Humboldt. -Vieira, 1955: 383; nec Humboldt. -Husson, 1957: 21, Prancha 2; nec Humboldt. -Carvalho, 1961: 6; 1962: 287; nec Humboldt. Ávila-Pires, 1964: 13; nec Humboldt. -Carvalho, 1965: 14; nec Humboldt. -Ximenez, 1973: 258; nec Humboldt. Coimbra-Filho, 1990: 1075; nec Humboldt. -Auricchio, 1995: 131; nec Humboldt.

Alouatta seniculus stramineus: Hershkovitz, 1949: 394, figura. 56; nec Humboldt. -Hill, 1962: 120; nec Humboldt. -Lima \& Seuánez, 1991; nec Humboldt.

Alouatta senicola [sic] straminea: Pinto \& Gomes, 1976: 54; nec Humboldt.

Alouatta seniculus straminae [sic]: McLaren et al., 1984: 466; nec Humboldt.

Alouatta macconelli [sic]: Bonvicino et al., 1995; nec Humboldt.

\section{Material examinado (total 198)}

BRASIL, Amapá: MPEG: 3350-51 (p, c, h); Rio Amapari: MPEG: 20349 (c); Macapá: MPEG: 2285 (p, c); Rio Maracá, Mazagão: MNRJ: 23150 (p), 23152 (p); MPEG: 608 (p), 1017 (c, h), 1018 (p, c, h), 1022 (c), 1026 (c, h), 1211 (p), 1228 (c, h), 1231 (p), 1232-33 (p, c), 1283 (c), 1658 (p, c), 1659 (p, c), 4081 (c), 4099 (c), 4101 (c); Rio Tracajatuba: MNRJ: 20374-76 (p, c), 23149 (p, c), 23151 (p, c); MZUSP: 19154-55 (p, c), 19156 (c), 19157-58 (p, c); 19161-63 (p, c); Vila Terezinha, Serra do Navio: MZUSP: 19159-60 (p, c),19164-65 (p, c), 19166 (p, c, h); Vila Velha do Caciporé, Oiapoque: MNRJ: 21130 (p); MPEG: 2283-84 (pele, crânio e hióide), 2286 (p, c, h); AMAZONAS: Igarapé Anibá: MNRJ: 6038 (p, c, h), 6039-40 (c, h); MZUSP: 5068 (c), 5092 (p, 
c), 5098 (p), 10573 (c, h); Rio Araguari: MPEG: 1203 (p, c); Araiú: MNRJ: 30469 (c); Bacabau: MPEG: 7061 (p, c); Usina Hidrelétrica de Balbina: MNRJ: 26937-40 (p, c); MPEG: 22160 (p, c, h), 22161 (p), 22162 (p, c, h), 22163 (p, c), 22164-71 (p), 22173 (c, h), 23051 (p, c); MZUSP: 22909 (p, c), 22913 (p, c), 23171 (p, c), 23761 (p, c), 23763-64 (p, c), 24796 (p, c, h), 24804-09 (animal inteiro, via úmida); Lago Batista: MZUSP: 5479 (p); Lago Camaçary: MNRJ: 6041 (c); Estrada AM-10 (Manaus-Itacoatiara): MPEG: 7050 (c), 7059-60 (c), 7063 (c), 7064 (c, h); Estrada AM01: MPEG: 7044 (p, c), 7045 (p, c, h), 7046 (p, c), 7047-48 (p), 7049 (p, c, h), $7051-53$ (p, c, h), 7054-56 (p, c), 7057 (p, c, h), 7058 (p, c), 7067-68 (p), 7070 (p), 8922 (p); Itacoatiara: MZUSP: 10567 (c), 10568 (c, h), 10572 (c, h); Itapiranga: MZUSP: 1908283 (p); Manaus: MNRJ: 23157 (p), 24117 (p, c, h), 24118 (p, c); MPEG: 7047-48 (c, h), 7221 (c); Silves: MZUSP: 5097 (p, c, h), 5255 (p), 10575 (c, h); 19077 (c, h), 19078 (c); Tupuruquare: MPEG: 7062 (p, c, h); PARÁ: Boiuçú: MZUSP: 5095 (p, c), 5096 (p, c, h), 5473 e 5474 (p, c), 19088 (c, h); Bom Jardim, Paissandú: MZUSP: $9949-50$ (p), 9951 e 9952 (p, c, h), 9953 (p, c), 9954 (p, c), 9957-58 (p, c, h), 19085 (c); Bravo: MZUSP: 5094 (p, c), 5435 (p), 5470-71 (p, c), 5476 (p, c), 5478 (p, c), 5480-81 (p, c), 7113 (c), 10496 (c), 19123 (c); Faro: MPEG: 874 (c, h); MZUSP: 995556 (p, c, h); Ilha Gurupá: MPEG: 23026-27 (p, c, h); Jaquara: MZUSP: 19121 (c, h); Rio Maicuru: MPEG: 5214-15 (c); Óbidos: MPEG: 481 (p), 5217 (c); MZUSP: 3637 (p, c), 3638-40 (p, c), 19086 (c); Oriximiná: MPEG: 10526 (c), 13246 (c), 13248-50 (c), 21013 (c), 21604 (p, c), 22062 (c), 22063-66 (c, h), 22068 (c, h); 23182 (p), 23255 (c, h), 23247 (c); Paru de Este, Almeirim: MNRJ: 21127-29 (p, c); Cachoeira do Tronco, Rio Erepecuru: MPEG: 1161 (c), 1168 (p, c), 1212 (p, c), 1244 (c); RORAIMA: Rio Mucujaí, Boa Vista: MNRJ: 23155 (c); MPEG: 1728 (p), 2373-74 (pele e crânio, hióide), 21876 (p, c, h), 21877 (p, c, h); MZUSP: 9672 (p, c, h); Venezuela: Santa Elena: MPEG: 21874-75 (p).

\section{Localidade-tipo}

O material na qual ELLIot (1910) se baseou para a descrição do táxon foi proveniente da Costa de Demerara, Guiana.

\section{Distribuição geográfica}

A figura 55 ilustra o mapa com a distribuição de $A$. macconnelli no Brasil, sempre na margem norte do Rio Amazonas (exceto um exemplar do Lago Batista), desde a costa do Estado do Amapá, incluindo as Ilhas Pará e Gurupá, até a margem leste dos Rios Negro e Branco. Esta distribuição inclui os Estados do Amapá, Pará, Roraima e Amazonas. Bonvicino et al. (1995) consideraram a ocorrência de A. macconnelli para a Ilha de Marajó, mas não há registro de qualquer exemplar desta espécie para a região, nem conhecimento mediante observação direta.

\section{Caracteres diagnósticos}

Pelagem dorsal ricamente dourada, com ou sem uma faixa mediana ruiva escura ao longo do dorso, desde a nuca até a base da cauda; membros anteriores, posteriores e cauda de coloração ruiva em várias tonalidades, desde avermelhada a ruiva escura ou marrom (Figs 48 a 50). Osso hióide no macho

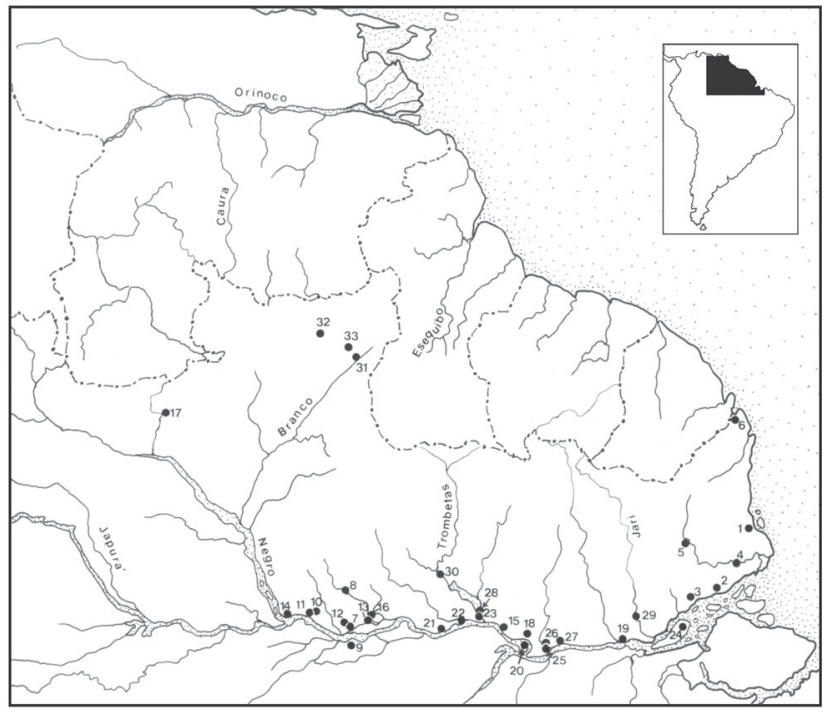

Figura 55. Mapa de distribuição geográfica de A. macconnelli no Brasil. Espécimes adicionais (Anexo II) e relatos da literatura estendem a distribuição deste táxon para as Guianas e a porção leste da Venezuela.

com tentório largo e de forma trapezoidal; bula hióidea com a região anterior à abertura inflada; abertura hióidea semicircular (Figs 56 e 58).

\section{Descrição geral}

As medidas cranianas e do osso hióide, de machos e de fêmeas, estão nas tabelas XIX e XX, respectivamente. Os adultos, de ambos os sexos, apresentam barba desenvolvida e enegrecida no mento, tornando-se ruiva escura próxima ao pavilhão auditivo; cabeça com pelagem ruiva escura a vermelha; pêlos da região anterior da cabeça, voltados para trás e os da nuca para frente, encontrando-se na região médio-dorsal da cabeça, conferindo-lhe uma crista; nuca com coloração ruiva escura. Redomoinho na região posterior do pescoço presente. Região das espáduas variando desde ruiva escura a dourada brilhante; restante da pelagem dorsal alaranjada com tonalidade dourada clara brilhante ou dourada-avermelhada, escurecendo em direção aos flancos; faixa médio-dorsal ao longo do eixo sagital, em parte dos espécimes, ruiva escura a castanho, destoando do restante do dourado dorsal presente (Figs 48 a 50). Pêlos dorsais e laterais, em geral, de base castanho-avermelhado, clareando gradativamente em direção ao ápice até tornar-se dourado, sem uma distinção evidente de faixas. Membros anteriores de coloração ruiva na região dos braços e escurecendo na região dos antebraços e mãos; membros posteriores de mesmo padrão que os anteriores, porém, levemente mais claros. Cauda com coloração ruiva escura. Pelagem geralmente curta e áspera. Os jovens são mais escuros que os adultos, com a pelagem da barba, cabeça, flancos, membros anteriores e posteriores, e cauda, no geral, de coloração ruiva escura; dorso mais claro que as regi- 

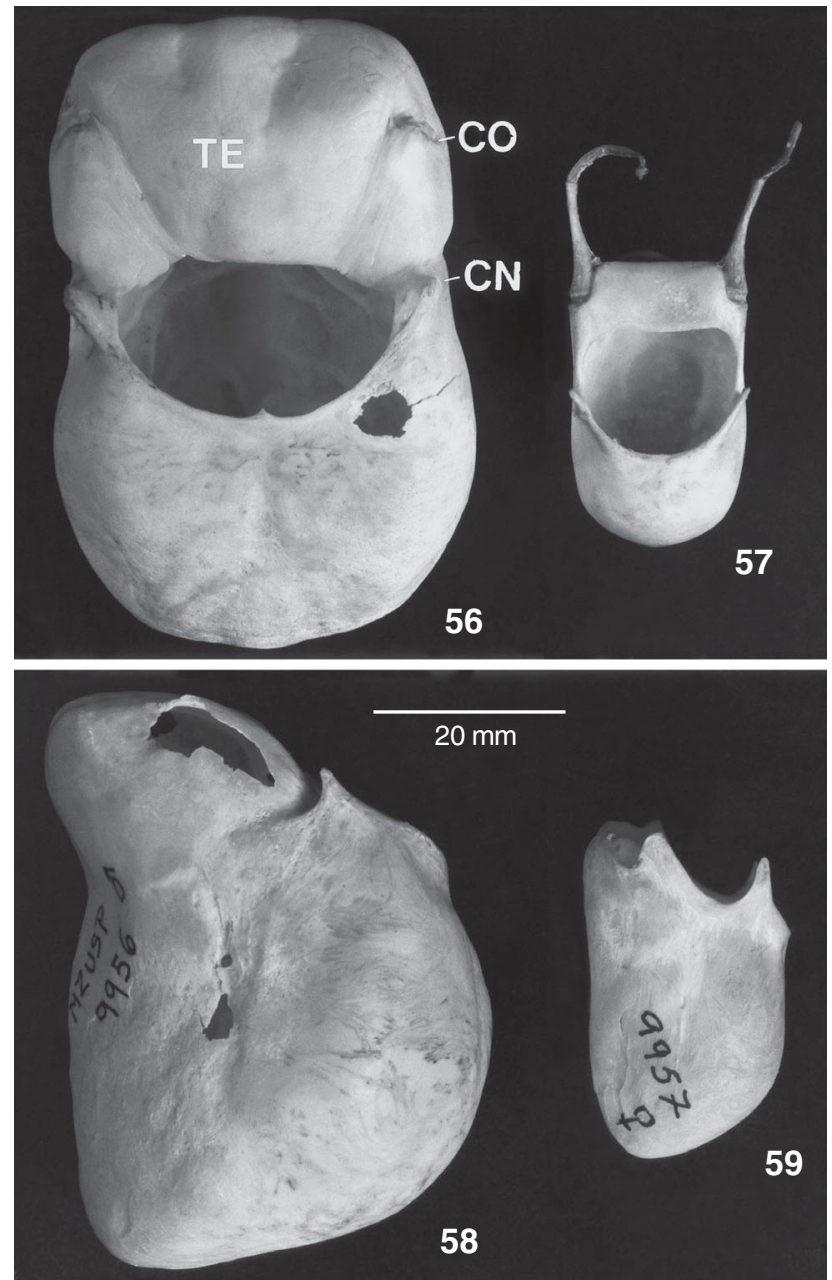

Figuras 56-59. Osso hióide de A. macconnelli: (56 e 58) indivíduo macho (MZUSP 9956) em vista ventral e lateral, respectivamente; (57 e 59) indivíduo fêmea (MZUSP 9957) em vista ventral e lateral, respectivamente. Note a morfologia do tentório, da abertura hióidea e o ponto de inserção ventral dos cornos semelhante àquela registrada para A. nigerrima (Fig. 51). (CN) Cornículo, (CO) corno, (TE) tentório.

ões adjacentes de coloração dourada-avermelhada, mas nunca atingem um grau acentuado de dourado brilhante ou pálido.

Osso hióide no macho adulto com comprimento total de 60,0 a 79,1 mm $(\mathrm{N}=21)$. Tentório desenvolvido: 18,8 a 35,0 $\mathrm{mm}(\mathrm{N}=22)$, liso e de forma trapezoidal com concavidade central (Figs 56 e 58). Cornículos reduzidos, lanceolados e inflados anteriormente, de forma a expandir a bula hióidea; cornos reduzidos e inflados anteriormente, resultando invariavelmente em uma aparência trilobada do tentório. Abertura hióidea semicircular. Bula hióidea desenvolvida e inflada na região anterior à abertura hióidea; trabéculas internas, em geral, presen- tes. Osso hióide na fêmea adulta com comprimento total de 32,4 a 56,4 mm ( $\mathrm{N}=15)$; tentório desenvolvido: 5,4 a 20,8 mm ( $\mathrm{N}=15$ ) e liso. Cornículos presentes, desenvolvidos e lanceolados. Abertura hióidea semicircular. Bula hióidea com paredes lisas e comprimidas dorso-ventralmente (Figs 57 e 59). Os ossos nasais são curvos em vista lateral.

Cariótipo. O número diplóide variou de 47 a 49 de acordo com a presença de um a três micro-cromossomos (Yunis et al. 1976, Lima \& Seú́nez 1991, Bonvicino et al. 1995).

\section{Variação}

A variação acentuada na coloração da pelagem neste táxon pode ser comparada àquela registrada para A. clamitans e $A$. belzebul. Abaixo, relata-se a variação encontrada nos espécimes do Brasil e, em uma segunda comparação mais abrangente, incluindo espécimes provenientes da Guiana, Suriname e Venezuela, com a finalidade de tomar decisões taxonômicas conclusivas. Ressalta-se que o estudo da variação conduzido aqui considera a presença de dois táxons para a margem norte do Rio Amazonas como historicamente definidas com base no recente estudo de Bonvicino et al. (1995). Assim, parte da descrição da variação e a separação das amostras a serem testadas são aprioristicamente escolhidas e permeadas pela proposta de Bonvicino et al. (1995) com um táxon ocorrendo desde a costa do Amapá até a margem esquerda do Rio Trombetas (denominada pelos autores de $A$. macconnelli) e o outro com distribuição desde margem à direita do Rio Trombetas até o Rio Negro (designada por $A$. straminea). Contudo, a hipótese a ser testada, é que de fato existe um único táxon ocorrendo no Escudo Guiano.

Inicia-se a o estudo de variação pela descrição da coloração geral da pelagem das amostras entre a costa do Amapá e o Rio Negro. Para esta região, há três padrões marcantes de coloração da pelagem que são assim sumariamente caracterizados como: 1) indivíduos com a possessão de dorso completamente alaranjado a dourado claro sem uma faixa sagital dorsal distintamente mais escura, ou quando presente, ela é incipiente e não se estende marcadamente ao longo de toda a região dorsal; as regiões da barba, cabeça, membros anteriores, posteriores e cauda, avermelhados e raramente ruivo escuro (Fig. 48); 2) indivíduos de coloração da pelagem dourada-avermelhada distribuída mais homogeneamente por todo o corpo e menos brilhantes que aqueles descritos anteriormente, resultando em um padrão mais escuro e mais avermelhado que os demais; 3) indivíduos com coloração dorsal alaranjada a dourada-avermelhada com uma faixa sagital médio-dorsal, desde a cabeça até a cauda, ruiva escura ou castanho, tanto quanto os membros e cauda (Fig. 50). Estes padrões gerais da coloração na pelagem foram aqueles registrados para a maioria dos espécimes estudados e provenientes do Brasil e do nordeste da América do Sul, embora haja outras variantes descritas abaixo. A separação inicial nestes três padrões mais freqüentes objetiva uma análise nas freqüências de suas distribuiçãos no Brasil e uma posterior diagnose das populações locais para tomar as decisões taxonômicas. A instabilidade taxonômica e nomenclatural referentes aos táxons do Es-

Revista Brasileira de Zoologia 23 (1): 64-144, março 2006 


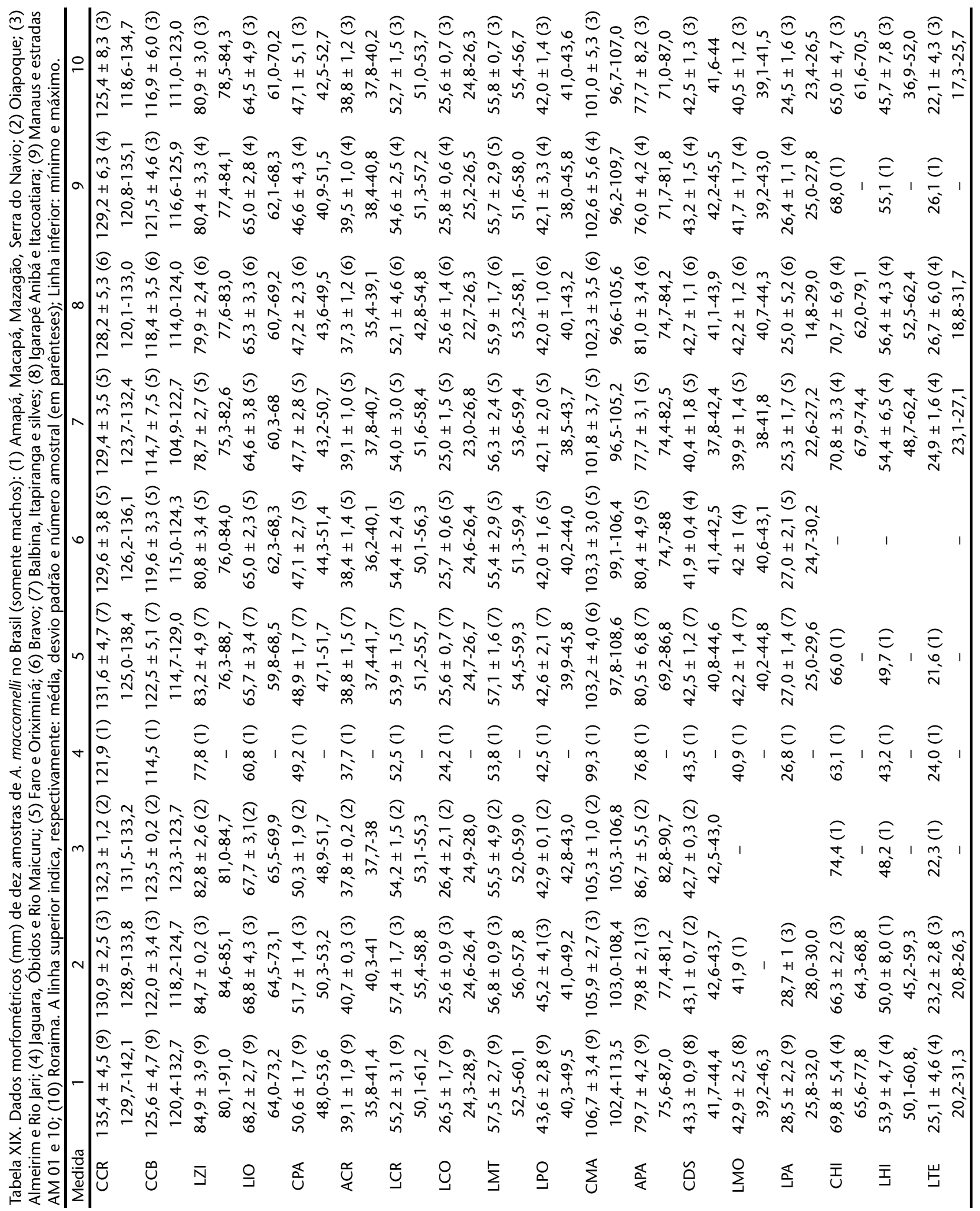

Revista Brasileira de Zoologia 23 (1): 64-144, março 2006 


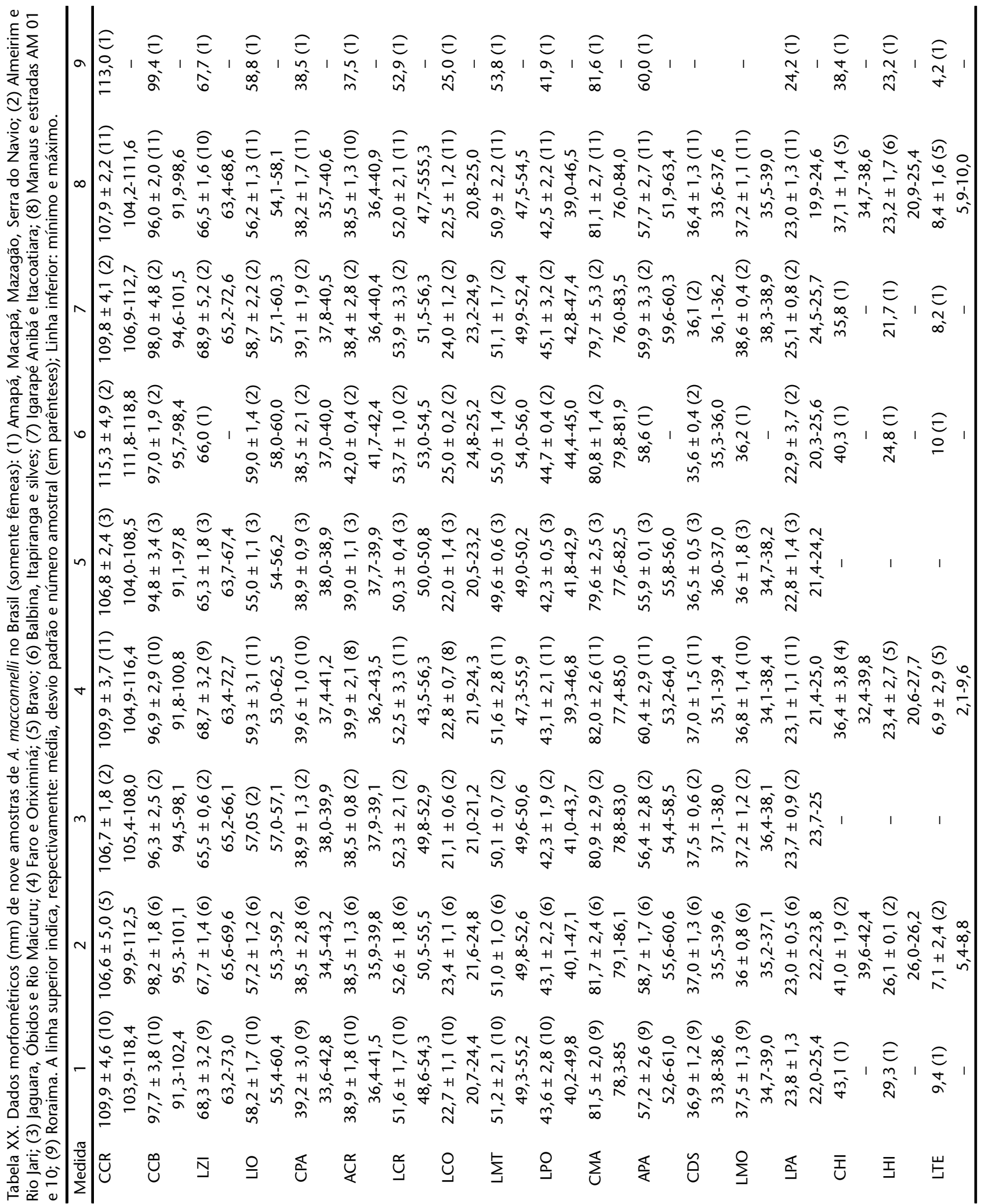


cudo Guiana estão intimamente relacionadas ao problema do elevado grau de variação como frisado por RyLANDS \& BRANDONJoNEs (1998), daí um estudo mais amplo na tentativa de esclarecer tais questões em aberto. Entretanto, as amostras do Brasil são basicamente provenientes da borda do Rio Amazonas com coleções menores e pontuais provenientes do norte do Amapá (Oiapoque) e Roraima, próximos aos Rios Branco e Negro. Assim, parte do estudo de variação, principalmente para áreas no norte do Amapá, Pará e Amazonas, fica prejudicado.

Analisando a ocorrência dos padrões, nota-se que, embora haja dois ou mais destes padrões descritos acima em qualquer área, há sempre uma predominância de um deles como exposto na tabela. XXI. Assim, na área mais a leste da distribuição (a mesma área delimitada por Boncicino et al. 1995 para $A$. macconnelli), desde a costa do Amapá até margem esquerda do Rio Trombetas, tem uma maior freqüência de indivíduos com o padrão de coloração da pelagem dourada clara (padrão 1). Este padrão coincide parcialmente com a descrição de A. macconnelli. Na extremidade oposta da distribuição, desde o oeste do Pará (margem direita do Rio Trombetas) até o Rio Negro, ocorre uma maior freqüência de indivíduos cuja coloração da pelagem é dourada com uma faixa dorsal ruivo escura (padrão 3). No entanto, em ambas as áreas ocorrem estes dois padrões de coloração. Esta diferença na freqüência de coloração nos extremos da área de distribuição da espécie levou alguns autores a considerarem dois táxons distintos em qualquer nível: A. macconnelli para o Amapá e leste do Pará e A. straminea para o oeste do Pará e a região de Manaus (CABRERA 1958, Bonvicino et al. 1995). Registrou-se um padrão de pelagem cujo dorso é mais ricamente colorido de vermelho (padrão 2) para espécimes em locais intermediários na distribuição (Bom Jardim). Na tabela XXI, relata-se mais detalhadamente a ocorrência destes padrões em regiões selecionadas de oeste para leste, todas próximas à margem esquerda do Rio Amazonas, e para amostras mais ao norte do país.

Registrou-se um quarto padrão de coloração da pelagem, embora não discutido acima devido à sua restrição geográfica, para exemplares provenientes de Itapiranga (MZUSP 19082, 19083), Silves (MZUSP 5255) e a rodovia AM-01 (MPEG 7044, 7058, 7067), todos no Estado do Amazonas. Estes indivíduos apresentam campos cromatogenéticos negros na cabeça, mem-

Tabela XXI. Freqüência de ocorrência dos padrões de coloração para A. macconnelli. Note a tendência em ocorrer padrões distintos em extremos da distribuição, mas com sobreposição considerável em cada área.

\begin{tabular}{|c|c|c|c|}
\hline Localidade & Padrão 1 & Padrão 2 & Padrão 3 \\
\hline $\begin{array}{l}\text { Manaus (inclui as estradas AM- } \\
01 \text { e AM-10), AM }\end{array}$ & $\begin{array}{l}\text { MNRJ 24117-18; MPEG 1058- } \\
59 .\end{array}$ & MPEG 7045, 7049, 7051. & $\begin{array}{l}\text { MPEG 5370, 7047-48, 7056-57, } \\
7060,7063,7066 .\end{array}$ \\
\hline $\begin{array}{l}\text { Itacoatiara (inclui Igarpé Anibá), } \\
\text { AM }\end{array}$ & & & MZUSP 5092, 5098. \\
\hline $\begin{array}{l}\text { Usina de Balbina (Rio Uatumã), } \\
\text { AM }\end{array}$ & MNRJ 26938, 29937. & $\begin{array}{l}\text { MZUSP 22909, } 22913,23171, \\
\text { 23761, 2373-64. }\end{array}$ & MZUSP 24796. \\
\hline Itapiranga (inclui Silves), AM & & & MZUSP 5093, 5097. \\
\hline Bom Jardim, PA & MZUSP 9949-54, 9957-58. & & \\
\hline Bravo (m. d. Rio Trombetas), PA & $\begin{array}{l}\text { MZUSP 5094, 5435, 5470-71, } \\
5476,5478,5480-81 .\end{array}$ & & \\
\hline Oriximiná (inclui Faro), PA & MZUSP 9955-56. & & \\
\hline $\begin{array}{l}\text { Boiuçu e Alenquerr (m. e. } \\
\text { Trombetas), PA }\end{array}$ & & & MZUSP, 5095, 5473-74. \\
\hline $\begin{array}{l}\text { Cachoeira Santo Antônio (Rio } \\
\text { Jari), PA }\end{array}$ & MPEG 1211. & & \\
\hline Almeirim, PA & MNRJ 27127-28 & & \\
\hline Mazagão (inclui Macapá), AP & MPEG 1658, 1231-32. & & $\begin{array}{l}\text { MNRJ 23150; MPEG } 2285, \\
1659,1233,608,1018 .\end{array}$ \\
\hline $\begin{array}{l}\text { Rio Tracajatuba (inclui Amapá), } \\
\text { AP }\end{array}$ & $\begin{array}{l}\text { MNRJ 20574-76, 23151; MZUSP } \\
\text { 19154-58, 19161-63, } 19165 .\end{array}$ & MPEG 1203. & MPEG 3350, 3351. \\
\hline $\begin{array}{l}\text { Vila Terezinha (Serra do Navio), } \\
\text { AP }\end{array}$ & $\begin{array}{l}\text { MZUSP 19159-60, 19164, } \\
19166 .\end{array}$ & & \\
\hline Oiapoque, AP & $\begin{array}{l}\text { MNRJ 21130, } 23152 ; \text { MPEG } \\
2283-84,2286 .\end{array}$ & & \\
\hline $\begin{array}{l}\text { Tupuruquare, AM e Boa Vista } \\
\text { (inclui Rio Mucujaí), RR }\end{array}$ & $\begin{array}{l}\text { MPEG 1728, 2373, 7062; } \\
\text { MZUSP } 9672 .\end{array}$ & & \\
\hline
\end{tabular}


bros, cauda e partes do dorso (Fig. 49). A presença peculiar de campos cromatogenéticos negros não foi evidenciado em nenhum outro indivíduo no restante das populações de A. macconnelli analisadas para o Brasil, levando inicialmente a supor que esta região possa ter sido um ponto de hibridação com $A$. nigerrima. As evidências para a suposição de hibridação no material analisado são: 1) Alouatta nigerrima é caracterizada por apresentar a coloração da pelagem toda negra, 2) ambas espécies são simpátricas na região de Oriximiná, margem norte do Rio Amazonas (Cruz Lima 1945, NAPIER 1976), e 3) elas são filogeneticamente próximas (Hershrovitz 1949, Oliveira 1996b), permitindo o cruzamento destas duas entidades evolutivas distintas. Os locais de proveniência destes espécimes reforçam a sugestão de hibridação entre $A$. nigerrima e $A$. macconnelli, pois eles estão localizados exatamente na zona intermediária na distribuição dos dois táxons (entre as longitudes 55 e $58^{\circ} \mathrm{W}$ ). Este seria mais um caso de distribuição periférica de uma espécie na área de ocorrência de outra dominante, caracterizando um padrão bem comum em Alouatta, como ocorre com A. caraya e A. clamitans.

Entretanto, Rylands \& BRANDON-Jones (1998) registraram os mesmos casos para espécimes mais ao norte, no Suriname e Guiana, depositados no Museu Britânico, e cuja coloração apresentavam campos cromatogenéticos negros. De mesma forma, Husson (1957) relatou espécimes jovens com partes (principalmente a barba) da pelagem enegrecida para os espécimes do Suriname e o holótipo de A. macconnelli, proveniente de Demerara, mostra a base dos pêlos negra (ElLiot 1910). Neste sentido, a outra hipótese levantada seria que os pêlos negros distribuídos em pequenos campos cromatogenéticos e em diversos graus, poderiam se expressar em decorrência de pressões seletivas ambientais ou mesmo aleatoriamente, como parte da freqüência gênica das populações.

Comparação com espécimes das Guianas. Para melhor definir a controvertida taxonomia dos animais do Escudo Guiano, comparou-se amostras do Brasil, descritas acima, com aquelas do norte e nordeste da América do Sul, incluindo além das Guianas, a Venezuela continental, a Ilha de Trinidad e a Colômbia (material complementar no Anexo II). Registrou-se animais descritos anteriormente como Padrão 1 (espécimes mais claros com dorso quase ou totalmente dourado) para o Rio Saramacca (FMNH 95492, 95494) e Nickerie (FMNH 93246-47, 95495-96), ambos no Suriname, Kartabo, Guiana (AMNH 36326, 42842, 64092, 64094, 140527-30, 142937), e Bolivar, Venezuela (AMNH 130483, 130486-87, 135458). Espécimes de dorso dourado com uma faixa escura característica ao longo do eixo médio-dorsal (Padrão 3) foram registrados para Kartabo, Guiana (AMNH 76816) e Rio Saramacca, Suriname (FMNH 95943), e animais avermelhados quase sem contraste dorso/ membros (Padrão 2) para Kartabo (AMNH 42843, 64093, 142940-43) e Tamatumari, Guiana (AMNH 36327-28).

Assim, nas "Guianas", a variação registrada não mostra relação com geografia e, portanto, os mesmos padrões de coloração da pelagem descritos para o Brasil, são encontrados lá.
Esta elevada variação sem uma definição geográfica nítida que poderia representar táxons distintos foi também notada e meticulosamente descrita por Husson (1957: 23) para o Suriname com a seguinte conclusão: " The fact that in the costal region three rather differently coloured groups of specimens of the subspecies under discussion were collected shows that there is a considerable variability within a small area. Our material is too small, however, to give a correct picture of variability of Alouatta seniculus straminea within Suriname".

Husson (1957) foi acertadamente cauteloso em tomar qualquer decisão taxonômica com base na pequena amostragem que tinha em mãos e os espécimes adicionais das "Guianas" e do Brasil analisados confirmam a elevada variabilidade fenotípica da coloração da pelagem em $A$. macconnelli sem um padrão geográfico distinto que permite reconhecer outro táxon além deste para o Escudo Guiano. Por outro lado, Rylands \& BRANDON-JONES (1998: 899) consideraram apenas um táxon para todo o Escudo Guiano mas de forma pouco convicta ao expressarem: "... There is no evidence that the red howlers north of the Rio Amazonas in Brazil are subspecifically identical to those described from the type locality of $A$. macconnelli on the Guyana coast". Neste caso, a cautela dos Rylands \& BRANDON-Jones (1998) refere-se aos dados citogenéticos discutidos naquela parte do artigo, o que de fato procede, pois a representatividade geográfica deste tipo de caráter é mínima (amostras pontuais), impossibilitando um estudo amplo de variação. Mas como mostrado acima, a variabilidade na coloração da pelagem não permite considerar, com confiança, mais que um táxon para a área em discussão (contra Bonvicino et al. 1995). Embora não se analisou qualquer espécime de Demerara (localidade-tipo de $A$. macconnelli), a variação na coloração da pelagem para áreas próximas, como Kartabo, Guiana, e Rio Saramacca e Nickerie, ambos no Suriname, sustentam a opinião que se tratam da mesma entidade taxonômica com base neste tipo de caráter. Os espécimes do norte do Amapá, Oiapoque, também apresentram pelo menos dois dos padrões de coloração delimitados acima (1 e 3) e que usualmente definiam duas subespécies.

Os ossos hióides, de mesma forma, variaram consideravelmente na morfologia geral e no tamanho (Tabs XIX e XX). Quanto à forma, há desde ossos hióides com a bula completamente ovalada, cuja região látero-ventral é lisa (MPEG 1017, Mazagão; MPEG 2283, Oiapoque, ambos do Estado do Amapá), até ossos com a bula apresentando extremo de inflação próximo à abertura hióide e afilando consideravelmente na extremidade anterior do osso, morfologia esta registrada para a maioria dos indivíduos estudados. O tentório também variou consideravelmente em sua forma desde aqueles compostos por uma placa lisa e côncava (MZUSP 9672, Rio Mucujaí, Roraima) até hióides com tentório acentuadamente convexo e trilobado, devido à inflação ventro-lateral na região dos cornos (MPEG 21877, Mucujaí, Roraima; MZUSP 10575, Silves, Amazonas). A condição intermediária são ossos apresentando a placa do tentório lisa e reta (MZUSP 3637, Óbidos; 5096, 19088, Boiuçú; 9951, 
9952, Paissandu, 19121, Jaquara, todos do Pará). A presença de trabéculas internas também foi variável individualmente, mas ocorrendo na vasta maioria dos indivíduos analisados.

As tabelas XIX e XX mostram os dados da estatística descritiva dos machos e fêmeas, respectivamente. As amostras comparadas foram provenientes de 10 regiões distintas, sendo que oito incluídas em um transecto leste-oeste, desde a costa do Estado do Amapá até a margem esquerda do Rio Negro, no Estado do Amazonas. Outras duas amostras são provenientes de áreas mais ao norte, uma de Roraima e a outra do Oiapoque, AP. O exame das tabelas XIX e XX mostra de forma generalizada que, embora haja uma tendência à diminuição na média das amostras de indivíduos machos no sentido leste-oeste, com os extremos bem diferenciados, há uma considerável variação local entre as populações analisadas. Assim, não é possível afirmar categoricamente que há uma distribuição clinal dos dados tampouco separar as amostras em dois táxons com base em um hiato morfométrico. Entretanto, a distribuição das médias ao longo deste eixo leste-oeste não é semelhante entre os sexos. As fêmeas apresentam esta variação de forma difusa e portanto pouco diz sobre a variação geográfica, enquanto os machos mostram um aspecto interessante: do Amapá até amostras do Rio Trombetas, há uma queda gradual (clinal) das médias na maioria das variáveis analisadas; Daí até amostras da região de Manaus, há uma flutuação na distribuição das médias, mas com uma tendência de aumento delas nas amostras do Pará (margem direita do Rio Trombetas) até o extremo oeste da distribuição, no Rio Negro. Isto poderia parcialmente estar de acordo com Bonvicino et al. (1995), que propuseram a distinção destas populações em duas espécies. De qualquer forma, os testes de variância entre as populações mostraram que não há diferenças significantes entre elas.

Para o reconhecimento de duas espécies, A. macconnelli e A. straminea, para o Escudo Guiano Bonvicino et al. (1995) empregaram teste estatístico multivariado (Análise Discriminante) que resultou em uma diferenciação contínua dos indivíduos no eixo leste-oeste da daquela porção da Amazônia. A figura 60 reproduz o gráfico resultante da análise de Bonvicino et al. (1995) e corrobora em parte, a variação contínua nas variáveis cranianas ao longo do Rio Amazonas, com os espécimes do Amapá tendendo a serem maiores que os do outro extremo da distribuição (Manaus e localidades próximas no AM). Contudo, a distribuição contínua das medidas, sem um hiato evidente, somado à elevada variação na coloração da pelagem e na morfologia do osso hióide, e a baixa diferenciação citogenética entre os espécimes do Rio Negro e do Amapá, não corroboram na totalidade os dados morfométricos expressos por eles.

Assim, para maiores investigações, foi elaborado um segundo teste estatítico multivariado em complemento ao univariado anteriormente apresentado aqui, considerando inicialmente a possibilidade de haver de fato dois táxons distintos como proposto por Bonvicino et al. (1995). Assim, na Análise de Componentes Principais elaborada empregou-se basicamente os mes-

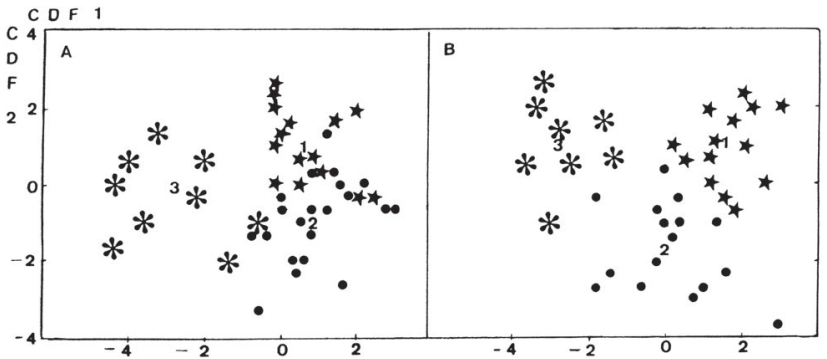

Figura 60. Gráfico mostrando o resultado da Análise Discriminante de função canônica elaborada por Bonvicino et al. (1995): (A) machos, (B) fêmeas. Os números entre os pontos indicam os centróides de: (1) A. macconnelli, (2) A. straminea, (3) A. seniculus segundo os autores.

mos espécimes que Bonvicino et al. e considerou-se os espécimes aprioristicamente pertencentes às duas espécies como sugerida pelos autores: A. macconnellii e A. straminea.

Elaborou-se um terceiro teste não relacionado à geografia, mas sim aos dois padrões mais freqüentes de morfologia da pelagem como delimitados aqui e descritos anteriormente, e que definem os táxons como reconhecido por alguns autores: pelagem dorsal dourada e faixa médio-dorsal ruiva-escura (Padrão 3) definindo A. straminea e coloração dorsal dourada brilhante sem a faixa médio-dorsal ou se presente, de forma incipiente (Padrão 1) e na qual define A. macconnelli. Esta análise teve a finalidade de testar se há uma relação entre as dimensões cranianas e do osso hióide com um padrão específico de coloração da pelagem, e conseqüentemente, inferindo uma distribuição simpátrica. Entre os machos, o teste $t$ evidenciou que as medidas significativamente diferentes entre as duas amostras e suas respectivas probabilidades (p) foram: largura zigomática (LZI) $(\mathrm{p}=0,03)$, altura craniana (ACR) $(\mathrm{p}=0,03)$, largura craniana (LCR), ( $p=0,06)$, largura condilar (LCO) $(p=0,023)$ e largura pós-orbital (LPO) $(p=0,03)$. Estes resultados indicam que os espécimes que apresentam a coloração da pelagem dorsal mais dourada também mostraram o crânio levemente mais largo que aqueles de pelagem dorsal com uma faixa escura distinta no dorso. As fêmeas se mostraram semelhantes mediante os testes estatísticos. Isto demonstra a tendência na diferenciação no eixo leste-oeste, mas sem uma distinção inqüívoca das populações.

A Análise de Componentes Principais (ACP) envolvendo os espécimes da margem norte do Rio Amazonas não distinguiu claramente duas populações e novamente os dados não sustentam o reconhecimento de duas entidades com base neste tipo de caráter. Os dados da ACP para os machos, incluindo 10 variáveis, estão plotados na tabela XXII. Nesta análise, os três primeiros CPs foram responsáveis por 58,7\%, 13,6\% e 8,7\% da variação total, respectivamente. A figura 61 ilustra o gráfico resultante desta análise incluindo os dois primeiros e principais CPs, sendo os espécimes representados por círculos denotando o que Bonvicino et al. (1995) consideraram A. straminea, 
Tabela XXII. Resultados da PCA em machos e fêmeas distribuídos ao norte do rio Amazonas. Os "eigenvalues" dos três PCs são 36,11, 9,14 e 6,43, respectivamente. Em negrito estão as variáveis que mais contribuíram para os Componentes Principais.

\begin{tabular}{|c|c|c|c|c|c|c|}
\hline \multirow{2}{*}{ Variáveis } & \multicolumn{3}{|c|}{ Machos } & \multicolumn{3}{|c|}{ Fêmeas } \\
\hline & PC1 & PC2 & PC3 & PC1 & PC2 & PC3 \\
\hline CCR & $-0,595$ & $-0,106$ & 0,537 & $-0,410$ & 0,557 & $-0,672$ \\
\hline LZI & $-0,360$ & $-0,093$ & $-0,471$ & $-0,481$ & $-0,262$ & 0,181 \\
\hline LIO & $-0,329$ & 0,000 & $-0,171$ & $-0,307$ & $-0,242$ & 0,008 \\
\hline CPA & $-0,298$ & 0,015 & 0,037 & $-0,266$ & 0,250 & 0,176 \\
\hline LCR & $-0,193$ & 0,182 & $-0,566$ & $-0,205$ & $-0,540$ & $-0,312$ \\
\hline LCO & $-0,075$ & $-0,014$ & $-0,088$ & $-0,090$ & $-0,073$ & $-0,009$ \\
\hline LMT & $-0,138$ & 0,914 & 0,174 & $-0,264$ & $-0,133$ & $-0,163$ \\
\hline LPO & $-0,241$ & 0,148 & $-0,216$ & $-0,071$ & $-0,387$ & $-0,306$ \\
\hline CMA & $-0,426$ & $-0,190$ & 0,145 & $-0,421$ & 0,140 & 0,250 \\
\hline APA & $-0,238$ & $-0,051$ & $-0,184$ & $-0,366$ & 0,107 & 0,421 \\
\hline CDS & & & & $-0,081$ & 0,037 & $-0,022$ \\
\hline LPA & & & & $-0,110$ & $-0,053$ & 0,164 \\
\hline
\end{tabular}

e o losango, A. macconnelli. Nela, nota-se que não é possível discernir com clareza dois táxons em qualquer eixo considerado, diferentemente da Análise Discriminante aplicada pelos autores com basicamente o mesmo conjunto de espécimes.

Os dados da ACP para as fêmeas, incluindo 12 variáveis, estão plotados na tabela XXII. Nesta análise, os três primeiros CPs foram responsáveis por 51,6\%, 13,1\% e 9,2\% da variação total, respectivamente. A figura 62 ilustra o gráfico resultante desta análise incluindo os dois primeiros e principais CPs e como nos machos, não há distinção suficiente para sustentar o reconhecimento de dois táxons. O que se nota, é que os espécimes representados por círculos, e cuja distribuição é a oeste do Rio Trombetas até o Rio Negro, mostram uma maior coesão que os demais no eixo do primeiro componente. Assim, conclui-se que mesmo mediante a aplicação da Análise Discriminante, que tem maior poder de separação de grupos pré-determinados [como conduzido aqui seguindo a proposta de Bonvicino et al. (1995)], não houve resultados suportanto a distinção em duas espécies para o Escudo Guiano.

A posição defendida no presente estudo em reconhecer apenas um táxon para a margem norte do Rio Amazonas, entre os Amapá e o Rio Negro, é corroborada pelos dados de Figueiredo et al. (1998). Os autores elaboraram um estudo filogeográfico com o objetivo de traçar as relações filogenéticas entre as populações de Alouatta (designados pelos autores como A. seniculus) que ocorrem no Escudo Guiano. Os autores incluíram as populações alvo que permitiram solver a mesma questão abordada aqui, ou seja, se há um ou dois táxons diagnosticáveis para aquela área. Figueiredo et al. (1998) empregaram o nucleotídeo COII do DNA mitocondrial e em ambas as análises, de distância ("Neighbor-Joining") e de parcimônia. Os re- sultados de ambas as análises evidenciaram que as populações do leste do Pará (margem esquerda do Rio Trombetas e Rio Jarí) e aquelas do oeste do mesmo Estado (margem direita do Rio Trombetas) e do Amazonas (Rio Uatumã) não se mostraram monofiléticas suportando dois clados distintos e portanto, impossibilitando o reconhecimento de dois táxons.

Em suma, os dados apresentados acima não sustentam o reconhecimento de dois táxons e portanto, a hipótese inicial é corroborada pelos testes e estudo de diversos complexos morfológicos e pelos dados moleculares da literatura (FIgUeiredo et al. 1998). Mesmo considerando toda a variação apresentada nos caracteres de pelagem, hióide e morfométricos, Alouatta macconnelli é facilmente diagnosticada quando comparada aos demais táxons de Alouatta que ocorrem no Brasil. Para fins práticos, comparou-se o táxon com aqueles vizinhos que também ocorrem na bacia Amazônica. Alouatta macconnelli difere de $A$. belzebul, na coloração dorsal da pelagem alaranjada a dourada em vez da negra e ruiva nas extremidades dos membros e cauda, como geralmente apresentada pela segunda espécie, ou mesmo quando o táxon apresenta a pelagem vermelha, é muito distinta do colorido alaranjado/dourado dorsal da primeira. Em adição, o osso hióide de $A$. macconnelli difere de $A$. belzebul na sua forma geral e principalmente, no desenvolvimento do tentório, sendo este maior e mais convexo na primeira espécie, conferindo-lhe uma abertura estreita e semicircular em vez de ampla e ovalada. Alouatta macconnelli difere de A. juara por este apresentar a coloração da pelagem completamente ruiva escura ou com a região das espáduas dourado escuro e opaco, contra a dourada-alaranjada brilhante dorsal da primeira. Alouatta macconnelli também apresenta a cauda completamente ruiva escura, pelo menos na sua porção final, enquanto em $A$. juara o terço apical é invariavelmetne ruivo claro a dourado. O tentório trapezoidal e a bula inflada com cornículos pontiagudos e vestigiais em A. macconnelli são notadamente distintos daquele de formas suaves com tentório ovaldado e uma borda ampla circundando lateralmente a abertura da câmara como apresentado em A. juara (ver descrição adiante). O dicromatismo sexual na pelagem, com machos ruivos escuros e fêmeas alaranjadas/douradas pálidas, registrado para $A$. puruensis inquestionavelmente a distingue de A. macconnelli. Em adição, o tentório de $A$. puruensis é acentuadamente curvado para o interior da câmara enquanto que em $A$. macconnelli a estrutura é inflada externamente. Comparações entre A. macconnelli e A. nigerrima já foram efetuadas na descrição do segundo táxon.

\section{História taxonômica}

A história nomenclatural de A. macconnelli é complexa, entremeada com a de $A$. seniculus (Linnaeus, 1766) e pelo uso do nome stramineus Humboldt, 1812 (sinônimo de A. caraya). Segundo LönNBERg (1941), BRISSON (1756: 9) foi o primeiro a descrever a forma de Alouatta que ocorre na Guiana Francesa, como "Simia seniculus, Cercopithecus barbatus saturate spadiceus. Cercopithecus maximus stentorosus". A descrição sucinta do autor não possibilita o reconhecimento preciso da espécie. Poste-

Revista Brasileira de Zoologia 23 (1): 64-144, março 2006 

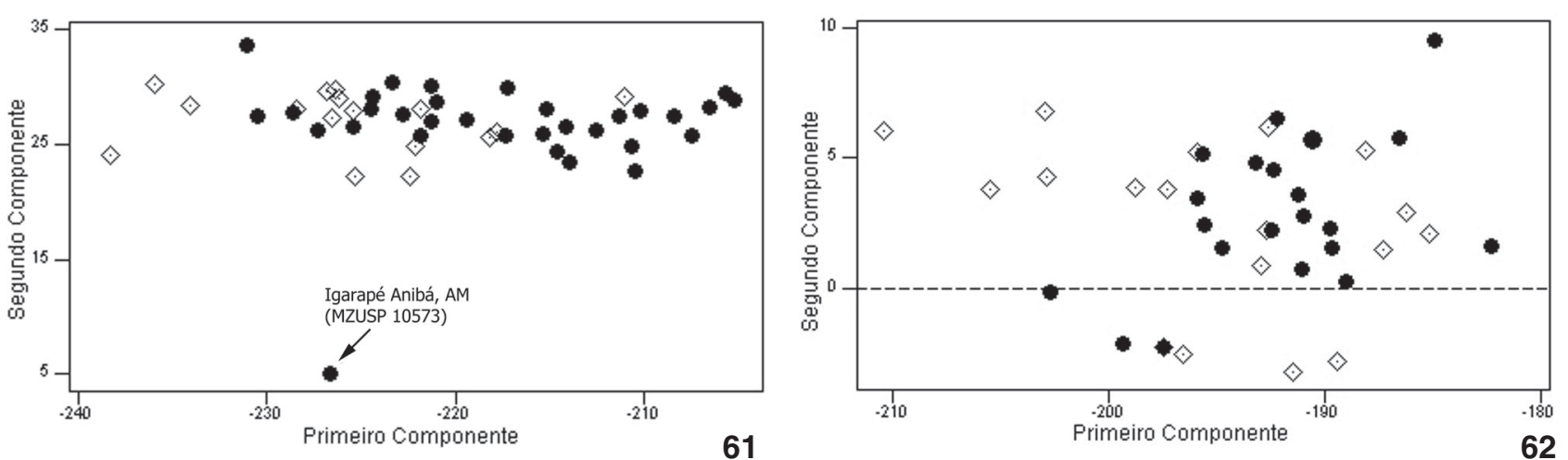

Figuras 61-62. Gráfico resultante da ACP incluindo espécimes machos (61) e fêmeas (62) representando, historicamente, A. macconnelli (losango) e A. straminea (círculos). O exemplar de Igarapé Anibá, como indicado, apresentou a largura e o comprimento craniano acima da média.

riormente, AUdebert (1797: 7) descreveu o mesmo táxon como: "Simia seniculus, caudata, barba rufa, cauda prehensili" e como sinônimo, o "L'Alouate" de Buffon. Apesar da descrição breve, o exame da figura 1 do trabalho de Audebert (1797) revelou que se trata de um animal de dorso e flancos dourados e membros ruivos, coincidindo com o padrão de coloração de $A$. macconnelli. Comparando os trabalhos acima com Linnaeus (1766), e analisando os exemplares da região Amazônica ocidental e oriental, nota-se que a espécie Simia seniculus de ambos, Audebert (1797) e Brisson (1756), e cuja proveniência é Cayenne, Guiana Francesa, não se trata da mesma Simia seniculus de Linnaeus (1766). Sendo assim, o nome S. seniculus fica restrito para designar apenas a espécie descrita por LinNAeus (1766) para a Colômbia e áreas próximas e cujo espécime na qual Linnaeus (1766) baseou sua descrição é proveniente de Cartagena, porção noroeste daquele país.

A confusão nomenclatural do táxon que ocorre no Escudo Guiano inicia com a descrição de Simia straminea Humboldt, 1812, com base em uma fêmea depositada no Museu de Paris a história da relação dos trabalhos de Humbold (1812) e Geoffroy SAint-Hilaire (1812), foi comentada anteriormente em A. caraya (Husson 1978, Rylands \& Brandon-Jones 1998). Humboldt (1812: 354) descreveu a espécie para as florestas do Grã-Pará, como: "Simia straminea, stentorosa, pilis basin versus subfuscis, apice straminei coloris. "Habite les forêts du Grand-Parà".

A partir das descrições de Humbold e Geoffroy Saint-Hilaire, ambas de 1812, autores posteriores não se preocuparam em conferir se straminea era a designação correta para os espécimes do Escudo Guiano. Neste caso, o espécime na qual Simia straminea foi descrita representa, de fato, uma fêmea da espécie conhecida para o Brasil central e há muito designada por $A$. caraya (ELLIOT 1913), e portanto, sinônimos com a prioridade do segundo nome porque ElLIOT o assim designou.

Elliot (1910) descreveu A. macconnelli a partir de um espécime depositado no Museu Britânico, e cuja coloração dorsal da pelagem é dourada clara de forma homogênea com os pêlos de base enegrecida, e diferindo de $A$. seniculus (Linnaeus, 1766), por não apresentar uma faixa sagital dorsal e os flancos ruivos escuros muito profundos. ElLIot (1910), assim como a maioria dos autores do XIX e início do XX, descreveu táxons baseado em amostras ínfimas, a maioria composta de um ou poucos exemplares, impossibilitando um estudo prévio da variação. Analisando a descrição de ElLIot (1910) e comparando-a com os dados do presente estudo, conclui-se que o padrão de coloração da pelagem do [holó]tipo faz parte do espectro de variação registrada para todas as populações do Escudo Guiano. O táxon foi praticamente esquecido após as obras de Tate (1939) e Cruz Lima (1945), ora considerado uma subespécie de $A$. seniculus, ora sinonimizada com ela (Hershrovitz 1949, Vieira 1955, Cabrera 1958, Husson 1957, Carvalho 1961, Hill 1962, Ávila-Pires 1964, Carvalho 1965, Coimbra-Filho 1990).

O estudo de Bonvicino et al. (1995) reacendeu a discussão sobre a validade dos táxons do complexo A. seniculus e teve como objetivo central testar a validade de A. macconnelli Elliot, 1910. Esta proposta de revalidação foi embasada na prerrogativa de que poderia haver dois táxons no Escudo Guiano, na área delimitada pelos Rios Orinoco e Negro: o táxon mais a leste seria uma forma com dimensões cranianas maiores além de diferenças citogenéticas e designada por A. macconnelli; do Rio Trombetas ao limite dos Rios Branco e Negro seria área de ocorrência de $A$. straminea, uma forma com crânio levemente menor. Bonvicino et al. (1995) basearam seu estudo inicialmente revalidando, ao nível específico, o táxon que ocorre por todo o Escudo Guiano (historicamente designada por A. seniculus straminea) e cuja pelagem, no geral, era mais dourada que $A$. seniculus, espécie que ocorre mais a oeste (segundo os autores, no Rio Juruá) e cuja coloração da pelagem dos membros é ruiva profunda e dorso levemente mais claro, mas nunca tão dourado e brilhante como os do Escudo Guiano. Em uma segunda etapa, os autores consideraram dois táxons para o Escudo Guiano como já definido acima. Bonvicino et al. (1995) basearam-se nos resultados de uma análise multivariada discrimi- 
nante para caracteres morfométricos e dados citogenéticos compilados do trabalho de Lima \& Seú́nez (1989) e Lima et al. (1990). As principais características apresentadas pelos autores para a separação dos dois grupos foram o tamanho maior e uma translocação cromossômica recíproca presente em A. macconnelli. Os autores propuseram que a característica citogenética atuaria como um fator de isolamento reprodutivo suficiente para impedir o fluxo gênico entre $A$. macconnelli e $A$. straminea. Contudo, as diferenças morfológicas entre as populações de Alouatta que ocorrem desde o Rio Negro até a costa do Estado do Amapá, de acordo com os dados apresentados aqui, apontam para uma tendência no processo de variação clinal no eixo leste-oeste da distribuição (para os machos), mas podendo ser interpretada também como uma variação em mosaico. De fato, os espécimes do Amapá tendem a ter uma maior freqüência de indivíduos mais dourados e claros (como o tipo de $A$. macconnelli), enquanto que os animais do extremo oposto tendem a serem mais escuros, mas ambos os padrões, além de outros como anteriormente descritos, ocorram ao longo de toda a distribuição do táxon. Aliado a isto, os dados biométricos plotados nas tabelas XIX e XX evidenciam, que apesar da tendência à diminuição gradativa no tamanho dos animais do Amapá para o Amazonas, não há uma interrupção evidente, e portanto, não houve diferenças morfométricas significativas entre as amostras quando relacionadas à geografia ou aos padrões de coloração da pelagem. Os resultados expressos no gráfico fornecido por Bonvicino et al. (1995) e reproduzidos aqui (Fig. 59) de certa maneira também corroboram os do presente estudo. O exame da figura mostra que há uma separação nítida, com a exceção de alguns indivíduos com grande dispersão, entre A. seniculus e A. straminea + A. macconnelli. Entretanto, o mesmo não pode ser aplicado aos dois últimos táxons. Embora haja uma modificação gradativa na forma dos crânios no sentido leste-oeste entre $A$. straminea e A. macconnelli, resultando em centróides separados, não há um hiato evidente entre os grupos como um todo o que questiona esta separação. Também não se pode atribuir às variações cromossômicas um suposto isolamento reprodutivo entre os dois táxons em discussão (M. LiMA, com. pes.), embora esta característica possa ser reconhecida como uma autapomorfia caso seja comprovada sua fixação nas populações do leste do Pará e Amapá (ver também Figueiredo et al. 1998, Oliveira et al. 2002). A confiança nos dados citogenéticos para definir a taxonomia deste complexo grupo precisa ser estabelecida mediante um estudo mais amplo de variação incluindo mais localidades no eixo leste-oeste, como já alertado por RyLAnDs \& Brandon-Jones (1998). Sendo assim, com base no nível acentuado de variação e ausência de uma diagnose precisa, estou desconsiderando a presença de dois táxons para o Escudo Guiano, prevalecendo o nome $A$. macconnelli.

Recentemente, Groves (2001a) sinonimizou A. macconnelli com A. insulanus Elliot, 1910, descrita com base no material proveniente de Quinam, Ilha de Trinidad, Venezuela, sendo o segundo táxon um sinônimo júnior. Embora os animais de Trinidad sejam avermelhados como o padrão 2 de coloração da pelagem descrito anteriormente, a tonalidade castanhoavermelhado dos espécimes da Ilha (designado pelo nome $A$. insulanus - ElLıт 1910) e depositados no Field Museum (FMNH 61855 de Saint Andrews e 61856-57 de Brickfield) são um tanto quanto distinto do avermelhado vivo dos animais amazônicos e portanto, esta sinonimização não é aceita aqui. Reforçando esta distinção na coloração da pelagem, o osso hióide de $A$. insulanus de Trinidad é semelhante ao de $A$. seniculus e $A$. juara, e muito distinto de A. macconnelli.

Embora a validade do referido táxon do Escudo Guiano esteja relativamente bem esclarecida, a nomenclatura empregada para a espécie merece algumas considerações. Como exposto anteriormente, $A$. straminea foi descrito com base em uma fêmea cuja ocorrência é o Brasil central (tradicionalmente referido como A. caraya - ver Rylands \& BRANDON-Jones 1998) e não se aplica a uma espécie amazônica. Assim, o nome disponível para a espécie do Escudo Guiano formalizado pelos autores e aceito até o momento (Groves 2001a) é A. macconnelli. Contudo, com o objetivo de esclarecer a identificação e a sinonimização correta de duas espécies descritas por Gray (1845), Mycetes laniger e M. auratus, RyLAnds \& Brandon-Jones (1998: 898) sugeriram que ambos pudessem ser sinônimos de A. macconnelli. De fato, Gray (1845: 219) descreveu primeiro Mycetes laniger como: "Reddish chestnut; middle of the back golden yellow; hair elongate, very soft and silk, dark Brown at the base, golden or chestnut at the tip, with a close under-fur of the head rather elongate. Inhab. Columbia".

Subseqüentemente, Gray (1845: 220) descreveu Mycetes auratus como: "Dark red chestnut-brown; back and sides golden yellow; hairs rather short and rigid, dark at the base; beard darker.....It is very like M. seniculus in colour and in the shortness and rigidness of the fur... Inhab. Brazils".

Observando as descrições, nota-se que ambos os táxons têm coloração ruiva por quase todo o corpo, excetuando o dorso amarelo-dourado. Entretanto, Mycetes laniger é proveniente da Colômbia e a análise do material daquele país (Anexo II) mostrou que os animais de fato apresentam o dorso dourado, mas com uma tonalidade mais escura que os animais do Escudo Guiano. Em adição, os animais da Colômbia têm os membros e cauda ruiva bem escura e opaca, que se estende para as regiões da nuca, espáduas e lombar, conferindo-lhe um manto escuro. Esta coloração da pelagem é coincidente com aquela que Rylands \& Brandon-Jones (1998) forneceram para o [holó]tipo de Mycetes auratus e um síntipo de Mycetes laniger. A somatória da coloração da pelagem e a origem colombiana do material tipo descartam a possibilidade de Mycetes laniger ser sinônimo sênior de $A$. macconnelli e ele deve ser sinonimizado com A. seniculus. A localidade-tipo de M. auratus foi esclarecida por Hill (1962) e Rylands \& Brandon-Jones (1998), que analisaram pessoalmente o [holó]tipo, e reconhecida por Groves (2001a) como Orinoco, Brazil. Embora saibamos que o Orinoco não percorre o território brasileiro, sua nascente está próxima à fronteira do Brasil, e pode ter sido uma referência mais ampla 
do coletor, muito comum naquela época. Neste sentido, a localidade-tipo de Mycetes auratus pode estar incluída na área mais oeste de ocorrência de A. macconnelli ou perifericamente a ela. Groves (2001a: 181) considerou Mycetes laniger e M. auratus como sinônimos dúbios de $A$. seniculus comentando que os tipos se parecem mais com A. macconnelli, mas propôs que fossem mantidos como incertae sedis. Pela descrição da pelagem de Mycetes auratus coincidente com a de $A$. seniculus, assume-se uma postura mais conservadora em considerá-los sinônimos e aceitar o nome A. macconnelli para o táxon do Escudo Guiano. Caso a sinonimização de $M$. auratus e A. macconnelli venha a se confirmar, o nome correto para designar a espécie em discussão deve ser Alouatta auratus (Gray, 1845) (A. RYLANDS, com. pes.).

\section{Alouatta juara Elliot, 1910 sp. rev.}

Alouatta senicula; Forbes, 1896: 192, partim.

Alouata [sic] seniculus; Trouessart, 1897: 32; 1904: 21, partim. -Ihering, 1904: 408.

Mycetes seniculus; Cabrera, 1900: 69; partim.

Alouatta juara Elliot, 1910: 80. Localidade-tipo: Rio Juara, Amazônia peruana (corrigida por IHERING, 1914, para o Rio Juruá, oeste da Amazônia brasileira). [Holó]tipo: British Museum ZD 1903.9.1.1 (pele, crânio e esqueleto), macho adulto (Elliot 1910, NAPIER, 1976). [Pará]tipo: British Museum ZD 1903.9.1.2 (pele, crânio, hióide e esqueleto), fêmea jovem (NAPIER, 1976). -Elliot, 1913: 283. -Lönnberg, 1947: 20.

Alouatta seniculus; Ihering, 1914: 252; nec Linnaeus (1766). Cabrera \& Yepes, 1940: 109; partim. -Chiarelli, 1972: 165; partim. -Napier, 1976: 83; partim. Saldanha, 1982: 77; partim. -Wolfheim, 1983: 228; partim. -Hirsch et al., 1991: 239; partim. -Groves, 1993: 255; partim.

Alouatta seniculus amazonica Lönnberg, 1941: 16. Localidade-tipo: Codajaz (= Codajás), margem esquerda do Rio Solimões, Estado do Amazonas. Descrição baseada em oito exemplares no Museu de História Natural de Estocolmo. -Hill, 1962: 124.

Alouatta seniculus juruana; Lönnberg, 1941: 18; emenda injustificada de Alouatta juara Elliot, 1910.

Alouatta seniculus seniculus; Hershkovitz, 1949: 384; partim. Mendez, 1953: 87; partim. -Cabrera, 1958: 157; partim. Hill, 1962: 118; partim. -Auricchio, 1995: 131; partim.

Alouatta seniculus juara; Cruz Lima, 1945: 77. -Vieira, 1948: 241; 1955: 383. -Carvalho, 1957: 4. -Hill, 1962: 124.

Alouatta jaura [sic]: Chiarelli, 1972: 166.

Alouatta seniculus joaraensis [sic]: Auricchio, 1995: 131.

\section{Material examinado (total 31)}

BRASIL: Acre: Taumaturgo: MPEG: 833-34 (p, c, h); Amazonas: Eirunepé: MZUSP: 5099 (p, c), 7114 (c), 10562 (c), 18940 (c), 18941 (p); Estirão do Ecuador: MPEG: 1606 (p, c, h), 1844 (p, c); Fonte Boa: MNRJ: 2418 (p, c, h), 21099 (p, c, h); Rio Juruá: MZUSP: 766 (p, c), 769 (p, c, h), 771-72 (c), 773 (p, c, h); Santa Cruz: MZUSP: 510 (p), 5102-03 (p, c), 5105 (p, c), 5106 (p), 5107-08 (p, c), 5257 (p), 7109 (c), 7111 (c), 10980-81 (c), 18942 (p, c); Lago Tracajá: MZUSP: 17540-41 (c).

\section{Localidade-tipo}

ElLiot (1910), ao descrever A. juara, forneceu como proveniência do material o Rio Juara [sic], Amazônia Peruana. Entretanto, o material analisado por ElLIot (1910) foi coletado por E. Garbe (Ihering 1904) e proveniente do Rio Juruá, Amazônia brasileira, como retificado por IHERING (1914: 252) e confirmado pela listagem da série-tipo por NAPIER (1976). Parte do material coletado por Garbe se encontra depositado no MZUSP.

\section{Distribuição geográfica}

Alouatta juara ocorre em toda a porção oeste da Amazônia brasileira, nos Estados do Acre e Amazonas (Fig. 43). O material analisado aqui é restrito às localidades ao sul do Rio Solimões e a oeste do Rio Purus. Caso se confirme a sinonimização de $A$. s. amazonica com A. juara como será visto adiante, a distribuição deverá ser estendida para a margem norte do Rio Solimões, em Codajás. Os espécimes de Oxapampa, Peru (Anexo II) podem ser referidos como A. juara, estendendo a distribuição do táxon além das fronteiras brasileiras.

\section{Caracteres diagnósticos}

Pelagem marrom-avermelhada escura com a região do manto e terço final da cauda ligeiramente mais clara, desde dourada a siena queimada (Fig. 45). Osso hióide nos machos com tentório convexo, completamente liso e de forma ovalada; cornículos inseridos em uma borda larga contornando lateralmente a abertura hióidea (Figs 63 e 65).

\section{Descrição geral}

As medidas cranianas e do osso hióide estão na tabela XXIII. Os adultos de ambos os sexos apresentam barba desenvolvida, ruiva-escura e enegrecida na região central. Pêlos da cabeça ruivos; ausência de topete. Coloração da pelagem na região do manto e lombar variando de ruiva escura a ruiva-amarelada opaca ou ligeiramente dourada; restante do dorso e os flancos de coloração ruiva escura a castanho (Fig. 45); pêlos dorsais com três faixas: região basal do pêlo ruiva escura, faixa mediana dourada e faixa apical novamente ruiva escura. Membros anteriores e posteriores com coloração ruiva escura nas suas regiões proximais (braços e coxas, respectivamente) escurecendo em direção às mãos e aos pés. Base da cauda de coloração ruiva escura tornando-se gradativamente dourada a partir da região mediana até o ápice. Animal com pelagem predominantemente ruiva escura.

Osso hióide com comprimento total de 52,8 a 71,6 mm $(\mathrm{N}=5)$. Tentório desenvolvido: 14,4 a 23,7 mm ( $=5)$, convexo e liso, conferindo-lhe a forma arredondada a ovalada (Figs 63 e 65). Cornículos inseridos em uma larga borda circundando lateralmente a abertura hióidea. Abertura da bula hióidea de forma semicircular. Bula hióidea formada por paredes lisas e inflada na região anterior aos cornículos. Os ossos nasais são curvos em perfil lateral. Osso hióide nas fêmeas adultas com comprimento total de 32,6 a 42,2 mm ( $\mathrm{N}=4)$. Tentório desenvolvido e liso: 7,6 a $19,2 \mathrm{~mm}(\mathrm{~N}=4)$. Cornículos desenvolvidos e de forma lanceolada. Abertura hióidea semicircular (Figs 65 e 67). Bula hióidea com paredes lisas e comprimida dorso-ventralmente.

\section{Revista Brasileira de Zoologia 23 (1): 64-144, março 2006}



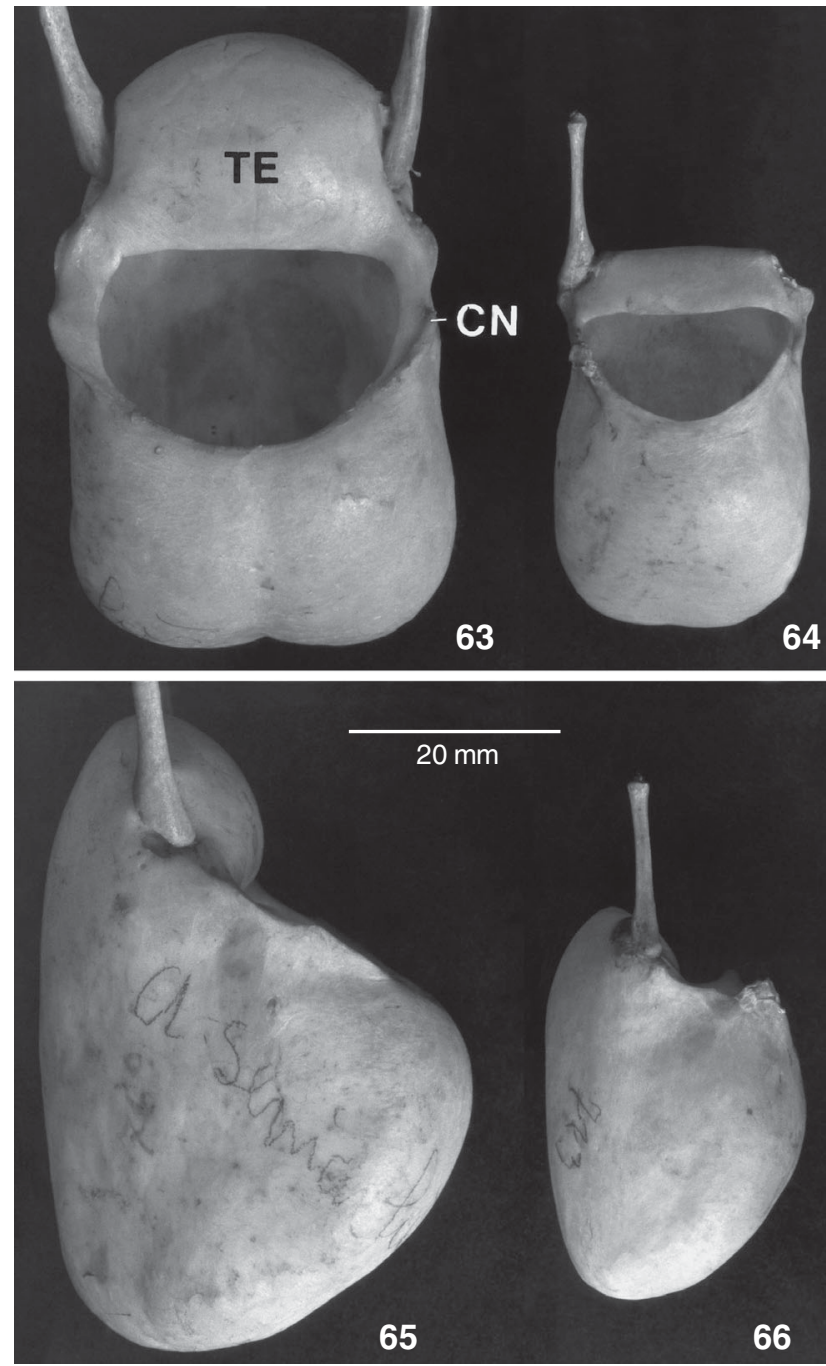

Figuras 63-66. Osso hióide de $A$. juara: (63 e 65) indivíduo macho (MZUSP 769) em vista ventral e lateral, respectivamente; (64 e 66) indivíduo fêmea (MZUSP 773) em vista ventral e lateral, respectivamente. Note o tentório liso, inflado e ovalado, e a borda ampla circundando a abertura hióidea semi-circular, que facilmente diferenciam a espécie de $A$. macconnelli (Fig. 56) e A. puruensis (Fig. 67, adiante). (CN) Cornículo, (TE) tentório.

Cariótipo. Segundo Lima \& SEú́nez (1991) o cromossomo de um único espécime analisado de Tefé, Amazonas, cuja proveniência coincide com a área de distribuição de $A$. juara, tem o sistema cromossômico semelhante ao de $A$. seniculus (Linnaeus, 1766) da Colômbia (Yunis et al. 1976, Bonvicino et al. 1995). Número diplóide variando de 43 a 45 de acordo com a presença de um, dois ou três micro-cromossomos, respectivamente. Cromossomo X acrocêntrico e o Y com dois braços, sem evidências de translocações nos cromossomos sexuais.
Tabela XXIII. Dados morfométricos ( $\mathrm{mm}$ ) de amostras de $A$. juara nos Estados do Amazonas e Acre, todas ao longo do Rio Juruá. Linha superior: média, desvio padrão e número de indivíduos analisados (em parênteses), respectivamente; linha inferior: mínimo e máximo.

\begin{tabular}{|c|c|c|}
\hline Variável & Macho & Fêmea \\
\hline \multirow[t]{2}{*}{ CCR } & $123,8 \pm 3,5(8)$ & $106,9 \pm 3,1(10)$ \\
\hline & $117,5-129,7$ & $101,0-110,7$ \\
\hline \multirow[t]{2}{*}{ CCB } & $111,4 \pm 3,7(8)$ & $94,3 \pm 2,1(10)$ \\
\hline & $105,8-115,8$ & $90,9-97,1$ \\
\hline \multirow[t]{2}{*}{ LZL } & $80,6 \pm 3,3(8)$ & $67,1 \pm 2,9(9)$ \\
\hline & $76,5-86,5$ & $61,8-70,2$ \\
\hline \multirow[t]{2}{*}{ LIO } & $62,3 \pm 1,9(8)$ & $55,8 \pm 1,8(10)$ \\
\hline & $60,3-65,4$ & $53,2-58,8$ \\
\hline \multirow[t]{2}{*}{ CPA } & $45,1 \pm 1,7(8)$ & $36,7 \pm 1,3(10)$ \\
\hline & $42,4-47,8$ & $34,5-39,2$ \\
\hline \multirow[t]{2}{*}{ ACR } & $39,6 \pm 0,9(8)$ & $38,4 \pm 1,3(10)$ \\
\hline & $38,9-40,8$ & $35,8-40,4$ \\
\hline \multirow[t]{2}{*}{ LCR } & $51,5 \pm 2,1(8)$ & $48,2 \pm 3,3(10)$ \\
\hline & $48,6-55,4$ & $41,1-51,7$ \\
\hline \multirow[t]{2}{*}{ LCO } & $23,5 \pm 0,9(8)$ & $22,1 \pm 0,9(10)$ \\
\hline & $22,5-25,0$ & $20,5-23,2$ \\
\hline \multirow[t]{2}{*}{ LMT } & $52,9 \pm 7,6(8)$ & $49,0 \pm 2,9(10)$ \\
\hline & $34,7-58,6$ & $43,0-54,0$ \\
\hline \multirow[t]{2}{*}{ LPO } & $40,0 \pm 2,1(8)$ & $41,0 \pm 2,0(10)$ \\
\hline & $37,2-43,5$ & $37,7-45,0$ \\
\hline \multirow[t]{2}{*}{ CMA } & $100,2 \pm 4,1(8)$ & $80,9 \pm 1,9(10)$ \\
\hline & $95,0-106,8$ & $76,7-79,5$ \\
\hline \multirow[t]{2}{*}{ APA } & $77,7 \pm 7,2(8)$ & $57,9 \pm 2,6(10)$ \\
\hline & $64,8-87,3$ & $52,7-61,3$ \\
\hline \multirow[t]{2}{*}{ CDS } & $43,8 \pm 1,3(8)$ & $367,0 \pm 1,3(9)$ \\
\hline & $41,0-45,0$ & $35,2-39,1$ \\
\hline \multirow[t]{2}{*}{ LMO } & $42,7 \pm 1,5(8)$ & $36,1 \pm 1,27(9)$ \\
\hline & $40,4-44,5$ & $34,1-38,1$ \\
\hline \multirow[t]{2}{*}{ LPA } & $25,5 \pm 1,7(8)$ & $21,3 \pm 1,9(10)$ \\
\hline & $22,6-27,4$ & $18,0-24,7$ \\
\hline \multirow[t]{2}{*}{$\mathrm{CHI}$} & $63,2 \pm 9,6(3)$ & $34,7 \pm 6,8(2)$ \\
\hline & $52,8-71,6$ & $32,6-42,2$ \\
\hline \multirow[t]{2}{*}{ LHI } & $42,7 \pm 3,4(3)$ & $25,7 \pm 2,1(2)$ \\
\hline & $40,0-46,6$ & $24,2-27,1$ \\
\hline \multirow[t]{2}{*}{ LTE } & $21,3 \pm 2,2(3)$ & $8,1 \pm 0,7(2)$ \\
\hline & $19,0-23,4$ & $7,6-8,6$ \\
\hline
\end{tabular}

\section{Variação}

A variação registrada para $A$. juara restringe-se à coloração da pelagem nas regiões dorsal e caudal, independe da procedência, idade ou sexo do animal. Entretanto, a baixa amostragem e a cobertura geográfica restrita podem estar su-

Revista Brasileira de Zoologia 23 (1): 64-144, março 2006 


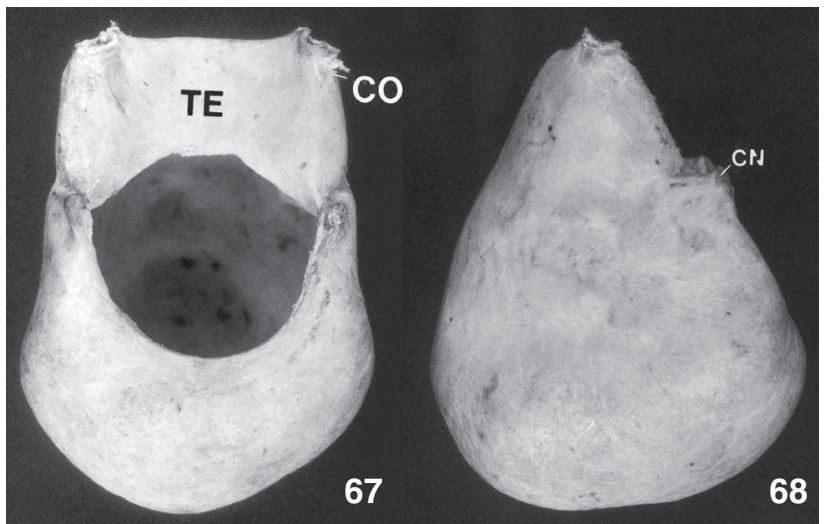

Figuras 67-68. Osso hióide de A. puruensis, indivíduo macho (MNR) 2773): (67) vista ventral; (68) vista lateral. Note o tentório liso e acentuadamente curvado para o interior da câmara. (CN) Cornículo, (CO) corno.

bestimando a variação entre os indivíduos ou populações desta espécie. O padrão de coloração dorsal encontrado na maioria dos indivíduos de $A$. juara é castanho-avermelhado escuro por todo corpo e clareando dorsalmente no eixo sagital, desde levemente dourado a siena queimada. Um indivíduo de Eirunepé (MZUSP 5257) e dois de Santa Cruz, Rio Eirú, (MZUSP 5099 e 18941) apresentaram dorso totalmente escuro sem a região médio-dorsal siena quiemada. A cauda, no geral, apresenta coloração ruiva escura na região basal tornando-se gradativamente mais clara até atingir a tonalidade dourada no terço apical. Em três indivíduos provenientes de Eirunepé (MZUSP 5257), Taumaturgo (MPEG 834) e Estirão do Ecuador (MPEG 1844), a cauda é ruiva escura por toda sua extensão sem o clareamento apical característico.

Para uma comparação objetivando definir morfometricamente $A$. juara, inicialmente aplicou-se o test $t$-Student em duas populações: uma representando A. juara e outra representando um táxon filogeneticamente próximo e de coloração da pelagem dourada com campos ruivos escuros, A. macconnelli, e cujos espécimes são provenientes da região Amazônica (Manaus, Estradas AM-01 e AM 10, Itacoatiara, Igarapé Anibá e Balbina). Escolheu-se estas localidades de A. macconnelli por serem as mais próximas longitudinalmente de $A$. juara, embora eles sejam provenientes da margem esqueda do Rio Amazonas. Uma terceira população comparada é proveneniente do Lago do Batista (margem leste do Rio Madeira), AM, e representa A. nigerrima. Não houve amostras suficientes para comparar $A$. juara com os espécimes representando $A$. puruensis: ambos os táxons apresentam distribuição peripátrica, com o segundo ocorrendo imediatamente à leste de A. juara, ao longo do Rio Purus.

Na primeira análise, comparando os dois táxons de pelagem ruiva/dourada ( $A$. juara e $A$. macconnellii), nota-se que os machos são estatisticamente diferentes em seis das 18 variáveis consideradas, enquanto as fêmeas foram divergentes em nove. Os machos de $A$. macconnelli foram maiores em ambos os eixos cranianos, o da largura e o do comprimento (axial), sugerindo que a maior dimensão craniana da espécie é generalizada. Por outro lado, das nove variáveis maiores nas fêmeas de A. macconnelli (Tab. XXIV), sete foram restritas à largura dos crânios entre ela e $A$. juara. Já na comparação entre $A$. juara e o táxon a leste, $A$. nigerrima, as fêmeas mostram muito menos variáveis se comparada à análise anterior.

Tabela XXIV. Resultado do test t-Student entre três espécies Amazônicas filogeneticamente próximas.

\begin{tabular}{|c|c|c|}
\hline \multirow{2}{*}{ Táxons } & \multicolumn{2}{|c|}{ A. juara } \\
\hline & Macho & Fêmea \\
\hline \multirow[t]{9}{*}{ A. macconnelli } & $\operatorname{CCR}(p=0,021)$ & $C C B(p=0,028)$ \\
\hline & CCB $(p=0,000)$ & LIO $(p=0,038)$ \\
\hline & LIO $(p=0,019)$ & $\mathrm{CPA}(p=0,010)$ \\
\hline & $\operatorname{LCO}(p=0,005)$ & $\operatorname{LCR}(p=0,000)$ \\
\hline & LPO $(p=0,027)$ & $\operatorname{LCO}(p=0,026)$ \\
\hline & LHI $(p=0,006)$ & LMT $(P=0,039)$ \\
\hline & & $\mathrm{LPO}(\mathrm{P}=0,025)$ \\
\hline & & $\operatorname{LPA}(P=0,023)$ \\
\hline & & $\mathrm{LHI}(\mathrm{P}=0.048)$ \\
\hline \multirow[t]{6}{*}{ A. nigerrima } & $\operatorname{CCR}(p=0,022)$ & $C C B(P=0,001)$ \\
\hline & $C C B(p=0,000)$ & $\mathrm{CPA}(\mathrm{P}=0,005)$ \\
\hline & $\mathrm{LIO}(p=0,000)$ & $\operatorname{LCR}(P=0,009)$ \\
\hline & $\mathrm{CPA}(\mathrm{p}=0,042)$ & $\operatorname{LMO}(P=0,044)$ \\
\hline & $\operatorname{LCR}(p=0,032)$ & \\
\hline & $\operatorname{CDS}(p=0,013)$ & \\
\hline
\end{tabular}

BonCicino et al. (1995) também definiram morfometricamente o táxon (os autores o denominaram, como historicamente tem sido feito, de $A$. $S$. seniculus) quando o compararam com $A$. macconnelli do Escudo Guiano mediante uma Análise Discriminante (Fig. 60). Assim, as divergências na morfologia e dimensões cranianas e hióideas, adicionadas à coloração única da pelagem e ao cariótipo distinguem facilmente esta espécie de $A$. macconnelli e $A$. nigerrima. De fato, $A$. juara se diferencia de $A$. macconnelli, por esta segunda apresentar a coloração da pelagem dorsal e lateral alaranjada/dourada brilhante em vez de ruivaescura, mostrar a cauda ruiva escurecendo na extremidade apical enquanto que em $A$. juara a estrutura é escura na base e clareando até atingir o siena queimado ou dourado apical e por fim, $A$. macconnelli tem o tentório trapezoidal, em vez de arredondado e convexo com em A. juara. Em adição, as diferenças citogenéticas dos dois táxons, tais como as taxas nos cromossomos com dois braços e o tamanho relativo dos cromossomos demonstrado por Lima \& SeuÁnez (1991) fortalecem a separação dos táxons e a validade de $A$. juara como espécie. 
Comparação com espécimes do oeste amazônico. Para a confirmação da identidade e diagnose precisa de $A$. juara, houve a necessidade de compará-la a outras formas descritas para o oeste e sudoeste amazônico, tais como A. seniculus sara, A. puruensis e $A$. fusca beniensis, e também espécimes representando a típica $A$. seniculus, táxons cuja validade e nível hierárquico estão para serem esclarecidos. A análise de caracteres qualitativos de vasto material depositado no AMNH e FMNH provenientes do Peru, Venezuela, Colômbia e Bolívia mostrou padrões de pelagem e morfologia hióidea bem definidos localmente, e estes caracteres em adição aos cromossômicos, quando vistos em conjunto, podem definir e validar alguns táxons descritos na literatura, assim como inferir sobre suas relações de parentesco. A tabela XXV mostra uma breve diagnose comparativa das espécies reconhecidas aqui para o território brasileiro e táxons usualmente reconhecidos para o oeste e norte da América do Sul na literatura.

Em termos de coloração da pelagem, inicia-se a comparação definindo A. seniculus com base em espécimes provenientes da Colômbia (Anexo II), cujo dorso é dourado escuro opaco, com os membros, cauda, cabeça, barba e o manto invadidos pela coloração ruiva escura a castanho. A coloração da cauda muda de tonalidade em direção ao seu ápice, de forma que o terço final se torna dourado. Assim, esta coloração dorsal difere de $A$. juara que a apresenta o dorso completamente ruivo-escuro ou quando há áreas douradas, estas se restringem a uma pequena porção na região entre as espáduas e de forma não marcante (Fig. 45), embora a cauda em A. juara mantenha a coloração como em A. seniculus. Neste sentido, ambos os táxons são considerados distintos e o nome $A$. seniculus não deve ser aplicado aos animais do Rio Juruá tampouco para outros táxons do sudoeste amazônico. Registrou-se o mesmo padrão de coloração da pelagem de A. juara para os espécimes peruanos de Santa Elena, (FMNH 86943 a 86948), Cerro Azul (FMNH 86949-950 e 122788122789), Yarinacocha (FMNH 55504-55505) e La Divisória (FMNH 64277), todos do Departamento de Loreto, e Itahuania, Departamento de Madre de Dios (FMNH 84215) (Anexo II), estendendo a distribuição de $A$. juara para fora do Brasil.

O osso hióide das populações em torno do Rio Juruá ( $A$. juara) e da Colômbia (A. seniculus) também mostram a mesma morfologia, mas infelizmente não há material disponível de Loreto, Peru. Neste caso, os hióides de todos os espécimes analisados apresentam a câmara principal com a inflação mais suave lateral (Figs 63 e 65) e ventralmente, diferentemente de $A$. macconnelli, $A$. puruensis e $A$. nigerrima. O tentório é liso, arredondado e convexo, diferentemente de qualquer táxon de Alouatta, cuja estrutura tem a forma retangular ou trapezoidal. Também, a lateral do osso apresenta, na maioria dos espécimes, uma borda laminar ampla circundando lateralmente a abertura hióidea que tende a ser maior que nas demais espécies relacionadas, e cujos cornículos são posicionados lateralmente à abertura hióidea, vestigiais e pontiagudos, e a abertura é claramente semicircular. Assim, a coloração da cauda ruiva escura com o terço apical mais claro e a morfologia hióidea semelhantes entre $A$. juara e $A$. seniculus inferem que ambos os táxons são filogeneticamente próximos.

Espécimes de Beni, Bolívia, e aqueles de Oxapampa, Peru, áreas próximas ao Rio Juruá, mostraram semelhanças na coloração da pelagem e na morfologia do osso hióide e são distintos de A. juara. A coloração da pelagem dos espécimes de Beni é castanho-avermelhado homogeneamente distribuída por todo o corpo, com a região médio-dorsal levemente mais clara, mas nunca atingindo o dourado de $A$. macconnelli ou mesmo de $A$. juara. Os membros, cauda e lateral do corpo são marrons-avermelhados e não atingem o grau de saturação escura como registrado para $A$. juara ou A. seniculus. O tentório é trapezoidal, largo e acentuadamente curvado para o interior da câmara. Assim, os espécimes descritos acima são característicos desta região de Beni e podem definir $A$. $f$. beniensis e não devem ser sinonimizados com $A$. juara. Este padrão de coloração dos animais de Beni demonstra que a tonalidade da pigmentação da pelagem é diferente daquele registrado para $A$. fusca ou A. clamitans, mesmo considerando a elevada variabilidade da última espécie, e portanto, se válida ou não, A. fusca beniensis é mais estritamente relacionada ao complexo A. seniculus (Tab. I) e não a $A$. fusca ou $A$. clamitans como historicamente aceito (HiLl 1962). Em adição às diferenças na tonalidade castanho-avermelhado da pelagem, os espécimes de Beni mostram um osso hióide completamente diferente dos animais da costa Atlântica, por possuírem um tentório característico como já descrito. Esta morfologia hióidea foi registrada também para os espécimes de Rondônia, área de distribuição de $A$. puruensis reforçando a relação distante entre $A$. clamitans e $A$. $f$. beniensis. O dicromatismo sexual ímpar de $A$. puruensis a distingue de $A$. f. beniensis.

A posição geográfica de $A$. $f$. beniensis próxima aos táxons do complexo $A$. seniculus também faz mais sentido do que o considerável hiato geográfico entre a primeira e $A$. fusca (e $A$. clamitans). É importante ressaltar que, excetuando A. belzebul, nenhuma linhagem monofilética em Alouatta (espécies, subespécies) mostrou distribuição amplamente disjunta. De fato, $A$. belzebul apresenta populações no extremo oriental da Floresta Amazônica e na costa Atlântica do Nordeste brasileiro, e o hiato separando estas populações e formado pela Caatinga/Cerrado é sabidamente recente (VIVo 1997), com muitas ilhas de mata úmida conectando ambos ecossistemas florestais. Por outro lado, as dimensões do hiato separando $A$. f. beniensis de $A$. fusca e $A$. clamitans são bem maiores e não há corredores florestais descritos que possam ligar no presente ou terem conectados estas populações via Brasil Central em tempos pretéritos. A outra rota conhecida de dispersão de mamíferos ao longo dos Andes em direção ao Paraguai e penetrando na Floresta Atlântica via as matas semidecíduas do interior do Mato Grosso do Sul e São Paulo, como ocorre em Callicebus (Hershrovitz 1988), é improvável para Alouatta. Neste caso, não há registro de populações do grupo $A$. fusca em áreas ao sul de Beni, atuando nesta conecção sudoeste Amazônico-Floresta Atlântica.

Revista Brasileira de Zoologia 23 (1): 64-144, março 2006 
Tabela XXV. Diagnose comparativa de alguns táxons historicamente reconhecidos para a Amazônica e relacionados ao complexo A. seniculus. Os quatro primeiros caracteres referem-se sempre à coloração da pelagem em áreas específicas e os demais à forma das estruturas hióideas. * Táxons que ocorrem no Brasil e reconhecidos no presente estudo.

\begin{tabular}{|c|c|c|c|c|c|c|c|}
\hline Caráter & A. seniculus & A. juara* & A. f. beniensis & A. puruensis* & A. insulanus & A. macconelli* & A. nigerrima* \\
\hline Membros & Ruivos escuros & Ruivos escuros & $\begin{array}{l}\text { Castanho-aver- } \\
\text { melhados }\end{array}$ & $\begin{array}{l}\text { Macho: ruivos } \\
\text { escuros; fêmea: } \\
\text { ruivos claros }\end{array}$ & $\begin{array}{l}\text { Castanho-aver- } \\
\text { melhados }\end{array}$ & $\begin{array}{l}\text { Ruivos, claros a } \\
\text { escuros }\end{array}$ & Negros \\
\hline Cauda & $\begin{array}{l}\text { Ruiva escura } \\
\text { com ápice } \\
\text { dourado }\end{array}$ & $\begin{array}{l}\text { Ruiva escura } \\
\text { com ápice } \\
\text { dourado }\end{array}$ & $\begin{array}{l}\text { Castanho-aver- } \\
\text { melhado }\end{array}$ & $\begin{array}{l}\text { Macho: ruiva } \\
\text { escura; fêmea: } \\
\text { ruiva clara }\end{array}$ & $\begin{array}{l}\text { Castanho-aver- } \\
\text { melhado }\end{array}$ & $\begin{array}{l}\text { Ruiva clara a } \\
\text { escura }\end{array}$ & Negra \\
\hline $\begin{array}{l}\text { Região médio- } \\
\text { dorsal }\end{array}$ & Dourada opaca & $\begin{array}{l}\text { Ruiva escura a } \\
\text { marrom }\end{array}$ & $\begin{array}{l}\text { Castanho-aver- } \\
\text { melhado a } \\
\text { levemente } \\
\text { dourada }\end{array}$ & $\begin{array}{l}\text { Macho: ruiva } \\
\text { escura; fêmea: } \\
\text { dourada }\end{array}$ & $\begin{array}{l}\text { Castanho-aver- } \\
\text { melhado }\end{array}$ & $\begin{array}{l}\text { Dourada } \\
\text { brilhante }\end{array}$ & Negra \\
\hline $\begin{array}{l}\text { Nuca e } \\
\text { espáduas }\end{array}$ & Ruiva escura & $\begin{array}{l}\text { Ruiva escura a } \\
\text { levemente } \\
\text { dourada }\end{array}$ & $\begin{array}{l}\text { Castanho-aver- } \\
\text { melhado }\end{array}$ & $\begin{array}{l}\text { Macho: ruiva } \\
\text { escura; fêmea: } \\
\text { dourada }\end{array}$ & $\begin{array}{l}\text { Castanho-aver- } \\
\text { melhado }\end{array}$ & $\begin{array}{l}\text { Dourada a } \\
\text { levemente ruiva }\end{array}$ & Negra \\
\hline Tentório & $\begin{array}{l}\text { Ovalado e } \\
\text { convexo }\end{array}$ & $\begin{array}{l}\text { Ovalado e } \\
\text { convexo }\end{array}$ & $\begin{array}{l}\text { Trapezoidal e } \\
\text { curvado } \\
\text { internamente }\end{array}$ & $\begin{array}{l}\text { Trapezoidal e } \\
\text { curvado } \\
\text { internamente }\end{array}$ & $\begin{array}{l}\text { Ovalado e } \\
\text { convexo }\end{array}$ & $\begin{array}{l}\text { Trapezoidal e } \\
\text { levemente } \\
\text { convexo }\end{array}$ & $\begin{array}{l}\text { Trapezoidal e } \\
\text { levemente } \\
\text { convexo }\end{array}$ \\
\hline $\begin{array}{l}\text { Abertura } \\
\text { hióidea }\end{array}$ & Arredondada & Arredondada & Semi-circular & Semi-circular & Arredondada & Semi-circular & Semi-circular \\
\hline $\begin{array}{l}\text { Lateral da } \\
\text { abertura } \\
\text { hióidea }\end{array}$ & $\begin{array}{l}\text { Placa laminar } \\
\text { larga }\end{array}$ & $\begin{array}{l}\text { Placa laminar } \\
\text { larga }\end{array}$ & $\begin{array}{l}\text { Pequeno } \\
\text { cornículo } \\
\text { pontiagudo }\end{array}$ & $\begin{array}{l}\text { Pequeno } \\
\text { cornículo } \\
\text { pontiagudo }\end{array}$ & $\begin{array}{l}\text { Placa laminar } \\
\text { larga }\end{array}$ & $\begin{array}{l}\text { Pequeno } \\
\text { cornículo } \\
\text { pontiagudo }\end{array}$ & $\begin{array}{l}\text { Pequeno } \\
\text { cornículo } \\
\text { pontiagudo }\end{array}$ \\
\hline
\end{tabular}

\section{História taxonômica}

A história taxonômica e nomenclatural de $A$. juara está intimamente relacionada àquela de $A$. seniculus da Colômbia. Linnaeus (1766) descreveu Alouatta seniculus como um animal de barba e corpo ruivos e cauda preênsil. A proveniência do material foi Cartagena, região noroeste da Colômbia. Após LinNAEus, os táxons do oeste da Amazônia foram sempre referidos por A. seniculus, embora outras espécies e subespécies tenham sido descritas, a maioria de validade duvidosa, tais como: Stentor chrysurus Geoffroy Saint-Hilaire (1828), A. s. rubicunda Allen, 1904, A. s. caucensis Allen, 1904, A. s. bogotensis Allen, 1914 e A. s. caquetensis Allen, 1914. A análise de material proveniente de várias áreas da Colômbia (Anexo II) e dados da literatura mostram que estes táxons são sinônimos subjetivos juniores de A. seniculus.

Dentre os muitos táxons criados naquela época, está Alouatta juara Elliot, 1910, diagnosticado pela coloração dourada escurecendo suavemente para um ruivo a marrom nos flancos, braços e pernas, sem delimitação clara entre o castanho-avermelhado e ou vermelho-dourado mais claro. A cauda apresenta coloração ruiva escura na base, clareando gradativamente até o ápice. A localidade-tipo fornecida pelo autor é o Rio Juara, na Amazônia Peruana. Posteriormente Ihering (1904) discorreu sobre a procedência do material analisado por ELliot (1910) e concluiu que este provém do Rio Juruá, oeste da Amazônia brasileira (IHERING 1914). A convicção de Ihering de que o material provinha do Rio Juruá está embasada no fato do material analisado por ElLiot (1910) ter sido coletado por E.
Garbe, sendo que este nunca esteve no Peru, mas sim na Amazônia ocidental brasileira. Para corroborar o discutido acima, IHeRING (1904) já havia registrado espécimes, a qual ele denominou de A. seniculus, para o Rio Juruá e com as características coincidentes daqueles que Elliot (1910) descreveu sua nova espécie.

Posteriormente, LÖNNBERG (1941) considerou A. juara ao nível subespecífico. O autor mudou tanto o nível hierárquico do táxon como sua grafia para A. seniculus juruana, alteração baseada na procedência do material indicada por IHERING (1914), o Rio Juruá. Esta mudança proposta por LÖNNBERG (1941) não tem fundamento nomenclatural, pois o nome $A$. juara foi criado intencionalmente para designar um táxon novo independente do nome correto da localidade-tipo, no caso, o Rio Juruá (e não Juara), caracterizando um caso de emenda injustificada que fere as regras do artigo 33.2 do Código Internacional de Nomenclatura Zoológica (1999). Recentemente, Groves (2001a) reconheceu, dentre os poucos táxons válidos da politípica $A$. seniculus, A. s. juara, e como sinônimos o A. s. puruensis e A. s. amazonica, ambos descritos por LÖNNBERG (1941).

LÖNNBERG (1941), na descrição das várias formas do complexo A. seniculus para a Amazônia brasileira, incluiu espécimes provenientes da margem norte do Rio Amazonas (referidos aqui por A. macconnelli), animais do sudoeste amazônico (referidos pelo autor como A. seniculus juruana) e espécimes de uma localidade intermediária, Codajás, Amazonas. Esta localidade está na margem norte do Rio Solimões e a oeste do Rio Negro. Ao descrever os espécimes, LöNNBERG (1941) notou que 
a pelagem era mais clara que aquela dos espécimes do Rio Juruá e mais escura que a dos indivíduos da margem oposta do Rio Negro, exceto por um macho juvenil de coloração branca amarelada que o autor designou como uma forma albina. Assim, pela coloração e posição geográfica intermediárias, LÖNNBERG (1941) considerou os espécimes de Codajás como uma forma única designando-os por uma nova subespécie, $A$. seniculus amazonica. Nota-se que LönNBERG (1941), ao longo de toda descrição comparativa de seu novo táxon sempre o comparou com a subespécie do Rio Juruá e não com os espécimes típicos de $A$. seniculus do noroeste da Colômbia tampouco de forma mais detalhada com os do leste do Rio Negro ou com as do Rio Purus. De fato, segundo Lönnberg (1941), os animais de Codajás apresentavam uma coloração da pelagem mais ricamente saturada de vermelho a marrom e não o dourado claro brilhante de $A$. macconnelli. Nestes termos, representa que $A$. s. amazonica poderia ser um sinônimo júnior de $A$. juara, em condordância com Groves (2001a).

Contudo, há discrepância entre a descrição de LÖNNBERG (1941) para A. seniculus amazonica e um espécime de Codajás depositado no Museu Britânico (ZD 1977.59), mencionado por Rylands \& BRANDON-Jones (1998: 90) como sendo dourada (laranja) pálida (“..pelage orange skin from Codajaz, Brazil, indicates the presence of a uniformly pale-pelaged population within this area"). Na lista dos primatas do British Museum, NAPIER (1976) não menciona este espécime mas a posição de RYLANDS \& BRANDON-Jones (1998) é que haveria uma população dourada pálida naquela porção do Rio Solimões. Por outro lado, os autores negligenciaram a descrição de LÖNNBERG (1941) sobre a variação na coloração da pelagem, e suas decisões taxonômicas e nomenclaturais, se A. straminea (Gumilla, 1758) ou A. seniculus amazonica Lönnberg, 1941, são inconclusivas. Não foi possível analisar espécimes de Codajás ou áreas próximas e com base nestes relatos da literatura, torna-se evidentemente difícil tomar qualquer decisão taxonômica a respeito desta população de Alouatta. Mas certamente que pela descrição detalhada e confiável de LÖNNBERG (1941) e o espécime dourado-pálido ZD 1977.59, fica patente a considerável variação na coloração da pelagem dos espécimes de Codajás.

\section{Alouatta puruensis Lönnberg, 1941 comb. nov.}

Alouatta seniculus puruensis Lönnberg, 1941: 16. Localidade-tipo: Jaburu, Rio Purus, Estado do Amazonas. Lectótipo: NRM A63 1217 (designado aqui) no Museu de História Natural de Estocolmo. -Cruz Lima, 1945: 76. -Carvalho, 1952: 22. -Vieira, 1955: 383. -Hill, 1962: 125.

Alouatta seniculus seniculus: Cabrera, 1958: 157; partim.

Alouatta seniculus: Napier, 1976: 83; partim. -Wolfheim, 1983: 228; partim. -Hirsch, 1991; partim.

\section{Material examinado}

Total 11. BRASIL, Acre: Plácido de Castro: MZUSP: 7333-34 (p); Sena Madureira: MNRJ: 23147 (p, c); Xapuri: MNRJ: 23145 (c), 23148 (c); Mato Grosso: Aripuanã: MPEG: 19707 (p, c, h);
Rondônia: Jamari: MNRJ: 2392-93 (p), 2773-74 (p, c, h). Santa Cruz: AMNH: 211544 (c, h).

\section{Localidade-tipo}

Ao descrever A. s. puruensis, LönnBERG (1941) não designou holótipo, fornecendo apenas os pontos de coleta dos exemplares, todos próximos ao Rio Purus, Estado do Amazonas: Igarapé do Castanha, Jaburú, Lábrea, Arumã e Rio Purus. Designa-se aqui o lectótipo e paralectótipos baseados nos espécimes analisados por LÖNNBERG (1941) para a descrição do táxon. Os dados adicionais sobre os espécimes foram fornecidos pelo Museu Sueco de História Natural. O espécime escolhido como lectótipo e proveniente de Jaburú, se deve ao fato de LöNNBERG (1941) ter coletado um macho e uma fêmea no local, confirmando o dicromatismo sexual diagnóstico da espécie. A designação do lectótipo aqui visa formalizar o espécime-referência que contém as características que definem Alouatta puruensis e no qual o nome se apóia.

Lectótipo: NRM A63 1217 (número original 1217), macho (adulto, segundo descrição original), coletado em 10 de dezembro de 1935 por A. M. Olalla. Material em boas condições, composto por crânio, pele e esqueleto com os ossos das mãos e pés na pele. Localidade-tipo: Jaburú (Rio Purus) (05³6'S$\left.64^{\circ} 03^{\prime} \mathrm{W}\right)$, Estado do Amazonas, Brasil. Dimensões externas e cranianas (transcritas de LÖNNBERG 1941): comprimento total do crânio: 124 mm; comprimento ocipto-nasal: 105 mm; comprimento côndilo-basal: 113,5 mm; constrição interorbital: 14 mm; largura da caixa craniana: $52 \mathrm{~mm}$; largura zigomática: 81 mm; comprimento do palato: 43,5 mm; comprimento da série de molares superiores: $36 \mathrm{~mm}$; comprimento da série de molares inferiores: $42 \mathrm{~mm}$; comprimento dos nasais: $21 \mathrm{~mm}$.

Paralectótipo: NRM A62 1239 (número original: 1239), fêmea subadulta (adulta, segundo descrição original), coletada em 16 de dezembro de 1935. Material: crânio, pele e esqueleto com os ossos das mãos e pés na pele. Localidade: Jaburú (Rio Purus), Estado do Amazonas, Brasil. NRM A62 1150 (número original 1150), fêmea adulta, coletada em 10 de dezembro de 1935 (coletado em 12 de dezembro, segundo descrição original). Material: crânio, pele e esqueleto com os ossos das mãos e pés na pele. Localidade: Igarapé do Castanha, Rio Purus (aproximadamente $03^{\circ} 52^{\prime} \mathrm{S}-61^{\circ} 23^{\prime} \mathrm{W}$ ), Estado do Amazonas, Brasil. NRM A62 1159 (numeração original: 1159), macho adulto, coletado em 25 de outubro de 1935. Material: crânio, pele e esqueleto com os ossos das mãos e pés na pele. Localidade: Arumã, Rio Purus $\left(04^{\circ} 44^{\prime} \mathrm{S}-62^{\circ} 08^{\prime} \mathrm{W}\right)$, Estado do Amazonas, Brasil. NRM A62 1256 (numeração original 1256), macho adulto, coletado em 27 de dezembro de 1935. Material: crânio, pele e esqueleto com os ossos das mãos e pés na pele. Localidade: Labrea, Rio Purus (07 $\left.16^{\prime} \mathrm{S}-64^{\circ} 47^{\prime} \mathrm{W}\right)$, Estado do Amazonas, Brasil.

\section{Distribuição geográfica}

A figura 43 mostra que $A$. puruensis ocorre ao longo de todo Rio Purus, em ambas as margens, e nas regiões adjacentes, no alto Rio Madeira, Estado de Rondônia. A localidade mais ao sul da espécie é Plácido de Castro, Acre.

Revista Brasileira de Zoologia 23 (1): 64-144, março 2006 


\section{Caracteres diagnósticos}

Dicromatismo sexual presente: coloração da pelagem nos machos ruiva escura com o dorso levemente dourado; fêmea com a coloração da cabeça, cauda, membros ruivos claros, quase alaranjados, e dorso dourado pálido, mas brilhante (Figs 46 e 47). Osso hióide nos machos com tentório trapedoizal e acentuadamente curvado para o interior da câmara (Figs 67 e 68).

\section{Descrição geral}

Coloração da pelagem, no macho adulto, ruiva escura homogênea por todo o corpo, exceto na região médio-dorsal, com matizes ruivos mais claros; base dos pêlos nesta região ruiva escura e pontas douradas (Fig. 46). A região apical da cauda também pode apresentar uma coloração mais clara, de tonalidade dourada. A coloração ruiva escura nunca atinge o padrão castanho-avermelhado escuro. Fêmea com barba rala, ruiva clara escurecendo posteriormente à orelha e na cabeça; pelagem dorsal e lateral dourada clara pálida e brilhante; membros anteriores ruivos claros, de tonalidade alaranjada, escurecendo na região do antebraço e nas mãos (Fig. 47); membros posteriores ruivos claros na região da coxa, escurecendo em direção distal, onde atinge uma tonalidade ruiva profunda, quase marrom, nos pés. Cauda ruiva-amarelada, de tonalidade alaranjada. Jovem com barba rala e negra; membros anteriores, posteriores e cauda de coloração ruiva escura; dorso mais claro que as regiões adjacentes do corpo, porém nunca dourado.

Os dois espécimes machos analisados e provenientes de Rondônia (MNRJ 2773, Jamari, e AMNH 211544, Santa Cruz) apresentram ossos hióides desenvolvidos, bem diferentes de qualquer táxon que ocorre no Brasil: a câmara hióide é medianamente desenvolvida, mas o tentório mostra uma morfologia ímpar por ser quadrangular, completamente liso e curvado para o interior da câmara (Figs 67 e 68). O estudo do hióide dos dois espécimes supracitados mostra que eles são desenvolvidos: no espécime de Jamari, o comprimento total do osso é $55,0 \mathrm{~mm}$ e o tentório $14,4 \mathrm{~mm}$; os cornículos são reduzidos e pontiagudos com a região anterior de inserção levemente inflada. Os cornos são reduzidos e inflados na região anterior. $\mathrm{O}$ interior do osso apresenta poucas trabéculas. Os ossos nasais são curvos em vista lateral.

\section{Variação}

O estudo de variação em $A$. puruensis é prejudicado pela baixa amostragem do material analisado $(\mathrm{N}=11)$. No entanto, o material analisado adicionado às descrições de LÖNNBERG (1941) e HiLl (1962) não indicam a presença de variação geográfica de nenhuma sorte para a espécie. Apesar da fêmea de A. puruensis proveniente de Plácido de Castro (MZUSP 7333) ter semelhança com A. macconnelli, por possuir um padrão geral de coloração dourada, sua coloração dorsal é mais clara e de tonalidade pálida e as regiões dos membros e cauda são alaranjadas, contrastando com a ruiva escura da outra espécie. Assim, esta coloração da pelagem está mais próxima àquela descrita para $A$. seniculus amazonica [macho jovem citado por LÖNNBERG (1941) e o exem- plar mencionado em Rylands \& BRANDON-Jones (1998)]. Uma fêmea coletada em Aripuanã, Estado do Mato Grosso (MZUSP, espécime ainda sem número de catálogo), mostrou a coloração da pelagem dorsal avermelhada mais escura que aquelas registradas para as outras duas fêmeas analisadas. Entretanto, este padrão não chega a atingir uma coloração ruiva escura como nos machos da espécie, tampouco como nas fêmeas típicas de $A$. juara.

Alouatta puruensis difere de qualquer táxon do gênero que ocorre no Brasil, principalmente por apresentar o osso hióide com o tentório trapezoidal e acentuadamente curvado para o interior da câmara (Figs 67 e 68). Como caracteres complementares, $A$. puruensis se distingue do táxon mais a oeste, Alouatta juara, por apresentar fêmeas claras (douradas) contra o colorido da pelagem ruiva escura a castanho-avermelhado da segunda espécie. Alouatta puruensis difere claramente do táxon mais a leste, A. nigerrima, por este último ser totalmente negro, e difere de A. macconnelli por este apresentar machos com a coloração dorsal da pelagem dourada, padrão não registrado para os machos ruivo-escuros de $A$. puruensis.

\section{História taxonômica}

LÖNNBERG (1941) descreveu Alouatta seniculus puruensis a partir de cinco exemplares provenientes de áreas próximas de ambas as margens do Rio Purus, Estado do Amazonas, de onde o nome do táxon provém: Igarapé do Castanha, Arumá (= Arumã), Jaburu e o próprio Rio Purus. LönnBerg (1941) forneceu como caráter diagnóstico para A. s. puruensis o dicromatismo sexual na coloração da pelagem, com machos ruivos escuros por todo o corpo e dorso mais claro, e fêmeas completamente douradas, com um leve escurecimento na cabeça. Autores posteriores (Cruz Lima 1945, CARvalho 1952, Hill 1962) seguiram a opinião de LöNnBERG (1941) tanto para a diagnose como para o reconhecimento subespecífico do táxon. CABRERA (1958) e autores mais recentes (NAPIER 1976, WolfHeim 1983, Groves 1993) consideraram A. s. puruensis sinônimo de A. seniculus (Linnaues, 1766) ou de A. s. juara Elliot, 1910 (Groves 2001a) invalidando assim o táxon. Recentemente, Groves (2001a: 181) sinonimizou ambas subespécies com A. s. juara, diagnosticando-a como: "Body is deeper, golden Brown, with sometimes a golden splotch in middle of back; rest is Brown-maroon; limbs, head, and tail can be nearly black".

Infelizmente, não foi possível a análise de espécimes de ambos os sexos de uma mesma localidade para confirmar o dicromatismo sexual na pelagem de A. puruensis, como o fez Lönnberg (1941), para espécimes de Jaburu. Contudo, o dicromatismo está restrito aos espécimes próximos ao Rio Purus e foi evidenciado aqui mediante a análise de duas fêmeas disponíveis (MPEG 19707, de Alvorada do Oeste e MZUSP 7333, de Plácido de Castro) que mostraram um padrão de coloração dourada clara no dorso e os membros e a cauda levemente mais escura; todos os machos analisados apresentaram um padrão de coloração ruiva escura a castanho. Portanto, esta diagnose generalizada sem distinção entre os sexos fornecida por Groves (2001a) e sua sinonimização com $A$. s. juara não é aceita aqui. 
Embora Alouatta puruensis apresente um conjunto de caracteres que o diferenciam dos táxons brasileiros do gênero pelo seu dicromatismo e pela estrutura ímpar do tentório no osso hióide, suas relações de parentesco são obscuras. A coloração da pelagem, ruiva escura nos machos é muito semelhante àquela de $A$. juara e se diferencia nitidamente da coloração dourada-avermelhada dos espécimes de Beni, Bolívia ( $A$. fusca beniensis). As fêmeas de pelagem dourada pálida de $A$. puruensis não lembra nenhum dos dois táxons mencionados acima. Espécimes de San Ignácio, Departamento de Puno, Peru (FMNH 79959-64), também mostraram dicromatismo sexual como apresentado por LÖNNBERG (1941) e se encaixam na descrição de A. s. puruensis: macho castanho escuro, e fêmea bem mais clara, quase dourada. Neste caso, o escurecimento ou clareamento dos espécimes se dá de forma suave e homogênea, sem contraste entre o dorso e as áreas periféricas, como os membros e a cauda. Assim, A. puruensis, como A. juara, tem seus limites geográficos estendidos para fora do Brasil.

Por outro lado, a morfologia hióidea de A. puruensis, descrita a partir de dois espécimes de Rondônia, não coincide com nenhuma outra apresentada pelas espécies do Brasil, mas é igual àquela registrada para indivíduos de Beni, Bolívia (Anexo II). Assim, a questão levantada aqui é: seria $A$. puruensis aliado a $A$. f. beniensis pela morfologia hióidea e ambos distintos um do outro pela coloração da pelagem, ou seria ela mais relacionada a A. juara pela coloração da pelagem nos machos, e distintas entre si pela morfologia hióidea?

\section{CONSIDERAÇÕES FINAIS}

Este trabalho finaliza um estudo mais amplo de taxonomia e variação geográfica de um dos grupos mais bem estudados de primatas sul-americanos, o gênero Alouatta. O gênero se distribui amplamente pela América do Sul e América Central e este trabalho abrangeu apenas os táxons do Brasil. Assim, procurou-se incluir uma amostragem considerável de espécimens e sempre que permitido, recorreu-se aos dados citogenéticos e moleculares para confrontar e testar os padrões evidenciados mediante a análise morfológica. Este procedimento forneceu mais argumentos e dados para o estudo da variação e para o reconhecimento dos táxons e seus respectivos níveis hierárquicos.

Após o estudo detalhado de variação geográfica com abrangente amostragem de espécimens e localidades cobrindo praticamente todo o Brasil, reconheceu-se 10 espécies de Alouatta para o Brasil. Este resultado, de certa maneira, diverge daqueles disponíveis na literatura. Por um lado, o número de táxons nominais válidos se mostrou reduzido quando comparado aos trabalhos que reconheceram subespécies. Estes estudos invariavelmente seguiram as propostas de CABRera (1958) e Hill (1962), que reconheceram um total de 12 subespécies de Alouatta para o Brasil. Esta situação foi mantida até recentemente por diversos autores (MitTermeier et al. 1988, Coimbra-Filho 1990, Rylands et al. 1995), e então modificada por GRoves (2001a), que reconhe- ceu os seguintes táxons para o Brasil: A. s. seniculus, A. s. juara, A. macconnelli, A. f. fusca, A. f. clamitans, A. belzebul e A. caraya. Os caracteres diagnósticos de coloração da pelagem, e principalmente, os cranianos fornecidos por Groves (2001a) para cada táxon mostraram-se variáveis, e portanto, inválidos para o propósito. Os resultados do presente estudo divergem tanto no reconhecimento dos táxons, como em suas diagnoses e níveis hierárquicos, dos demais autores. As espécies de Alouatta reconhecidas têm como base a presença de características únicas ou um conjunto exclusivo de caracteres que as definem inequivocadamente, em complemento aos aspectos zoogegráficos. Não é intencionado estender a questão do conceito de espécie aqui aplicado, mas para complemento deste assunto, ver CRACRAFT (1983, 1989), Marroig (1995), Groves (2001b) e Vane-Wright (2003). As espécies reconhecidas apresentam distibuição alo- ou parapátrica e a única possível hibridação ocorreu entre $A$. caraya e $A$. clamitans, espécies consideras válidas, em uma restrita região do nordeste do Estado do Paraná. Outra evidência que fortalece a decisão em reconhecer os táxons somente no nível específico refere-se à comprovação do não monofiletismo das espécies politípicas. Estudos prévios de relações de parentesco em Alouatta com base em vários tipos de caracteres (morfologia, Hershrovitz 1949 e dados apresentados no presente estudo; citogenética, Oliverra 1996; molecular, Figueiredo et al. 1998), têm revelado o não monofiletismo de todas as espécies politípicas. Por exemplo, A. nigerrima, há muito tempo relacionada a $A$. belzebul (Linnaeus, 1766) mostra afinidades filogenéticas estreitas com as espécies do complexo A. seniculus mediante uma análise mais ampla dos caracteres. $\mathrm{O}$ mesmo pode ser dito para $A$. fusca quando considerados os táxons do leste do Brasil e o de Beni, na Bolívia, se analisadas a coloração da pelagem concomitantemente com a morfologia do hióide e craniana. Neste caso, A. fusca beniensis mostra afinidades com os táxons distribuídos ao longo dos Rios Juruá e Purus. Por outro lado, não se pode compreender de forma mais ampla todo o processo de variação e diferenciação dos táxons do complexo $A$. seniculus ( $A$. seniculus, A. macconnelli, A. juara, A. insulanus), sem a inclusão de $A$. nigerrima e $A$. fusca beniensis como tem sido feito até o presente (parafiletismo).

O tratamento taxonômico e a definição das espécies não podem ser acompanhados de uma análise filogenética conclusiva de Alouatta, embora tratou-se abaixo e de forma sumária, os principais e mais recentes estudos lidando diretamente com os aspectos filogenéticos para o gênero. Esta discussão é de grande relevância, pois permite uma visão panorâmica de como os principais grupos de espécies têm sido historicamente formados, e recentemente testados mediante hipóteses alternativas empregando novos dados. Com o emprego da metodologia cladística concomitante com o uso de caracteres adicionais nas análises (molecular e citogenéticos), em complemento aos tradicionais morfológicos, têm-se questionado o monofiletismo de determinadas espécies politípicas e por conseqüência, a própria validade das subespécies. De fato, as subespécies de Alouatta

Revista Brasileira de Zoologia 23 (1): 64-144, março 2006 
são historicamente caracterizadas por semelhança na coloração da pelagem e morfologia craniana e em menor grau, empregando dados citogenéticos, e sempre definidas por um estudo comparativo entre elas. Sendo as espécies politípicas nãomonofiléticas, esta definição das subespécies baseado em níveis de divergência dos caracteres com seus táxons considerados aprioristicamente irmãos, e não uma delimitação baseada em autapormofias, ou seja, populações coesas compartilhando uma ou mais características exclusivas, torna este conceito subespecífico frágil e arbitrário.

Alouatta indiscutivelmente pertence ao grupo dos atelíneos (tribo Alouattini), e embora haja hipóteses alternativas sobre sua posição filogenética (ou fenética, KAY 1990), presentemente considera-se o gênero como grupo irmão do outros três gêneros viventes na qual compõem a tribo Atelini: Ateles; Brachyteles Spix, 1823, e Lagothrix (Ford 1986, SCHNEIDER et al. 1993, Schneider \& Rosenberger 1996, Horovitz et al. 1998, Horovitz 1999). Contudo, as relações filogenéticas dos principais grupos taxonômicos dentro de Alouatta, sejam estes, grupos de espécies, ou subespécies compondo uma espécie politípica, são incertas. Embora se tenha uma série de artigos recentes empregando dados moleculares, morfológicos e citogenéticos direcionados ao entendimento das relações filogenéticas em Alouatta (Hershrovitz 1949, Meireles et al. 1999, Oliveira et al. 2002, Cortés-Órtiz et al. 2003), os métodos distintos de análise, a representatividade taxonômica incompleta e a ausência de análises mais globais (evidência total) têm levado a resultados divergentes (Figs 69 a 71).

Historicamente, nos últimos 70 anos, Alouatta tem sido composto por cinco espécies: A. palliata (com várias subespécies), A. caraya, A. belzebul (com 4 ou 5 subespécies), A. seniculus (com várias subespécies) e $A$. fusca (com três subespécies). Recentemente, algumas das subespécies têm sido aceitas por especialistas como espécies válidas ( $A$. pigra, A. sara, A. coibensis, e $A$. nigerrima), mas sem uma base filogenética. Hershкоvitz (1949) foi quem primeiro, baseado na morfologia do hióide, explicitamente propôs uma filogenia para a diferenciação destes cinco grupos dentro de Alouatta. O autor assumiu que a morfologia hióidea em $A$. palliata era primitiva pela sua estrutura simples (bula hióidea rasa, ausência de tentório) e a complexidade crescente em A. fusca, A. belzebul e A. seniculus era derivada. Alouatta caraya apresentava uma condição intermediária. Um aspecto interessante no estudo de Hershrovitz (1949) é a sua sugestão, com base na morfologia hióidea, que $A$. belzebul nigerrima estava mais próxima de $A$. seniculus que de $A$. $b$. belzebul, questionando assim o monofiletismo daquela espécie politípica e implicitamente, o nível subespecífico de $A$. $b$. nigerrima.

As relações filogenéticas dentro de Alouatta propostas por Gregorin (dados aqui apresentados) (Fig. 69), empregando dados de morfologia craniana e de coloração da pelagem em complemento aos do osso hióide, foram basicamente coincidentes com aquelas propostas por Hershrovitz (1949). Contudo, o autor utilizou-se de uma maior representatividade taxonômica,

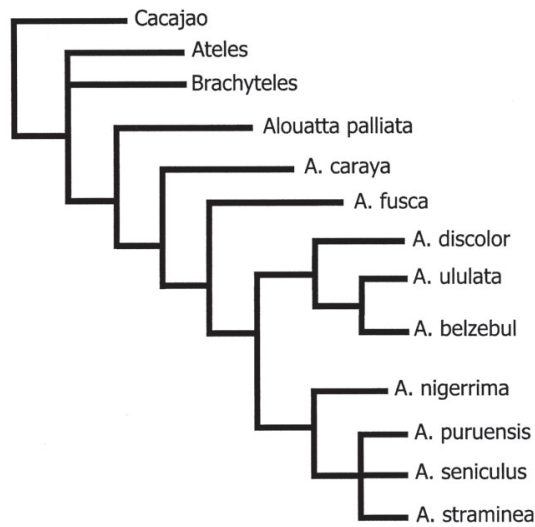

69

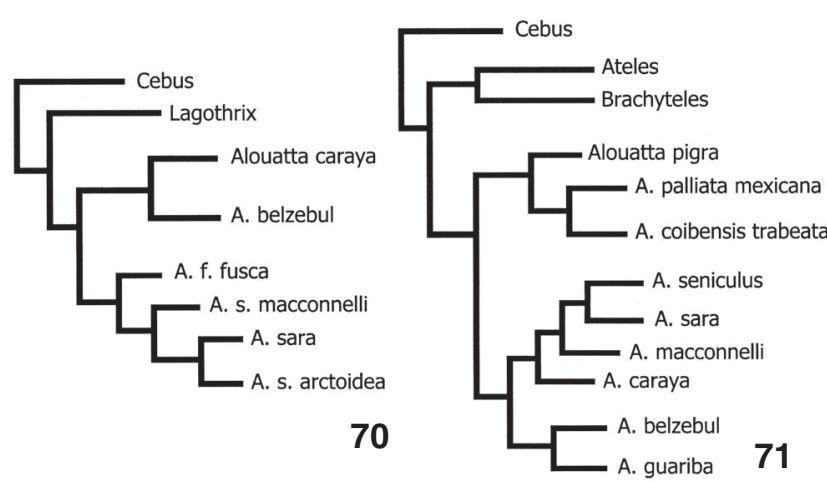

Figuras 69-71. Relações filogenéticas de Alouatta empregando três conjuntos distintos de dados: (69) morfologia (GreGORIN, presente estudo), (70) citogenética (Olivelra et al. 2002), (71) molecular (CORTÉs-Órtiz et al. 2003). Note que as topologias são completamente divergentes entre as análises.

estudando todas as subespécies reconhecidas para o Brasil e algumas da América Central e demais partes da América do Sul. Assim, o autor evidenciou o parafiletismo da maior parte das espécies politípicas, em particular a posição de $A$. b. nigerrima mais próxima de $A$. seniculus e a consideração dúbia do táxon de Beni, Bolívia (A. f. beniensis) como próxima filogeneticamente da subespécie da Floresta Atlântica. Na filogenia expressa na figura 69, A palliata e $A$. caraya são as mais primitivas, e o clado mais derivado era composto por $A$. fusca e A. belzebul + A. seniculus. Embora sendo explícito na metodologia aplicada e utilizando-se de muitos táxons terminais, o estudo é falho em empregar poucos caracteres (um total de 32), e majoritariamente do osso hióie, para a definição das relações filogenéticas dentro de Alouatta. Estes resultados foram corroborados por Meireles et al. (1999) empregando dados de mioglobina.

Recentemente, OliverRa et al. (2002) aplicaram técnicas de hibridação cromossômica in situ em sete táxons de Alouatta, a saber: A. caraya, A. belzebul, A. seniculus macconnelli (com duas 
populações distantes geograficamente), A. s. sara, A. s. arctoidea A. f. fusca e A. f. clamitans. Os resultados de Oliveira et al. (2002) (Fig. 70) são discrepantes daqueles apresentados anteriormente por considerar A. caraya e A. belzebul (sensu stricto) grupos irmãos e por outro lado, $A$. fusca mais próxima de $A$. seniculus. Os autores reforçam a idéia de caracterizar as populações de $A$. fus$c a$ da Floresta Atlântica como duas espécies distintas, baseados nas diferenças citogenéticas. Embora também explícito metodologicamente, o estudo de Oliveira et al. (2002) não é satisfatório por empregar apenas um conjunto de caracteres, citogenéticos (embora 98 caracteres tenham sido usados), e principalmente, pela não inclusão de táxons-alvo (mais subespécies) para definir as relações de parentesco e testar o monofiletismo de espécies politípicas. Neste sentido, os autores não incluíram A. palliata para verificar sua posição dentro do gênero, e $A$. $b$. nigerrima, $A$. f. beniensis, $A$. $b$. discolor, mantendo muitas das questões taxonômicas e mesmo filogenéticas em aberto. Sabe-se que a representavidade taxonômica influencia drasticamente em arranjos filogenéticos (SANDERSon \& Donoghue 1989).

Mais recentemente, o estudo filogenético baseado em dados moleculares (ATP6, ATP8, parte do citocromo $b$, gene CAL e RAG1) elaborado por Cortés-Órtiz et al. (2003) é conflitante com as duas análises previamente discutidas (Fig. 71). Os autores consideraram os seguintes táxons na análise: $A$. p. palliata, A. p. mexicana, A. p. aequatorialis, A. c. coibensis, A. c. trabeata, A. pigra, A. s. seniculus, A. sara, A. macconnelli, A. b. belzebul e $A$. fusca. Embora com maior representatividade taxonômica que a análise de Oliveira et al. (2002), para fins taxonômicos, a proposta de CoRTés-ÓRTIz et al. (2003) contribuiu basicamente para o complexo A. palliata cuja distribuição é praticamente centro-americana. Os dados moleculares indicam que $A$. belzebul se posiciona filogenéticamente mais próximo de $A$. guariba e não de $A$. caraya como sugerido pelos dados citogenéticos. Neste sentido, o complexo A. seniculus (que inclui $A$. sara e $A$. macconnelli) está mais próximo a $A$. caraya. $\mathrm{O}$ complexo $A$. palliata forma um clado à parte. A não inclusão de amostras representando as duas subespécies reconhecidas de $A$. fusca à época, as três de $A$. belzebul, e $A$. nigerrima (já considerada espécie válida pelos autores) também não esclareceram para as questões taxonômicas desejadas.

A datação molecular proposta por CoRTÉs-ÓRTIZ et al. (2003) para o surgimento de Alouatta (6,8 milhões de anos) é compatível com aquela sugerida anteriormente por GREGORIN (dados não publicados) e ambas em divergência dos 3,2 milhões de anos como proposto por Scheneider et al. (1993). Neste caso, propõe-se uma idade pliocênica para Alouatta, e contra um processo de especiação pleistocênica, baseado, em três aspectos: 1) o fóssil mais estritamente relacionado a Alouatta, Stirtonia Hershkovitz, 1970, tem datação entre 17-15 milhões de anos; 2) após a separação Alouatta + Atelini, esta tribo teve dois estágios evolutivos a mais, resultando no aparecimento dos três gêneros viventes que a compõem (Ateles, Lagothrix e Brachyteles); e 3) embora os Alouattini apresentem uma única linhagem recente, Alouatta, mostra uma quantidade considerável de autapomorfias (29 segundo Ford 1986), sugerindo um tempo considerável de separação de seu clado irmão, os Atelini. Assim, é evidente que não há uma filogenia definitiva ou claramente mais robusta para Alouatta, devido aos procedimentos metodológicos apresentados. Se por um lado filogenias moleculares são informativas e apresentam algumas "vantagens" inerentes pelo próprio tipo de dados (maior segurança na codificação), a ausência de amostras representando subespécies que ocorrem em áreas remotas (representatividade taxonômica) é uma desvantagem que deve ser considerada e este problema é reduzido ou mesmo inexistente em estudos morfológicos. Certamente que a aquisição de dados moleculares diretamente das peles de museus e uma análise de evidência total seria desejável para estudos mais conclusivos. Neste sentido, qualquer cenário biogeográfico para a diferenciação das espécies de Alouatta deve ser visto com cautela.

$\mathrm{O}$ padrão zoogeográfico registrado aqui mostra que as espécies de Alouatta apresentam, no geral, distribuição alopátrica ou peripátrica, com os grandes rios (Amazonas, Tapajós, Madeira, Paraná, Negro) ou cadeias de montanhas (maciço da Serra do Espinhaço) formando, na maioria das vezes, barreiras geográficas efetivas entre os eles. À exceção de $A$. belzebul, nenhuma espécie mostrou distribuição definitivamente disjunta. Apenas uma possível área de simpatria foi registrada entre A. clamitans e A. caraya ao longo da margem leste do Rio Paraná, nos Estados da região sul do Brasil. Outros dois casos de simpatria ainda necessitam de mais elementos para a sua comprovação: A. nigerrima e A. macconnelli na margem norte do Rio Amazonas, no Estado do Pará; e $A$. belzebul e $A$. macconnelli em uma estreita faixa ao longo da costa do Estado do Amapá. Um quarto caso seria entre $A$. discolor e A. nigerrima em Itaituba. Todos estes pontos de possível simpatria evidenciam um padrão de dispersão esporádica de determinadas populações, cujas espécies invasoras ficam sempre à periferia da distribuição da espécie preestabelecida.

Quanto à variação geográfica, ela foi marcante em $A$. clamitans no eixo norte-sul da distribuição e A. macconnelli, no traçado leste-oeste como discutido exaustivamente na literatura. Alouatta caraya, a espécie que apresentou a maior área de distribuição geográfica e incluindo várias formações, como as matas semidescíduas, o complexo de vegetação do Pantanal e o Cerrado, não apresentou variação geográfica notável na morfologia da pelagem, do osso hióide e nos dados citogenéticos, como os dois táxons anteriores. A compreensão da variação é o cerne para as decisões taxonômicas, pois se acentuada, é um dos maiores obstáculos para uma diagnose precisa dos táxons reconhecidos, sendo importante salientar que a variabilidade não está restrita aos dados morfológicos, mas também aos citogenéticos. Os estudos citogenéticos incluindo novas metodologias e maior amplitude amostral têm gerado resultados interessantes para a definição dos táxons e suas relações de parentesco (Oliveira 1995, 1996, Oliveira et al. 2001).

Revista Brasileira de Zoologia 23 (1): 64-144, março 2006 
Contudo, eles também demonstram variação, ao menos geográfica, e somente estudos incluindo amostras amplas representadas por espécimes provenientes de localidades estratégicas ou mesmo de táxons cuja validade é historicamente questionável (A. ululata, A. discolor e A. puruensis), seriam esclarecedores. Um esforço neste sentido certamente resultará em dados mais consistentes para a taxonomia de Alouatta e complementará os hiatos deixados pelo estudo morfológico.

\section{AGRADECIMENTOS}

Agradeço aos curadores ou responsáveis pelas coleções de mamíferos dos museus visitados pela permissão na análise do material: Heraldo Britski e Mario de Vivo (MZUSP), João A. Oliveira (MNRJ), José S. S. Júnior e Sueli A. Marques-Aguiar (MPEG), Michel Miretzki (MHNCI), Alfredo Langguth (UFPB), Bruce Patterson (FMNH) e Nancy B. Simmons (AMNH). Um agradecimento especial a Mario de Vivo pela orientação ao longo de muitos anos de estudo em sistemática, e a Alexandre R. Percequillo, Fernando Passos e Fernando D. de Ávilla-Pires pela leitura criteriosa do manuscrito. Ao Dr. Olaf H.H. Mielke pelas críticas e sugestões valiosas sobre as questões nomenclaturais. A Rogério V. Rossi e Gilson E. Iack-Ximenes pelas inúmeras sugestões e incentivo, e a Edivaldo Oliveira e Wilsea Figueiredo, ambos da Universidade Federal do Pará, pelo fornecimento dos dados citogenéticos e moleculares, respectivamente. Ao Dr. Per Ericson e Olavi Grönwall, ambos do Museu Sueco de História Natural, pelo fornecimento de dados sobre espécimes importantes depositados naquela instituição. A Stella Franco, João A.L. Queiroz, Gabriel S. Sugliano, Andrea Nunes, Cibele Bonvicino, Alexandre U. Christoff, Richard W. Thorington e Anthony Rylands pelo apoio e informações relevantes sobre Alouatta. A Ricardo Montiel pela elaboração das figuras coloridas. Este projeto foi financiado pelo Conselho Nacional de Pesquisa e Desenvolvimento Tecnológico $(\mathrm{CNPq})$ e parcialmente pela Fundação de Amparo à Pesquisa do Estado de São Paulo (FAPESP) processo número 01/ 10292-1. À Fundação de Amparo à Pesquisa do Estado de Minas Gerais (FAPEMIG), processo CRA 2823/05.

\section{REFERÊNCIAS BIBLIOGRÁFICAS}

Allen, J.A. 1900. On mammals collected in Southeastern Peru, by Mr. H.H. Keays, with descriptions of new species. Bulletin of the American Museum of Natural History, New York, 13 (18): 219-227.

Allen, J.A. 1911. Mammals from Venezuela collected by Mr. M.A. Carriker, Jr., 1909-1911. Bulletin of the American Museum of Natural History, New York, 30 (10): 239-273.

AlLEN, J.A. 1916a. Mammals collected on the Roosevelt Brazilian expedition, with field notes by Leo E. Miller. Bulletin of the American Museum of Natural History, New York, 35 (30): 559-610.

ALLEN, J.A. 1916b. List of mammals collected in Colombia by the American Museum of Natural History expeditions, 1910-
1915. Bulletin of the American Museum of Natural History, New York, 35 (18): 191-238.

Almeida, R.T.; D.S. Pimentel \& E.M.S. Silva. 1995. The red-handed howling monkey in the state of Pernambuco, North-East Brazil. Neotropical Primates, Washington, 3 (4): 174-176.

ANDERSON, M.A. 1804. A general history of Quadrupeds. G. \& R. Waite.

Anderson, R.P. \& C.O. Handley JR. 2002. Dwarfism in insular sloths: biogeography, selection, and evolutionary rate. Evolution, Lancaster, 56 (5): 1045-1058.

Anderson, S. 1997. Mammals of Bolivia, taxonomy and distribution. Bulletin of the American Museum of Natural History, New York, 231: 1-652.

Anderson, S.; B.R. Riddle; T.L. Yates. \& J.A. Cook. 1993. Los mamíferos del Parque Nacional Amboró y la región de Santa Cruz de la Sierra, Bolivia. Special Publications of Museum Southwestern Biology, Albuquerque, 2: 1-58.

Anthony, J.; O. Serra \& R.G. Serra. 1949. La surface de la voute palatine repportée a la capacité cranienne chez les singes platyrhiniens (étude portant sur 523 spécimens sauvages). Bulletin de la Société d'Anthropologie, Paris, 10 (9): 129145.

Armada, J.L.A.; C.M.L. Barroso; M.M.C.J. Lima; A.P.C. Muniz \& H.N. SeuÁnez. 1987. Chromosome studies in Alouatta belzebul. American Journal of Primatology, Los Angeles, 13: 283296.

Audebert, J. B. 1797. Histoire Naturelle des Singes et des Makis. Paris, Chez Desray Libraire, III+24+39+44p.

Auricchio, P. 1995. Primatas do Brasil. São Paulo, Terra Brasilis, $168 \mathrm{p}$.

Ávila-Pires, F.D. DE. 1964. Mamíferos colecionados na região do Rio Negro (Amazonas, Brasil). Boletim do Museu Paraense Emilio Goeldi, Zoologia, Belém, 42: 1-23.

Ávila-PiRes, F.D. DE. 1966. Observações gerais sobre a mastozologia do Cerrado. Anais da Academia Brasileira de Ciências, Rio de Janeiro, 38(suplemento): 331-340.

Ávila-Pires, F.D. DE. 1989. Mamíferos da França Equinocial (Maranhão, Brasil). Revista Brasileira de Zoologia, Curitiba, 6 (3): 423-442.

Ávila-Pires, F.D. \& E. GolvêA. 1977. Mamíferos do Parque Nacional de Itatiaia. Boletim do Museu Nacional, Zoologia, Rio de Janeiro, 291: 1-29.

AZARA, F. de. 1801. Apuntamientos para la historia natural de los quadrúpedes del Paraguay y Rio de la Plata. Madrid, Imprenta de la Viuda de Ibarra, vol. 2, p. 5-406+407-499.

Azevedo, T.R. de; D. El AchKar; M. De F. Martins \& A. Ximenez., 1982. Lista sistemática dos mamíferos de Santa Catarina conservados nos principais museus do estado. Revista Nordestina de Biologia, João Pessoa, 5 (1): 93-104.

Ayres, J.M. \& K. Milton. 1981. Levantamento de primatas e habitat no Rio Tapojós. Boletim do Museu Paraense Emilio Goeldi, Nova Série, Belém, 111 : 1-11.

Barroso, C.M.L.; M.I.C. Sampaio; M.P.C. Schneider; A.R. Hamel;

Revista Brasileira de Zoologia 23 (1): 64-144, março 2006 
F.M. Salzano \& H.N. SeuÁnez. 1988. Adenosine Deaminase Isozyme variation in Alouatta belzebul with review of data from others primates. Revista Brasileira de Genética, Ribeirão Preto, 11 (3): 643-652.

BAtes, H.W. 1864. Naturalist on the River Amazonas. London, J. Murray, $2^{\text {nd }}$ ed., 466 p.

Bertoni, A. DE W. 1939. Catálogos sistemáticos de los vertebrados del Paraguay. Revista de la Sociedad Cientifica del Paraguay, Asunción, 4 (4): 3-14.

Bodini, R. \& R. Pérez-Hernandèz. 1987. Distribution of the species and subspecies of cebids in Venezuela. Fieldiana Zoology, Chicago, 39: 231-244.

Bonvicino, C.R.; A. Langguth \& R.A. Mittermeier. 1989. A study of pelage and geographic distribution in Alouatta belzebul (Primates; Cebidae). Revista Nordestina de Biologia, João Pessoa, 6 (2): 139-148.

Bonvicino, C.R.; M. Fernandes \& H.N. Seuánez. 1995. Morphological analysis of Alouatta seniculus species group (Primates, Cebidae). A comparision with biochemical and karyological data. Human Evolution, Firenze, 10 (2): 169-176.

Brisson, M.J. 1756. Regnum Animale. Paris, VIII+382p.

вRоOKs, D.M. 1996. Some observations on primates in Paraguay. Neotropical Primates, Washington, 4 (1): 15-19.

BuFFON, G.L.L. 1767. Histoire naturelle générale et particulière avec description du cabinet du roi. Paris, vol. 15, p. 6+207+ CCXXIV.

Burmeister, H. 1854. Systematische Uebersicht der Thiere Brasiliens. Erster Thell. Saugethiere (Mammalia). Berlin, Georg Reimer, 341p.

Cabrera, A. 1900. Estudios sobre una collección de monos americanos. Annais de la Sociedad Espanhola de Historia Natural, Madrid, 9 (29): 65-93.

Cabrera, A. 1912. Catálogo metódico de las colecciones de mamíferos del Museu de Ciencias Naturales de Madrid. Trabajos del Museu Nacional Ciencias Naturales Madrid, Madrid, 11: $1-447$.

Cabrera, A. 1939. Los monos de la Argentina. Physis, Buenos Aires, 16: 3-29.

Cabrera, A. 1940. Los Nombres cientificos de algunos monos americanos. Ciencia, Mexico, 9: 402-405.

Cabrera, A. 1958. Catalogo de los mamiferos da America del Sur. Revista del Museu Argentino de Ciencias Naturales «Bernardino Rivadavia”, Ciencia Zoologica, Buenos Aires, 4: 1-307.

Cabrera, A. \& J. Yepes. 1940. Mamiferos Sud-Americanos. Buenos Aires, Compañia Argentina de editores, 370p.

Carneiro, A.J. De S. 1908. Mammiferos do Estado da Bahia. Salvador, Litho-Typ. e Encadernação Reis \& C, VI+31p.

Carvalho, C.T. DE. 1952. Resultados de uma expedição científica ao Território do Acre: Mamíferos. Papéis Avulsos de Zoologia, São Paulo, 11 (2): 21-32.

Carvalho, C.T. DE. 1957. Alguns mamíferos do Acre ocidental. Boletim do Museu Paraense Emilio Goeldi, Zoologia,
Belém, $6: 1-22$.

Carvalho, C.T. DE. 1960. Sobre alguns mamíferos do sudeste do Pará. Arquivos de Zoologia, São Paulo, 11 (5):121-132.

CarvalHo, C.T. DE. 1961. Esboço mastofaunístico do território do Rio Branco. Revista de Biologia Tropical, San Jose, 9 (1): $1-15$.

Carvalho, C.T. DE. 1965. Comentários sobre os mamíferos descritos e figurados por Alexandre Rodrigues Ferreira em 1790. Arquivos de Zoologia, São Paulo, 12: 7-70.

Carvalho, C.T. DE. 1980. Mamíferos dos parques e reservas de São Paulo. Silvicultura, São Paulo, 13/14: 49-72.

Carvalho, C.T. \& A.J. Toccheton., 1969. Mamíferos do nordeste do Pará, Brasil. Revista de Biologia Tropical, San Jose, 15 (2): 215-226.

Castelnau, F. DE. 1855 (1856). Expédition dans les parties centrales de L'Amérique du Sud, de Rio de Janeiro a Lima, et de Lima au Para. Paris, P. Bertrand, Séptième Partie, Zoologie, vol. 1, 116p.

Chame, M; A. Araújo \& L.F. Ferreira. 1995. Premiéres observations sur la faune de la Serra da Capivara, Sudest du Piauí, Brésil. Études Américanistes Interdisciplinares, Paris, 2 (4): $33-$ 40.

Chame, M. \& F. Olmos. 1997. Two howler species in Southern Piauí, Brazil? Neotropical Primates, Washington, 5 (3): 7477.

Chiarelli, A. B. 1972. Atlas of Living Primates. London, Academic Press, VII+363p.

Coimbra-Filho, A.F. 1990. Sistemática, distribuição geográfica e situação atual dos símios brasileiros (Platyrrhini-Primates). Revista Brasileira de Biologia, Rio de Janeiro, 50 (4): 10631079.

Coimbra-Filho, A; I.G. CÂmara \& A.B. Rylands. 1995. On the geographic distribution of the red-handed howling monkey, Alouatta belzebul, in North-East Brazil. Neotropical Primates, Washington, 3 (4): 176-179.

Coimbra-Filho, A. \& I.G. CÂmara. 1996. Os Limites Originais do Bioma Mata Atlântica na Região Nordeste do Brasil. Rio de Janeiro, Fundação Brasileira para a Conservação da Natureza, 86p.

Consigliere, S; R. Stanyon; U. Koehler; G. Agoramoorthy \& J. Wienberg. 1996. Chromosome painting defines genomic rearrangements between red howler monkey subspecies. Chromosome Research, Exceter, 4 (3): 264-270.

Cope, E.D. 1889. On the mammalia obtained by the naturalist exploring expedition to southern Brazil. American Naturalist, Chicago, 23 (266): 129-150.

Cortés-Ortiz, L; E. Bermingham; C. Rico; E. Rodríguez-Luna; I. SAMPAIO, \& M. RuIz-García. 2003. molecular systematics and biogeography of the Neotropical monkey genus, Alouatta. Molecular Phylogenetics and Evolution, Basel, 26 (1): 6481.

Cracraft, J. 1983. Species concepts and speciation analysis. Current Ornithology, Bloomington, 2: 159-187.

Revista Brasileira de Zoologia 23 (1): 64-144, março 2006 
Cracraft, J. 1989. Speciations and its Ontology: The Empirical Consequences of Alternative Species Concepts for Understanding Patterns and Processes of Differentiation, p. 29-59. In: D. Otte \& J.A. Endler (Eds). Speciation and its Consequences. Sunderland, Sinaver, XIII+679p.

Crespo, J.A. 1952. Presence of the reddish howling monkey (Alouatta guariba clamitans Cabrera) in Argentina. Jounal of Mammalogy, Lawrence, 35 (1): 117-118.

Crespo, J.A. 1974. Comentarios sobre nuevas localidades para mamíferos de Argentina y de Bolívia. Revista del Museu Argentino de Ciencias Naturales "Bernardino Rivadavia", Zoologia, Buenos Aires, 11 (1): 1-31.

Cruz Lima, E. 1945. Mamiferos da Amazonia. Introdução geral e primatas. Contribuições do Museu Paraense Emilio Goeldi de História Natural e Etnografia, Belém, 1: 1-274.

Cuvier, G. 1798. Tableau Élémentaire de l'Histoire Naturelle des Animaux. Paris, Baudouin, XVI+710p.

Desmarest, A.G. 1804. Tableau methodique des mammiféres. Nouveau Dictionarie Histoire Naturelle, Paris, 24 (6): 558.

DesmaRest, A.G. 1816. Nouveau dictionaire d'histoire naturelle appliquée aux arts...par une Société de Naturalistes et d'Agruculteurs. Paris. Nouvelle edition, vol. 1.

Desmarest, A.G. 1820. Mammalogie ou description des espéces de mammiféres. Paris, VIII+276p.

Desmarest, A.G. 1827. Dictionnarie des Sciences Naturelles. Paris, vol. 47, p. 17-20.

Di Bitetti, M.S; G. Placci; A.D. Brown \& D.I. Rode. 1994. Conservation and population status of the brown howling monkey (Alouatta fusca clamitans) in Argentina. Neotropical Primates, Belo Horizonte, 2 (4): 1-3.

Dollman, G. 1910. A note on Alouatta discolor of Spix. Annals and Magazine of Natural History, London, 8 (6): 422-424.

ElLIot, D.G. 1910. Description of a new species of monkeys of the genera Galago, Alouatta, and Cercopithecus. Annals and Magazine of Natural History, London, 18 (5): 77-83.

ELLIOT, D.G. 1912. Descriptions of new Species of Monkeys of the Genera Galago, Cebus, Alouatta, and Cercopithecus. Annals and Magazine of Natural History, London, 8 (5): 77-83.

Elliot, D.G. 1913. A review of the primates. New York, American Museum Natural History, vol. 1, CXXVI+317p.

ERXleben, J.C.P. 1777. Systema regni animalis per classes, genera, species, varietalis cum synonymia et historia animalum. Classis I. Mammalia. Leipzig, XLVIII+636p.

Fernandes, M.E.B. 1995. Notes on the geographic distribution on howler monkeys in the Marajó archipelago, Pará, Brazil. International Journal of Primatology, New York, 15 (6): 919-926.

Figueiredo, W.; N.M. Carvalho-Filho; H. Scheneider \& I. Sampaio. 1998. Mitochondrial DNA sequences and the taxonomic status of Alouatta seniculus populations in northeastern Amazônia. Neotropical Primates, Washington, 6 (3): 7377.

Revista Brasileira de Zoologia 23 (1): 64-144, março 2006
FIsCHER, G. 1813. Zoognosia tabulis synopticis illustrata. Moscow, vol. 2.

FisCHER, J.B. 1829. Synopsis mammalium. Stutgart, XLII+527p.

Flesher, K. 2001. Primates of the Chapada das Mangabeiras, Piauí, Brasil: a northern extension to the Alouatta caraya. Neotropical Primates, Washington, 9 (1): 19-22.

Forbes, H.O. 1896. A hand-book to the Primates. London, E. Lloyd, vol. 1, 286p.

Ford, S.M. 1986. Systematics of the New World Monkeys, p. 73-135. In: D.R. Swindler \& J. ERWIN (Eds). Systematics, evolution, and anatomy. Comparative primates biology. New York, Alan R. Liss, vol. 1, 836p.

Geoffroy Saint-Hilaire, E. 1806. Memóire les Singes à main importante en les Ateles. Annals Museum Histoire Naturelle de Paris, Paris, 7: 260-273.

Geoffroy Saint-Hilaire, E. 1812. Tableau des quadrumanes ou des animaux composant le premier orDre de la classe des mammifères. Annals du Museum d'Histoire Naturelle de Paris, Paris, 19: 85-122.

Geoffroy Saint-Hilaire, E. 1829. Cours de l'histoire naturelle des Mammifères. Paris, Pichon et Didier, Leçon IX, 36p.

Geoffroy Saint-Hilaire, I. 1851. Catalogue méthodique de la collection des mammifères de la collection des osseaux et des collections annexes du Muséum d'Histoire Naturelle de Paris. Paris, Guide et Baudry, XV+VII+96p.

George, T.K; S.A. Marques; M. De Vivo; L.C. Branch; N. Gomes \& R. Rodrigues. 1988. Levantamento de mamíferos no ParnaTapajós. Brasil Florestal, Brasília, 63: 33-37.

Gmelin, J.F. 1788. Systema Naturae. Lipsiae, Imprensis Georg. Emanuel Beer, $13^{\text {rd }}$ ed., XII+50p.

Goeldi, E.A. 1893. Os mammiferos do Brasil. Rio de Janeiro, Classica de Livraria Alves, 180p.

Goeldi, E.A. 1902. Maravilhas da natureza, na ilha de Marajó (Rio Amazonas). Boletim Museus Paraense, Belém, 3: 370399.

Goeldi, E.A. \& G. Hagmann. 1904. Prodomo de um catalogo critico, commentado da collecção de mammiferos no Museu do Pará (1894-1903). Boletim do Museu Paraense História Natural e Ethinologia, Belém, 4 (1): 38-122.

Goldman, E.A. 1913. Descriptions of new mammals from Panamá and México. Smithsonian Miscellaneous Collections, Washington, 60 (22): 1-20.

Gray, J.E. 1845. On the howling monkeys (Mycetes, Illiger). Annals and Magazine of Natural History, London, 105: 217-221.

Gray, J.E. 1870. Catalogue of monkeys, lemurs and fruiteating bats in the collection of the British Museum. London, Trustees of the British Museum, VIII+137p.

Groves, C.P. 1993. Primates, p. 243-277. In: D.E. WiLson \& D.M. REEDER (Eds). Mammals Species of the World. A taxonomic and geographic reference. Washington, Smithsonian Institution Press, XVII+1207p.

Groves, C.P. 2001a. Primate Taxonomy. Washington, 
Smithsonian Institution Press, VIII+350p.

Groves, C.P. 2001b. Why taxonomic stability is a bad idea, or why are there so few species of primates (or are there?). Evolutionary Anthropology, Stony Brook, 10 (6): 192-198.

Guedes, P.G; D.M. Borges-Nojosa; J.A.G. DA Silva \& L.O. Salles. 2000. Novos registros de Alouatta no estado do Ceará (Primates, Atelidae). Neotropical Primates, Washington, 8 (1): 29-30.

Gumilla, P.J. 1758. Histoire naturelle civile et géographique de l'Orinoqué et des principales rivières qui si jettent, Paris.

Gyldenstolpe, N. 1951. The ornithology of the Rio Purus region in western Brazil. Arkiv für Zoologi, Estocolmo, 2 (2): 1320.

Hagmann, G. 1908. Die Landsäugetiere der Insel Mexiana. Archiv für Rassen und Gesellschafts-Biologie, München, 1: 1-31.

Hensel, R. 1867. Beitrage zur Kenntniss der Thierwelt Brasiliens. Zoologischer Garten, Berlin, 8: 361-374.

Hensel, R. 1872. Beiträge zur Kenntniss der Säugethiere SüdBrasiliens. Berlin, Abhandlungen K. Akademie der Wissenschaften, 130p.

Hershrovitz, P. 1949. Mammals of Northern Colombia. Preliminary report no. 4: monkeys (primates), with taxonomic revisions of some forms. Proceedings of the United States National Museum, Washington, 98 (3232): 323-327.

Hershrovitz, P. 1964. Primates, Comparative Anatomy and Taxonomy, V. Cebidae, part B. A monography by W. C. Osman Hill. A critical review with a summary of the volumes on New World Primates. American Journal of Physical Anthropology, Columbus, 21 (3): 391-398.

Hershrovitz, P. 1968. Metachromism or the principle of evolutionary change in mammalian tegumentary colors. Evolution, Lancaster, 22 (3): 556-575.

Hershrovitz, P. 1988. Origin, speciation, and distribution of South American titi monkeys, genus Callicebus (Family Cebidae, Platyrrhini). Proceedings of the Academy Natural History Sciences of Phyladelphia, Philadelphia, 140 (1): 240-272.

Hill, C. W. O. 1962. Primates: comparative anatomy and taxonomy. V. Cebidae, part B. Edinburgh, Edinburgh University Press, VII+537p.

Hirano, Z.M.B; R. Tramonte; A.R. Silva; R.B. Rodrigues \& W.F. dos SANTOS. 2003. Morphology of epidermal glands responsible for releaase of colored secretions in Alouatta guariba clamitans. Laboratory Primates Newsletter, Providence, 42 (2): 4-6.

Hirsch, A; E.C. Landau; A.C.M. Tadeschi \& J.O. Menegheti. 1991. Estudo comparativo das espécies do gênero Alouatta Lacépède, 1799 (Platyrrhini, Atelidae) e sua distribuição geográfica na América do Sul, p. 239-262. In: A.B. RyLANDS \& A.T. Bernardes (Eds). A Primatologia no Brasil. Belo Horizonte, Fundação Biodiversitas, 459p.

Hirsch, A.; R.J. Subirá \& E.C. Landau. 1994. Levantamento de primatas e zoneamento das matas na região do Parque Estadual do Ibitipoca, Minas Gerais, Brasil. Neotropical Primates, Belo Horizonte, 2 (3): 4-6.

Horovitz, I. 1999. A phylogenetic study of living fossils platyrrhines. American Museum Novitates, New York, 3269: 140.

Horovitz, I.; R. Zardoya \& A. Meyer. 1998. Platyrrhine systematics; a simultaneous analysis of molecular and morphological data. American Journal of Physical Anthropology, Columbus, 106: 261-281.

Humboldt, A. DE. 1812. Recueil d'observations de zoologie et d'anatomie comparée, faites dans l'ocean Atlantique, dans l'intérieur du nouveau continent et dans la mer du sur pendant les annés $1799,180,1801,1802$ et 1803. In: A. DE Humboldt \& A. Bompland (Eds). Voyage aux régions équinoxiales du nouveaus continent, fait en 1799-1804. Paris, vol. 1, VIII+368p.

Husson, A.M. 1957. Notes on the Primates of Suriname. Studies on fauna of Suriname and other Guyanas, Amsterdam, 1 (2): 13-40.

IczN (International Commission on Zoological Nomenclature). 1922. Under suspension Simia, Simia satyrus and Pithecus: Opnion 114. Smithsonian Miscelaneous Collections, Washington, 73 (6): 25-26.

IczN (International Commission on Zoological Nomenclature). 1999. International Code of Zoological Nomenclature. London, The Natural History Museum, $4^{\text {th }}$ ed., 306p.

IHering, H.V. 1892. Os mammíferos do Rio Grande do Sul. Anais do Estado do Rio Grande do Sul, Porto Alegre, 19: 96-123.

Ihering, H.V. 1894. Os mammiferos de São Paulo. São Paulo, Tipografia Diário Oficial, 30p.

Ihering, H.V. 1904. O Rio Juruá. Revista do Museu Paulista, São Paulo, 6: 385-460.

Ihering, H.V. 1914. Os bugios do genero Alouatta. Revista do Museu Paulista, São Paulo, 9: 231-280

Illiger, J.C.W. 1811. Prodomus Systematics Mammalium et Avium Additis Terminis Zoographicis Utriusque Classis, Eorunque Versione Germanica. Berlim, Berolini, Sumptibus C. Salfeld, XVIII+301p.

Illiger, J.C.W. 1815. Überblick der Säugthiere nach ihrer Vertheilung über die Welttheile. Berlim.

JEnTink, F.A. 1887. Catalogue Ostéologiques des Mammifères. Leiden, Museum d'Histoire Naturelle des Pays-Bas, E.J. Brill, Tome 9, I-XII+360p.

KAY, R.F. 1990. The phyletic relationships of extant and fossil Pitheciinae (Platyrrhini, Anthropoidea). Journal of Human Evolution, New York, 19 (1-2): 175-208.

Kerr, R. 1792. The Animal Kingdom, a Zoologial System of the Celebrated Sir. Charles Linnaeus. Edinburgh, VII+40p. KINZEY, W.G. 1982. Distribuition of primates and forest refuges, p. 455-482. In: G.T. Prance (Ed). Biological Diversification in the Tropics. New York, Columbia University Press, XVI+714p.

Revista Brasileira de Zoologia 23 (1): 64-144, março 2006 
KuHL, H. 1820. Beiträge zur Zoologie und Vergleichenden Anatomie. Frankfurt, Hermannschen Buchhandlung, 152p.

LACÉPÈDE, B.G.E. DE LA V. 1799. Tableau des divisions, sousdivisions, ordres et genres de Mammifères. Paris, Plassan, $18 \mathrm{p}$.

Langguth, A; D.M. Teixeira; R.A. Mittermeier \& C. Bonvicino. 1987. The red-handed howler monkey in Northeastern Brazil. Primate Conservation, Washington, 8 (1): 36-39.

LAWrence, B. 1933. Howler monkeys of the palliata group. Bulletin of the Museum of Comparative Zoology, Harvard, 75 (8): 313-354.

Lesson, R.P. 1827. Manuel de Mammalogie ou Histoire Naturelle des Mammifères. Paris, J.B. Baillière et Fils., 441p.

Lesson, R.P. 1840. Species de Mammifères: Bimanes et quadrimanes; suivi d'un memoire sur les Oryctéropes. Paris, J.B. Baillère, VIII+291p.

Lima, M.M.C. \& H.N. Seuánez. 1989. Cytogenetic characterization of Alouatta belzebul with atypical pelage coloration. Folia Primatol, Basel, 52: 97-101.

Lima, M.M.C. \& H.N. Seú́nez. 1991. Chromosome studies in red howler monkey, Alouatta seniculus stramineus (Platyrrhini, Primates): description of an X1X2Y1Y2/X1X1X2X2 sex-chromosome system and karyological comparasions with other subspecies. Cytogenetic Cell Genetics, Basel, 57 (2-3): 151-156.

Lima, M.M.C.; M.I.C. Sampaio; M.P.C. Schneider; W. Scheffrahn; H.N. Schneider \& F.M. Salzano. 1990. Chromosome and protein variation in red howler monkeys. Revista Brasileira de Genética, Ribeirão Preto, 13 (4): 789-802.

LinNAEUS, C. 1758. Systema Naturae per Regna tria naturae, classes, ordines, genera, species cum bracteribus, differentiis, synonymis, locis. Regnum Animale. Estocolmo, Holmiae, $10^{\text {th }}$ ed., $823 \mathrm{p}$.

LinnaEus, C. 1766. Systema Naturae per Regna tria naturae, classes, ordines, genera, species cum bracteribus, differentiis, synonymis, locis. Regnum Animale. Estocolmo, Holmiae, 12 ed., vol. 1, 532p.

LÖNNBERG, E. 1941. Notes on members of the genera Alouatta and Aotus. Arkiv für Zoologi, Estocolmo, 33A (10): 1-44.

Lorini, M.L. \& V.G. Persson. 1990. A contribuição de AnDre Mayer à história natural do Paraná (Brasil) II. Mamíferos do terceiro planalto paranaense. Arquivos de Biologia e Tecnologia, Curitiba, 33 (1): 117-132.

Machado, A.B.M; G.A.B. da Fonseca; R.B. Machado; L.M. DE S. Aguiar \& L.V. Lins. 1998. Livro vermelho das espécies ameaçadas de extinção da fauna de Minas Gerais. Belo Horizonte, Fundação Biodiversitas, 605p.

MacPhee, R.D.E; I. Horovitz; O. Arredondo \& O.J. Vasquez. 1995. A new genus fot eh extinct Hispaniolan monkey Saimiri bernensis Rímoli, 1977, with note on its systematic position. American Museum Novitates, New York, 3134: 1-21.

Marcgrave, J. 1648. Historae Rerum Naturalium Brasiliae. Leiden, Lungdun. Batavorum. Historia Natural do Brasil
(1942). Tradução José Procópio de Magalhães, Edição do Museu Paulista, São Paulo, Imprensa Oficial, CIV+293p.

Marroig, G. 1995. Espécies ou subespécies em Callithrix. Neotropical Primates Washington, 3 (1): 10-13.

Mascarenhas, B.M. \& J.A.S.N. De Mello. 1987. Triatomídeos de Amazônia: ocorrência de triatomíneos na área do reservatório da HiDrelétrica de Tucuruí (Pará) e observações sobre o ciclo evolutivo de Rhodnius robustus Larrousse, 1927 (Hemiptera, Triatominae). Acta Amazonica, Manaus, 16/17: 607-616.

McLaren, S.B; D.A. Schlitter \& H.A. Genoways. 1984. Catalog of the recent Scandentia and Primates in the Carnegie Museum of Natural History. Annals of Carnegie Museum, Pittsburgh, 53: 463-487.

Meerwarth, H. 1903. Simios (macacos) do novo mundo. Chave para a obra monographica de H. Schlegel: Les singes (americans), 1876. Boletim do Museu Paraense Emilio Goeldi, Belém, 3: 121-154.

Meireles, C M; J. Czelusnick; M.P. Schneider; J.A.P.C. Muniz; M.C. Brigido; H.S. Ferreira \& M. Goodman. 1999. Phylogenetic relationships among Brazilian howler monkeys, genus Alouatta (Platyrrhini, Atelidae), based on - globin pseudogene sequeneces. Genetics and Molecular Biology, Ribeirão Preto, 22 (3): 337-344.

Melville, R.V. \& J.D.D. Smith. 1987. Official Lists and Indexes of Names and Works in Zoology. London, International Trust on Zoological Nomenclature, 366p.

Mendes, S.L. 1989. Estudo ecológico de Alouatta fusca (Primates, Cebidae) na estação ecológica de Caratinga. MG. Revista Nordestina de Biologia, João Pessoa, 6 (2): 71-104.

Mendez, J.L. 1953. Estudio de los mamiferos colectados. Memórias de la Sociedad de Ciencias Naturales "La Salle", Caracas, 13 (34): 81-120.

Miller, F.W. 1930. Notes on some mammals of southern Matto Grosso, Brazil. Journal of Mammalogy, Lawrence, 11 (1): $10-22$.

MindING, J. 1829. Über die Geographische Vertheilung der Säugethiere. Berlin, Enslinsche Buchhandlung.

Miranda-Ribeiro, A. 1914. Mammiferos. Publições e Comunicações das Linhas Telegráficas e Estratigráficas do MattoGrosso ao Amazonas, Rio de Janeiro, 17 (anexo 5): 1-49.

Miranda-Ribeiro, A. 1924. Alguns factos e mais dois simios novos da nossa fauna. Boletim do Museu Nacional, Rio de Janeiro, 12 (30): 211-215.

Mittermeier, R.A. \& A.F. CoImbra-Filho. 1981. Systematics: species and subspecies, p. 29-109. In: A.F. Coimbra-Filho \& R.A. Mittermeier (Eds). Ecology and Behavior of Neotropical Primates. Rio de Janeiro, Academia Brasileira de Ciências, vol 1, 496p.

Mittermeier, R.A.; A.F. Coimbra-Filho \& C.M.C. Valle. 1984. A conservação internacional de primatas, com ênfase nos primatas da Mata Atlântica no Brasil, p. 263-270. In: M.T. DE Mello (Ed.). A Primatologia no Brasil. I. Rio de Janeiro, Sociedade Brasileira de Primatologia, 402p. 
Mittermeier, R.A; A.R. Rylands \& A.R. Coimbra-Filho. 1988. Species and subspecies, p. 13-75. In: R.A. Mittermeier; A.B. Rylands; A. Coimbra-Filho \& G.A.B. Fonseca (Eds). Ecology and Behavior of Neotropical Primates. 2. Washington, World Wild Life Foundation, 610p.

Mudry-De-Pargament, M.D; M.L. Labal-De-Vinuesa; O.J. Colillas \& S. Brieux-de-Salum. 1984. Banding patterns of Alouatta caraya. Revista Brasileira de Genética, Ribeirão Preto, 7 (2): 373-379.

Müller, G.C.K; A. Krambeck; Z.M.B. Hirano \& H.H. Da S. Filho. 2000. Levantamento preliminar do endoparasitas do tubo disgetivo de bugios Alouatta guariba clamitans. Neotropical Primates, Washington, 8 (3): 107-108.

Muniz, J.A.P.C. \& W.R. KIngston. 1989. Relato da situação atual do Centro Nacional de Primatas, p. 259-270. In: C.J. SAAvedra; R. A. Mittermeier \& I.B. Santos (Eds). La Primatologia en Latinoamerica. Arequipa, WWF, 286p.

Murphey, R.M. 1976. Mammalia Americae Australe: a table of taxonomic and vernacular names. Ciencia Interamericana, Washington, 17 (1/4): 1-40.

Napier, P.H. 1976. Catalogue of primates in the British Museum (Natural History). Part 1: Families Callitrichidae and Cebidae. Publication of the British Museum of Natural History, London, 744: 1-121.

Neiva, A. \& B. Penna. 1916. Viagem científica pelo norte da Bahia, sudoeste de Pernambuco, sul do Piauhí e de norte de Goiaz. Memórias do Instituto Oswaldo Cruz, Rio de Janeiro, 8 (3): 74-224.

Neville, M.K; K.E. Slander; F. Braga \& A.B. Rylands. 1988. The howling monkeys, genus Alouatta. Pp. 349-453. In: R.A. Mittermeier; A.B. Rylands; A. Coimbra-Filho \& G.A.B. Fonseca (Eds). Ecology and behavior of Neotropical Primates. 2. Washington, World Wild Life Foundation, 610p.

NoWAK, R.M. \& J.L. PARADISO. 1983. Walker's mammals of the world. Baltimore, Johns Hopkins University Press, vol. 1, XLIV+568p+LXI.

Nunes, A.P; J.M. Ayres; E.S. Martins \& J.S. Silva. 1988. Primates of Roraima (Brazil). I. Northeastern part of the territory. Boletim do Museu Paraense Emilio Goeldi, Zoologia, Belém, 4 (1): 87-10.

OLFERS, I. 1818. Bemerkungen zu Illiger's Ueberblick der Säugthiere, nach ihrer Vertheilung über die Welttheile, rücksichtlich der Südamericanischen Arten. In: W.L. Eschwege (Ed.). Journal von Brasilien, Weimar, 15 (2): 1-304.

Oliveira, E.H.C. 1995. Chromosomal Variation in Alouatta fusca. Neotropical Primates, Washington, 3 (4): 181-182.

Oliveira, E.H.C. 1996. Cytogenetic and phylogenetic studies of Alouatta from Brasil and Argentina. Neotropical Primates, Washington, 4 (4): 156-157.

Oliveira, E.H.C; M. Neusser; W.B. Figueiredo; C. Nagamachi; J.C. Pieczarka; I.J. Sbalqueiro; J. Wienberg \& S. Muller. 2002. The phylogeny of howler monkeys (Alouatta, Platyrrhini): reconstruction by multicolor cross-species chromosome paiting. Chromosome Research, Exceter, 10 (8): 669-683. Pelzeln, A. von. 1883. Brasilische Saügethiere. Resultate von Johann Naterer's Reisen in der Jahren 1817 bis 1835. Wien, A. Hólder, II+140p.

Pereira, F.R.; A.M. Gonçalves; F.R. Melo \& R.N. Feio. 1995. Primates from the vinicity of Viçosa, Minas Gerais, Brazil. Neotropical Primates, Washington, 3 (4): 171-173.

Persson, V.C. \& M.L. Lorini. 1988. Contribuição ao conhecimento mastofaunístico da porção centro-sul do estado do Paraná. Acta Biologica Leopoldensia, São Leopoldo, 12 (1): 79-88.

Pine, R.H. 1973. Mammals (exclusive of bats) of Belém, Pará, Brazil. Acta Amazonica, Manaus, 3 (2): 47-79.

PINTO, L.P. \& E.Z.F. SETz. 2000. Sympatry and new locality for Alouatta blezebul discolor and Alouatta seniculus in Southern Amazon. Neotropical Primates, Washington, 8 (4): 150-151.

PINTO, R.M. \& D.C. Gomes. 1976. Contribuição ao conhecimento da fauna helmintológica da região amazônica - Cestódeos. Memórias do Instituto Oswaldo Cruz, Rio de Janeiro, 74 (1): 53-64.

Printes, R.C.; M.V.A. Liesenfeld \& L. Jerusalinky. 2001. Alouatta guariba clamitans Cabrera, 1940: a new southern limit for the species and for Neotropical primates. Neotropical Primates, Washington, 9 (3): 118-121.

Pynter, R.A. \& M.A. TraYlor JR. 1991. Ornithological Gazetteer of Brazil. Harvard, Harvard College, VIII+789p.

Ravosa, M.J. \& C.F. Ross. 1994. Craniodental allometry and heterochrony in two howler monkeys: Alouatta seniculus and A. palliata. American Journal of Primatology, Los Angeles, 33 (4): 277-299.

RichaRD, M.A. 1835. Oeuvres complètes De Buffon. Histoire des Animaux. Paris, Pourrat Frères.

Rode, P. 1938. Catalogue des types de mammifères du Muséum National d'Histoire Naturelle, OrDre des primates, sousorDres des Simiens. Bulletin du Muséum d'Histoire Naturelle de Paris, Paris, 10 (3): 202-251.

Ruschi, A. 1964. Macacos do Estado do Espirito Santo. Boletim do Museu de Biologia Professor Mello Leitão, Zoologia, Santa Teresa, 23A: 1-23.

Ruschi A. 1965. Lista dos mamíferos do Estado do Espírito Santo. Boletim do Museu de Biologia Professor Mello Leitão, Zoologia, Santa Teresa, 24A: 1-40.

Rylands, A.B. 1994a. Bugio, Guariba, Barbado, Alouatta fusca, p. 161-170. In: G.A.B. Fonseca; A.B. Rylands \& Y.L.R. Leite (Eds). Livro vermelho dos mamíferos brasileiros ameaçados de extinção. Belo Horizonte, Fundação Biodiversitas, $\mathrm{XX}+459 \mathrm{p}$.

Rylands, A.B. 1994b. Guariba-preto, guariba-de-mãos-ruivas, Alouatta belzebul belzebul, p. 153-159. In: G.A.B. FonsECA; A.B. Rylands; C.M.R. Costa; R.B. Machado \& Y.L.R. Leite. (Eds). Livro vermelho dos mamíferos brasileiros ameaçados de extinção. Belo Horizonte, Fundação Biodiversitas, XX+459p.

Rylands, A.B. \& D. Brandon-Jones. 1998. Scientific nomenclature of the Red Howlers from the northeastern Amazon in Brazil, 
Venezuela, and the Guianas. International Journal of Primatology, New York, 19 (5): 879905.

Rylands, A.B.; G.A.B. DA Fonseca; Y.L.R. Leite \& A.R. Mittermeier. 1996. Primates of the Atlantic Forest, p 21-51. In: M.A. NARCONK; A.L. Rosenberger \& P.A. Garber (Eds). Adaptative radiations of Neotropical Primates. New York, Plenum Press, 553p.

Rylands, A.B; W.R. Sirironelo; V.L. Tornisielo; R.L. De SA; M.C.M. KierulfF \& I.B. SANTos. 1988. Primates of the Rio Jequitinhonha Valley, Minas Gerais, Brazil. Primate Conservation, Washington, 9: 10-109.

Rylands, A.B. \& A. Keuroghlian. 1989. Primate populations in continuos forest and forest fragments in central Amazonian. Acta Amazonica, Manaus, 18 (3-4): 291-307.

RYlands, A.B; R.A. MitTermeir \& E. RodríGuez-luna. 1995. A species list for the New World primates (Platyrrhini): distribution by country, endemism, and conservation status according to the Mace-Land System. Neotropical Primates, Washington, 3 (Suppl.): 113-160.

Rylands, A.B; H. Schneider; R.A. Mittermeier; C. Groves \& E. Rodríguez-LunA. 2000. An assessment of the diversity of New World primates. Neotropical Primates, Washington, 8 (2): 61-93.

SALDANHA, P.H. 1982. Os primatas sul-americanos em face às investigações genéticas, p. 65-81. In: P. SAldanHa (Ed.). Genética comparada de primatas brasileiros. Ribeirão Preto, Sociedade Brasileira de Genética, 172p.

SAmpaio, I; M.P.C. Schneider \& H. Schneider. 1996. Taxonomy of the Alouatta seniculus group: biochemical and chromosome data. Primates, Aichi, 37 (1): 65-73.

SANDERSON, I.T. 1949. A brief review of the mammals of Suriname (Dutch Guiana), based upon a collection made in 1938. Proceedings of the Zoological Society of London 119 (3): 755-788.

Sanderson, M.J. \& M.J. Donoghue. 1989. Patterns of variation in levels of homoplasy. Evolution, Lancaster, 43 (8): 17811795.

Santos, I.B; R.A. Mittermeier; A.B. Rylands \& C.M.C. Valle. 1987. The distribution and conservation status of primates in Southern Bahia, Brazil. Primate Conservation, Washington, 8: 126-131.

Schlegel, H. 1876. Monographie des singes. Leiden, E.J. Brill. SCHNeIder, H. \& A.L. Rosenberger. 1996. Molecules, morphology, and platyrrhine systematics, p. 1-19. In: M.A. Norconk; A.L. Rosenberger \& P.A. Garber (Eds). Adaptative radiations of Neotropical Primates. New York, Plenum Press, 553p.

Schneider, H.; M.I.C. SAMPaio; M.P.C. SchneIder; J.M. Ayres; C.M.I. Barroso; A.R. Hamel; B.T.F. Silva \& F.M. Salzano. 1991. Coat color and biochemical variation in amazonian wild populations of Alouatta belzebul. American Journal of Physical Anthropology, Columbus, 85 (1): 85-93.

Schneider, H; M.P.C. Schneider; I. Sampaio, M.L. Harada; M. Stanhope; J. Czelusniak. M. Goodman. 1993. Moleculare Phylony of the New World Monkeys (Platyrrhini, Primates).
Molecular Phylogenetics and Evolution, London, 2 (3): $225-242$

Schomburgk, R. 1848. Reisen in Britisch-Guiana in den jahren 1840-1844. Leipzig, vol. 1.

Schultz, A.H. 1926. Studies on the variability of Platyrrhini monkeys. Journal of Mammalogy, Lawrence, 7 (4): 286-305.

Schultz, A.H. 1960. Age Changes and variability in the skull and teeth of the central american monkeys Alouatta, Cebus and Ateles. Proceeding of the Zoological Society of London 133 (3): 337-390.

SClater, P.L. 1872. On the quadrumana found in America noth of Panama. Proceedings of the Zoological Society of London (1): 2-8.

SERRA, O.D. 1952. A seqüência eruptiva dos dentes definitivos nos símios platyrrhina e sua interpretação filogenética. Anais da Faculdade de Farmácia e Odontologia, São Paulo, 10: 215-301.

SERRA, O.D. 1957. Singular anomalia maxilo-dental em um bugio (Alouatta nigerrima - Primates, Mammalia). Papéis Avulsos de Zoologia, São Paulo, 13 (3): 45-49.

SHAW, G. 1800. General Zoology or Systematic Natural History. London, G. Kearsley, vol. 1, part 1.

SiLVA JR., E.C. 1981. A preliminary survey of brown howler monkeys (Alouatta fusca) at the Cantareira Reserve (São Paulo, Brazil). Revista Brasileira de Biologia, Rio de Janeiro, 41 (4): 897-909.

SLACK, M.D. 1862. Monograph of the prehensile-tailed Quadrumana. Proceedings of the Academy of Natural Science of Philadelphia, Philadelphia, 14: 507-519.

SPIX, J.B. von. 1823. Simiarum et vespertilionum Brasiliensium species novae ou Histoire Naturelle des Espèces Nouvelles de Singes et de Chauves-souris observées et recueillies pendant le voyage dans l'intérieur du Brésil. Munique, Typis Francisci Seraphici Hubschmanni, VIII+72p.

Stallings, J.R. 1989. Status y conservación de primatas en el Paraguay, p. 133-151. In: C.J. SaAvedra; R.A. Mittermeier \& I.B. SAntos (Eds). La Primatologia en Latinoamerica. Arequipa, WWF, 286p.

TATE, G.H.H. 1939. The mammals of the Guiana region: general environment and faunistic treatment. Bulletin of the American Museum of Natural History, New York, 76 (5): 151-229.

ThomAs, O. 1911. The mammals of the Tenth Edition of Linnaeus, an attemp to fix the types of the genera and the exact bases and localities of the species. Proceedings of the Zoological Society of London: 120-155.

Thomas, O. 1912. On small mammals from the lower Amazon. Annals and Magazine of Natural History, London, 9 (8): 84-90.

Thomas, O. 1913. New mammals from South America. Annals and Magazine of Natural History, London, 8 (12): 567-574.

Thorington JR., R.W. \& S. Anderson. 1984. Primates, p. 187-217. In: S. ANDERson \& J.K. JONES Jr. (Eds). Orders and families of

Revista Brasileira de Zoologia 23 (1): 64-144, março 2006 
recent mammals of the world. New York, John Wiley \& Sons, VIII+453p.

Thunberg, C.P. 1823a. Fauna Americae Meridionalis. Upsaliae, Palmblad et C, 11p.

Thunberg, C.P. 1823b. Fauna Cayanensis. Upsaliae, Palmblad et C., $12 p$.

Trouessart, E.L. 1897. Catalogous Mammalium tam Viventium quam Fossilium. Fasciculus I. Primates, Prosimiae, Chiroptera, Insectivora. Berolini, R. Friedlander \& Sohn, $\mathrm{V}+218 \mathrm{p}$.

VANE-WRIGHT, R.I. 2003. Indifferent philosophy versus almighty authority: on consistency, consensus and unitary taxonomy. Systematics and Biodiversity, London, 1 (1): 3-11.

Vanzolini, P.E. 1992. A supplement to the Ornithological Gazetteer of Brazil. São Paulo, Museu de Zoologia, Universidade de São Paulo, 252p.

VAZ, S.M. 1981. Contribuição ao estudo da fauna de mamíferos do Parque Nacional da Serra dos Órgãos. Boletim Fundo Brasileiro para a Conservação da Natureza, Rio de Janeiro, 16: 104-114.

VAZ, S.M. 1983. Contribuição ao estudo da fauna de mamíferos da Reserva Biológica de Poço das Antas. Brasil Florestal, Brasília, 55: 33-35.

Vieira, C.C. 1944. Os símios do estado de São Paulo. Papéis Avulsos de Zoologia, São Paulo, 4 (1): 1-31.

Vieira, C.C. 1948. Nova contribuição ao conhecimento dos mamíferos do Rio Juruá. Boletim do Museu Paraense Emilio Goeldi, Belém, 10: 239-274.

Vieira, C.C. 1951. Notas sobre os mamíferos obtidos pela expedição do Instituto Butantã ao Rio das Mortes e serra do Roncador. Papéis Avulsos de Zoologia, São Paulo, 10 (4): 105-125.

VieIRA, C.C. 1955. Lista remissiva dos mamíferos do Brasil. Arquivos de Zoologia, São Paulo, 8 (10): 341-474.

Vieira, C.C. 1957. Sobre Mamíferos do Estado do Maranhão. Papéis Avulsos de Zoologia, São Paulo, 13 (10): 125-132.

Villalba, J.S; C.M. Priogionini \& A.C. SAPpa. 1995. Sobre la posible presencia de Alouatta caraya em Uruguay. Neotropical Primates, Washington, 3 (4): 173-174.

VIVo, M. DE. 1991. Taxonomia de Callithrix Erxleben, 1777 (Callitrichidae, Primates). Belo Horizonte, Fundação Biodiversitas, 99p.

VIVO, M. DE. 1997. Mammalian evidence of historical ecological chance in the Caatinga semiarid vegetation of Northeastern Brazil. Journal of Comparative Biology, Ribeirão Preto, 2 (1): $65-73$.

Voss, W.A. 1973. Ensaio da lista sistemática dos mamíferos do Rio Grande do Sul, Brasil. Pesquisas Zoológicas, Porto Alegre, 25: 1-35.

WAGNER, J.A. 1840. Die Säugthiere in Abbildulungen nach der Natur mit Beschreibungen von Dr. Johann Christian Daniel von Schreber. Erlangen, Suppl., vol. 1, XIV+551p.

WAGNER, J.A. 1855. Die Säugthiere in Abbildulungen nach der Natur mit Beschreibungen von Dr. Johann Christian Daniel von Schreber. Leipzig, Suppl., vol. 5, XVI+810p.

Wallace, A. 1854. On the monkeys of the Amazon. Proceeding of the Zoological Society of London, London, 1854: 451454.

WIED, P. 1823. Abbildungen zur naturgeschichte brasiliens. Weimar, Verlage des Grossherzogl. Sachs. priv. Landes Industrie Comptoirs, pt. 4, p.16.

WIED, M. 1826. Beitrage zur Naturgeschichte von Brasilien. Weimar, Lands, vol. 2, 620p.

Wolfheim, J.H. 1983. Primates of the World. Chur Swit, Harwood Academic Publishers Gmbh, XXIII+831p.

Ximentz, A. 1973. Algunos mamiferos venezoelanos en las colleciones del Museo Nacional de Historia Natural (Montevideo, Uruguay). In: Actas VI Congresso Latinoamericano Zoologia, México, vol. 1, p. 257-262.

ZAR, J.H. 1999. Biostatistical Analysis. Upper Saddle River, Prentice Hall, XII+663p.

Yunis, E.J.; O.M.T. Caballero; C. Ramirez \& E.Z. Ramirez. 1976. Chromosomal variation in the primates Alouatta seniculus seniculus. Folia Primatologica, Basel, 25 (2-3): 215-225.

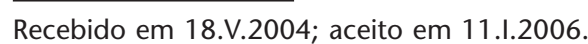

Anexo I. Lista de topônimos brasileiros.

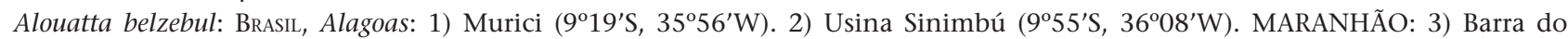
Corda (Aldeia São Pedro) (5 $\left.5^{\circ} 32^{\prime} \mathrm{S}, 4^{\circ} 16^{\prime} \mathrm{W}\right)$. 4) Imperatriz $\left(5^{\circ} 32^{\prime} \mathrm{S}, 4^{\circ} 29^{\prime} \mathrm{W}\right)$. PARÁ: 5) Igarapé Araripe (126 Km sul da barragem Tucuruí, m. e. Rio Tocantins) (localidade retirada de Mascarenhas \& Mello 1987). 06) Rio Bacajá (boca) ( ${ }^{\circ} 36^{\prime} S, 5^{\circ} 54^{\prime}$ W). 7) Belém ( $\left.1^{\circ} 26^{\prime} \mathrm{S}, 48^{\circ} 29^{\prime} \mathrm{W}\right) .8$ ) Cametá ( $\left.{ }^{\circ} 15^{\prime} \mathrm{S}, 49^{\circ} 30^{\prime} \mathrm{W}\right)$. 9) Canoal (30 Km sul da Barragem Tucuruí, m. d. Rio Tocantins) (localidade retirada de Mascarenhas \& Mello 1987). 10) Rio Capim (1º $\left.40^{\prime} \mathrm{S}, 47^{\circ} 47^{\prime} \mathrm{W}\right)$; localidade-tipo de Simia belzebul, citado em Cabrera (1958). 11) Serra dos Carajás (inclui áreas de Cobre e Manganês) $\left(6^{\circ} 10^{\prime} S, 50^{\circ} 15^{\prime} W\right)$. 12) Ilha Caviana $\left(0^{\circ} 05^{\prime} S\right.$, $\left.50^{\circ} \mathrm{W}\right)$. 13) Vale do Caraípe (= Caraipé) $\left(3^{\circ} 50^{\prime} \mathrm{S}, 4^{\circ} 44^{\prime} \mathrm{W}\right)$. 14) Chiqueirinho (70 Km sul da barragem Tucuruí, m. d. Rio

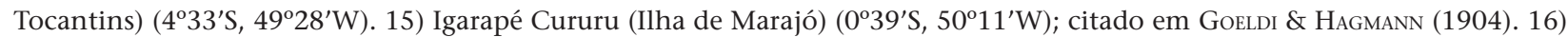

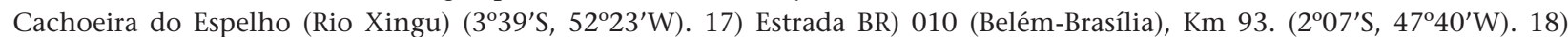

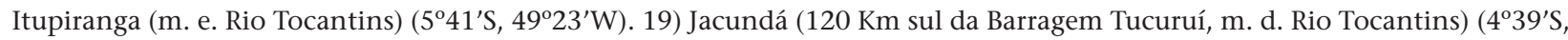




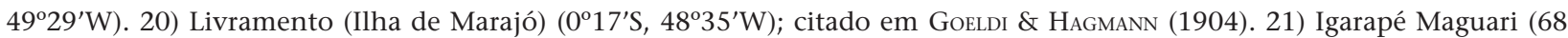

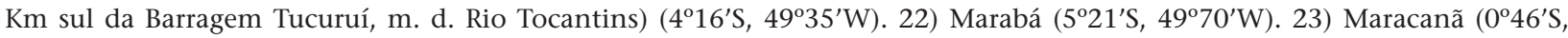

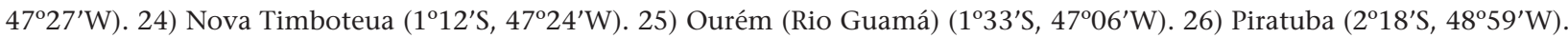
27) Paragominas ( $\left.3^{\circ} \mathrm{S}, 47^{\circ} 19^{\prime} \mathrm{W}\right)$. 28) Ponta de Pedras (Rio Ariri, Ilha de Marajó) ( $\left.0^{\circ} 50^{\prime} \mathrm{S}, 4^{\circ} 07^{\prime} \mathrm{W}\right)$. 29) Rio Pracupy (Portel) $\left(1^{\circ} 57^{\prime} \mathrm{S}, 50^{\circ} 49^{\prime} \mathrm{W}\right)$. 30) Santo Antônio (m. d. Rio Tocantins) (2 $\left.2^{\circ} 49^{\prime} \mathrm{S}, 49^{\circ} 40^{\prime} \mathrm{W}\right)$. 31) Saúde (170 Km sul da Barragem Tucuruí, m.

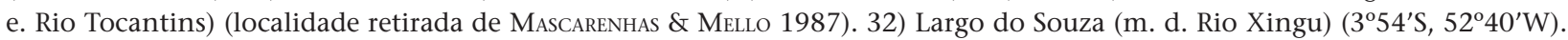
33) Igarapé Taperebá (Chaves, Ilha de Marajó) $\left(0^{\circ} 10^{\prime} \mathrm{S}, 4^{\circ} 07^{\prime} \mathrm{W}\right)$. 34) Ilha Tocantins $\left(4^{\circ} 25^{\prime} \mathrm{S}, 4^{\circ} 32^{\prime} \mathrm{W}\right)$. 35) Usina Hidrelétrica de Tucuruí ( $\left.4^{\circ} 25^{\prime} \mathrm{S}, 49^{\circ} 40^{\prime} \mathrm{W}\right)$. 36) Vila Brabo (30 Km sul da Barragem Tucuruí, m. d. Rio Tocantins) $\left(4^{\circ} 16^{\prime} \mathrm{S}, 4^{\circ} 35^{\prime} \mathrm{W}\right)$. Paraíba: 37) Sapé (Fazenda Pacatuba) ( $\left.7^{\circ} 06^{\prime} \mathrm{S}, 35^{\circ} 13^{\prime} \mathrm{W}\right)$. Pernanbuco: 38) Água Preta (Usina Sacramento) $\left(8^{\circ} 42^{\prime} \mathrm{S}, 35^{\circ} 31^{\prime} \mathrm{W}\right)$; citado em Hirsch et al. (1991). Piauí: 39) Angico, Parnaguá (citado em Neiva \& Penna 1916). Rio Grande do Norte: 40) Mata da Estrela, Baía Formosa (citado em Coimbra-Filho et al. 1995). Tocantins: 41) Araguaína ( $\left.7^{\circ} 21^{\circ} \mathrm{S}, 48^{\circ} 13^{\prime} \mathrm{W}\right)$.

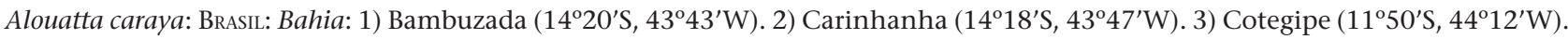

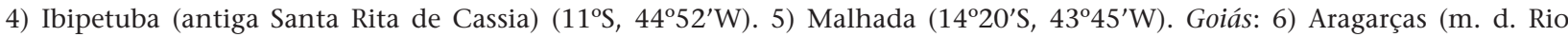

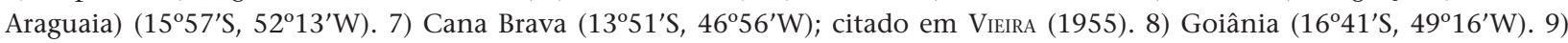
Inhumas (12 $\left.27^{\prime} \mathrm{S}, 46^{\circ} 56^{\prime} \mathrm{W}\right)$; citado em Vieira (1955). 10) Niquelândia (antiga São José do Tocantins) $\left(14^{\circ} 27^{\prime} \mathrm{S}, 4^{\circ} 27^{\prime} \mathrm{W}\right)$. 11) Rio Palma (12 $33^{\circ}$ 'S, $\left.47^{\circ} 52^{\prime} \mathrm{W}\right)$. 12) Barra do Rio São Domingos ( $\left.12^{\circ} 43^{\prime} \mathrm{S}, 47^{\circ} 46^{\prime} \mathrm{W}\right)$. 13) São Miguel (12 $\left.25^{\prime} \mathrm{S}, 4^{\circ} \mathrm{W}\right)$. Maranhão: 14) alto do Rio Parnaíba (9 $\left.9^{\circ} 06^{\prime} \mathrm{S}, 4^{\circ} 58^{\prime} \mathrm{W}\right)$. Mato Grosso: 15 Rio Arrais (alto Rio Xingu) $\left(11^{\circ} 25^{\prime} \mathrm{S}, 57^{\circ} 44^{\prime} \mathrm{W}\right)$. 16) Cáceres (= São

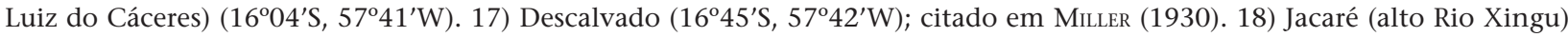

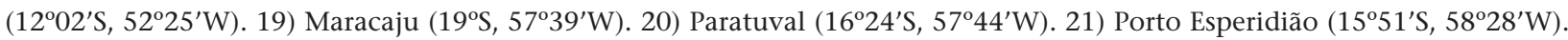

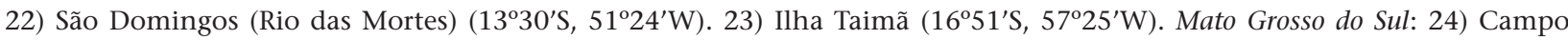

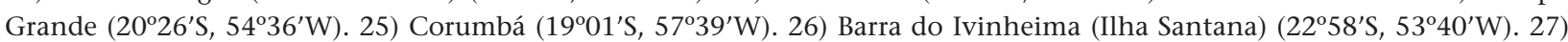

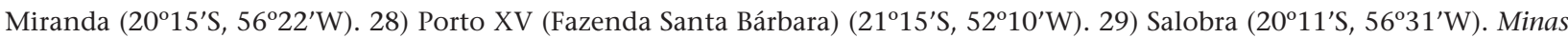
Gerais: 30) Araguari (m. d. Rio Grande) (18 $\left.\left.8^{\circ} 38^{\prime} \mathrm{S}, 48^{\circ} 11^{\prime} \mathrm{W}\right) .31\right)$ Brasília de Minas (antiga Contendas) $\left(16^{\circ} 12^{\prime} \mathrm{S}, 4^{\circ} 26^{\prime} \mathrm{W}\right)$;

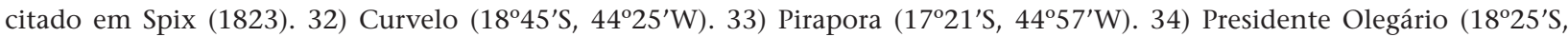
46²5’W). Pará: 35) Conceição do Araguaia (Rio Araguaia) (localidade retirada de HiRsch et al. 1991); citado em Hirsch et al.

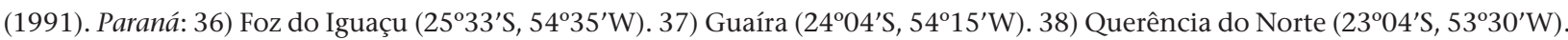
39) Rio Pacaraí $\left(23^{\circ} 28^{\prime}\right.$ S, $\left.53^{\circ} 56^{\prime} \mathrm{W}\right)$. 40) Sertão do Rio Paraná (entre os municípios de Guaíra e São Pedro do Paraná, segundo

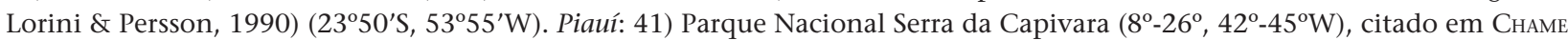
et al. (1985). 42) Chapada das Mangabeiras $\left(9^{\circ}-11^{\circ}, 45^{\circ}-47^{\circ} \mathrm{W}\right)$, citado em Flesher (2001). Rio Grande do Sul: 43) São Francisco de Assis (29 $\left.33^{\prime} \mathrm{S}, 5^{\circ} 08^{\prime} \mathrm{W}\right)$. 44) São Luiz Gonzaga ( $\left.28^{\circ} 24^{\prime} \mathrm{S}, 5^{\circ} 58^{\prime} \mathrm{W}\right)$. São Paulo: 45$)$ Catanduva $\left(21^{\circ} 08^{\prime} \mathrm{S}, 4^{\circ} 58^{\prime} \mathrm{W}\right)$; observação pessoal. 46) Itapura $\left(20^{\circ} 40^{\prime} \mathrm{S}, 51^{\circ} 31^{\prime} \mathrm{W}\right)$.

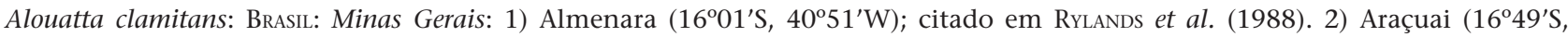

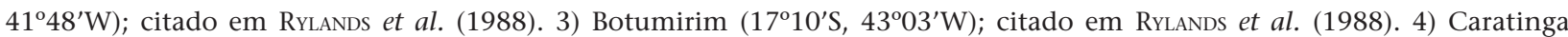

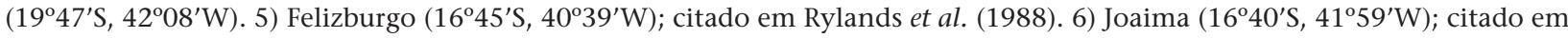

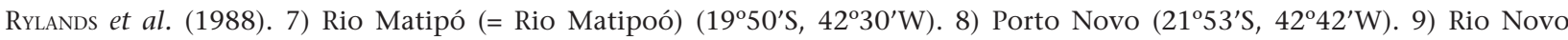
$\left.\left(21^{\circ} 29^{\prime} \mathrm{S}, 43^{\circ} 08^{\prime} \mathrm{W}\right) .10\right)$ Salto de Divisa (15 $\left.57^{\prime} \mathrm{S}, 40^{\circ} 05^{\prime} \mathrm{W}\right)$; citado em Rylands et al. (1988). Paraná: 11) Biturama (= Bituruna)

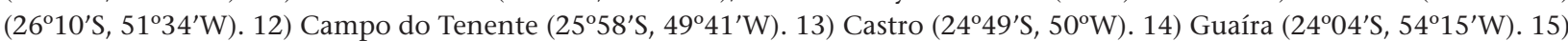
Icaraima $\left(23^{\circ} 23^{\prime} \mathrm{S}, 53^{\circ} 41^{\prime} \mathrm{W}\right)$. 16) Palmeiras (Fazenda Santa Rita) $\left(25^{\circ} 25^{\prime} \mathrm{S}, 5^{\circ}\right)$. 17) Palmas (Fazenda Estância Nova) (26 $30^{\prime} \mathrm{S}$, $\left.52^{\circ}\right)$. 18) Porto Camargo ( $\left.23^{\circ} 21^{\prime} \mathrm{S}, 53^{\circ} 44^{\prime} \mathrm{W}\right)$. 19) Querência do Norte ( $\left.23^{\circ} 04^{\prime} \mathrm{S}, 53^{\circ} 30^{\prime} \mathrm{W}\right)$. 20) Roça Nova $\left(25^{\circ} 34^{\prime} \mathrm{S}, 5^{\circ} 2^{\circ} 55^{\prime} \mathrm{W}\right)$; citado em Napier (1976). 21) Sertão do Rio Paraná (entre os municípios de Guaíra e São Pedro do Paraná, segundo LoRINI \&

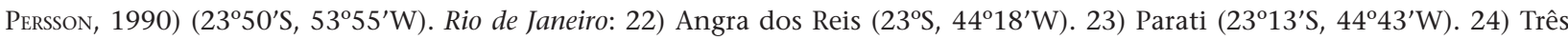

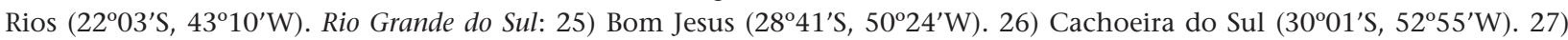

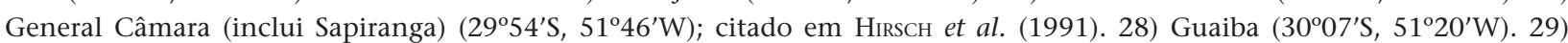

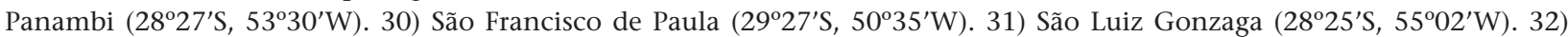

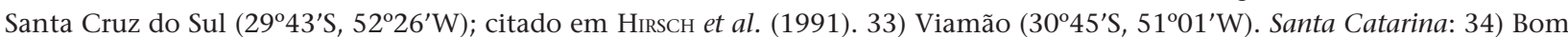

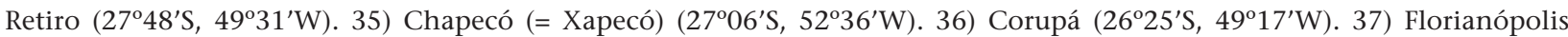

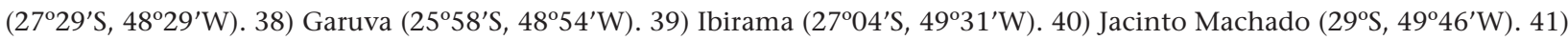
Jaraguá do Sul $\left(26^{\circ} 29^{\prime} \mathrm{S}, 4^{\circ} 04^{\prime} \mathrm{W}\right)$. 42) Joinville (26 $\left.{ }^{\circ} 18^{\prime} \mathrm{S}, 48^{\circ} 50^{\prime} \mathrm{W}\right)$. 43) Praia Grande $\left(29^{\circ} 12^{\prime} \mathrm{S}, 4^{\circ} 57^{\prime} \mathrm{W}\right)$. 44) São Joaquim

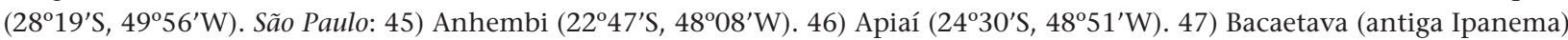

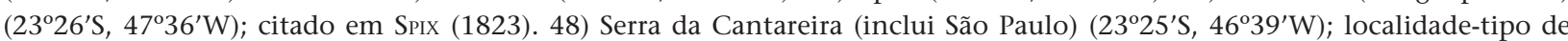
Alouatta fusca clamitans. 49) Itararé ( $\left.24^{\circ} 07^{\prime} \mathrm{S}, 49^{\circ} 20^{\prime} \mathrm{W}\right)$.; citado em Pelzeln (1883). 50) Lins (Fazenda Varjão) $\left(21^{\circ} 39^{\prime} \mathrm{S}, 4^{\circ} 45^{\prime} \mathrm{W}\right)$.

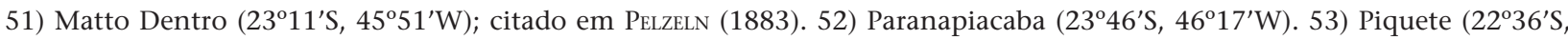

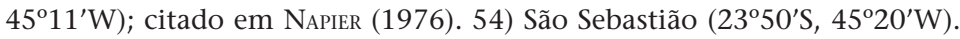

Revista Brasileira de Zoologia 23 (1): 64-144, março 2006 


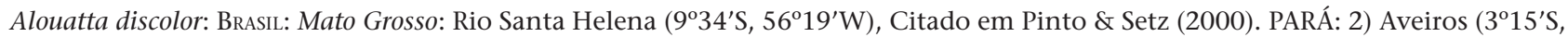
$55^{\circ} 20^{\prime} \mathrm{W}$ ); localidade-tipo de Alouatta belzebul tapajozensis; citado em LönnBerg (1941). 3) Barreira (inclui Monte Cristo) (m. d. Rio Tapajós) ( $\left.4^{\circ} 04^{\prime} \mathrm{S}, 55^{\circ} 45^{\prime} \mathrm{W}\right)$. 4) Boiuçú (= Buiuçú), Rio Amazonas ( $\left.1^{\circ} 55^{\prime} \mathrm{S}, 55^{\circ} 17^{\prime} \mathrm{W}\right)$. 05) Serra do Cachimbo ( $\left.8^{\circ} 57^{\prime} \mathrm{S}, 54^{\circ} 54^{\prime} \mathrm{W}\right)$. 6) Caxiricatuba (m. d. Rio Tapajós) ( $\left.2^{\circ} 45^{\prime} \mathrm{S}, 5^{\circ} 02^{\prime} \mathrm{W}\right)$. 07) Rio Cururu (m. d. Rio Tapajós) $\left(8^{\circ} \mathrm{S}, 56^{\circ} \mathrm{W}\right)$. 8) Fordlândia (m. d. Rio

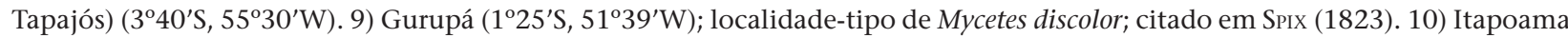
(inclui Marai) ( $\left.3^{\circ} 18^{\prime} \mathrm{S}, 5^{\circ} 12^{\prime} \mathrm{W}\right)$; citado em Lönnberg (1941). 11) Ilha Mexiana $\left(0^{\circ} 02^{\prime} \mathrm{S}, 4^{\circ} 35^{\prime} \mathrm{W}\right)$; localidade-tipo de Mycetes belzebul mexianae. 12) Piquiatuba (inclui Santarém e Rio Tapajós) (m. d. Rio Tapajós) (2²7'S, 5455’W). 13) Porto de Moz

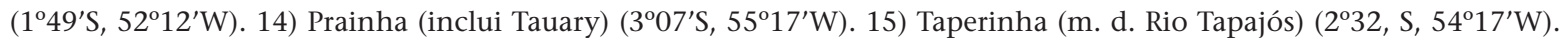

Alouatta fusca: BrasiL: Bahia: 1) Rio Paraguassú (localidade não determinada); localidade-tipo de Alouatta guariba; citado em Cabrera

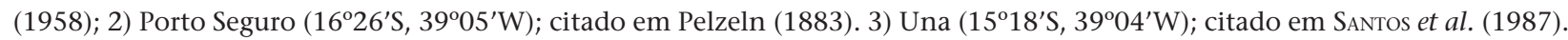

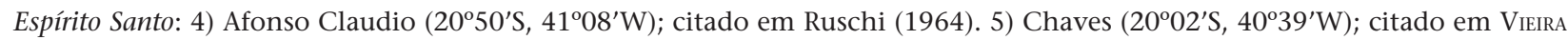

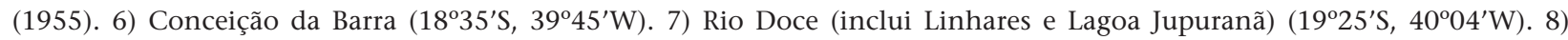

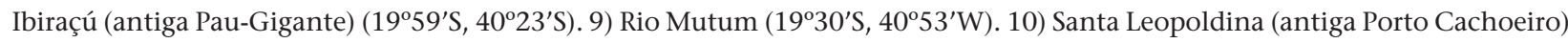

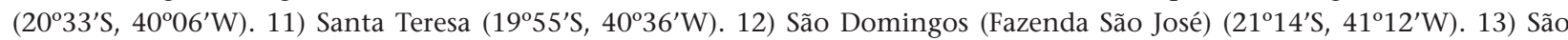
Mateus (18 $\left.44^{\prime} \mathrm{S}, 3^{\circ} 51^{\prime} \mathrm{W}\right)$; citado em Ruschi (1964). Minas Gerais: 14) Alegria Simonésia (20 $\left.{ }^{\circ} 07^{\prime} \mathrm{S}, 4^{\circ} 2^{\circ} 01^{\prime} \mathrm{W}\right)$. 15) Floresta

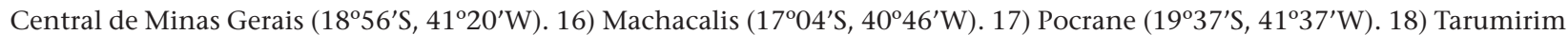

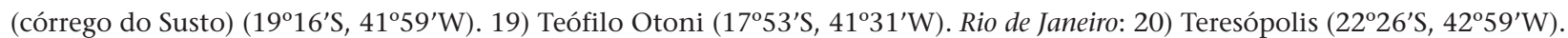

Alouatta juara: Brasil: Acre: 1) Taumaturgo ( $\left.8^{\circ} 57^{\prime} \mathrm{S}, 72^{\circ} 48^{\prime} \mathrm{W}\right)$. Amazonas: 2) Eirunepé (m. e. Rio Juruá) (6 $\left.6^{\circ} 40^{\prime} \mathrm{S}, 6^{\circ} 53^{\prime} \mathrm{W}\right)$. 3) Estirão do Ecuador (Rio Javari) ( $\left.4^{\circ} 26^{\prime} \mathrm{S}, 71^{\circ} 30^{\prime} \mathrm{W}\right)$. 4) Fonte Boa $\left(1^{\circ} 08^{\prime} \mathrm{N}, 67^{\circ} 12^{\prime} \mathrm{W}\right)$. 5) Lago Tracajá, Rio Japurá ( $\left.\left.3^{\circ} 09^{\prime} \mathrm{S}, 6^{\circ} 46^{\prime} \mathrm{W}\right) .06\right)$

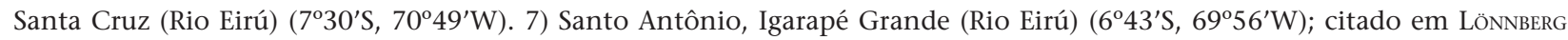
(1941).

Alouatta macconnelli: Brasil: Amapá: 1) Amapá ( $\left.2^{\circ} \mathrm{N}, 50^{\circ} 50^{\prime} \mathrm{W}\right)$. 02) Macapá $\left(0^{\circ}, 51^{\circ} 02^{\prime} \mathrm{W}\right)$. 3) Rio Maracá, Mazagão (inclui Rio Vila Nova) $\left.\left(0^{\circ} 20^{\prime} \mathrm{S}, 51^{\circ} 50^{\prime} \mathrm{W}\right) .04\right)$ Posto do DNER (Rio Tracajatuba) $\left.\left(0^{\circ} 56^{\prime} \mathrm{N}, 51^{\circ} \mathrm{W}\right) .5\right)$ Vila Terezinha (Serra do Navio) $\left(0^{\circ} 58^{\prime} \mathrm{N}\right.$,

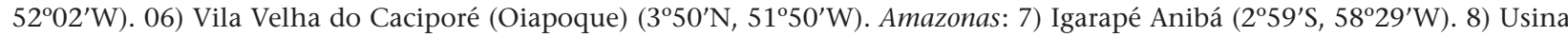

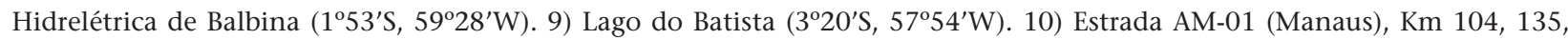
160, $\left.170\left(3^{\circ} \mathrm{S}, 5^{\circ} 20^{\prime} \mathrm{W}\right) .11\right)$ Estrada AM-10 (Manaus-Itacoatiara), Km $\left.47\left(3^{\circ} 01^{\prime} \mathrm{S}, 59^{\circ} \mathrm{W}\right) .12\right)$ Itacoatiara $\left.\left(3^{\circ} 08^{\prime} \mathrm{S}, 58^{\circ} 26^{\prime} \mathrm{W}\right) .13\right)$ Itapiranga $\left.\left(2^{\circ} 45^{\prime} \mathrm{S}, 58^{\circ} 01^{\prime} \mathrm{W}\right) .14\right)$ Manaus (inclui Bacabau) $\left.\left(3^{\circ} 08^{\prime} \mathrm{S}, 60^{\circ} \mathrm{W}\right) .15\right)$ Patuá $\left(1^{\circ} 48^{\prime} \mathrm{S}, 55^{\circ} 23^{\prime} \mathrm{W}\right)$. 16) Silves $\left(2^{\circ} 50^{\prime} \mathrm{S}\right.$,

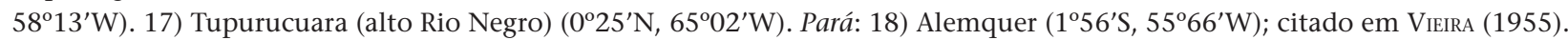

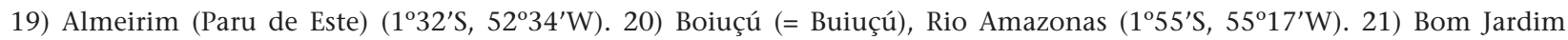

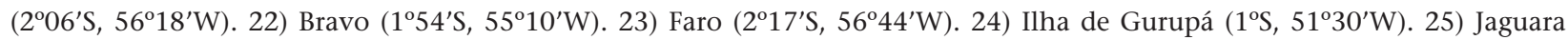

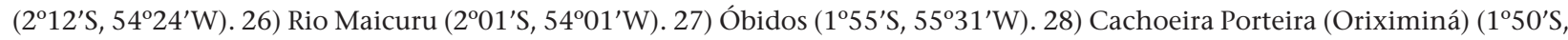
$\left.\left.57^{\circ} 02^{\prime} \mathrm{W}\right) .29\right)$ Cachoeira Santo Antônio (Rio Jari) $\left(0^{\circ} 39^{\prime} \mathrm{S}, 52^{\circ} 31^{\prime} \mathrm{W}\right)$. 30) Cachoeira do Tronco (Rio Erepecurú) $\left(1^{\circ} 04^{\prime} \mathrm{S}, 56^{\circ} 02^{\prime} \mathrm{W}\right)$. Roraima: 31) Boa Vista $\left(2^{\circ} 49^{\prime} \mathrm{N}, 60^{\circ} 40^{\prime} \mathrm{W}\right)$. 32) Ilha de Maracá $\left(0^{\circ} 22^{\prime} \mathrm{N}, 51^{\circ} 20^{\prime} \mathrm{W}\right)$ citado em Nunes et al. (1988). 33) Rio Mucujaí (Fazenda Capitão Ene) ( $\left.2^{\circ} 40^{\prime} \mathrm{N}, 60^{\circ} 58^{\prime} \mathrm{W}\right)$. Guiana Francesa: 34$)$ Cayenne ( $\left.4^{\circ} 56^{\prime} \mathrm{N}, 52^{\circ} 20^{\prime} \mathrm{W}\right)$; localidade-tipo de Simia straminea; citado em LÖNNBERG (1941). 35) costa de Demerara (Georgetown) $\left(6^{\circ} 48^{\prime} \mathrm{N}, 58^{\circ} 10^{\prime} \mathrm{W}\right)$; localidade-tipo de Alouatta macconnelli; citado em ElLiot (1910). 36) Tamatumari ( $\left.5^{\circ} 22^{\prime} \mathrm{N}, 5^{\circ} \mathrm{W}\right)$; citado em Allen (1916b). Suriname: 37 ) Moengotapoe ( $\left.5^{\circ} 35^{\prime} \mathrm{N}, 5^{\circ} 15^{\prime} \mathrm{W}\right)$; citado em Husson (1957). 38) Nassau ( $\left.4^{\circ} 48^{\prime} \mathrm{N}, 54^{\circ} 36^{\prime} \mathrm{W}\right)$; citado em Husson (1957). 39) Nickerie $\left(3^{\circ} 06^{\prime} \mathrm{N}, 56^{\circ} 27^{\prime} \mathrm{W}\right)$; citado em

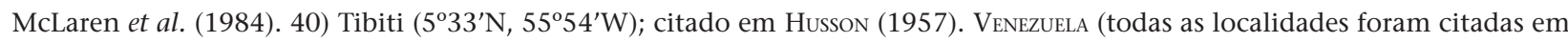
Bodini \& Pérez-Hernàndez, 1987, exceto a de número 48): 41) Cacuri (4º $\left.\left.49^{\prime} \mathrm{N}, 6^{\circ} 26^{\prime} \mathrm{W}\right) .42\right)$ Calo Yureba, Ventuari ( $3^{\circ} 35^{\prime} \mathrm{N}$, $\left.66^{\circ} 46^{\prime} \mathrm{W}\right)$. 43) Cerro La Neblina $\left(0^{\circ} 59^{\prime} \mathrm{N}, 66^{\circ} 10^{\prime} \mathrm{W}\right)$. 44) Guayoba, Río Caura $\left(7^{\circ} 20^{\prime} \mathrm{N}, 6^{\circ} 10^{\prime} \mathrm{W}\right)$. 45) Guri, represa $\left(7^{\circ} 40^{\prime} \mathrm{N}\right.$, $\left.63^{\circ} \mathrm{W}\right)$. 46) Hato Bella Vista, El Palmar $\left(8^{\circ} \mathrm{N}, 62^{\circ} \mathrm{W}\right)$. 47) Río Purinami $\left(3^{\circ} 19^{\prime} \mathrm{N}, 65^{\circ} 15^{\prime} \mathrm{W}\right)$. 48) Santa Elena $\left(4^{\circ} 37^{\prime} \mathrm{N}, 61^{\circ} 08^{\prime} \mathrm{W}\right)$. 49) San Martín de Turumban $\left(6^{\circ} 42^{\prime} \mathrm{N}, 61^{\circ} 02^{\prime} \mathrm{W}\right)$.

Alouatta nigerrima: Brazil: Amazonas: Borba AMNH 92321; Igarapé Aruá, Rio Madeira AMNH 91786-787; Lago do Batista MNRJ 5927, 5984, 6042-6052; MZUSP 4815, 5289-5298, 5396, 5398, 5399, 540-5402, 5404, 10490, 10492, 10493, 10494, 10564, 10566, 10570, 10574, 54816; Rosarinho AMNH 92322-330. PARÁ: Aramanay AMNH 95028-031; Igarapé Amorim AMNH 9530812, Igarapé Brabo AMNH 95033-036; Itaituba MPEG 8126, 8128, 8129, 8478, 8493, 8495; MZUSP 3646; Óbidos MZUSP 3643; Oriximiná MPEG 02, 501, 502, 515, 692, 693, 695-699, 701; Parque Nacional do Tapajós MZUSP 19119; Samaúma MZUSP 1903; Urucurituba MZUSP 1901, 1902.

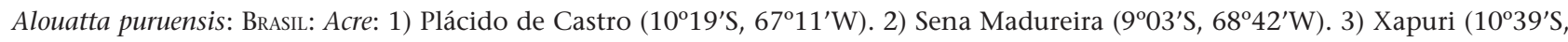
68 $\left.31^{\circ} \mathrm{W}\right)$. Amazonas: 4) Arumá (= Arumã) $\left(4^{\circ} 44^{\prime} \mathrm{S}, 62^{\circ} 08^{\prime} \mathrm{W}\right)$; citado em Lönnberg (1941). 5) Castanho, Igarapé (m. d. Rio

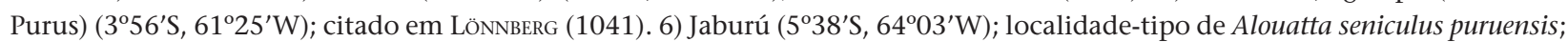

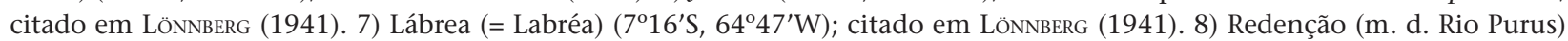

Revista Brasileira de Zoologia 23 (1): 64-144, março 2006 
$\left(4^{\circ} 04^{\prime} \mathrm{S}, 62^{\circ} 38^{\prime} \mathrm{W}\right)$. Mato Grosso: 9) Aripuanã $\left(9^{\circ} 16^{\prime}, 60^{\circ} 39^{\prime}\right)$. Rondônia: 10) Rio Jamari (Represa de Samuel) $\left(8^{\circ} 45^{\prime} \mathrm{S}, 7^{\circ} 27^{\prime} \mathrm{W}\right)$. 11) Salto Theotôni (= Teotônio) ( $\left.8^{\circ} 51^{\prime} \mathrm{S}, 64^{\circ} 02^{\prime} \mathrm{W}\right)$; citado em Pelzeln (1883).

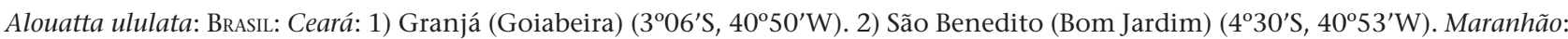
3) Boa Vista ( $\left.3^{\circ} 13^{\prime} \mathrm{S}, 42^{\circ} 34^{\prime} \mathrm{W}\right)$. 4) Humberto de Campos (antiga Miritiba) (2 $\left.37^{\prime} \mathrm{S}, 4^{\circ} 27^{\prime} \mathrm{W}\right)$; localidade-tipo de Alouatta ululata.

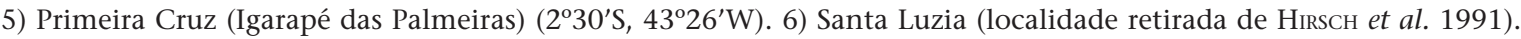

Anexo II. Material complementar examinado.

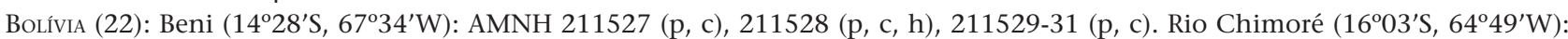
AMNH 14654 (p, c), 14656 (p, c, h), 38808-09 (p, c). Río Ibaré (14³7’S, 64º57’W): AMNH 211532 (p), 211533 (p, c, h), 211534-37 (p, c), 211538 (p, c, h). Río Yapacani $\left(16^{\circ} 0^{\prime} \mathrm{S}, 62^{\circ} 45^{\prime} \mathrm{W}\right)$ : FMNH 51875 (p, c, h), 51876 (p, c) Santa Cruz (Rio Chimoré) (11 $\left.17^{\circ} \mathrm{S}, 6^{\circ} 23^{\prime} \mathrm{W}\right)$ : AMNH 211540 (p, c), 211541-43 (p, c, h).

Colômbia (36): El Naranjo ( $\left.3^{\circ} 47^{\prime} \mathrm{N}, 76^{\circ} 44^{\prime} \mathrm{W}\right)$ : AMNH 14651 (p, c), 14653 (p, c), 23352 (p, c, h), 23341 (p). La Frijolera (7º10’ $75^{\circ} 25^{\prime} \mathrm{W}$ ): AMNH 37808-09 (p, c). Lomitas ( $\left.3^{\circ} 38^{\prime} \mathrm{N}, 76^{\circ} 38^{\prime} \mathrm{W}\right)$ : AMNH 32146 (p, c). Rio Frio $\left(4^{\circ} 09^{\prime} \mathrm{N}, 7^{\circ} 18^{\prime} \mathrm{W}\right)$ : AMNH $33066^{-}$ 68 (p), 35814-17 (c). San Juan Nepomuceno (9 $\left.57^{\prime} \mathrm{N}, 7^{\circ} 05^{\prime} \mathrm{W}\right)$ : FMNH 68826-27 (p, c, h). Santander $\left(2^{\circ} 45^{\prime} \mathrm{N}, 7^{\circ} 55^{\prime} \mathrm{W}\right)$ :

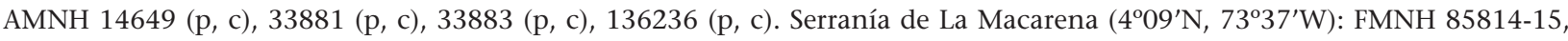

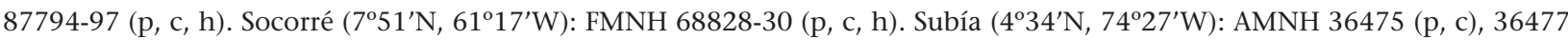
(p, c). Unguía $\left(8^{\circ} 01^{\prime} \mathrm{N}, 77^{\circ} 04^{\prime} \mathrm{W}\right)$ : FMNH 69591 (p, c, h). Valdivia $\left(7^{\circ} 18^{\prime} \mathrm{N}, 75^{\circ} 23^{\prime} \mathrm{W}\right)$ : FMNH 69592 (p, c). Villavicencio (4º09’ 73 $37^{\prime}$ W): AMNH 136233 (p, c, h), 136235 (p, c, h), 136237-38 (p, c, h).

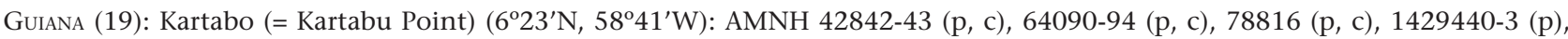

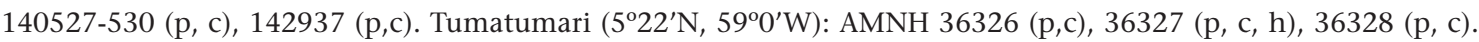

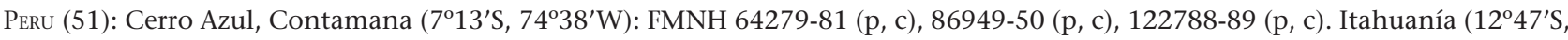

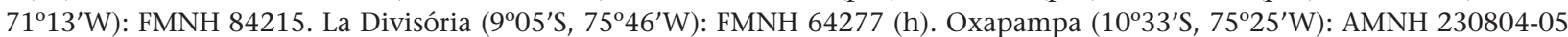

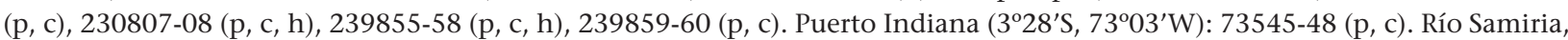
Santa Elena ( $\left.4^{\circ} 42^{\prime} \mathrm{S}, 74^{\circ} 13^{\prime} \mathrm{W}\right)$ : 86943-48 (p, c). Río Urubamba (boca) $\left(10^{\circ} 44^{\prime} \mathrm{S}, 73^{\circ} 45^{\prime} \mathrm{W}\right)$ : AMNH $76020-23$ (p, c), $98322-24$ (p,

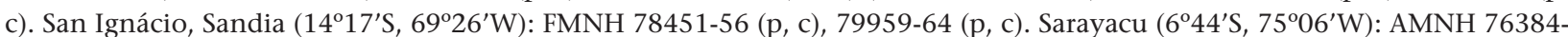
85 (p, c). Yarina-Cocha $\left(8^{\circ} 15^{\prime} \mathrm{S}, 74^{\circ} 43^{\prime} \mathrm{W}\right)$ : FMNH 55504 (p, c), 55505 (c, h)

SuRINAme (8): Brokopondo (River Saramacca e Finisanti) ( $\left.4^{\circ} 20^{\prime} \mathrm{N}, 55^{\circ} 20^{\prime} \mathrm{W}\right)$ : FMNH 95492 (p, c, h), 95492 (p). Kayser Gebergte (Nickerie) $\left(3^{\circ} 03^{\prime} \mathrm{N}, 56^{\circ} 35^{\prime} \mathrm{W}\right)$ : FMNH 93246-48 (p, c, h). Wilhelmina Mountain $\left(3^{\circ} 45^{\prime} \mathrm{N}, 56^{\circ} 30^{\prime} \mathrm{W}\right)$ : FMNH 95494 (p), 95495 (p, c), $95496(\mathrm{p})$.

Venezuela (19): Latal $\left(10^{\circ} 10^{\prime} \mathrm{N}, 63^{\circ} 55^{\prime} \mathrm{W}\right)$ : AMNH $69591-93$ (p, c). Monte Auyán-Tepuí (555’N, 62³2’W): AMNH 135483 (p,c), 135486-87 (p, c), 135458 (p,c). Río Cassiquiare (= Casiquiare) $\left(2^{\circ} 01^{\prime} \mathrm{N}, 67^{\circ} 07^{\prime} \mathrm{W}\right)$ : AMNH 78487-89 (p, c). TRINIDAD: Brickfield: FMNH 61856 (p, c, h), 61857 (p, c). Plum Mitan: AMNH $169607-09$ (p, c), 169632-34 (p). Monte Harris, Saint Andrews: FMNH $61855(\mathrm{p}, \mathrm{c})$. 